\title{
WestVirginiaUniversity
}

THE RESEARCH REPOSITORY @ WVU

Graduate Theses, Dissertations, and Problem Reports

2002

\section{Long-term creep of encased polymer liners}

Shalini Rangarajan

West Virginia University

Follow this and additional works at: https://researchrepository.wvu.edu/etd

\section{Recommended Citation}

Rangarajan, Shalini, "Long-term creep of encased polymer liners" (2002). Graduate Theses, Dissertations, and Problem Reports. 1411.

https://researchrepository.wvu.edu/etd/1411

This Thesis is protected by copyright and/or related rights. It has been brought to you by the The Research Repository @ WVU with permission from the rights-holder(s). You are free to use this Thesis in any way that is permitted by the copyright and related rights legislation that applies to your use. For other uses you must obtain permission from the rights-holder(s) directly, unless additional rights are indicated by a Creative Commons license in the record and/ or on the work itself. This Thesis has been accepted for inclusion in WVU Graduate Theses, Dissertations, and Problem Reports collection by an authorized administrator of The Research Repository @ WVU. For more information, please contact researchrepository@mail.wvu.edu. 


\title{
Long-Term Creep of Encased Polymer Liners
}

\author{
Shalini Rangarajan \\ Thesis Submitted to the \\ College of Engineering and Mineral Resources \\ At \\ West Virginia University
}

In Partial Fulfillment of the Requirements for the

Degree of

\author{
Master of Science \\ In \\ Mechanical Engineering
}
Ever Barbero, Ph.D., Chair and Advisor
Rakesh Gupta, Ph.D.
Victor Mucino, Ph.D.

\author{
West Virginia University \\ Morgantown, West Virginia \\ 2002
}

Keywords: aging, buckling, modulus of elasticity, long-term modulus, time-temperature superposition principle 


\section{Abstract \\ Long-Term Creep of Encased Polymer Liners}

\section{Shalini Rangaraian}

Due to increasing costs and inconveniences in replacing deteriorated sewer pipelines by conventional excavation methods, the trenchless or 'no-dig' technology is being extensively used. In trenchless technology, a polymer or reinforced polymer is applied to the inside of the deteriorated host pipe to prevent ground water from seeping into the sewer pipelines. In this work, a testing method was developed to determine the long-term creep behavior of encased polymer liners.

Short-term tests, following the ASTM D790 procedure, were conducted on pipe liner samples to determine the initial elastic modulus and compare it to the elastic modulus obtained from long-term testing of the encased liner.

Long-term tests were conducted on $6 \mathrm{ft}$ length, 12 in diameter polymer liner samples encased in steel pipes. Fabrication service was provided by the industries participating in the research. The thicknesses of the polymer liners were selected according to the typical use of each product in the field. Three samples each of five liner materials were tested under constant external hydraulic pressure to find their long-term structural properties and to present creep-buckling models. A pressure regulator, pressure transducer, and several pressure gages at different points in the water line were used to maintain constant hydraulic pressure. A novel method was developed for sealing the ends of the encased liner samples for testing. The long-term creep data was collected with strain gages bonded along the inner circumference of the liner and connected to a Data Acquisition System (DAS). The temperature of the liners was monitored continuously with the use of a thermocouple. The strain data collected from the DAS was compensated for differences in temperature throughout the period of testing, initial deformation, and coefficient of thermal expansion. Several viscoelastic models were investigated in order to fit the data. The data is used to predict the long-term modulus used in design. 


\section{Acknowledgements}

I would like to express my thanks and sincere gratitude to my advisor and committee chair, Dr. Ever Barbero. His constant encouragement, valuable guidance and unending patience made this possible for me. I would also like to thank Dr. Rakesh Gupta and Dr. Victor Mucino for taking time out of their schedule and consenting to be on my committee.

Thanks are due to my project mates Ed Wen, for his valuable advice, Michael Julius, for helping me with the experimental setup and giving me his TTSP data, and Kevin Ford for cutting the samples. But most of all, thanks for the wonderful time that I had with you. Thanks to everyone in the MAE workshop who helped on the experimental setup.

I would like to thank my brother Shridharan Rangarajan and my good friend and mentor, Ganesh Chandrasekaran for their guidance. Thanks to Sundar Jayashekar for his immense support.

Most credit for any achievement of mine goes to my parents Nalina and K.S. Rangarajan for making me what I am today. Above all, I thank God for being so merciful. 


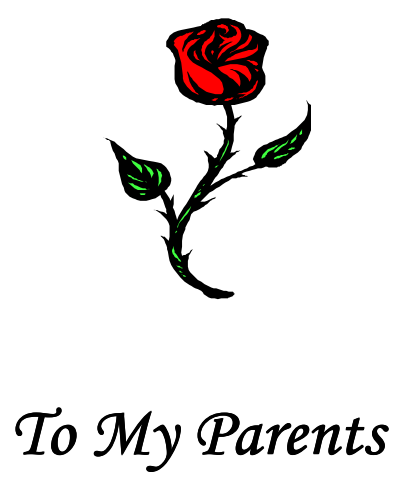




\section{Table Of Contents}

Title Page

Abstract ii

Acknowledgements iii

Table Of Contents $\quad$ v

List Of Tables viii

List Of Figures $\quad$ X

CHAPTER 1: INTRODUCTION AND LITERATURE REVIEW 1

1.1 Introduction 1

1.2 Literature review 2

CHAPTER 2: SHORT-TERM TESTS 12

$\begin{array}{ll}2.1 \text { Introduction } & 12\end{array}$

2.2 Experimental Procedure $\quad 12$

2.2.1 Apparatus And Testing Machine 12

2.2.2 Test Environmental Conditions 13

$\begin{array}{ll}\text { 2.2.3 Specimen Preparation } & 13\end{array}$

$\begin{array}{ll}\text { 2.2.4 Specimen Testing } & 14\end{array}$

2.3 Experimental Results And Data Interpretation 16

$\begin{array}{ll}\text { 2.3.1 Computation of Tangent Modulus } & 17\end{array}$

2.4 Temperature Compensation 19 
4.7 Calculation Of Material Properties Using Standard Linear Solid (SLS) Model 
Appendix B: Data Files 


\section{LIST OF TABLES}

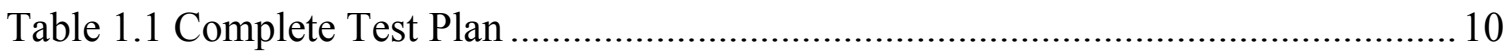

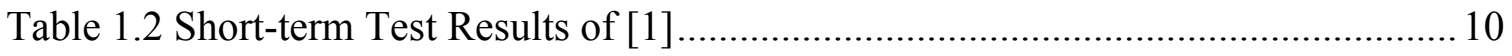

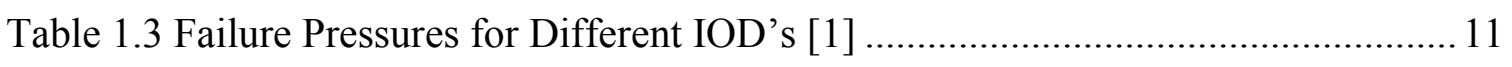

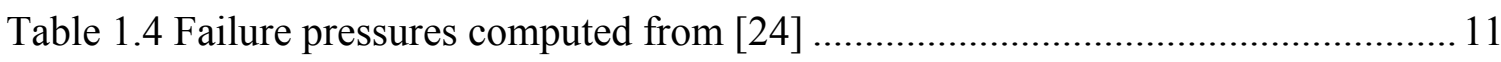

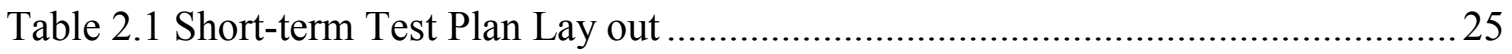

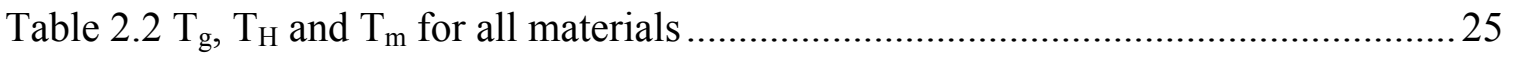

Table 2.3 Ratio of Initial Mid span Deflection to Span for Material D ..........................26

Table 2.4 Values of E (GPa) for Various Fits for Material A ....................................... 27

Table 2.5 Values of E (GPa) for Various Fits for Material B .....................................2 28

Table 2.6 Values of E (GPa) for Various Fits for Material C .....................................2 29

Table 2.7 Values of E (GPa) for Various Fits for Material D ...................................... 30

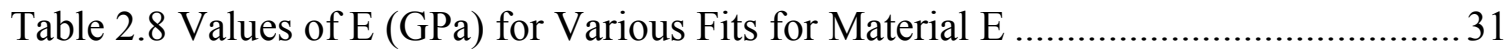

Table 2.9 Modulus of Elasticity (GPa) at $21.1{ }^{0} \mathrm{C}$ for Various Testing Conditions for all

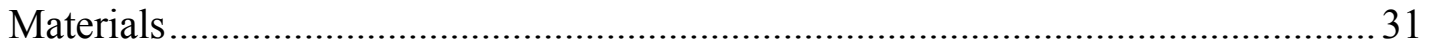

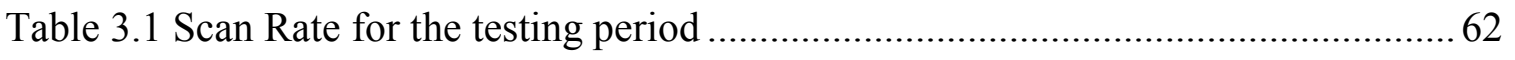

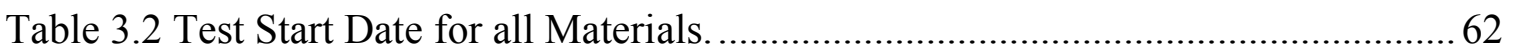

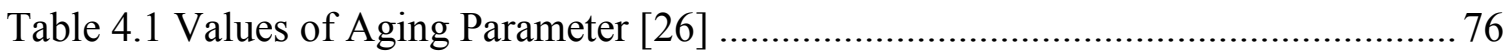

Table 4.2 Results of the Four-Parameter Fit on the Three Samples of Material B.......... 76

Table 4.3 Results of the SLS Model Fits on the Three Samples of Material A............... 76

Table 4.4 Results of the SLS Model Fits on the Three Samples of Material B ............... 77

Table 4.5 Results of the SLS Model Fits on the Three Samples of Material C ............... 77 
Table 4.6 Results of the SLS Model Fits on the Three Samples of Material D............... 77

Table 4.7 Results of the SLS Model Fits on the Three Samples of Material E ............... 78

Table 4.8 Comparison Between the Elastic Modulus (GPa) obtained from ASTM D790

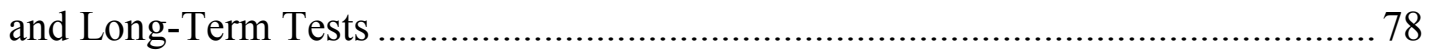

Table 4.9 Values of $\mathrm{E}_{\mathrm{inf}}$ in GPa (Forcing $\mathrm{E}_{0}$ to be equal to ASTM D790 test value) ....... 78 


\section{LIST OF FIGURES}

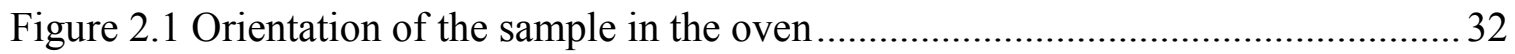

Figure 2.2 Load Vs. Deflection Curve for Material A .................................................. 32

Figure 2.3 Load Vs. Deflection Curve for Material B ................................................ 33

Figure 2.4 Load Vs. Deflection Curve for Material C ............................................... 33

Figure 2.5 Load Vs. Deflection Curve for Material D ................................................. 34

Figure 2.6 Load Vs. Deflection Curve for Material E ................................................ 34

Figure 2.7 Load Vs. Deflection Curve for Material A (initial data discarded) ................ 35

Figure 2.8 Load Vs. Deflection Curve for Material B (initial data discarded) ................ 35

Figure 2.9 Load Vs. Deflection Curve for Material C (initial data discarded) ................ 36

Figure 2.10 Load Vs. Deflection Curve for Material D (initial data discarded) ............... 36

Figure 2.11 Load Vs. Deflection Curve for Material E (initial data discarded) ............... 37

Figure 2.12 Flexural Stress Vs. Flexural Strain Curve for Material A ........................... 37

Figure 2.13 Flexural Stress Vs. Flexural Strain Curve for Material B............................. 38

Figure 2.14 Flexural Stress Vs. Flexural Strain Curve for Material C............................. 38

Figure 2.15 Flexural Stress Vs. Flexural Strain Curve for Material D ........................... 39

Figure 2.16 Flexural Stress Vs. Flexural Strain Curve for Material E............................ 39

Figure 2.17 Linear fit of Stress Vs. Strain Curve up to 2\% strain for Material A ............ 40

Figure 2.18 Linear fit of Stress Vs. Strain Curve up to 2\% strain for Material B............ 40

Figure 2.19 Linear fit of Stress Vs. Strain Curve up to 2\% strain for Material C............ 41

Figure 2.20 Linear fit of Stress Vs. Strain Curve up to 2\% strain for Material D ........... 41

Figure 2.21 Linear fit of Stress Vs. Strain Curve up to Break Point for Material E ......... 42 
Figure $2.224^{\text {th }}$ Order Polynomial fit of Stress Vs. Strain Curve for Material A ............. 42

Figure $2.234^{\text {th }}$ Order Polynomial fit of Stress Vs. Strain Curve for Material B .............. 43

Figure $2.244^{\text {th }}$ Order Polynomial fit of Stress Vs. Strain Curve for Material C ............. 43

Figure $2.254^{\text {th }}$ Order Polynomial fit of Stress Vs. Strain Curve for Material D .............. 44

Figure $2.264^{\text {th }}$ Order Polynomial fit of Stress Vs. Strain Curve for Material E............... 44

Figure $2.274^{\text {th }}$ Order Polynomial fit of Stress Vs. Strain Curve for Material A

(Considering deflections only up to $10 \%$ of the span) ........................................ 45

Figure $2.284^{\text {th }}$ Order Polynomial fit of Stress Vs. Strain Curve for Material B

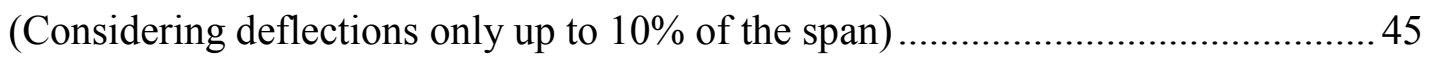

Figure $2.294^{\text {th }}$ Order Polynomial fit of Stress Vs. Strain Curve for Material C

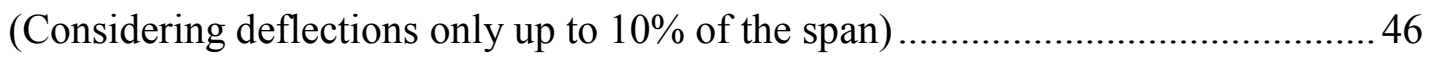

Figure $2.304^{\text {th }}$ Order Polynomial fit of Stress Vs. Strain Curve for Material D

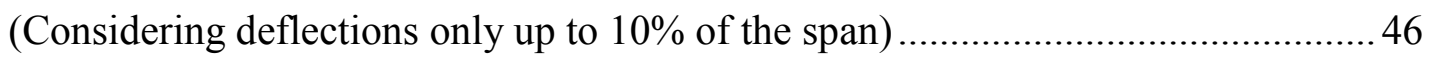

Figure $2.314^{\text {th }}$ Order Polynomial fit of Stress Vs. Strain Curve for Material E

(Considering deflections only up to Break Point) .............................................. 47

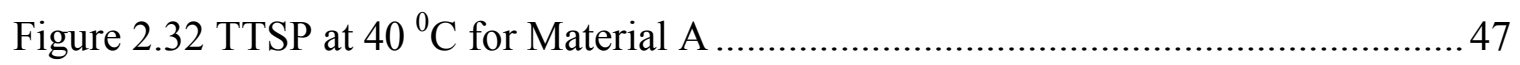

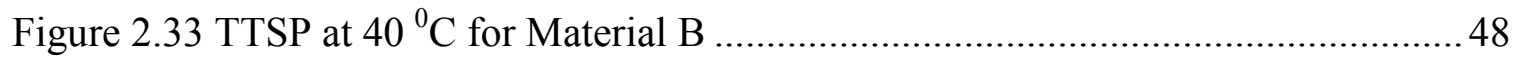

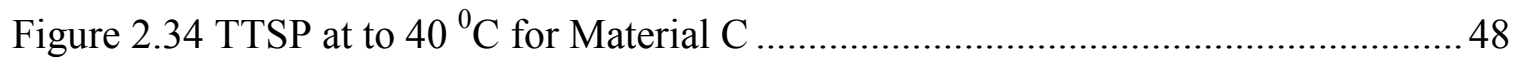

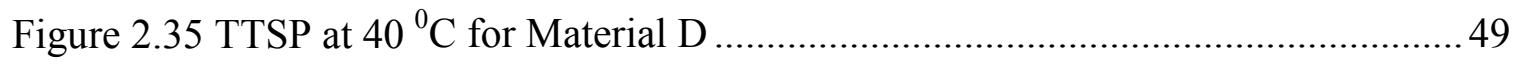

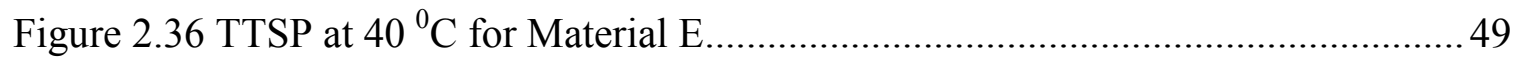

Figure 2.37 Log of Shift Factor Vs. Temperature for 40 and $21.1{ }^{0} \mathrm{C}$ for Material A ...... 50

Figure 2.38 Log of Shift Factor Vs. Temperature for 40 and $21.1{ }^{0} \mathrm{C}$ for Material B ......50

Figure 2.39 Log of Shift Factor Vs. Temperature for 40 and $21.1{ }^{\circ} \mathrm{C}$ for Material C ......51 
Figure 2.40 Log of Shift Factor Vs. Temperature for 40 and $21.1{ }^{0} \mathrm{C}$ for Material D ...... 51

Figure 2.41 Log of Shift Factor Vs. Temperature for 40 and $21.1{ }^{0} \mathrm{C}$ for Material E.......52

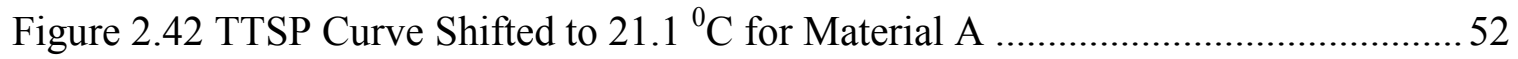

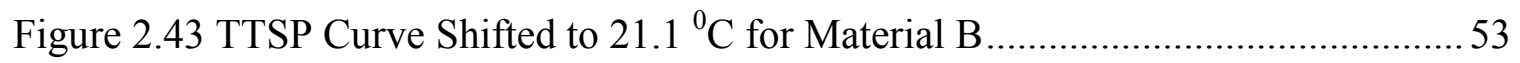

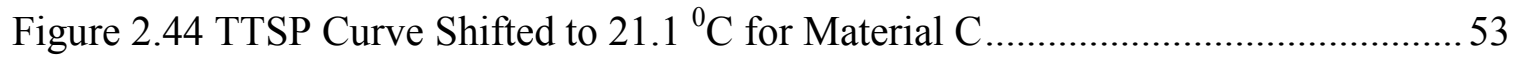

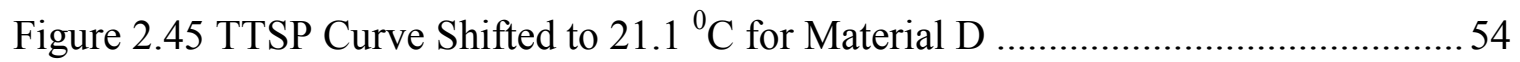

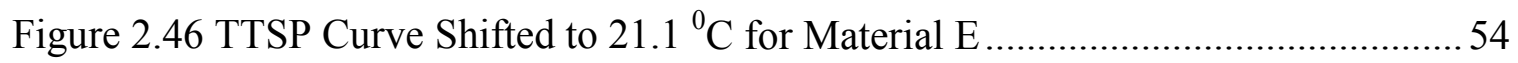

Figure 3.1 Steel pipe with polyethylene spacer....................................................... 59

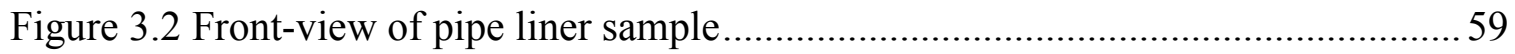

Figure 3.3 End seals with Hydrotite ${ }^{\circledR}$, Polyethylene spacer and Epoxy grout ..................60

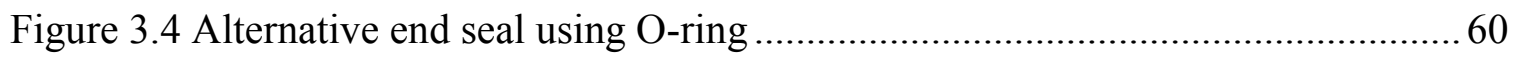

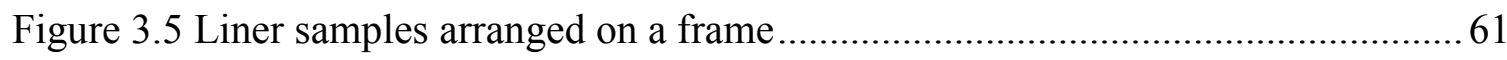

Figure 3.6 Strain gage placement in the liner sample ........................................... 61

Figure 4.1 Strain Vs. Time For The Gages In Pipe A1 .............................................. 79

Figure 4.2 Strain Vs. Time For The Gages In Pipe A2 ............................................ 79

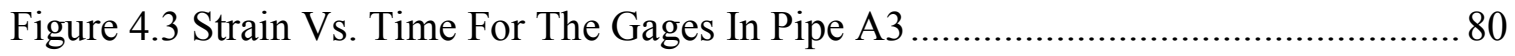

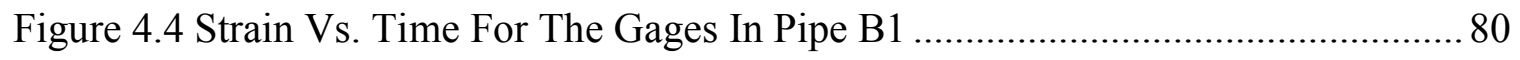

Figure 4.5 Strain Vs. Time For The Gages In Pipe B2 .......................................... 81

Figure 4.6 Strain Vs. Time For The Gages In Pipe B3 ….................................... 81

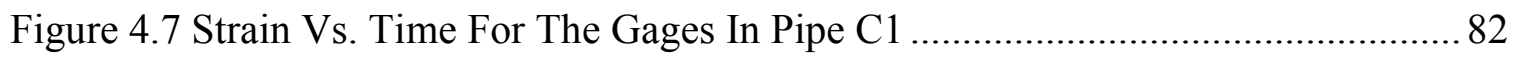

Figure 4.8 Strain Vs. Time For The Gages In Pipe C2 …................................... 82

Figure 4.9 Strain Vs. Time For The Gages In Pipe C3 …....................................... 83

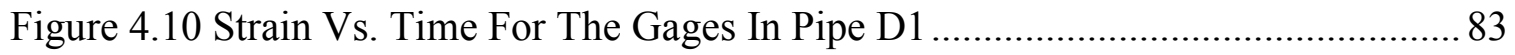


Figure 4.11 Strain Vs. Time For The Gages In Pipe D2 ........................................... 84

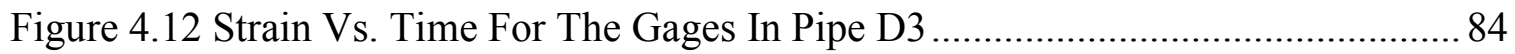

Figure 4.13 Strain Vs. Time For The Gages In Pipe E1 ......................................... 85

Figure 4.14 Strain Vs. Time For The Gages In Pipe E2 …...................................... 85

Figure 4.15 Strain Vs. Time For The Gages In Pipe E3 ........................................... 86

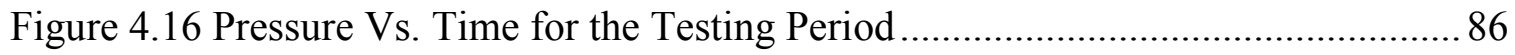

Figure 4.17 Temperature Vs. Time For The Testing Period ......................................... 87

Figure 4.18 Comparison Of Experimental Strain And Strain Corrected For Thermal

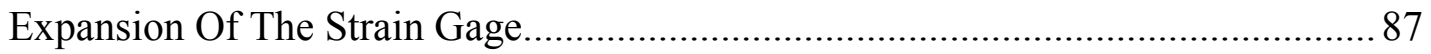

Figure 4.19 Comparison Of Actual Strain Data And DFT Points For One Gage............. 88

Figure 4.20 Comparison of the Liner Before the Application of load till the initial ........ 89

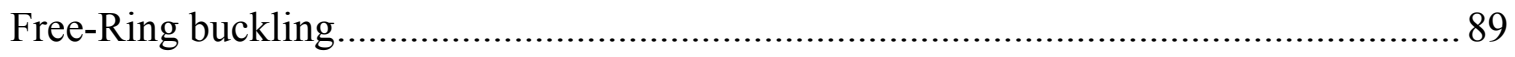

Figure 4.21 Liner Radius (a) and Angle $\theta$ at which the Gages are placed....................... 89

Figure 4.22 Strain and Deflected Shape at 11,500 hours for Pipe A1 ......................... 90

Figure 4.23 Strain and Deflection at 11,500 hours for Pipe A2 .................................. 91

Figure 4.24 Strain and Deflection at 11,500 hours for Pipe A3 ................................. 92

Figure 4.25 Strain and Deflection at 3,100 hours for Pipe B1 ................................... 93

Figure 4.26 Strain and Deflection at 3,100 hours for Pipe B2 .................................... 94

Figure 4.27 Strain and Deflection at 3,100 hours for Pipe B3 .................................... 95

Figure 4.28 Strain and Deflection at 3,100 hours for Pipe $\mathrm{C} 1$..................................... 96

Figure 4.29 Strain and Deflection at 3,100 hours for Pipe C2 ................................... 97

Figure 4.30 Strain and Deflection at 3,100 hours for Pipe C3 .................................. 98

Figure 4.31 Strain and Deflection at 3,100 hours for Pipe D1 .................................. 99 
Figure 4.32 Strain and Deflection at 3,100 hours for Pipe D2 .................................. 100

Figure 4.33 Strain and Deflection at 3,100 hours for Pipe D3 .................................. 101

Figure 4.34 Strain and Deflection at 3,100 hours for Pipe E1 ................................. 102

Figure 4.35 Strain and Deflection at 3,100 hours for Pipe E2 .................................. 103

Figure 4.36 Strain and Deflection at 3,100 hours for Pipe E3 .................................. 104

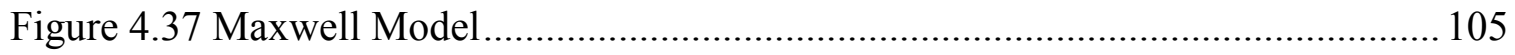

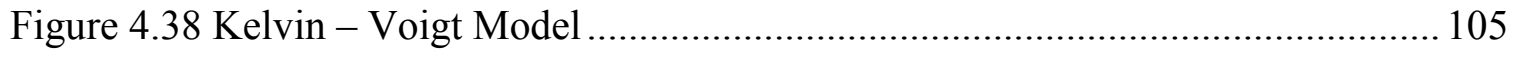

Figure 4.39 Standard Linear Solid (SLS) Model ................................................... 105

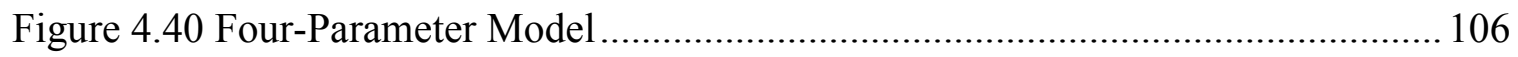

Figure 4.41 SLS model fit of three samples of Material A (A1, A2 and A3)............... 106

Figure 4.42 SLS model fit of three samples of Material B (B1, B2 and B3)................ 107

Figure 4.43 SLS model fit of three samples of Material C (C1, C2 and C3)............... 107

Figure 4.44 SLS model fit of three samples of Material D (D1, D2 and D3)............... 108

Figure 4.45 SLS model fit of three samples of Material E (E1, E2 and E3)................ 108 


\section{CHAPTER 1: INTRODUCTION AND LITERATURE REVIEW}

\subsection{INTRODUCTION}

In present days, rehabilitation of existing sewer lines is done using the "trenchless" or "no-dig" technology. Conventional excavation methods are no longer being used due to high costs and traffic disruptions. In trenchless lining, a polymer or reinforced polymer is applied to the inside of the existing host-pipe without disturbing the soil or any aboveground facilities. Trenchless lining can be carried out without any excavation and by using the existing manholes. Several technologies offer various solutions, including thermoplastic and thermoset polymers and composites, which can be cured within the host-pipe or mechanically installed to fit the host pipe. No accepted unbiased testing procedure has yet been established that allows a fair comparison of various products for a particular field installation.

The main purpose of a liner is to prevent water and sediment leakage into the sewer pipe. Therefore a liner encased by a host sewer pipe is mainly subjected to the external head of water that builds up once the hydraulic integrity is restored (Boot and Welch 1995). The liner may also carry some soil pressure if the host pipe is severely deteriorated (Gabriel 1990). Regardless of the source of external pressure, the encased liner fails by creep buckling under external pressure (Schrock and Gumbel 1997).

The objective of this thesis was to develop a long-term testing procedure to conduct long-term tests on full-size (12 in diameter X 6 feet length) encased liner samples of different liner materials and to find the long-term time-dependent properties of the liner. The main consideration was to measure the creep compliance of the liners 
produced in standard industry conditions. The data obtained from the long-term test was compensated for variations in ambient temperature over the entire period of testing. Initial and time-dependent deformation modes of the liner were derived from the strain data. Creep models were fit to the long-term test data for the different liner materials. Short-term bending tests of samples (192 mm length X $25 \mathrm{~mm}$ width X $10 \mathrm{~mm}$ depth) were done following the ASTM D 790 procedure to find the initial elastic modulus of the materials and compare them to that found by numerical modeling of long-term test data. The test plan is shown in Table 1.1.

\subsection{LITERATURE REVIEW}

Over the years, extensive research has been conducted on the structural behavior of pipeline rehabilitation systems. Stiffness and stability of the liner under external hydrostatic pressure is a design limit state for all types of plastic sewer linings (Schrock and Gumbel 1997). Since long-term buckling is an important factor to be considered for the choice of wall thickness of the liner, a vital part of lining system characterization would be to determine a reliable and experimentally verified procedure to find the longterm modulus of the material. Various short-term, medium-term, and long-term tests have been conducted previously on encased polymer liners to find their buckling pressures, effect of deformities on buckling pressure, effects of geometry on buckling pressure, etc. The literature review presented below focuses on structural testing performed on encased polymer liners. Emphasis has been laid on the experimental method and set-up chosen for testing the encased liners.

In 1996, Boot and Welch [1] defined the long-term constitutive behavior of tightfitting thin walled polymeric lining used for the repair of deteriorated sewer linings. 
Short-term tests were conducted on the liner by increasing the pressure on it until failure. To determine the material properties of the liner, tensile and four-point bending tests were performed on the liner samples as per the BS 2782 standard. The tests were repeated after 17 months to determine the effect of ageing on the liner material. It was seen that the value of modulus of elasticity increased considerably due to ageing, hence showing that the material got stiffer over age. The results for the short-term tests are shown in Table 1.2.

For the buckling tests, steel pipes of $1 \mathrm{~m}$ length $\mathrm{X} 1 \mathrm{~m}$ diameter encased the polymer liners. The liner diameter and thickness were $450 \mathrm{~mm}$ and $10 \mathrm{~mm}$ respectively, so the liner was free to buckle without constraint from the host pipe. The liners were installed with small Imperfections On the inner Diameter (IOD). Liners with 0, 5 and $10 \%$ imperfections were tested. Steel plates held in place by four vertical steel bars closed the ends of the steel pipe. The liner ends were sealed using rubber seals. First foam sheet and Perspex were glued to the ends of the steel plate and then the rubber was used to seal the polymer liner to the Perspex, forming an airtight seal. Air supply was used to continuously increase the pressure between the steel pipe and the liner. The deflection of the liner was measured by Linear Variable Differential Transformers (LVDT's) mounted along the inner circumference of the liner. Buckling profiles were made and the buckling pressures were determined. It was seen that liners with lesser or no imperfections failed at a higher pressure than the liners with high imperfections. The experimental buckling pressures are tabulated in Table 1.3. Our predictions of the failure pressure for liner with no imperfection are presented in Table 1.4. Two cases were considered. In the first case, the liner was considered to be a very long tube with free ends [24]. 


$$
\begin{gathered}
q^{\mid}=\frac{1}{4} \frac{E}{\left(1-v^{2}\right)} \frac{t^{3}}{r^{3}} \\
l>4.90 r \sqrt{\frac{r}{t}}
\end{gathered}
$$

where $q$ is the failure pressure, $E$ is the modulus of elasticity, $t, r, l$ are the thickness, radius and length of the liner respectively, and $v$ is the Poisson's ratio (material of the liner not mentioned, value taken to be equal to 0.3 ). It should be noted that the liner dimensions did not satisfy the condition. The failure pressure was also calculated assuming the liner to a short tube of length $l$, ends held circular, but not otherwise constrained, or long tube held circular at intervals $l$.

$$
q^{\mid}=0.807 \frac{E t^{2}}{l r} \sqrt[4]{\left(\frac{1}{1-v^{2}}\right)^{3} \frac{t^{2}}{r^{2}}}
$$

From Table 1.4, we can see that the maximum failure pressure that can be obtained from using equations 1.1 and 1.2 is lesser than the experimental value [1].

Mathematical modeling was undertaken to predict the long-term buckling properties. It was concluded that once the deteriorated pipe was lined, the most significant loading on the liner would be the pressure of the external ground water. Hence one of the most important design criterion would be the resistance of the liner to creep buckling under the pressure of ground water, within the host pipe.

Straughan, Guice and Mal-Duraipandian [2] conducted short-term tests in 1995 on encased polymer liners to determine the test pressure for long-term tests. Cured-inplace pipe (CIPP) and Fold and Form pipe (FFP) liners installed in steel casing, were tested to failure. The liner formed a snug fit with the $6 \mathrm{ft}$ length, 12 in inner diameter, schedule 40 steel pipes. The length to diameter (L/d) ratio was 6 to minimize the end 
effects. Hydraulic pressure was applied in the space between the steel host pipe and the polymer liner pipe. A pressure regulator controlled the intensity of pressure acting on the liner and individual pressure gages were provide to monitor the pressure on each test specimen. For the short-term tests, the pressure was increased at a constant rate till the liner buckled and the buckling pressure was noted. This was used to estimate the test pressure to be used in the long-term test. The long-term test pressure was maintained a constant. It was chosen so that the liner would buckle within a 10,000-hour testing period. As soon as the buckle occurred, the specimen was shut off and the pressure recorded. The long-term modulus was calculated from the Timoshenko and Gere (1961) equation for buckling of unconfined ring.

$$
\mathrm{P}_{c r}=\frac{2 K E_{L}}{\left(1-v^{2}\right)} \times \frac{1}{(D R-1)^{3}}
$$

where $P_{c r}$ is the critical buckling pressure, $E_{L}$ is the long-term modulus of elasticity of the liner, $v$ is the Poisson's ratio ( 0.3 average), $D R$ is the dimension ratio of the liner (mean liner diameter / average liner thickness) and $K$ is the enhancement factor of the soil and existing pipe adjacent to the liner (arbitrarily taken as $K=7$ ).

The long-term modulus of elasticity determined using the experimentally found buckling pressure underestimated the value published by the manufacturer, hence calling for a standardized procedure for determining the long-term flexural properties of encased liners. In practice, long-term means 50 years. Therefore reference [2] accelerated the failure by increasing the pressure to whatever value was needed to buckle the liner less than 10,000 hours. In the context of accelerated testing, this means that the acceleration factor was the pressure. The behavior of polymers is non-linear viscoelastic over broad 
ranges of stresses, meaning that the behavior is not linearly proportional to stress. In general, creep strain is given by

$$
\varepsilon_{c}=\varepsilon-\varepsilon_{e}=a \sigma^{b} t^{\eta}
$$

where $\varepsilon_{\mathrm{e}}$ is the elastic strain, $a, b, \eta$ are material parameters. When $b \neq 1$, stress (pressure) cannot be used as an acceleration factor. Over narrow ranges of stress, the behavior can be approximated as linear $(b=1)$. Therefore liners must be tested at stress (pressure) levels close to those encountered in the field.

In the same year, short-term and long-term tests on circular and non-circular encased liners by Chunduru, Barber and Bakeer [3], indicated that the long-term buckling resistance of the considered HDPE liners, was about one-third of the short-term critical buckling resistance. Short-term tests were carried out by applying a uniform pressure between the steel casing and the HDPE liner. The liner was reformed to fit closely in to the steel casing. The ends were sealed by bolting together two steel plates with a plexi glass plate in between them. The inner steel plate fit tightly with the flared ends of the liner. The air pressure was controlled with a pressure regulator and two pressure gages at the two ends of the pipe helped to monitor the pressure. Pressure was increased gradually till the liner buckled. Tests were also conducted on circular and oval shaped chambers.

The critical buckling pressure was found to be inversely proportional to $(d / t)^{3}(d$ is the diameter and $\mathrm{t}$ is the thickness). Pipes of the same diameter but different thickness had different buckling pressures. Increase in ovality reduced the critical buckling pressure. Pipe liners having the same dimension and tested under same conditions recorded different failure pressures, hence they claimed that stresses resulting from the manufacture of the pipe were an important factor to be considered for the design of pipe 
liners. The Timosheko buckling formula was modified to account for ovality, lining factor, stress concentration factor, and factor of safety as

$$
P c r=\frac{2 E C \alpha \beta}{\left[\left(1-v^{2}\right)(S D R)^{3} F S\right]}
$$

where $C$ is the reduction factor to account for ovality (ranges between 1 and 6,1 for pipe that is totally unrestrained and 6 for a pipe that is fully constrained), $\beta$ is the stress concentration factor, and FS is the factor of safety (taken as 2.5 to 3 ).

Further tests conducted on HDPE liners of varying Standard Dimension Ratios (SDR, equals DR-1) have shown that thick small diameter liners failed faster than the thick large diameter liners, and that a factor of safety of 3 to 4 needs to be applied to the short-term buckling pressure of the liner to determine the long-term (meaning 10,000 hours) resistance of the flexible liner [4]. Tests on deformed and deteriorated HDPE liners showed that the ultimate buckling resistance for a tightly formed liner may be 3 to 6 times higher than that of a deformed liner. Therefore a load factor (or factor of safety) of 4 was recommended for design of HDPE liners installed in deformed or extremely deteriorated host pipes [5].

Different methods have been used to determine the deformation of the buckled liner during the tests. Image processing methods like shining a light through one end of the liner and using a video camera at the other end to tape the deflection have been used to monitor the deformation of the liner [6].

In 1997, Alders, Bakeer, and Barber [7] compared different methods to measure the deformation of the liners during the buckling tests. Simple methods like shining a light through the liner or videotaping the liner were sufficient to records patterns of 
failure but were inadequate to measure the exact deformation of the liner. A liner voltage displacement transducer (LVDT) was used in conjunction with a data acquisition system to accurately measure the deformation of the plastic liner throughout the length.

In this work, the deformed shape is derived from the strain data. Furthermore in this work, in order to determine the long-term flexural properties of the liner, a viscoelastic model is fit to the long-term test data. There are various viscoelastic models, of which some of them are the Maxwell model, Kelvin model, Standard Solid model of Maxwell and Kelvin types and the Four-parameter model. The Maxwell model consists of a spring and dashpot in series and describes very well the instantaneous elastic deformation. The Kelvin model has a spring and a dashpot in parallel and exhibits creep at a decaying rate. Standard linear solid (SLS) model describes both the instantaneous elastic deformation and creep at a decaying rate. A Maxwell type SLS model consists of a spring in parallel with the Maxwell model and a Kelvin type SLS model has a spring in series to the Kelvin model. The Four-parameter model is the combination of Maxwell and Kelvin models.

In 1994, Shaarf and Dello Russo [8] used ASTM D2412 in a comprehensive study of the durability of PVC pipes immersed in sulfuric acid. They reported load-relaxation data over a period of 2 years. The relaxation data was fitted using an equation derived from Findley's power law (1987).

In 1996, Moore and Hu [9] studied the work done on time-dependent relaxation response of HDPE pipe liner under parallel plate loading. It was found that linear viscoelastic models provided a reasonable prediction of the response of the pipe. A multi Kelvin model was used to find the secant modulus of the material. 
In the same year, Farshad and Flueler [10] did viscoelastic modeling of long-term creep data using the four-parameter linear viscoelastic model. It was found to fit well the creep data obtained from long-term testing of the HDPE liner pipe. The model consists of 2 combinations of spring and dashpot, one in series and one in parallel. The short-term and long-term elastic moduli were obtained from the four-parameter model. 


\begin{tabular}{|c|c|c|c|c|}
\hline \multirow[b]{2}{*}{ Product } & \multirow[b]{2}{*}{ Material } & \multirow{2}{*}{$\begin{array}{c}\text { SHORT-TERM TEST } \\
\text { No. Of Specimens }\end{array}$} & \multirow{2}{*}{$\begin{array}{l}\text { LONG-TERM TEST } \\
\text { No. Of Specimens }\end{array}$} & \multirow[b]{2}{*}{ Manufacture Date } \\
\hline & & & & \\
\hline A & Polyvinyl Chloride & 5 hoop, 5 longitudinal & 3 & $10 / 11 / 2000$ \\
\hline B & Polyvinyl Chloride & 5 hoop, 5 longitudinal & 3 & $2 / 1 / 2001$ \\
\hline C & Polyvinyl Chloride & 5 hoop, 5 longitudinal & 3 & $2 / 1 / 2001$ \\
\hline D & High Density Polyethylene & 5 top, 5 bottom curved & 3 & $2 / 15 / 2001$ \\
\hline $\mathbf{E}$ & $\begin{array}{l}\text { Polyester Reinforced with } \\
\text { Polyester Fibers }\end{array}$ & 5 longitudinal & 3 & $\sim$ \\
\hline
\end{tabular}

Table 1.1 Complete Test Plan

\begin{tabular}{|c|c|c|}
\hline Sample age & $t_{e}$ (shortly after spraying) & $t_{e}+17$ months \\
\hline Tension E (N/mm²) & $964 \pm 53$ & $1626 \pm 13$ \\
\hline Ultimate Stress $\left(\mathrm{N} / \mathrm{mm}^{2}\right)$ & $11.4 \pm 0.1$ & $16.1 \pm 0.6$ \\
\hline Ultimate Strain (\%) & $3.12 \pm 0.29$ & $3.08 \pm 0.32$ \\
\hline $\begin{array}{l}\text { Brittle Fracture and } \\
\text { Bending } E\left(\mathrm{~N} / \mathbf{m m}^{2}\right)\end{array}$ & $1108 \pm 22$ & $1663 \pm 58$ \\
\hline
\end{tabular}

Table 1.2 Short-term Test Results of [1] 


\begin{tabular}{|c|c|}
\hline IOD (\%) & Failure pressure (KN/m $\mathbf{~})$ \\
\hline 0 & $255 \pm 9$ \\
\hline 5 & $180 \pm 7$ \\
\hline 10 & $125 \pm 8$ \\
\hline
\end{tabular}

Table 1.3 Failure Pressures for Different IOD's [1]

\begin{tabular}{|c|c|c|}
\hline$E\left(N / m^{2}\right)$ & $\begin{array}{c}\text { Failure Pressure }\left(\mathrm{KN} / \mathrm{m}^{2}\right) \\
\text { Assuming } \infty \text { length } \\
\text { (Equation 1.1) }\end{array}$ & $\begin{array}{c}\text { Failure Pressure }\left(\mathrm{KN} / \mathrm{m}^{2}\right) \\
\text { Assuming short length } \\
\text { (Equation 1.2) }\end{array}$ \\
\hline Tension $\left(t_{e}\right)$ & 23.25 & 78.23 \\
\hline Bending $\left(t_{e}\right)$ & 26.72 & 89.92 \\
\hline Tension $\left(t_{e}+17\right.$ months) & 39.21 & 131.95 \\
\hline Bending $\left(t_{e}+17\right.$ months) & 40.11 & 134.96 \\
\hline
\end{tabular}

Table 1.4 Failure pressures computed from [24] 


\section{CHAPTER 2: SHORT-TERM TESTS}

\subsection{INTRODUCTION}

Short-term testing was done following the ASTM D790-99 procedure, to determine the flexural properties of the polymer liner samples. The tangent modulus obtained from short-term tests of different materials, was compared to the initial elastic modulus obtained by fitting a viscoelastic model to the long-term data. Ten samples of material $\mathrm{A}, \mathrm{B}$ and $\mathrm{C}$, five in longitudinal direction, and five in hoop direction were considered for testing. Material D could not be flattened in the hoop direction, hence only longitudinal samples were tested, 5 each with the curvature on top and bottom. Five samples of material E in the longitudinal direction were tested. The tests were conducted using the Instron Dynamic and Static Material Test System, at room temperature and humidity. Table 2.1 shows the complete layout of the test plan.

\subsection{EXPERIMENTAL PROCEDURE}

All tests were performed using three point loading system with the loading at one half of the support span using a $5 \mathrm{KN}$ load cell. The testing was done following the ASTM D790 procedure.

\subsubsection{APPARATUS AND TESTING MACHINE}

The tests were conducted using the WVU Three-Point Loading Fixture based on ASTM D790-99. The fixture used one loading point at one half of the support span of $192 \mathrm{~mm}$ (7.56 in) and could support a sample with a maximum width of $25 \mathrm{~mm}$ (0.98 in). 
All the three load points had a radius of $7.94 \mathrm{~mm}(0.313 \mathrm{in})$, which allowed a minimum specimen depth of $4.96 \mathrm{~mm}$ (0.195 in) according to ASTM D790-99 section 6.2.

\subsubsection{TEST ENVIRONMENTAL CONDITIONS}

The tests were conducted at room temperature and humidity conditions. The temperature and relative humidity were recorded during the tests from a thermometer and hygrometer placed not more than $60 \mathrm{~cm}$ (2 feet) from the specimen, as per ASTM D618 Section 3.2.4. The tolerances were held to $+/-2{ }^{0} \mathrm{C}$ and $+/-15 \%$ relative humidity.

\subsubsection{SPECIMEN PREPARATION}

New liner samples were produced at the vendor facility of each material or from field installations. In either case, the samples were taken from rounded pipe (processed into a cylindrical configuration). All liner samples were cut perpendicular to the direction of extrusion and had a minimum length of $3 \mathrm{ft}$. If the installation prohibited the removal of samples at this length, three samples not less than $1 \mathrm{ft}$ in length each was provided. The $3 \mathrm{ft}$ samples collected from the field were cut into three pieces, each with a length of $1 \mathrm{ft}$. The samples were then cleaned using a mild soap and water solution.

In case of the thermoset liner, the vendor, for the purpose of measuring the thickness of the bagging material, also provided two samples at least $930 \mathrm{~cm}^{2}$ of dry hose comprising both main hose and the lining hose. The liner test section had at least one flat surface.

Once cleaned, the samples were flattened. In order to flatten them, the pipe was first cut longitudinally into four equal quadrants. One of these sections was placed, concave side down, on a piece of flat aluminum with a thickness of $12.7 \mathrm{~cm}(1 / 2 \mathrm{in})$ and 
overall dimensions slightly greater than the sample and placed in an oven. The orientation of the sample in the oven indicated the hoop-wise direction of the sample as shown in Figure 2.1. A second identical aluminum plate was placed on top of the sample and additional weights were added on it. The samples, aluminum plates and additional weights were then heated to $T_{H}$ (specimen heating temperature) and maintained at that temperature for not less than 48 hours. The specimen heating temperature, $\mathrm{T}_{\mathrm{H}}$, was determined to be $15{ }^{0} \mathrm{C}$ above the glass transition temperature $\left(\mathrm{T}_{\mathrm{g}}\right)$ of the material, but below its melting point $\left(T_{m}\right)$. The values of $T_{g}$ and $T_{H}$ for the materials tested are given in Table 2.2.

Ten specimens, five in longitudinal and five in hoop direction for materials A, B and C, were cut from the flattened liner sample. Since material D could not be flattened, 10 specimens were cut in the longitudinal direction from the pipe itself. Specimens for material E were cut from the flat pipe liner sample provided by the manufacturer. The specimens had a minimum aspect ratio of 16 to 1 . They had a maximum width of $25 \mathrm{~mm}$ and a minimum depth of $4.96 \mathrm{~mm}$. In no case was the depth of the specimen allowed to exceed the width.

The specimens were annealed in the oven at temperature $T_{H}$ for 30 minutes. They were then quenched between aluminum plates for 24 hours. Testing was done between the $24^{\text {th }}$ and $26^{\text {th }}$ hour.

\subsubsection{SPECIMEN TESTING}

Each specimen was tested one at a time for the determination of its flexural properties. Testing was commenced immediately after the 24-hour period and was completed before the end of the $26^{\text {th }}$ hour. The thickness and width of each specimen 
were measured at both ends and at the center of the span using a micrometer as per Section 6.3 of ASTM D790. The values measured were averaged for calculations. All measurements were made in SI units as per section 1.3 of the standard.

The specimen was placed in the fixture and the fixture was mounted on the Instron testing machine. The Instron testing machine was attached to a computer, which controlled the operations of the testing machine. The rate of application of load was calculated from equation (1) of the standard. Procedure B (10.2) was followed.

$$
R=\frac{Z l^{2}}{6 d}
$$

where $R$ is the Rate of crosshead motion in $\mathrm{mm} / \mathrm{mm}$,

$Z$ is the Rate of straining of the outer fiber $(=0.1$ for Procedure $B)$,

$l$ is the support span in $\mathrm{mm}$, and

$d$ is the depth of the beam in $\mathrm{mm}$.

The test was automatically terminated when the maximum deflection (D) was reached. The value of maximum deflection for each specimen was calculated from equation (2) of the ASTM standard.

$$
D=\frac{r l^{2}}{6 d}
$$

where $D$ is the mid-span deflection in $\mathrm{mm}$

$r$ is the strain in $\mathrm{mm} / \mathrm{mm}(=0.05 \mathrm{~mm} / \mathrm{mm}$ as in Section 10.7 .1 of the standard).

The width and depth of the specimen, the rate of loading and the maximum deflection were entered in the software program controlling the Instron testing machine. After making sure that the specimen was snugly fit into the fixture, the test was started. 
The beginning of application of load is almost instantaneous. The test automatically stopped once the maximum deflection was reached. The load and the corresponding deflection data for the specimen were automatically recorded into a file. Load and deflection data was recorded at a rate of 10 data points per second. After testing, the specimen was removed from the fixture and a new specimen could then be tested.

\subsection{EXPERIMENTAL RESULTS AND DATA INTERPRETATION}

Load and the corresponding deflection data were obtained from the file. Load versus deflection curves were plotted for each specimen (Figure 2.2). The initial portion of the curve for each specimen was discarded. This was due to the allowance given for the specimen not being snugly fit in the fixture. The plots of load vs. deflection of all specimens before and after discarding the initial portion of data are shown in Figures 2.2 to 2.11. The flexural stress and flexural strain were calculated using equations (3) and (4) of the ASTM D790-99 standard.

$$
\sigma_{f}=\frac{3 P l}{2 b d^{2}}
$$

where $\sigma_{\mathrm{f}}$ is the stress in the outer fibers at the midpoint (MPa), and $P$ is the load at the given point in the load-deflection curve in $\mathrm{KN}$.

$$
\varepsilon_{f}=\frac{6 \Delta d}{L^{2}}
$$

where $\varepsilon_{\mathrm{f}}$ is the strain in the outer fiber in $\mathrm{mm} / \mathrm{mm}$, and $\Delta$ is the maximum deflection of the center of the beam in $\mathrm{mm}$.

The plots between flexural stress and flexural strain for different materials are shown in Figures 2.12 to 2.16 . 


\subsubsection{COMPUTATION OF TANGENT MODULUS}

As per the ASTM standard, the tangent modulus of elasticity is the ratio, within the elastic limit, of stress to corresponding strain, calculated by drawing a tangent to the steepest initial straight-line portion of the load deflection curve. In order to find the slope of the steepest initial portion, various curves were fitted to the stress-strain data.

A linear equation was initially used to fit the flexural stress vs. flexural strain data to obtain the modulus of elasticity. Since only the initial portion of the data was to be considered, the flexural strain up to $2 \%$ was taken for the calculations. The remaining data was discarded. For the thermoset material the data up to the breaking point of the specimen or the value of $2 \%$ strain, whichever was lesser, was considered. A linear equation was fit to the data. The equation,

$$
y=m x+c
$$

would yield $\mathrm{m}$ as the slope of the equation.

The goodness of the fit was measured using the R-squared value. The R-squared value or the Coefficient of Determination has a range from 0 to 1 and is a measure of how good a given trend line corresponds to the actual data. A good fit is when the R-squared value is close to or equal to one. A value very close to one was obtained from the linear fit of the data. Hence the value of $m$ obtained was taken to be the value of tangent modulus of elasticity. The plots of the stress-strain curve up to $2 \%$ strain along with the linear fit are shown for different materials from Figure 2.17 to Figure 2.21. However, the data is not exactly linear on the $0-2 \%$ range, which motivated us to seek a better method to find the slope of the initial straight portion of the stress-strain curve. 
Therefore, it was attempted to fit a fourth-order polynomial to the whole data. The polynomial gave a very good coefficient of determination and a higher value of the modulus of elasticity when compared to the linear fit of the data.

The fourth order polynomial can be written as

$$
y(x)=a x^{4}+b x^{3}+c x^{2}+d x+e
$$

The slope of the fourth-order polynomial can be found by differentiating the equation with respect to $\mathrm{x}$.

$$
\text { slope }=\frac{d y}{d x}=4 a x^{3}+3 b x^{2}+2 c x+d
$$

In order to find the slope at the steepest initial portion, the slope of the curve was evaluated at a very small value of $x, \delta x$.

$$
\frac{d y}{d x}(\delta x)=4 a(\delta x)^{3}+3 b(\delta x)^{2}+2 c(\delta x)+d
$$

$\delta x$ being a very small quantity, all powers of $\delta x$ were neglected. Hence the slope at the initial portion of the stress strain curve was equal to the coefficient $d$.

$$
\frac{d y}{d x}(\delta x) \cong d
$$

The slope of the initial portion of the curve was found out by fitting a fourth order polynomial to the stress-strain curve as shown from Figures 2.22 to 2.26 , and the value of the coefficient $d$ was taken to be the value of the tangent modulus of elasticity. For the thermoset material, the portion of the graph till the specimen cracked due to the loading was taken into consideration.

It was observed that for higher strains, the deflection of the sample exceeded $10 \%$ of the span of the sample. As per the standard, the above equations for flexural stress and 
flexural strain do not hold good for deflections greater than $10 \%$ of the span. Hence the data was considered only till the deflection reached $10 \%$ of the span. The values of deflection above $10 \%$ of the span were neglected.

On fitting the four-parameter model to this data, the values of modulus of elasticity were obtained without violating any rule in the ASTM D790 standard. Hence these values were taken to be the final values. The plots are shown from Figures 2.27 to 2.31. A comparison of the modulus of elasticity found by the three methods mentioned above is shown from Tables 2.2 to 2.6 .

Specimens of material D (HDPE) could not be flattened as per the above procedure and hence had a radius of curvature along the length of the specimen. The initial center deflection divided by the span is shown in Table 2.3. Testing procedure was the same for material $\mathrm{D}$ as was for other materials. For curved beams having an $\mathrm{R} / \mathrm{h}$ (where $\mathrm{R}$ is the distance from the center of curvature of the curved beam to the centroid of the beam cross section and $\mathrm{h}$ is the depth of the beam) greater than 5.0, the straight beam formulae can be used [15]. The $\mathrm{R} / \mathrm{h}$ ratio for the specimens of material $\mathrm{D}$ was found to be greater than 5 , hence the straight beam formulae were used to find the flexural stress and strain.

\subsection{TEMPERATURE COMPENSATION}

The properties of viscoelastic materials display large changes with changing temperature. Depending on the temperature, the polymer can exhibit glass-like or rubberlike behavior. Glass transition temperature or $\mathrm{T}_{\mathrm{g}}$ is the temperature below, which the amorphous polymer is glass-like and above which it is rubber-like. The melting point, $\mathrm{T}_{\mathrm{m}}$, is the temperature at which the molecular chains slide past each other resulting in the 
flow of the material. At low temperatures, due to very less free volume, the molecules are very tightly packed and the polymer is very stiff. As the temperature increases, the free volume increases and hence the mobility of the molecules increases. The material becomes less stiff and the modulus of elasticity decreases. When the temperature is very high, above the melting point, the polymer begins to flow.

The modulus of elasticity is equal to the relaxation modulus at a fixed time. The relaxation modulus is a function of both time and temperature. Keeping either the time or the temperature a constant and testing for varying modulus of elasticity is a simple task. But in order to find the effect of both on the modulus of relaxation (or on its inverse, the creep compliance), the Time-Temperature Superposition Principle (TTSP) is used. In TTSP, tests of short durations are conducted on the material at different temperatures. It has been observed that if the curve at one temperature is kept as a reference, and all the other curves of different temperatures are shifted over time by dividing the time with a shift factor $\mathrm{a}_{\mathrm{T}}$, then a master curve of creep compliance is obtained for a particular temperature. Mathematically, the compliance (D) at a temperature $\mathrm{T}_{1}$ and time $t$ is equal to the compliance at temperature $\mathrm{T}_{2}$ and time $\mathrm{t} / \mathrm{a}_{\mathrm{T}}$.

$$
D\left(T_{1}, t\right)=D\left(T_{2}, \frac{t}{a_{T}}\right)
$$

Tests were conducted at the West Virginia University testing facility [18], to determine the TTSP master curve for all the materials considered in this study. Tests of 6 minutes duration were conducted on samples of dimensions $15 \mathrm{~mm} \mathrm{X} 10 \mathrm{~mm} \mathrm{X} 1.5 \mathrm{~mm}$. The tests were conducted at various temperatures between $12.5{ }^{\circ} \mathrm{C}$ to $92.5{ }^{0} \mathrm{C}$. The plots of compliance vs. time for the tests conducted were made. Changing the values of $\mathrm{a}_{\mathrm{T}}$, and superimposing different curves to form one curve, a master curve was obtained at a 
reference temperature of $40{ }^{\circ} \mathrm{C}$ for different materials as shown from Figures 2.32 to 2.36 .

From the tests conducted by [20], plots were made of the logarithm of the shift factors $\mathrm{a}_{\mathrm{T}} \mathrm{vs}$. the temperature for each material. It was seen that the points on the graph could be fit by a straight line (linear equation). The linear equation was used to find the values of $\mathrm{a}_{\mathrm{T}}$ at different temperatures. To shift the master curve from the reference temperature to any desired temperature, the value of $\mathrm{a}_{\mathrm{T}}$ for that temperature was found using the equation and was forced to be equal to one. The values of $\mathrm{a}_{\mathrm{T}}$ for the other temperatures were changed correspondingly and the curve was shifted to the desired temperature. The plots of shift factors vs. temperature at $40{ }^{\circ} \mathrm{C}$ and $21.1{ }^{\circ} \mathrm{C}$ are shown in Figures 2.37 to 2.41 .

The plots of compliance vs. time divided by the shift factor for different materials at standard room temperature of $21.1{ }^{\circ} \mathrm{C}$ are shown in Figures 2.42 to 2.46 .

The ASTM D790 tests being conducted at different temperatures produced modulus of elasticity that could not be fairly compared with each other. This is because of the influence of temperature on the properties of viscoelastic materials. Hence to draw a comparison of the modulus of elasticity, the values obtained at different temperatures were all shifted to the reference room temperature of $21.1{ }^{\circ} \mathrm{C}$ using the master curve at $21.1^{0} \mathrm{C}$.

It was noticed that the initial slope of the stress-strain curve from the ASTM testing was at around a time of 12 seconds after the testing commenced. ASTM D790 was conducted at temperature $\mathrm{T}_{\mathrm{a}}$ (say $25^{\circ} \mathrm{C}$ ) to obtain the modulus $\mathrm{E}_{\mathrm{a}}$. The reciprocal of the compliance at 12 seconds $\left(D_{a}^{-1}\right)$ was found on the master TTSP curve at $T_{a}$. The same 
was done to the master TTSP curve at the reference temperature $\mathrm{T}_{\mathrm{R}}=21.1{ }^{0} \mathrm{C}$ to get the reciprocal of the compliance $D_{R}^{-1}$ at temperature $T_{R}$. The percentage difference between both was calculated and was applied to the modulus of elasticity $E_{a}$ found by the ASTM test at $T_{a}$ to get the actual modulus $E_{R}$ at $T_{R}$, as

$$
\begin{gathered}
\% d=\frac{D_{a}^{-1}-D_{R}^{-1}}{D_{R}-1} \times 100 \\
E_{R}=\frac{\% d \times E_{a}}{100}
\end{gathered}
$$

\subsection{SPECIAL CASES OF TESTING}

Some special cases were considered in the test plan, as shown in Table 2.1. The effect of age on the modulus of elasticity was studied. Tests following the same method were conducted on the samples after aging them. Tests were also conducted on samples that were never annealed. These were termed as produced samples. The as produced samples were tested in the longitudinal direction and were cut from the one-foot pipe sample directly. For materials A, B and C, the samples, which were annealed for the 24hour test, were tested after more than 6000 hours. The same procedure of temperature correction, as mentioned above, was followed to find the modulus of elasticity at $21.1{ }^{0} \mathrm{C}$. Table 2.8 shows the Modulus of Elasticity for all the materials and testing cases at a reference temperature of $21.1{ }^{0} \mathrm{C}$.

\subsection{SUMMARY}

The final value of Modulus of Elasticity reported is the average of the values of the tests for each material. A summary of the points that were considered during testing is given below: 
1. Procedure B of the ASTM D790 standard was used (Strain rate = $0.1 \mathrm{~mm} / \mathrm{mm} / \mathrm{min})$.

2. For materials $\mathrm{A}, \mathrm{B}$ and $\mathrm{C}$, ten samples of each material were tested, 5 in longitudinal and 5 in hoop direction. For material D, 10 samples were tested in the longitudinal direction, five with the curvature on the top and five with curvature on the bottom and for material E, 5 samples were tested in the longitudinal direction.

3. Samples of materials $A, B, C$ and $E$ were annealed in the furnace prior to testing for a temperature $15^{0} \mathrm{C}$ above the $\mathrm{T}_{\mathrm{g}}$.

4. Quenching was done in between aluminum plates for 24 hours at room temperature.

5. The test was completed within 2 hours of removing from the aluminum plates.

\subsection{CONCLUSIONS}

The following are the conclusions drawn from the ASTM D790 testing of polymer liner samples:

1. The measurements of width and depth of the samples had to be taken accurately to obtain the right results.

2. Once tested, the sample could not be flipped over and tested again immediately. They had to be annealed or relaxed, to be tested again.

3. Annealing above the $T_{g}$ rejuvenated the sample and hence the modulus values obtained were found to be nearly the same every time the samples were annealed and tested. 
4. The slope of the flexural stress vs. flexural strain curve up to $2 \%$ did not yield the right modulus for the material and hence could not be considered as slope of the initial portion of the curve.

5. The fourth-order polynomial of the complete stress strain curve did not yield the right modulus of elasticity of the material because for higher strains, the deflection exceeded $10 \%$ of the span thus violating the ASTM D790 standard.

6. The fourth-order polynomial fitted to the flexural stress vs. flexural strain curve after truncating deflections greater than $10 \%$ of the span gave the accurate modulus of elasticity of the material.

7. As the age of the material increased, it was found that the material became stiffer and the modulus of elasticity of the material increased. For materials A, B, C, the modulus approached asymptotically the modulus of the as produced material which correspond to the longest age available for testing. The age $t_{e}$ of as-produced samples at time of testing was computed using the date of manufacture from Table 1.1 .

8. The testing temperature has an influence on the modulus of elasticity, i.e. a test conducted at a higher temperature would yield a modulus of elasticity lower than that yielded by a test conducted at lower temperature. Thus it is necessary to know the temperature shift factors for different aging conditions to draw a fair conclusion. 


\begin{tabular}{|c|c|c|c|c|}
\cline { 2 - 5 } \multicolumn{1}{c|}{} & \multicolumn{4}{c|}{ Test Time te (hours) } \\
\cline { 2 - 5 } \multicolumn{1}{c|}{} & 24 & As Produced & 6000 & 6500 \\
\hline Material A & $5 \mathrm{~L}, 5 \mathrm{H}$ & $5 \mathrm{~L}$ & $5 \mathrm{~L}, 5 \mathrm{H}$ & $5 \mathrm{~L}$ \\
\hline Material B & $5 \mathrm{~L}, 5 \mathrm{H}$ & $5 \mathrm{~L}$ & $5 \mathrm{~L}, 5 \mathrm{H}$ & $\sim \sim$ \\
\hline Material C & $5 \mathrm{~L}, 5 \mathrm{H}$ & $5 \mathrm{~L}$ & $5 \mathrm{~L}, 5 \mathrm{H}$ & $\sim \sim$ \\
\hline Material D & $\sim \sim$ & $5 \mathrm{~T}, 5 \mathrm{~B}$ & $\sim \sim$ & $\sim \sim$ \\
\hline Material E & $10 \mathrm{~L}$ & $5 \mathrm{~L}$ & $\sim \sim$ & $\sim \sim$ \\
\hline
\end{tabular}

L - Longitudinal Direction

$\mathrm{H}$ - Hoop Direction

$\mathrm{T}$ - Curvature on Top

B - Curvature on Bottom

Table 2.1 Short-term Test Plan Lay out

\begin{tabular}{|c|c|c|c|}
\hline Material & $\mathbf{T}_{\mathbf{g}}\left({ }^{0} \mathbf{C}\right)$ & $\mathbf{T}_{\mathbf{H}}\left({ }^{0} \mathbf{C}\right)$ & $\mathbf{T}_{\mathbf{M}}\left({ }^{0} \mathbf{C}\right)$ \\
\hline A & 70 & 85 & $\sim$ \\
\hline B & 90 & 105 & $\sim$ \\
\hline C & 85 & 100 & $\sim$ \\
\hline D & -30 & $*$ & 116 \\
\hline E & 135 & $150^{* *}$ & $\sim$ \\
\hline
\end{tabular}

* Samples could not be flattened.

Tested with negligible curvature.

** Flat samples were provided by the manufacturers.

Table 2.2 $T_{g}, T_{H}$ and $T_{m}$ for all materials 


\begin{tabular}{|c|c|c|}
\hline Sample Name & Initial Deflection $\Delta(\mathrm{mm})$ & $\Delta /$ span $(192 \mathrm{~mm})$ \\
\hline DB1 & 0.0963 & 0.000501563 \\
\hline DB2 & $\sim$ & $\sim$ \\
\hline DB3 & 0.0963 & 0.000501563 \\
\hline DB4 & 0.0962 & 0.000501042 \\
\hline DB5 & 0.0964 & 0.000502083 \\
\hline DC1 & 0.0987 & 0.000514063 \\
\hline DC2 & 0.0987 & 0.000514063 \\
\hline DC3 & 0.0987 & 0.000514063 \\
\hline DC4 & 0.0987 & 0.000514063 \\
\hline DC5 & 0.0987 & 0.000514063 \\
\hline AVERAGE & 0.0976 & 0.000508507 \\
\hline
\end{tabular}

Table 2.3 Ratio of Initial Mid span Deflection to Span for Material D 


\begin{tabular}{|c|c|c|c|}
\hline & $\begin{array}{l}\text { Time te } \\
\text { Temp C } \\
\text { Hum \% }\end{array}$ & $\begin{array}{c}24 \text { Hours } \\
19 \\
23 \\
\end{array}$ & \multirow[b]{2}{*}{$\begin{array}{l}\text { 4th order polymomial } \\
\text { defl upto } 10 \% \text { of span }\end{array}$} \\
\hline & \multirow[t]{2}{*}{$\begin{array}{l}\text { Linear E quation } \\
\text { Strain upto } 2 \%\end{array}$} & \multirow{2}{*}{$\begin{array}{c}\text { 4th order polynomial } \\
\text { Complete curve }\end{array}$} & \\
\hline & & & \\
\hline AL1 & 1.6397 & 1.6878 & 1.8374 \\
\hline AL2 & 1.4014 & 1.4502 & 1.5883 \\
\hline AL3 & 2.0699 & 2.1262 & 2.3221 \\
\hline AL4 & 1.6292 & 1.6505 & 1.8192 \\
\hline AL5 & 1.5941 & 1.6216 & 1.7962 \\
\hline AVERAGE & 1.6669 & 1.7073 & 1.9881 \\
\hline ST DEV & 0.2451 & 0.2513 & 0.2997 \\
\hline $\mathrm{Cu}$ & $15 \%$ & $15 \%$ & $15 \%$ \\
\hline & & HOOP & \\
\hline AH 1 & 1.8361 & 1.7194 & 1.8936 \\
\hline АH 2 & 1.7468 & 1.8154 & 1.9912 \\
\hline AH 3 & 2.1907 & 2.2488 & 2.4993 \\
\hline AH 4 & 1.5953 & 1.6275 & 1.7992 \\
\hline AH 5 & 1.5334 & 1.5777 & 1.7574 \\
\hline AVERAGE & 1.7805 & 1.7978 & 1.8726 \\
\hline ST DEV & 0.2588 & 0.2680 & 0.2706 \\
\hline $\mathrm{Cu}$ & $15 \%$ & $15 \%$ & $14 \%$ \\
\hline AVERAGE & 1.7237 & 1.7525 & 1.9304 \\
\hline ST DEV & 0.2451 & 0.2495 & 0.2759 \\
\hline $\mathrm{Cu}$ & $14 \%$ & $14 \%$ & $14 \%$ \\
\hline
\end{tabular}

Table 2.4 Values of E (GPa) for Various Fits for Material A 


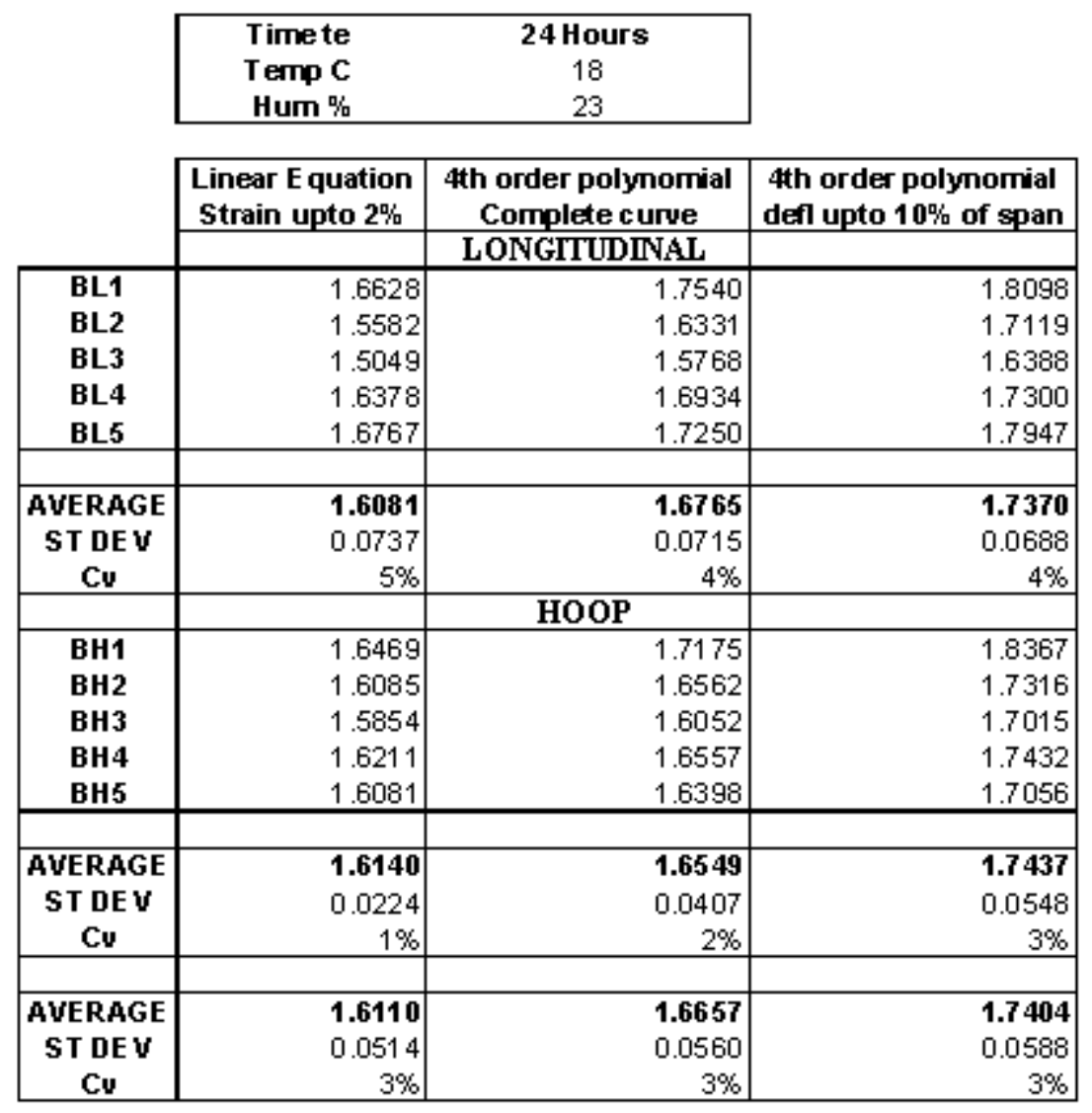

Table 2.5 Values of E (GPa) for Various Fits for Material B 


\begin{tabular}{|c|c|c|c|}
\hline & $\begin{array}{l}\text { Time te } \\
\text { Temp C } \\
\text { Hum \% }\end{array}$ & $\begin{array}{c}24 \text { Hours } \\
19 \\
23 \\
\end{array}$ & \\
\hline & $\begin{array}{l}\text { Linear E quation } \\
\text { Strain upto } 2 \%\end{array}$ & $\begin{array}{c}\text { 4th order polynomial } \\
\text { Complete curve }\end{array}$ & $\begin{array}{l}\text { 4th order polynomial } \\
\text { defl upto } 10 \% \text { of span }\end{array}$ \\
\hline CL1 & 13233 & LONGITUDINAL & 1 \\
\hline CL2 & $\begin{array}{l}1.3535 \\
1.3837\end{array}$ & $\begin{array}{l}1.4554 \\
1.4119\end{array}$ & $\begin{array}{l}1.536 \\
1.4598\end{array}$ \\
\hline CL3 & 1.3557 & 1.4593 & 1.5238 \\
\hline CL4 & 1.5371 & 1.6322 & 1.6742 \\
\hline CL5 & 1.6504 & 1.7636 & 1.8396 \\
\hline AVERAGE & 1.4561 & 1.5445 & 1.6070 \\
\hline ST DEV & 0.1325 & 0.1487 & 0.1517 \\
\hline $\mathrm{Cu}$ & $9 \%$ & $10 \%$ & $9 \%$ \\
\hline & & HOOP & \\
\hline CH1 & 1.4725 & 1.5686 & 1.6551 \\
\hline $\mathrm{CH} 2$ & 1.3811 & 1.4637 & 1.5303 \\
\hline CH3 & 1.3903 & 1.4396 & 1.4835 \\
\hline CH 4 & 1.4073 & 1.4863 & 1.5549 \\
\hline CH5 & 1.3637 & 1.4405 & 1.5212 \\
\hline AVERAGE & 1.4030 & 1.4797 & 1.5490 \\
\hline ST DE V & 0.0419 & 0.0533 & 0.0646 \\
\hline $\mathrm{Cu}$ & $3 \%$ & $4 \%$ & $4 \%$ \\
\hline AVERAGE & 1.4295 & 1.5121 & 1.5780 \\
\hline ST DEV & 0.0968 & 0.1107 & 0.1141 \\
\hline $\mathrm{Cu}$ & $7 \%$ & $7 \%$ & $7 \%$ \\
\hline
\end{tabular}

Table 2.6 Values of E (GPa) for Various Fits for Material C 


\begin{tabular}{|c|c|c|c|}
\hline & $\begin{array}{l}\text { Time te } \\
\text { Temp C } \\
\text { Hum \% }\end{array}$ & $\begin{array}{c}\text { virgin } \\
23.5 \\
37 \\
\end{array}$ & \multirow[b]{2}{*}{$\begin{array}{l}\text { 4th order polynomial } \\
\text { defl upto } 10 \% \text { of span }\end{array}$} \\
\hline & \multirow[t]{2}{*}{$\begin{array}{l}\text { Linear E quation } \\
\text { Strain upto } 2 \%\end{array}$} & \multirow{2}{*}{$\begin{array}{c}\text { 4th order polynomial } \\
\text { Complete curve }\end{array}$} & \\
\hline & & & \\
\hline DB1 & 0.5672 & 0.8484 & 0.8908 \\
\hline DB2 & & $\sim$ & $n$ \\
\hline DB3 & 0.5918 & 0.8998 & 0.9519 \\
\hline DB4 & 0.6200 & 0.9206 & 0.9732 \\
\hline DB5 & 0.6342 & 0.9562 & 1.0025 \\
\hline AVERAGE & 0.6033 & 0.9063 & 0.9546 \\
\hline ST DEV & 0.0298 & 0.0451 & 0.0473 \\
\hline $\mathrm{Cu}$ & $5 \%$ & $5 \%$ & $5 \%$ \\
\hline & & TOP CURVED & \\
\hline DT1 & 0.6298 & 0.8424 & 0.8791 \\
\hline DT2 & 0.5800 & 0.7849 & 0.8302 \\
\hline DT3 & 0.6095 & 0.8166 & 0.9058 \\
\hline DT4 & 0.6334 & 0.8422 & 0.9118 \\
\hline DT5 & 0.6290 & 0.8635 & 0.9017 \\
\hline AVERAGE & 0.6163 & 0.8299 & 0.8857 \\
\hline ST DE V & 0.0224 & 0.0302 & 0.0334 \\
\hline $\mathrm{Cu}$ & $4 \%$ & $4 \%$ & $4 \%$ \\
\hline AUERAGE & 0.5997 & 0.8521 & 0.9052 \\
\hline ST DEV & 0.0242 & 0.0507 & 0.0516 \\
\hline $\mathrm{Cu}$ & $4 \%$ & $6 \%$ & $6 \%$ \\
\hline
\end{tabular}

Table 2.7 Values of E (GPa) for Various Fits for Material D 


\begin{tabular}{|cc|}
\hline Time te & Virgin \\
Temp C & 25.5 \\
Hum \% & 64 \\
\hline
\end{tabular}

\begin{tabular}{|c|r|r|}
\cline { 2 - 3 } \multicolumn{1}{c|}{} & \multicolumn{1}{c|}{$\begin{array}{c}\text { Linear E quation } \\
\text { up to Breaking Point }\end{array}$} & $\begin{array}{l}\text { 4th order polynomial } \\
\text { up to Breaking Point }\end{array}$ \\
\cline { 2 - 3 } \multicolumn{1}{c|}{ EL1 } & 2.6624 & 2.4808 \\
EL2 & 1.9606 & 2.0557 \\
EL3 & 1.9602 & 1.9791 \\
E L4 & 2.3653 & 2.4261 \\
E L5 & 2.1436 & 2.1554 \\
\hline & & 2.2194 \\
\hline AVE RAGE & $\mathbf{2 . 2 1 8 4}$ & 0.2234 \\
ST DE & 0.2989 & $10 \%$ \\
Cv & $13 \%$ & \\
\hline
\end{tabular}

Table 2.8 Values of E (GPa) for Various Fits for Material E

\begin{tabular}{|c|c|c|c|c|c|c|c|}
\hline Time te (hours) & $\mathbf{2 4}$ & $\mathbf{6 2 4 0}$ & $\mathbf{6 2 6 4}$ & $\mathbf{6 6 4 8}$ & As Produced & $\mathbf{2 4}$ & As Produced \\
\hline Material A & 1.7760 & $\sim$ & 1.7185 & 2.0288 & $1.9293(8448)$ & 1.7570 & $1.9403(8496)$ \\
\hline Material B & 1.6708 & 1.9066 & $\sim$ & $\sim$ & $2.00046(6672)$ & $\sim$ & $\sim$ \\
\hline Material C & 1.5149 & 1.6718 & $\sim$ & $\sim$ & $1.719(6672)$ & $\sim$ & $\sim$ \\
\hline Material D & $\sim$ & $\sim$ & $\sim$ & $\sim$ & $0.95046(5448)$ & $\sim$ & $\sim$ \\
\hline Material E & 2.2638 & $\sim$ & $\sim$ & $\sim$ & $1.8581(\sim)$ & $\sim$ & $\sim$ \\
\hline
\end{tabular}

Values in ( ) indicate age te (hours) of "as produced" samples at the time of testing

Table 2.9 Modulus of Elasticity (GPa) at $21.1{ }^{0} \mathrm{C}$ for Various Testing Conditions for all Materials 


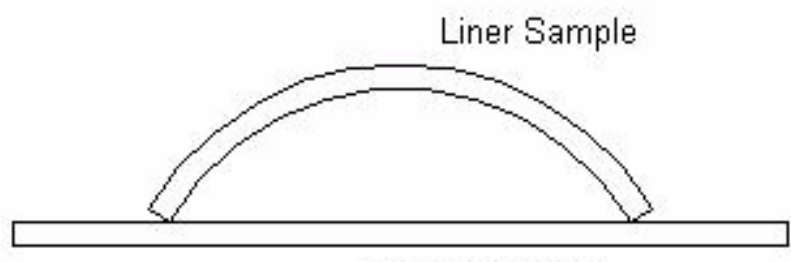

Aluminum Plate

Figure 2.1 Orientation of the sample in the oven

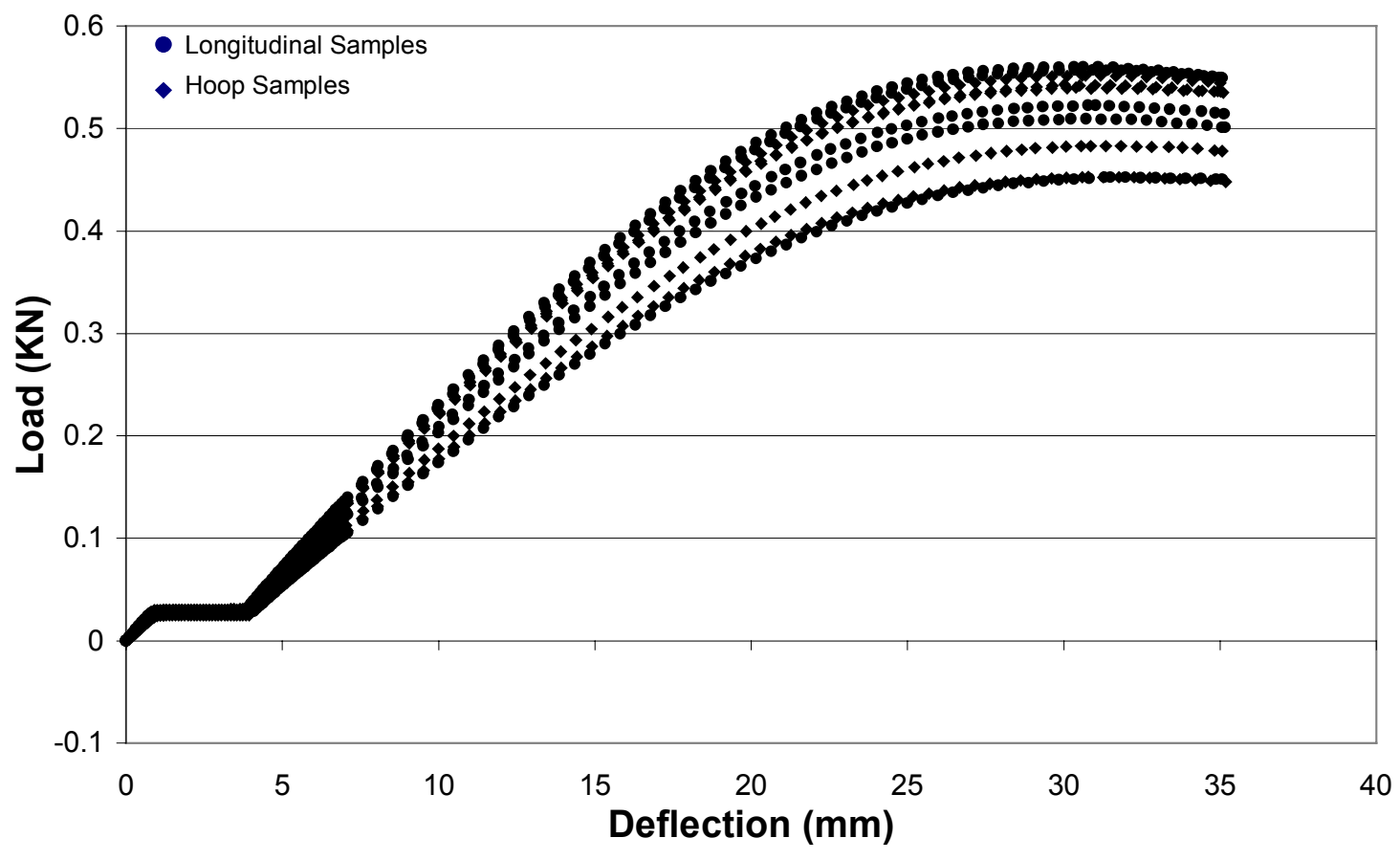

Figure 2.2 Load Vs. Deflection Curve for Material A 


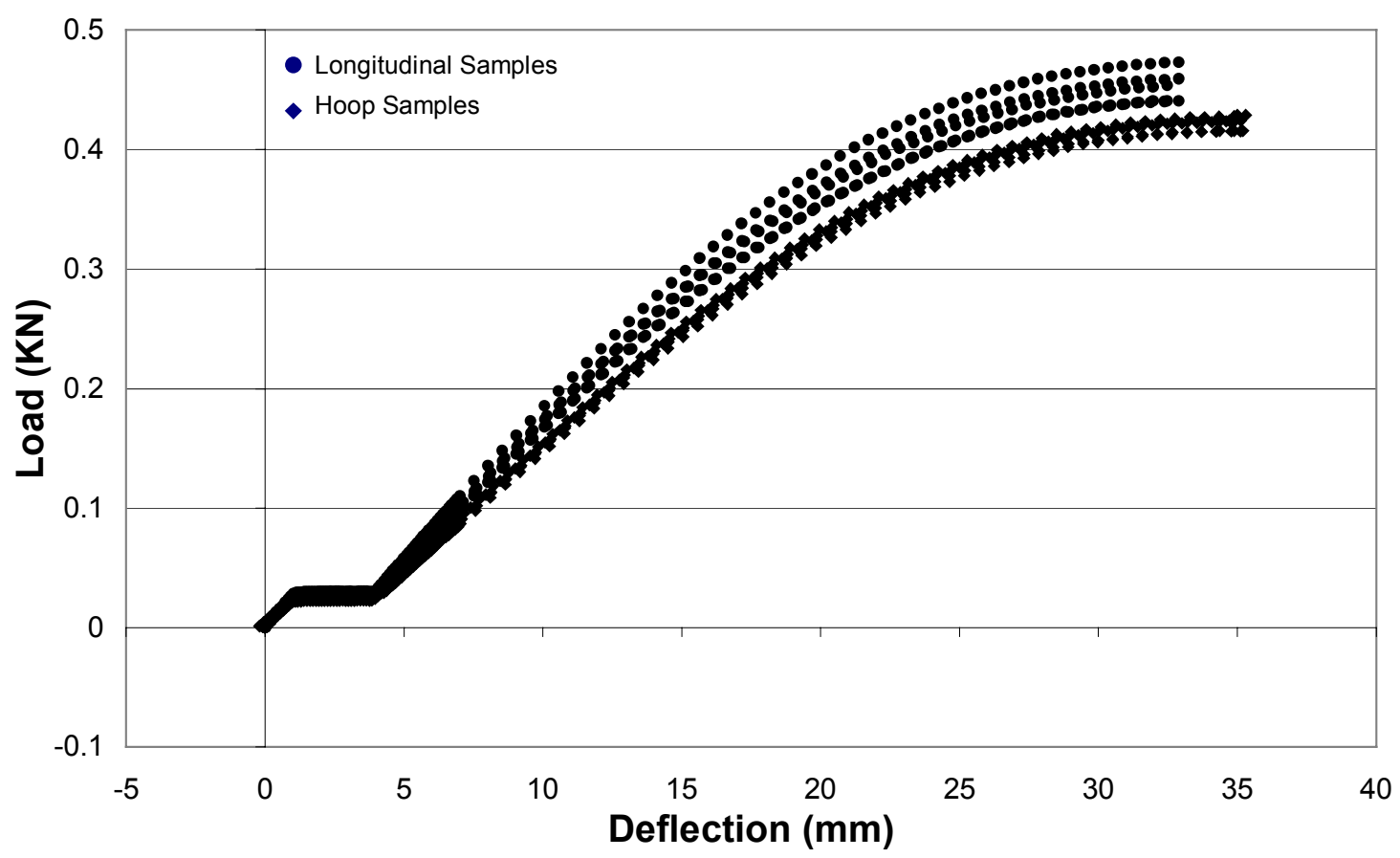

Figure 2.3 Load Vs. Deflection Curve for Material B

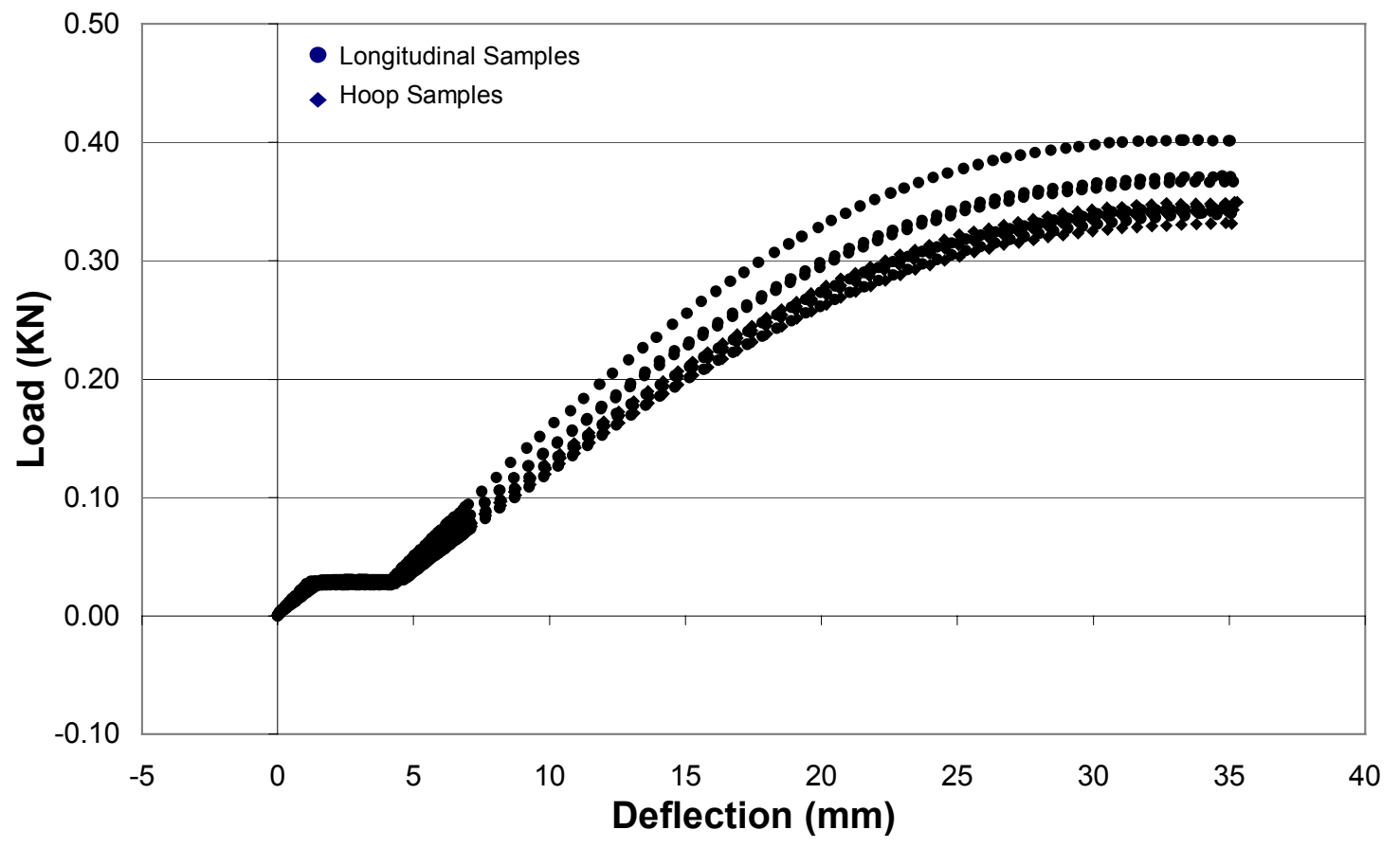

Figure 2.4 Load Vs. Deflection Curve for Material C 


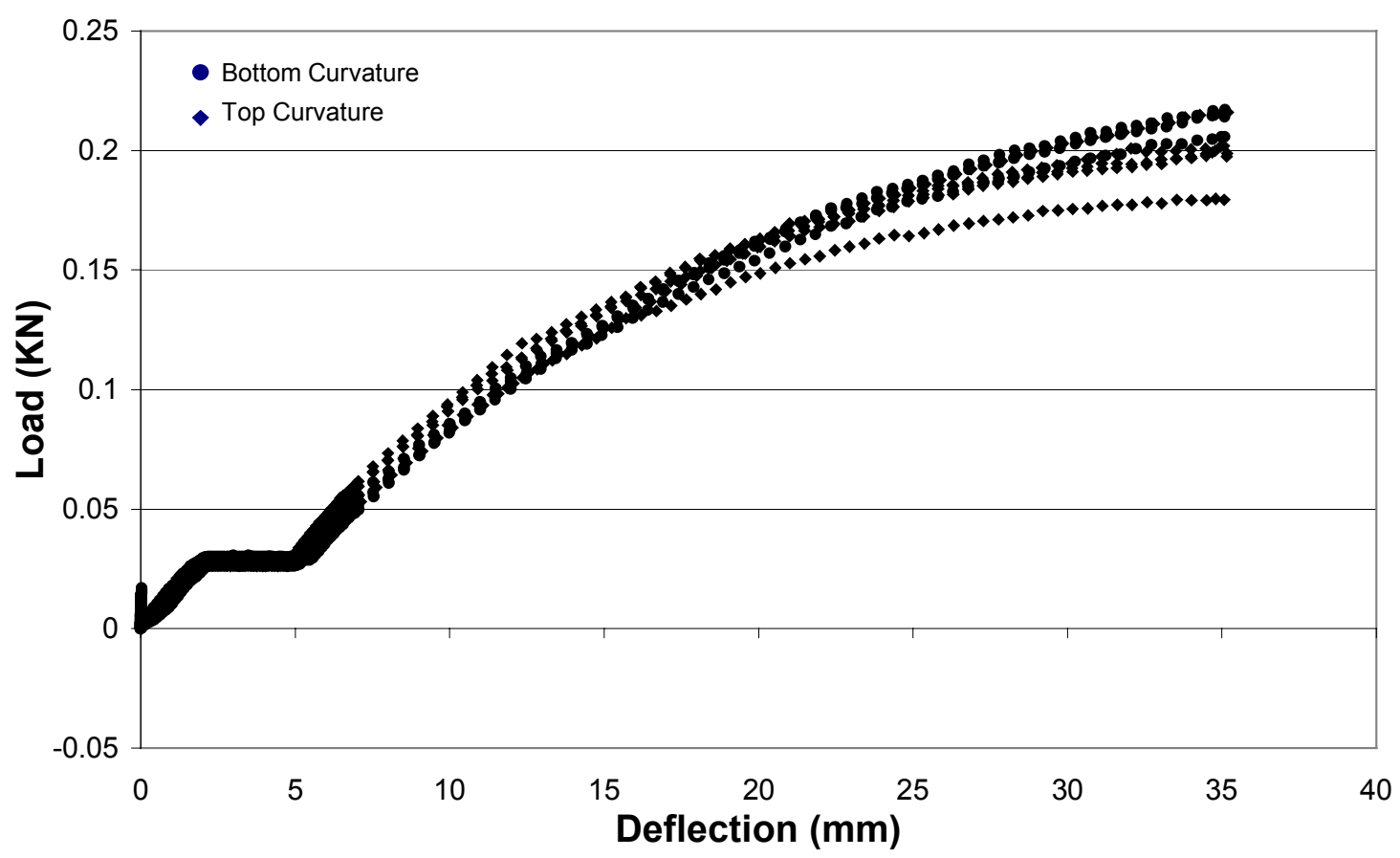

Figure 2.5 Load Vs. Deflection Curve for Material D

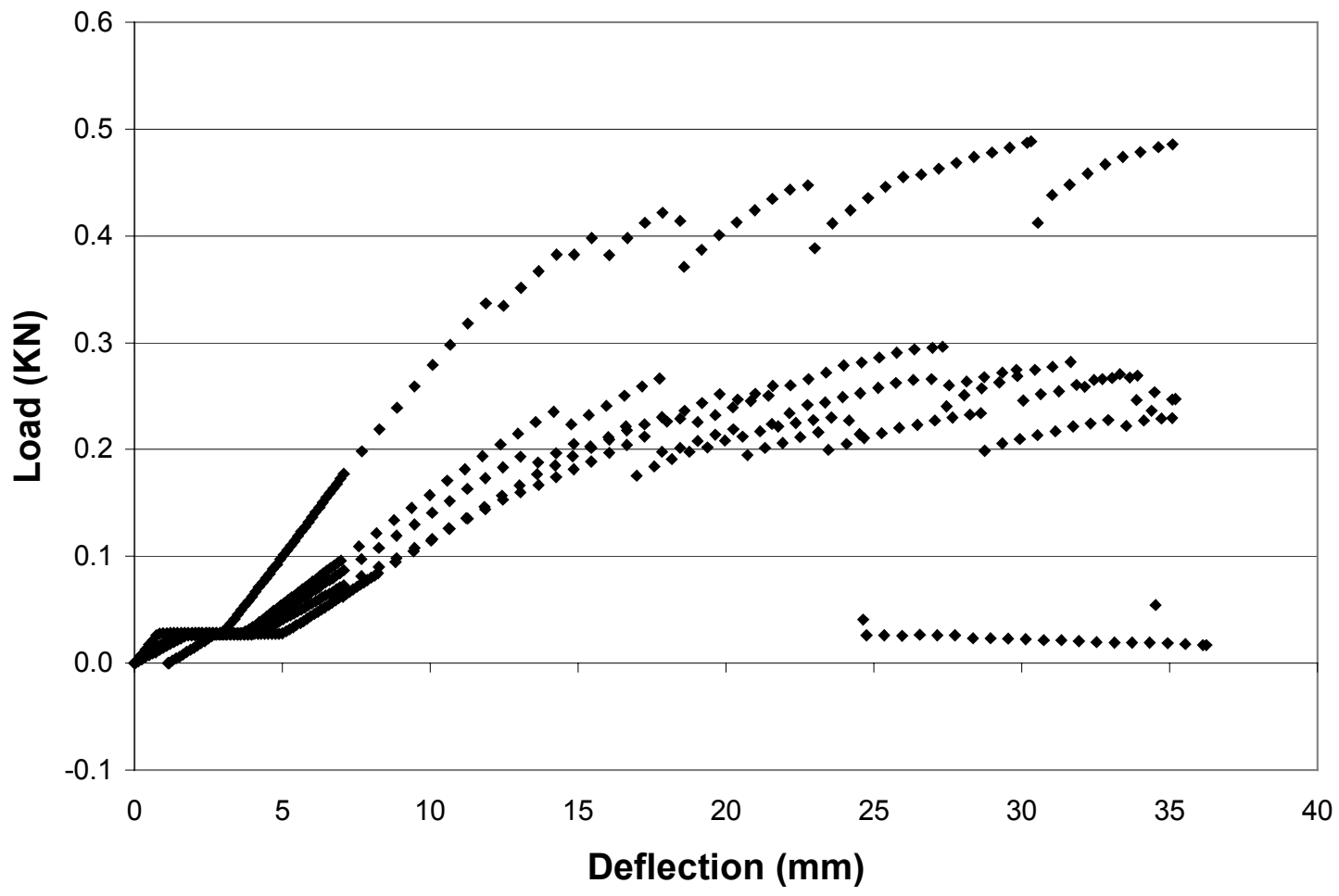

Figure 2.6 Load Vs. Deflection Curve for Material E 


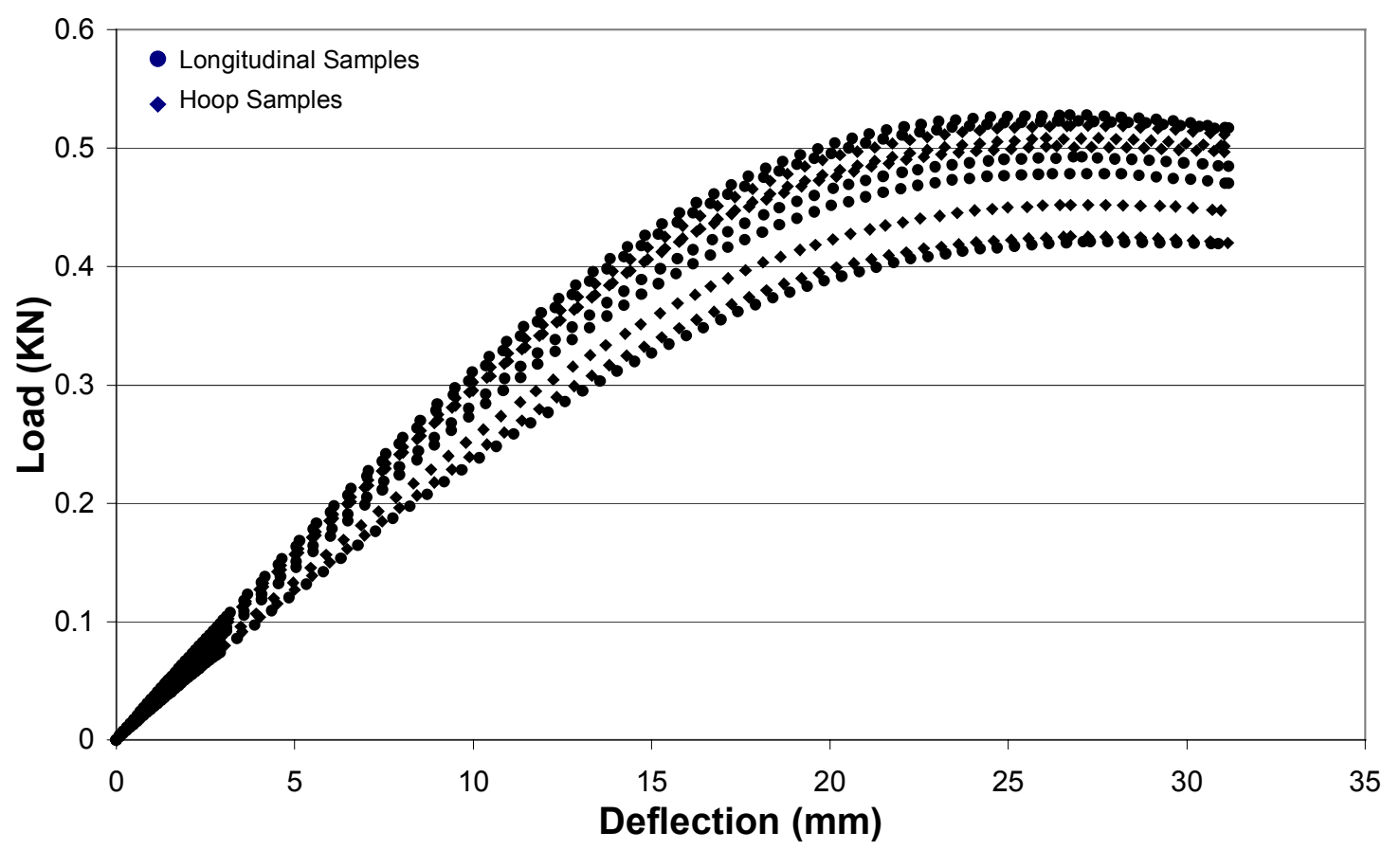

Figure 2.7 Load Vs. Deflection Curve for Material A (initial data discarded)

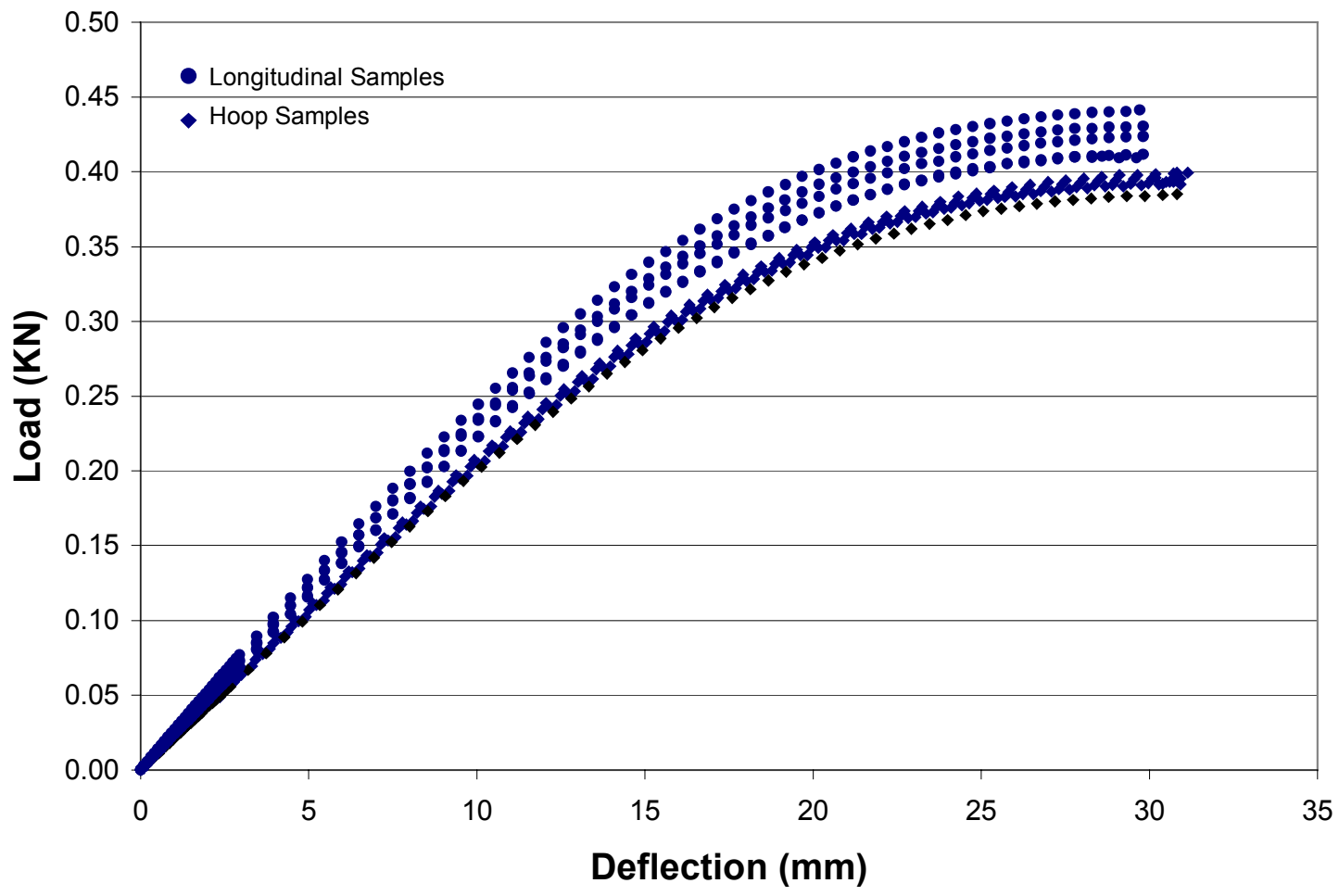

Figure 2.8 Load Vs. Deflection Curve for Material B (initial data discarded) 


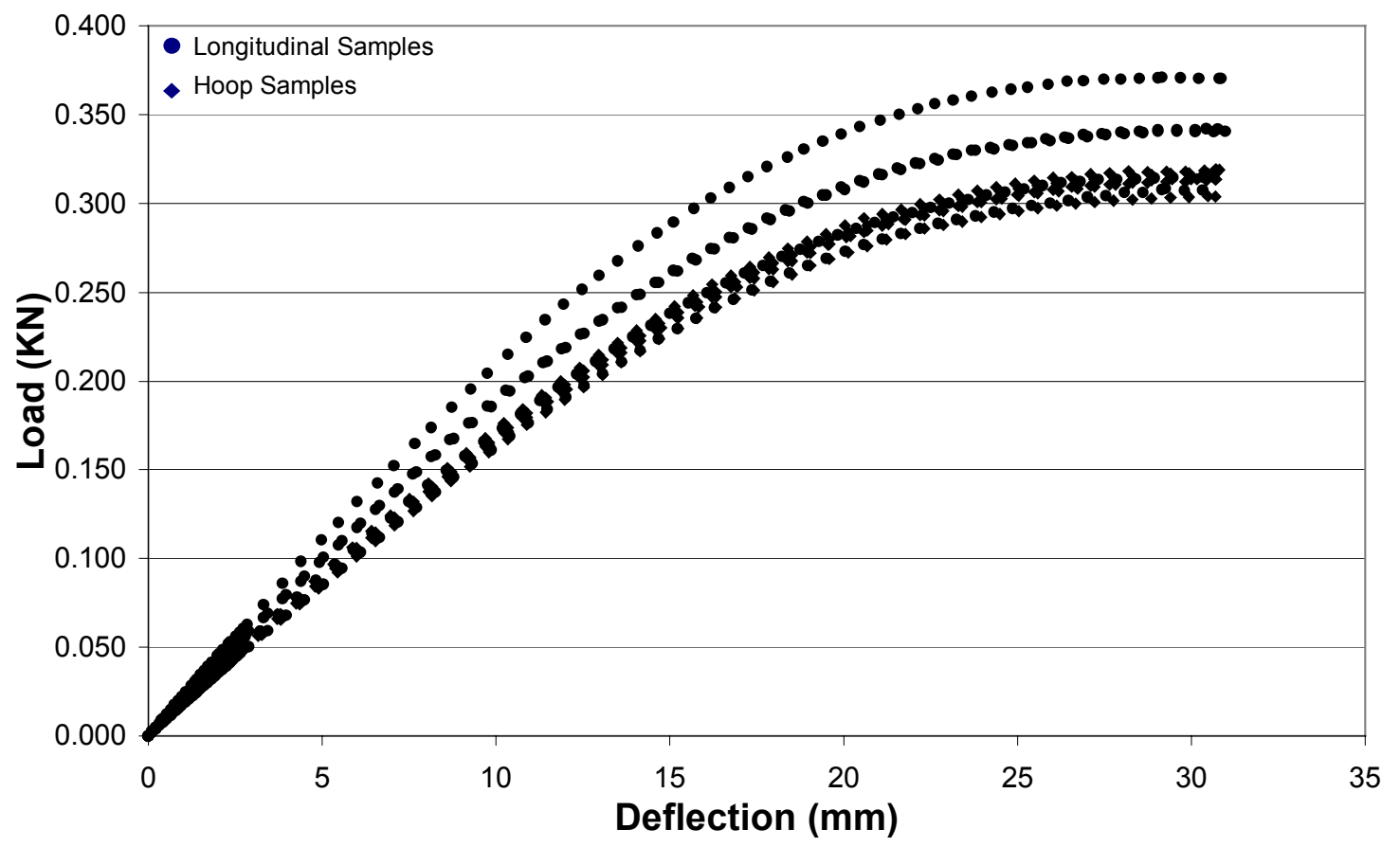

Figure 2.9 Load Vs. Deflection Curve for Material C (initial data discarded)

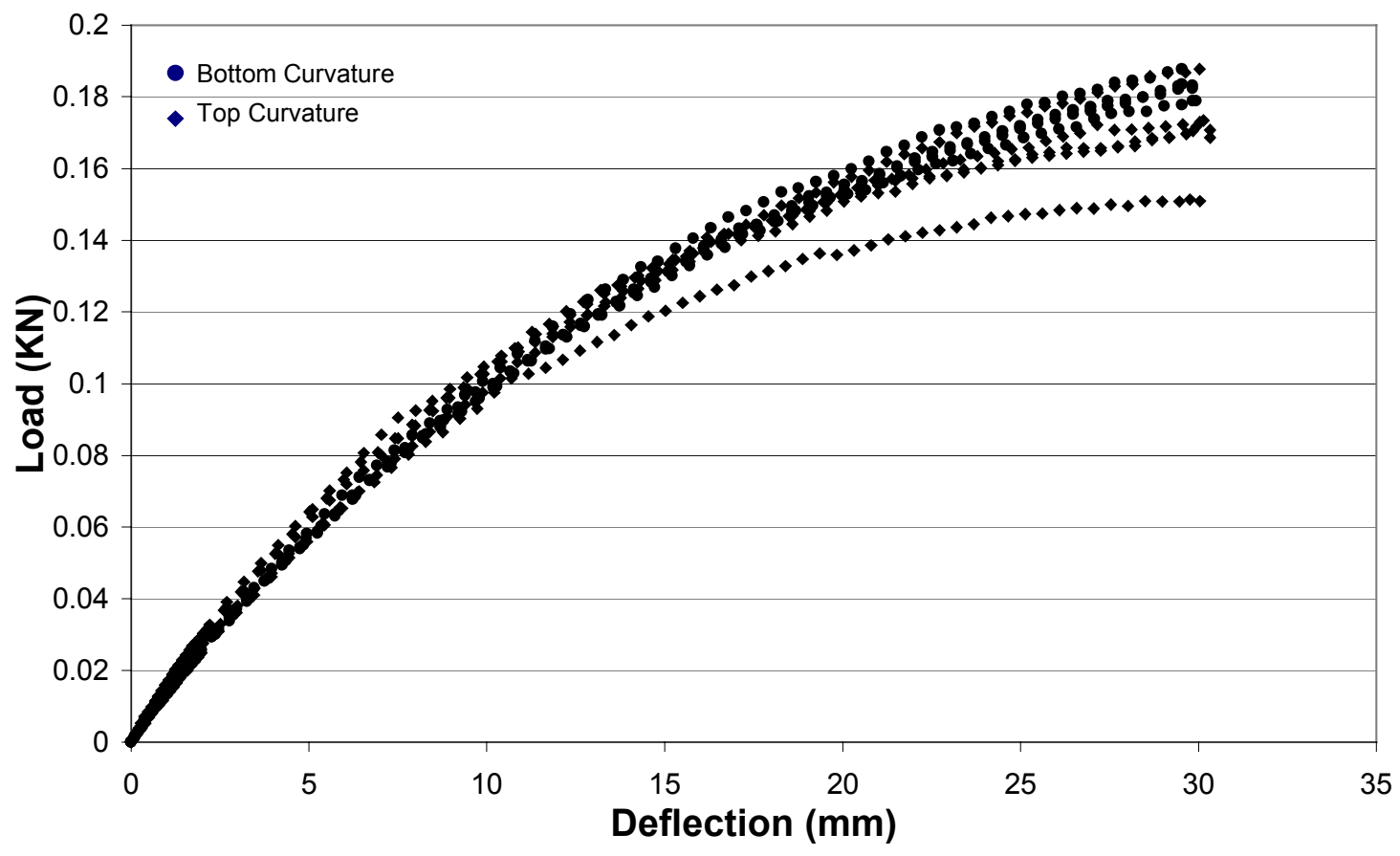

Figure 2.10 Load Vs. Deflection Curve for Material D (initial data discarded) 


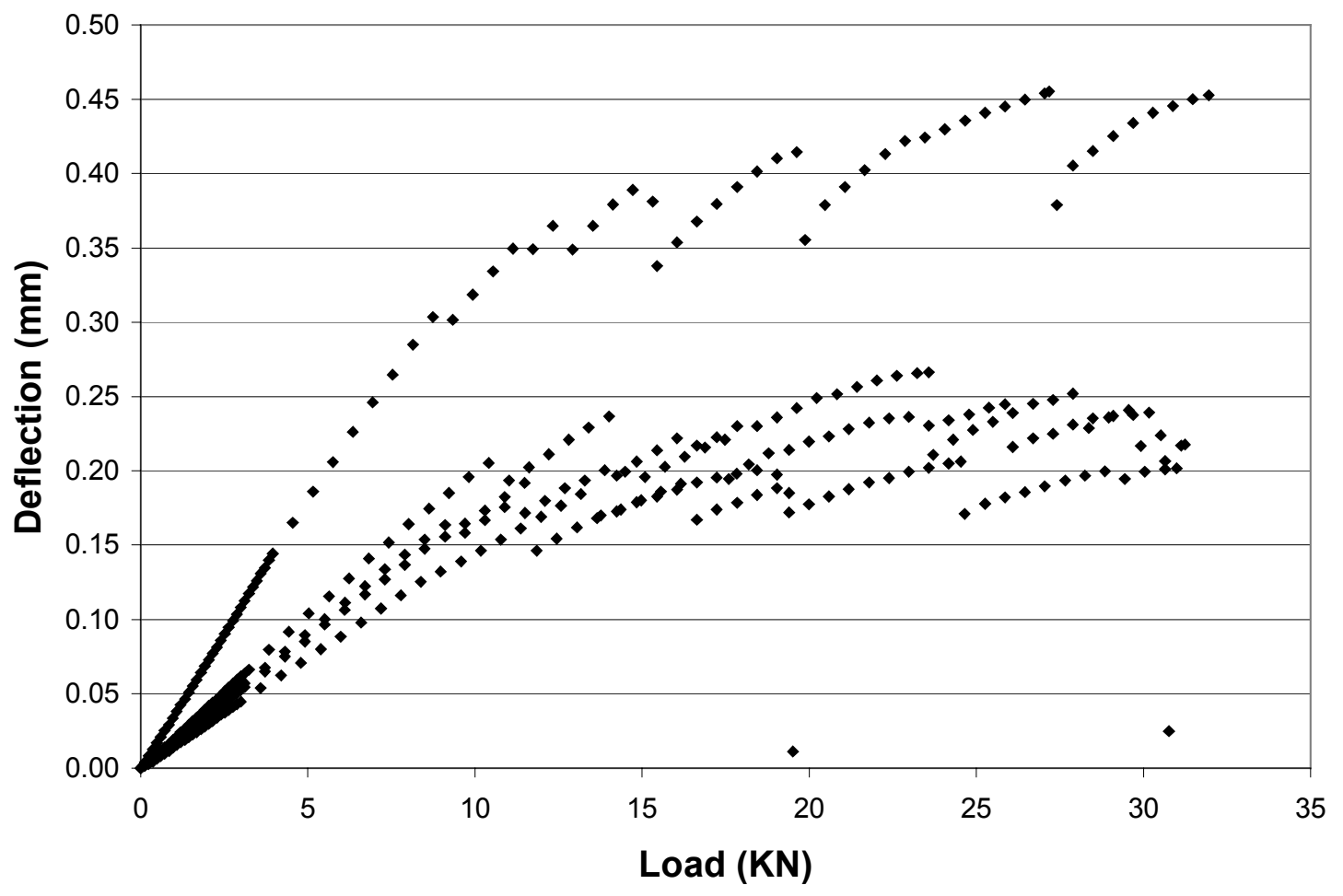

Figure 2.11 Load Vs. Deflection Curve for Material E (initial data discarded)

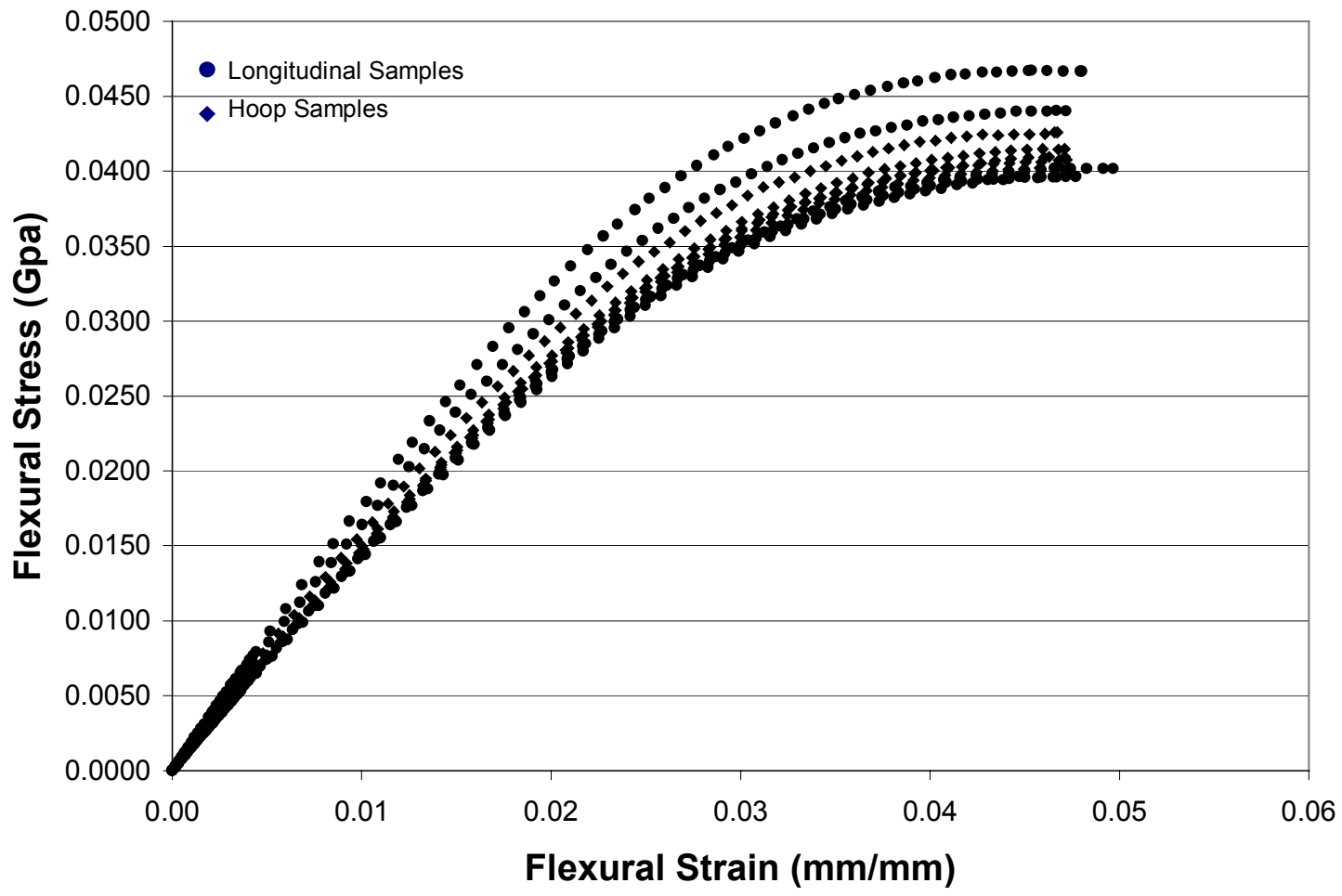

Figure 2.12 Flexural Stress Vs. Flexural Strain Curve for Material A 


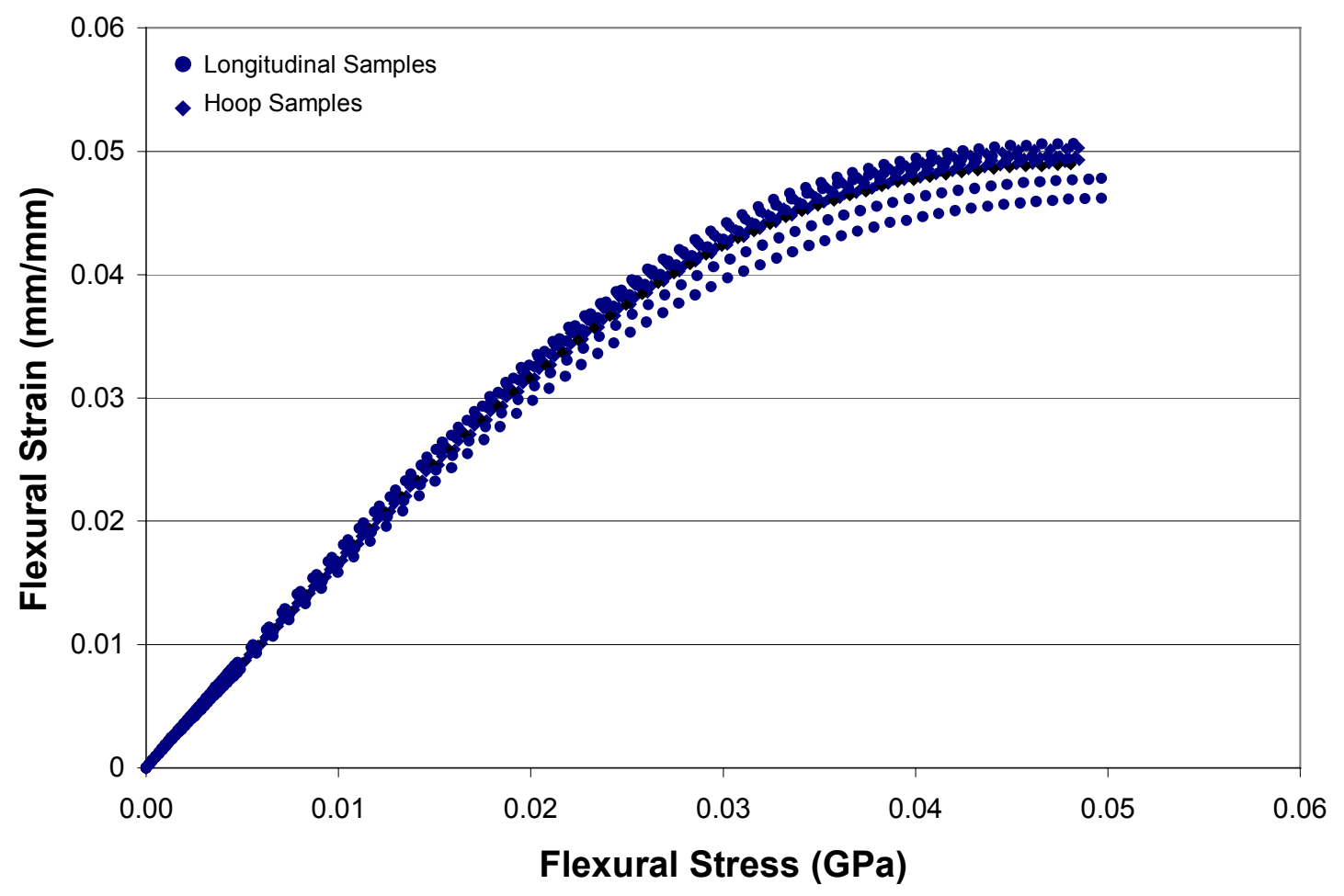

Figure 2.13 Flexural Stress Vs. Flexural Strain Curve for Material B

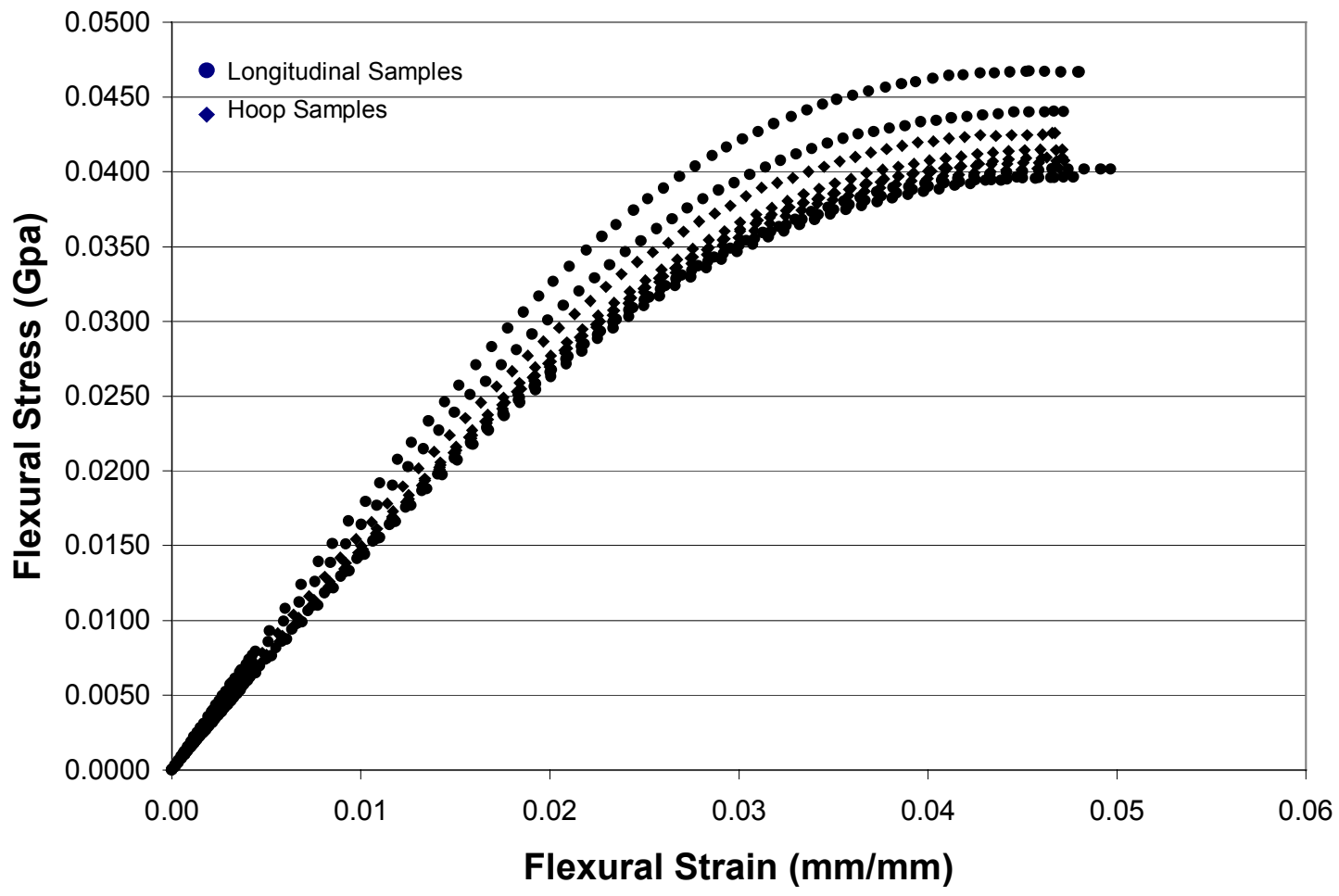

Figure 2.14 Flexural Stress Vs. Flexural Strain Curve for Material C 


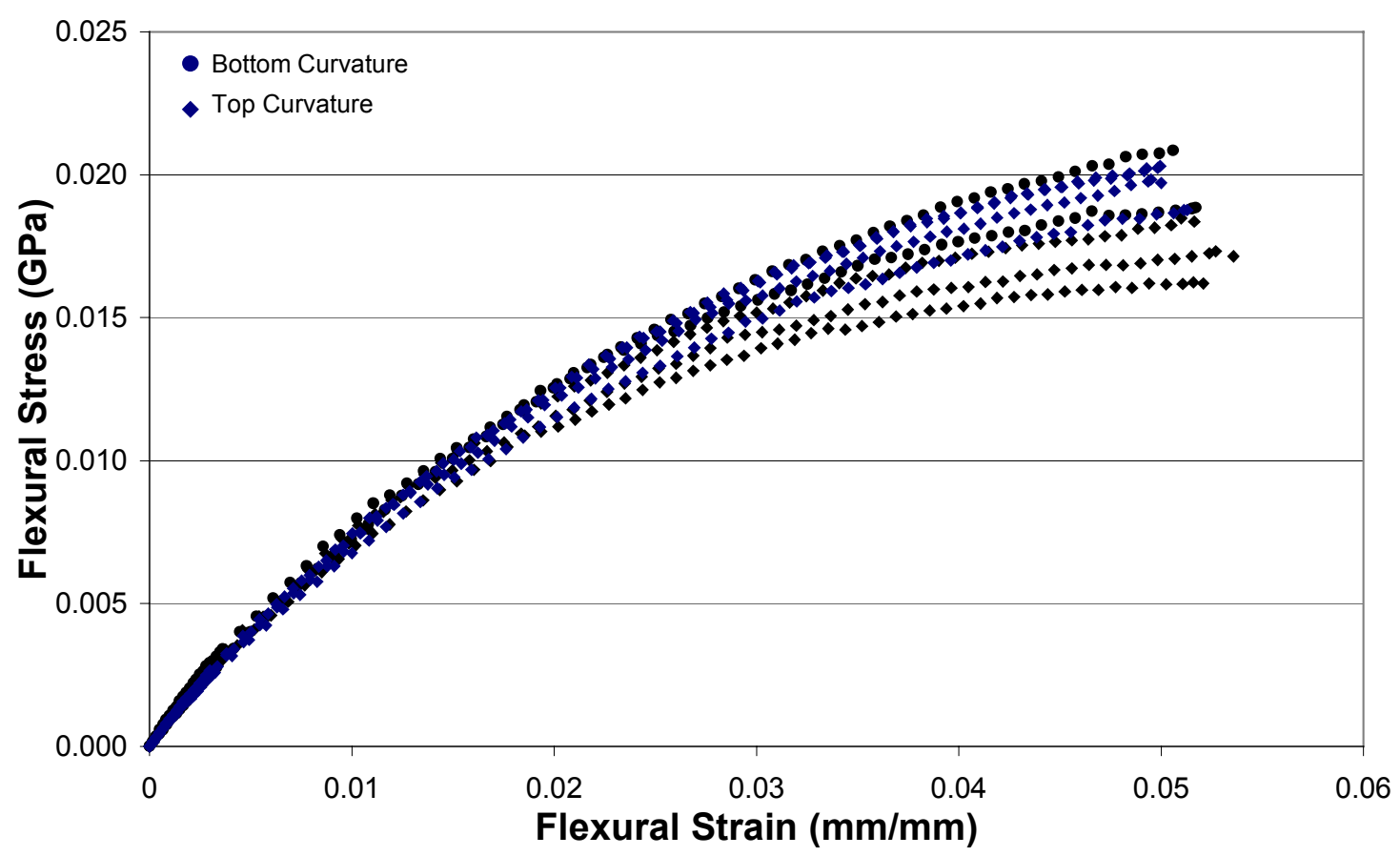

Figure 2.15 Flexural Stress Vs. Flexural Strain Curve for Material D

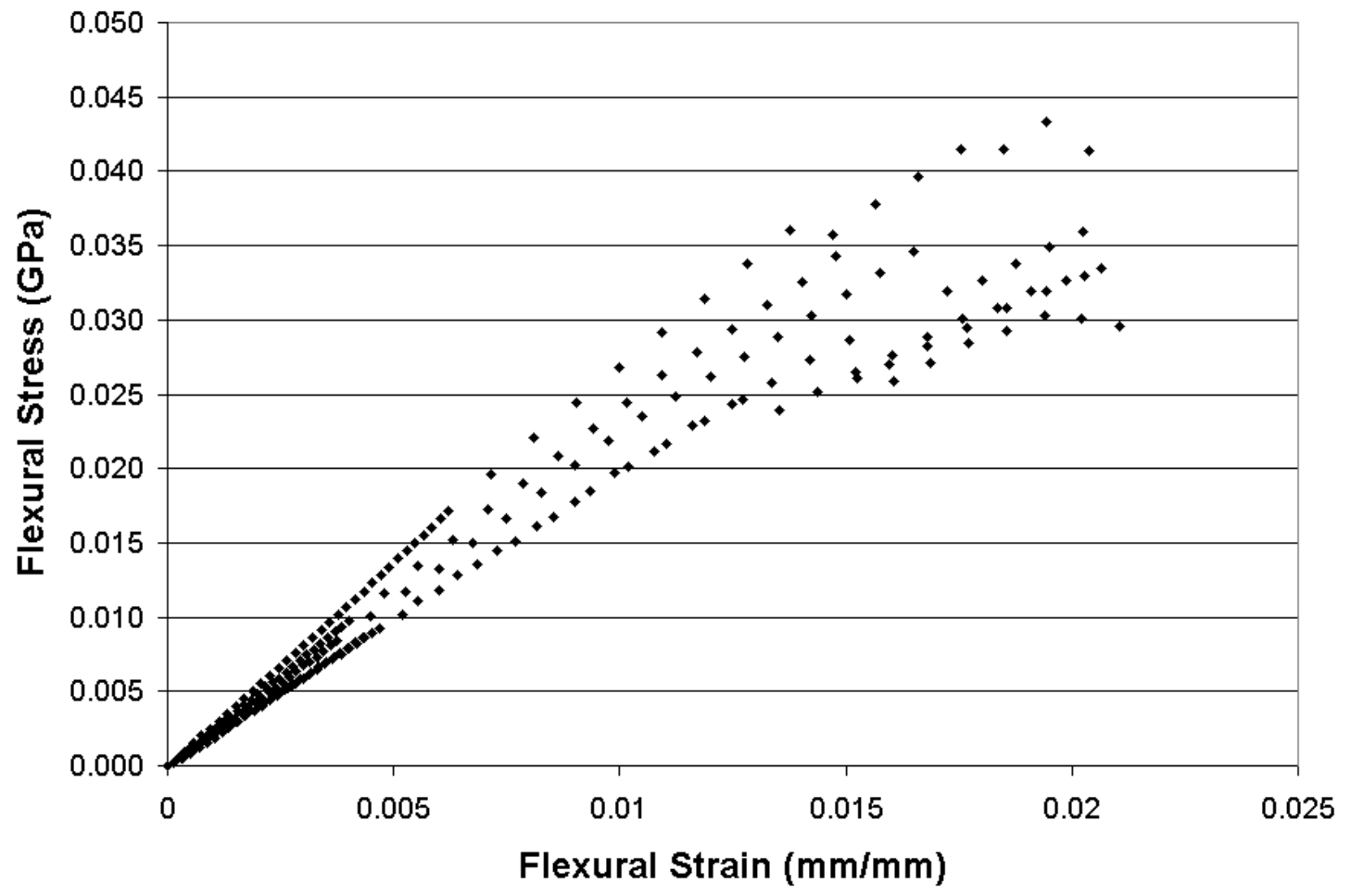

Figure 2.16 Flexural Stress Vs. Flexural Strain Curve for Material E 


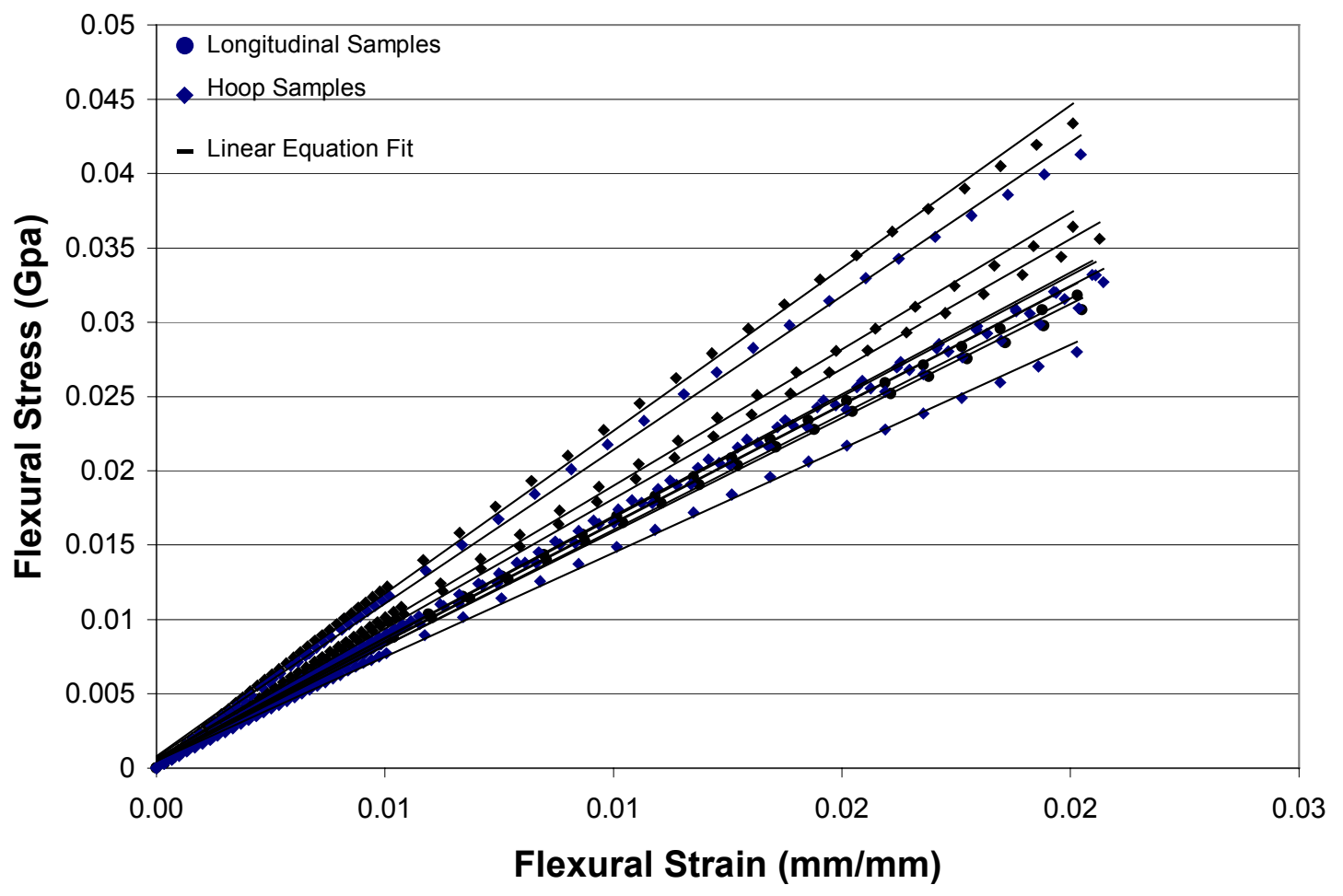

Figure 2.17 Linear fit of Stress Vs. Strain Curve up to 2\% strain for Material A

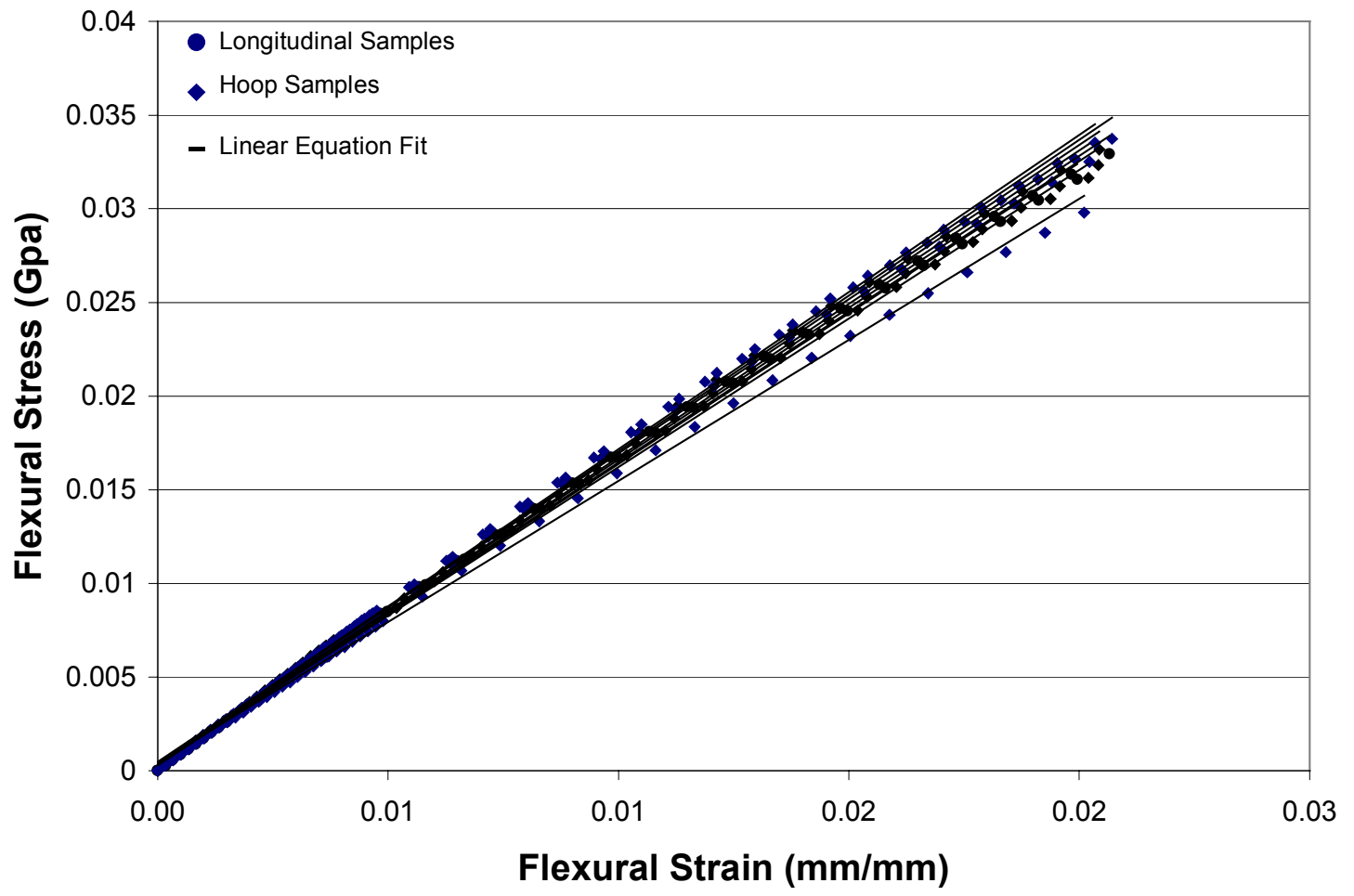

Figure 2.18 Linear fit of Stress Vs. Strain Curve up to 2\% strain for Material B 


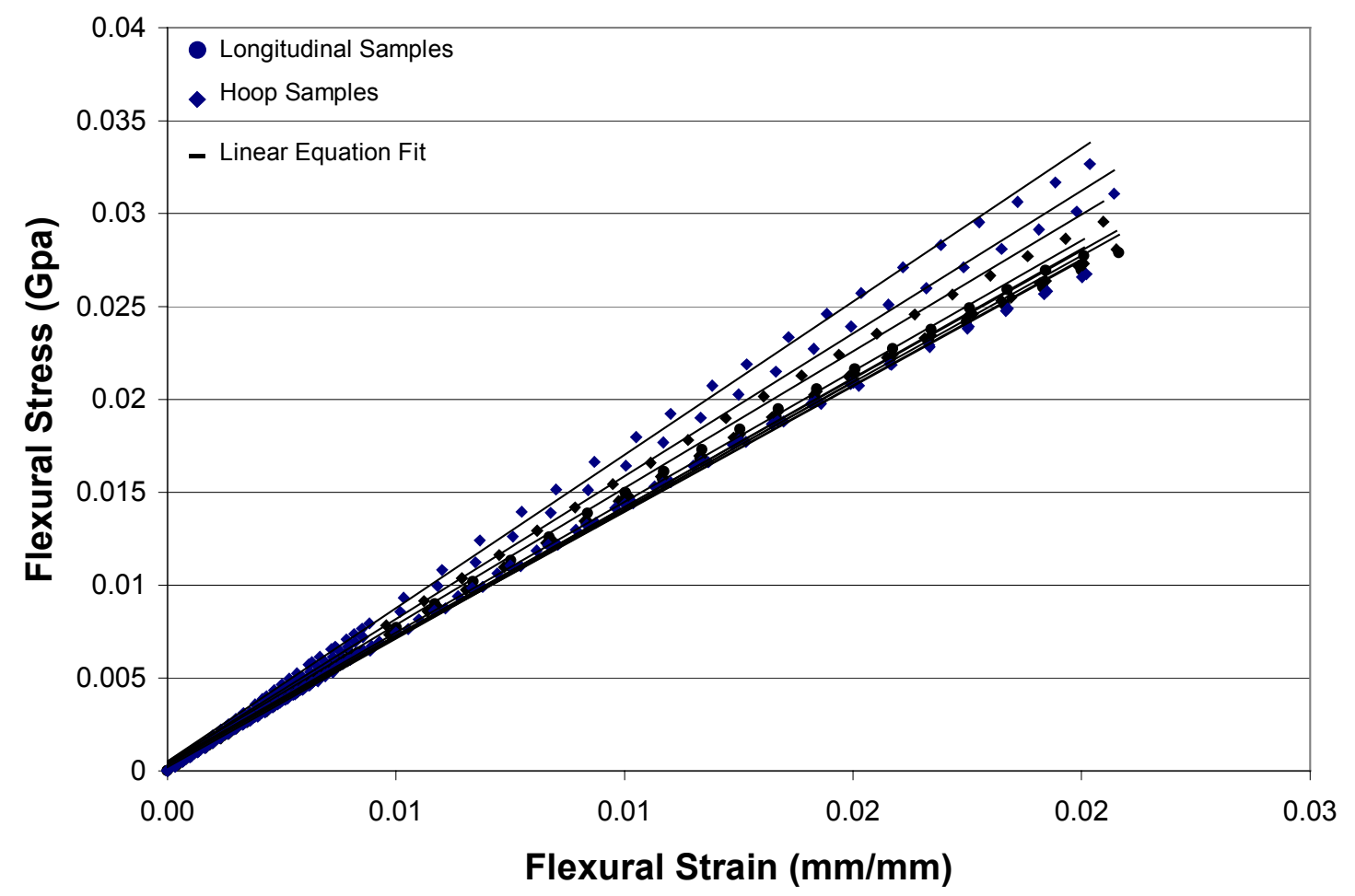

Figure 2.19 Linear fit of Stress Vs. Strain Curve up to 2\% strain for Material C

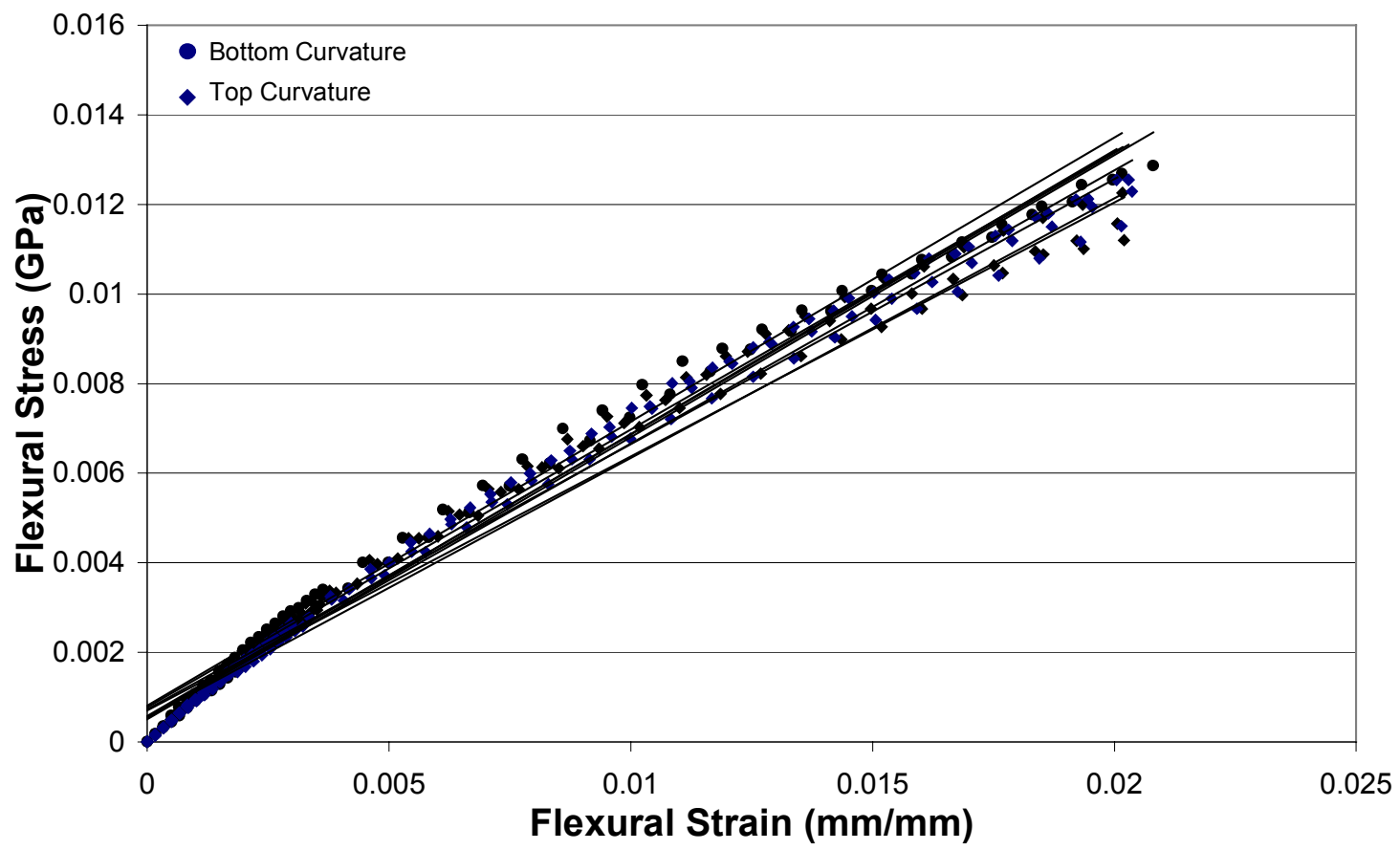

Figure 2.20 Linear fit of Stress Vs. Strain Curve up to 2\% strain for Material D 


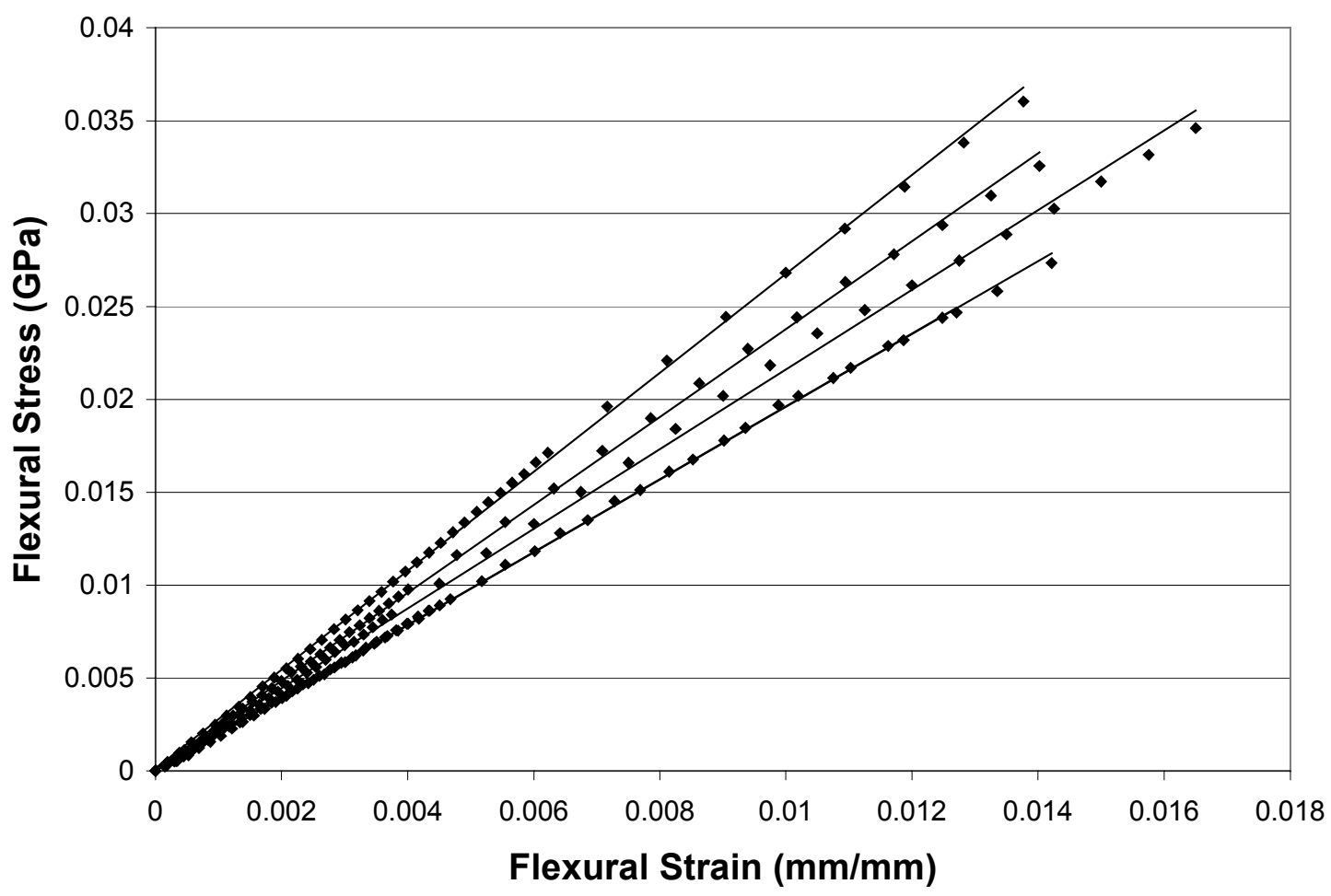

Figure 2.21 Linear fit of Stress Vs. Strain Curve up to Break Point for Material E

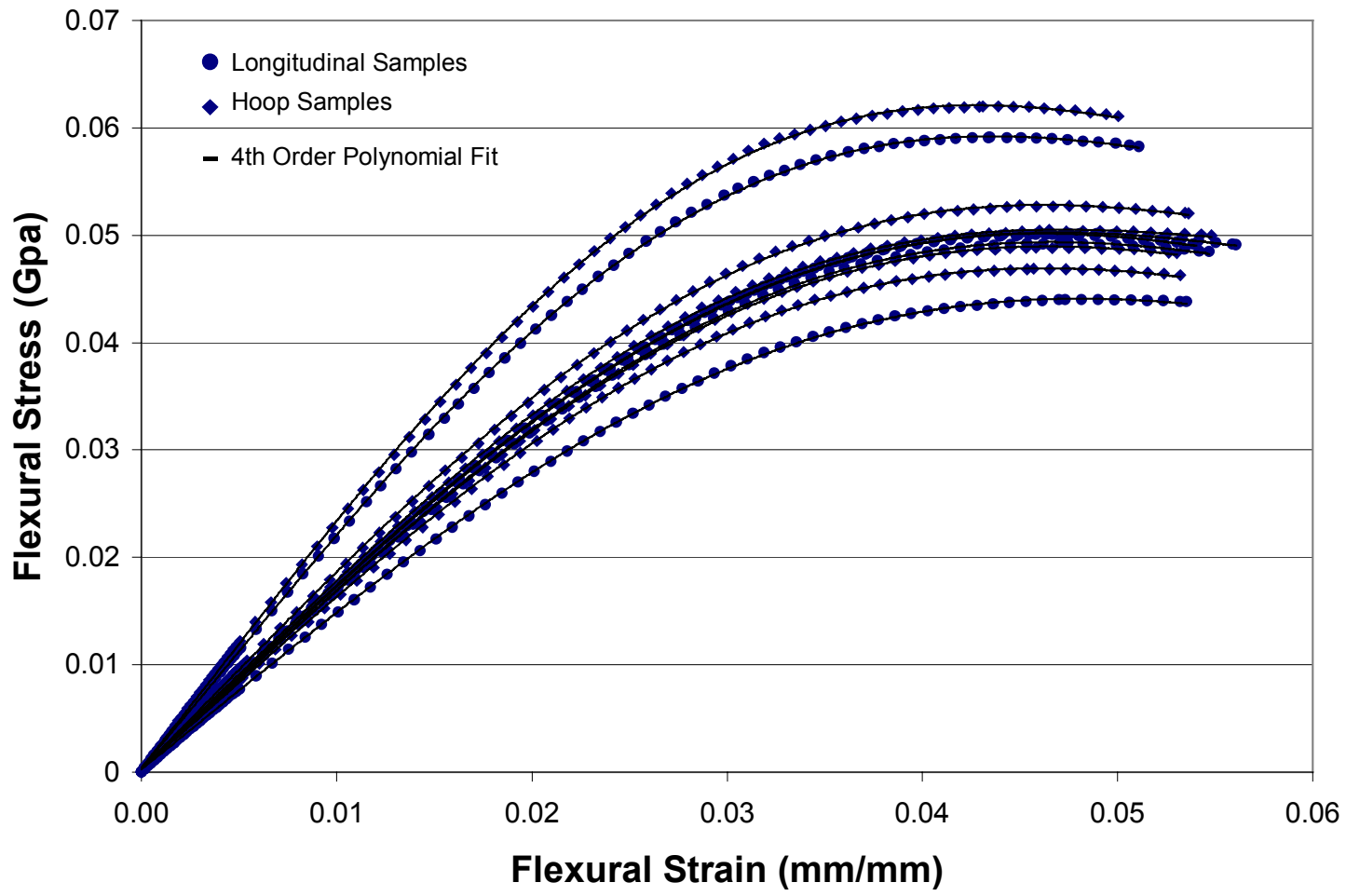

Figure 2.22 $4^{\text {th }}$ Order Polynomial fit of Stress Vs. Strain Curve for Material A 


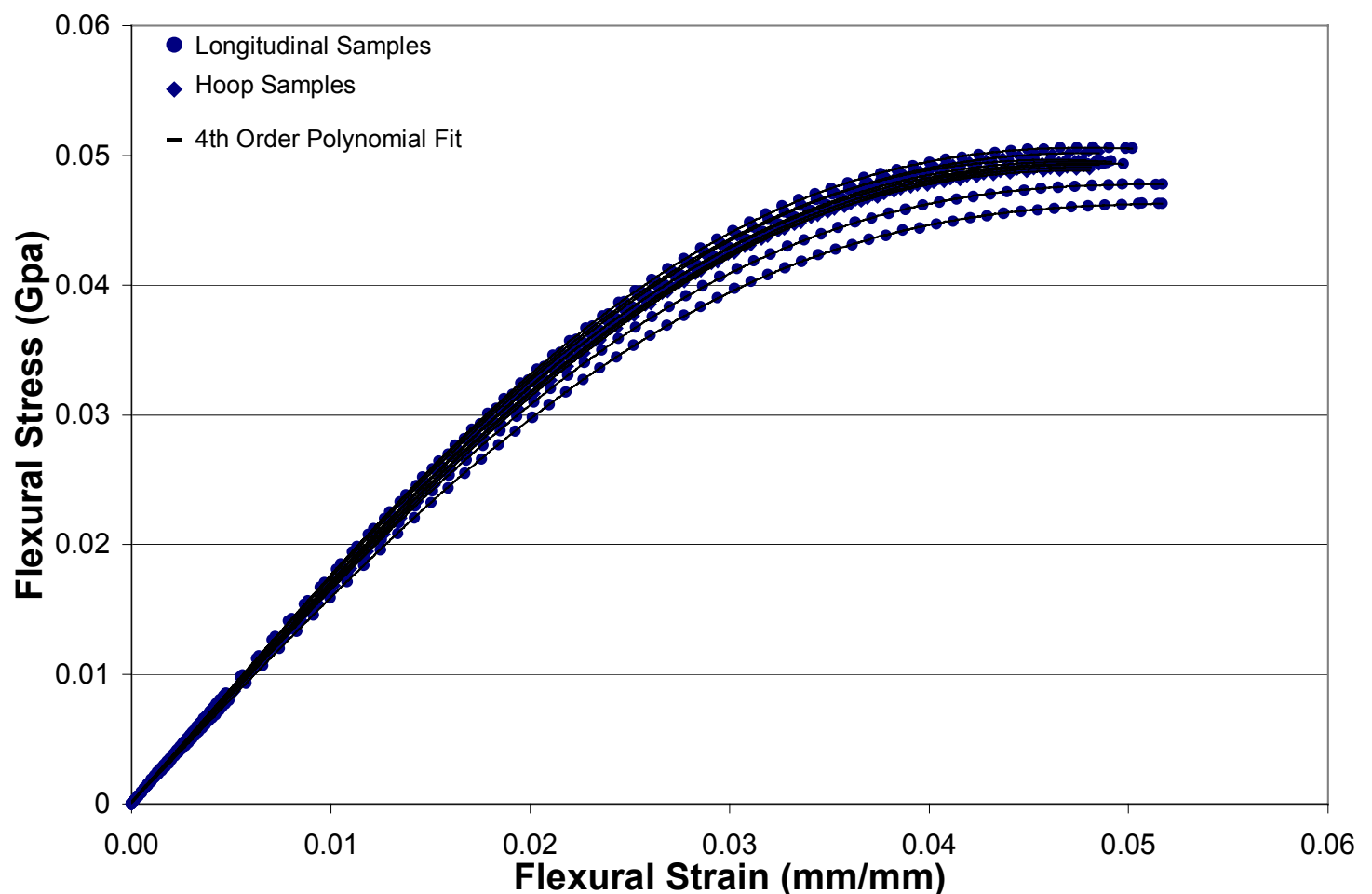

Figure 2.23 $4^{\text {th }}$ Order Polynomial fit of Stress Vs. Strain Curve for Material B

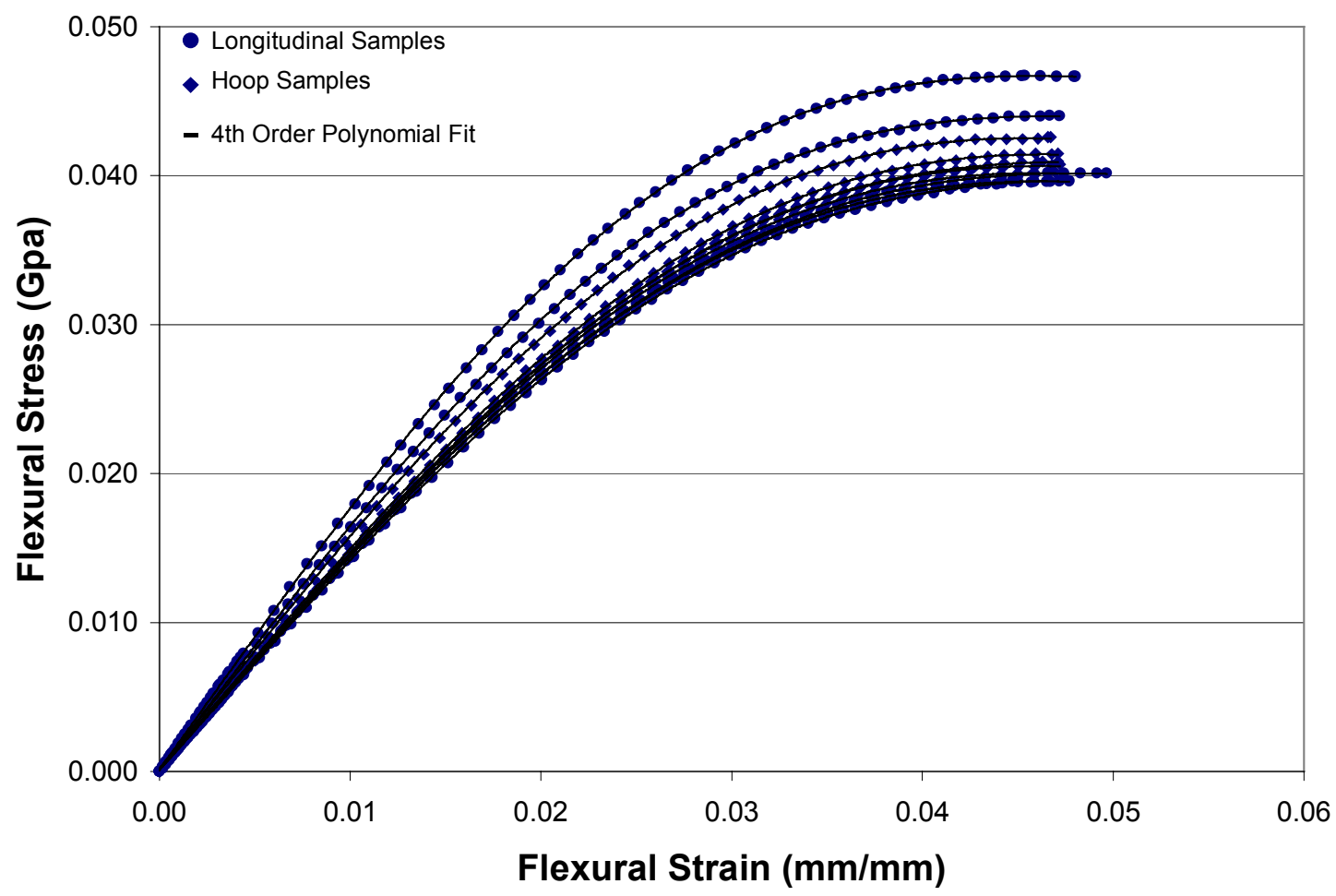

Figure 2.24 $4^{\text {th }}$ Order Polynomial fit of Stress Vs. Strain Curve for Material C 


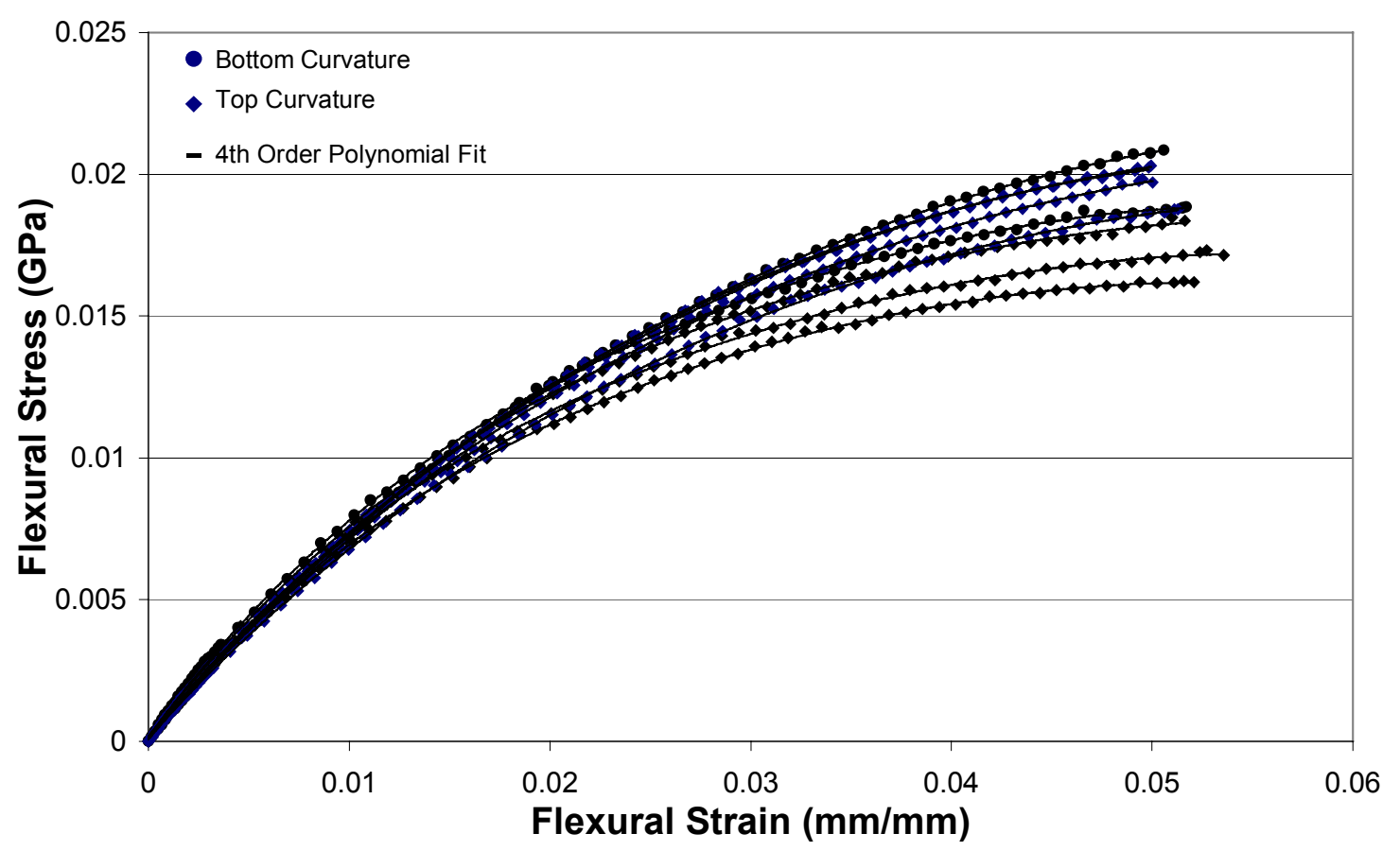

Figure 2.25 $4^{\text {th }}$ Order Polynomial fit of Stress Vs. Strain Curve for Material D

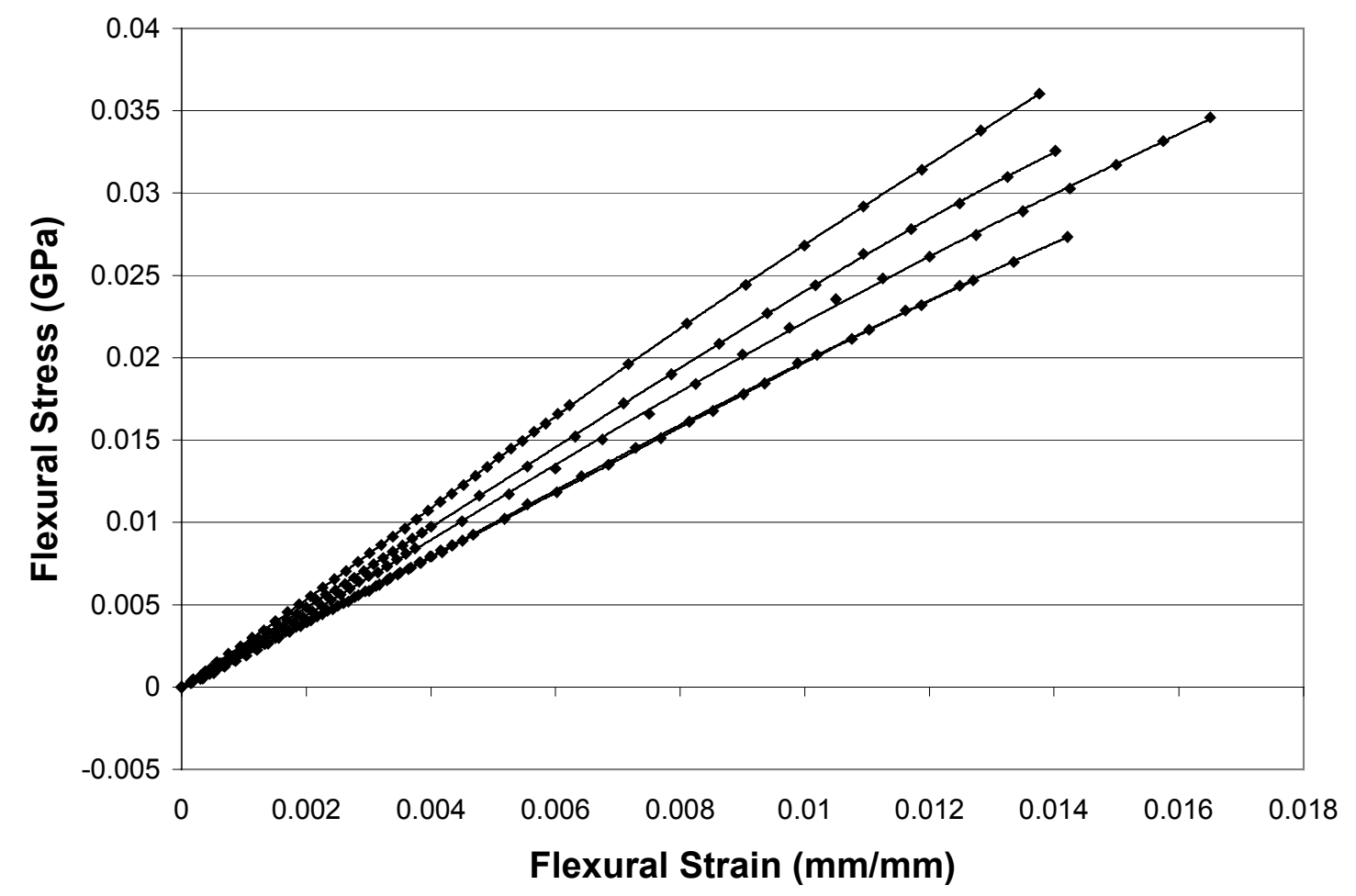

Figure 2.26 $4^{\text {th }}$ Order Polynomial fit of Stress Vs. Strain Curve for Material E 


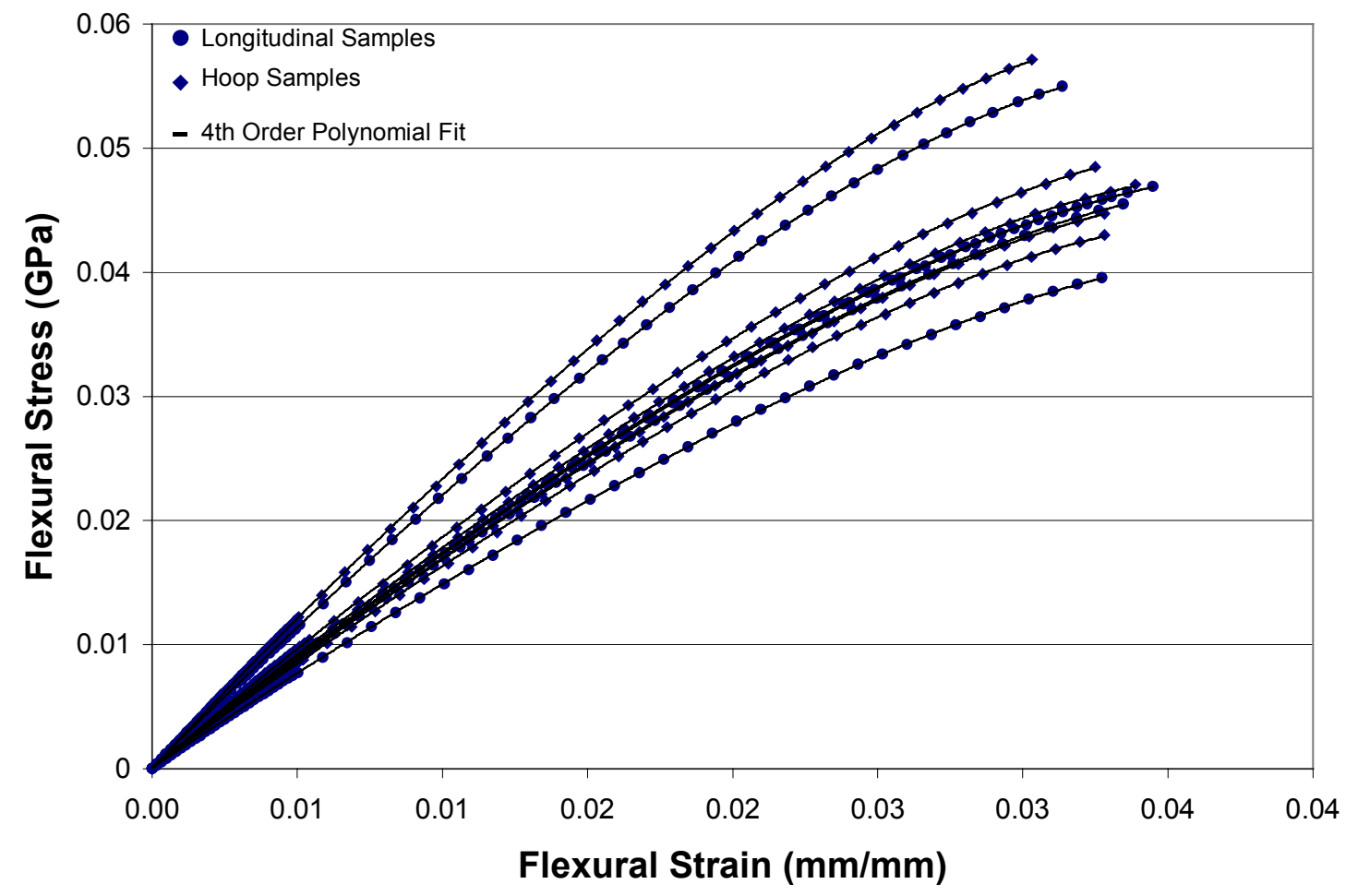

Figure 2.27 $4^{\text {th }}$ Order Polynomial fit of Stress Vs. Strain Curve for Material A (Considering deflections only up to $10 \%$ of the span)

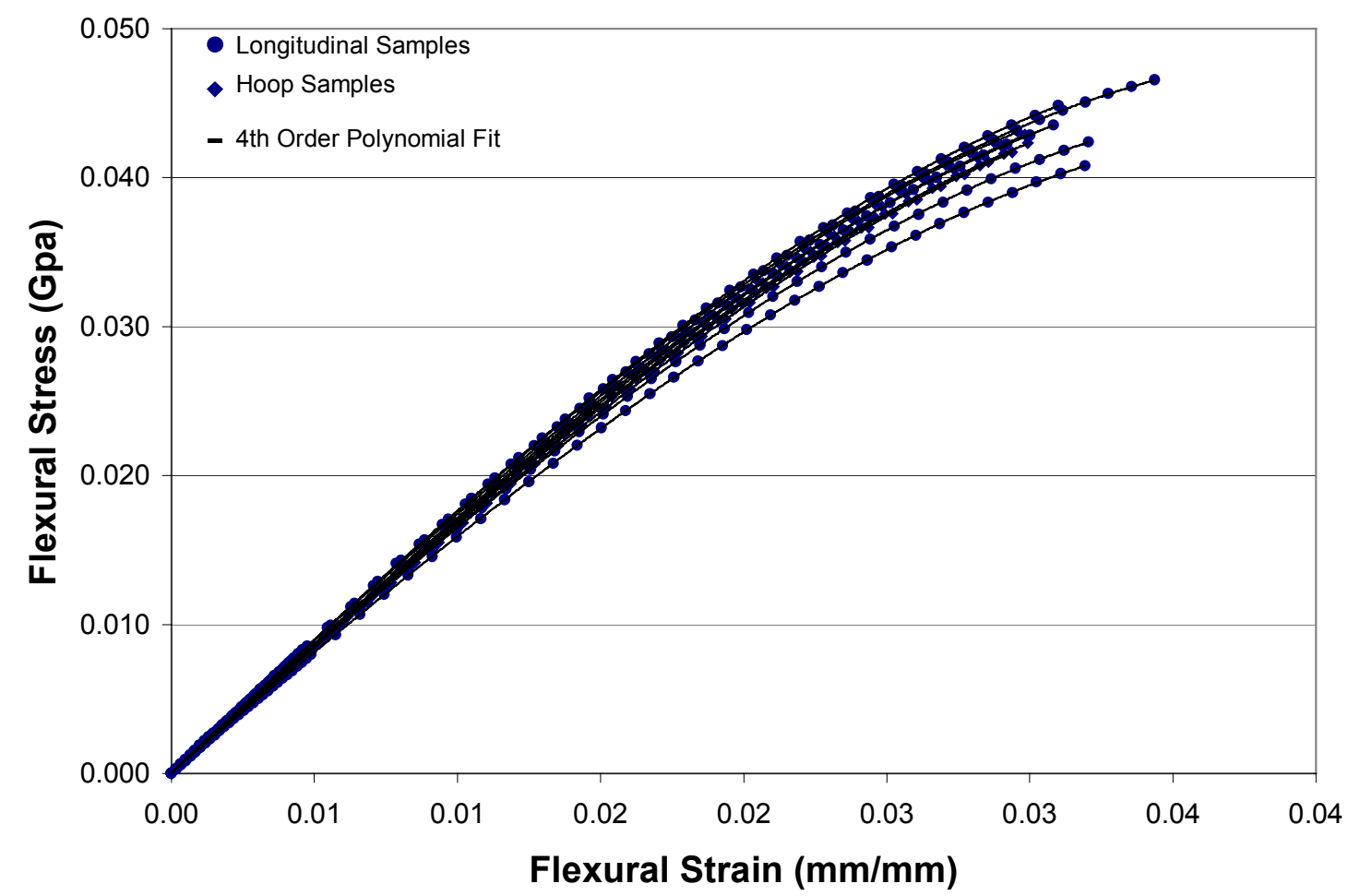

Figure 2.28 $4^{\text {th }}$ Order Polynomial fit of Stress Vs. Strain Curve for Material B (Considering deflections only up to $10 \%$ of the span) 


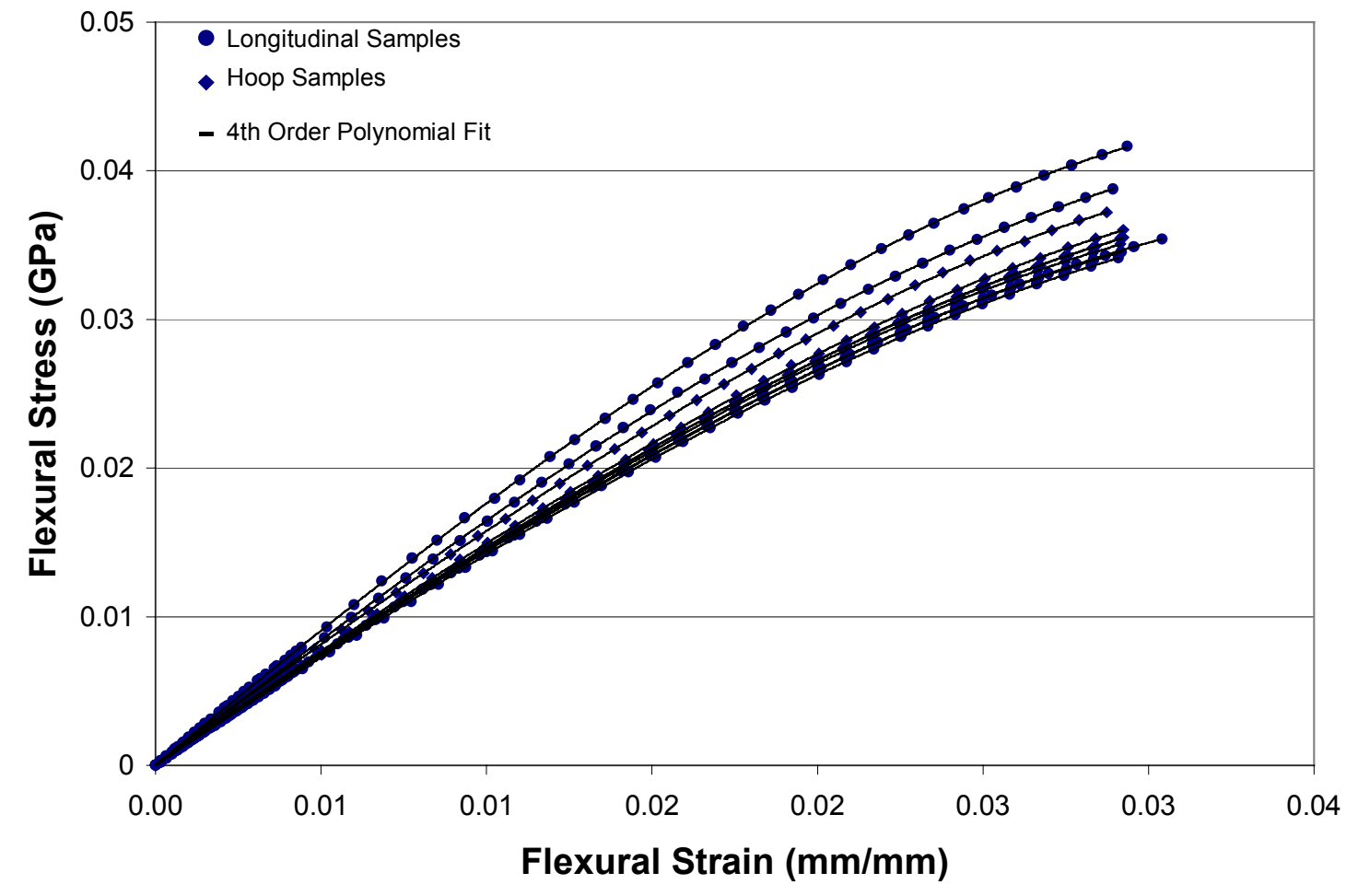

Figure 2.29 $4^{\text {th }}$ Order Polynomial fit of Stress Vs. Strain Curve for Material C (Considering deflections only up to $10 \%$ of the span)

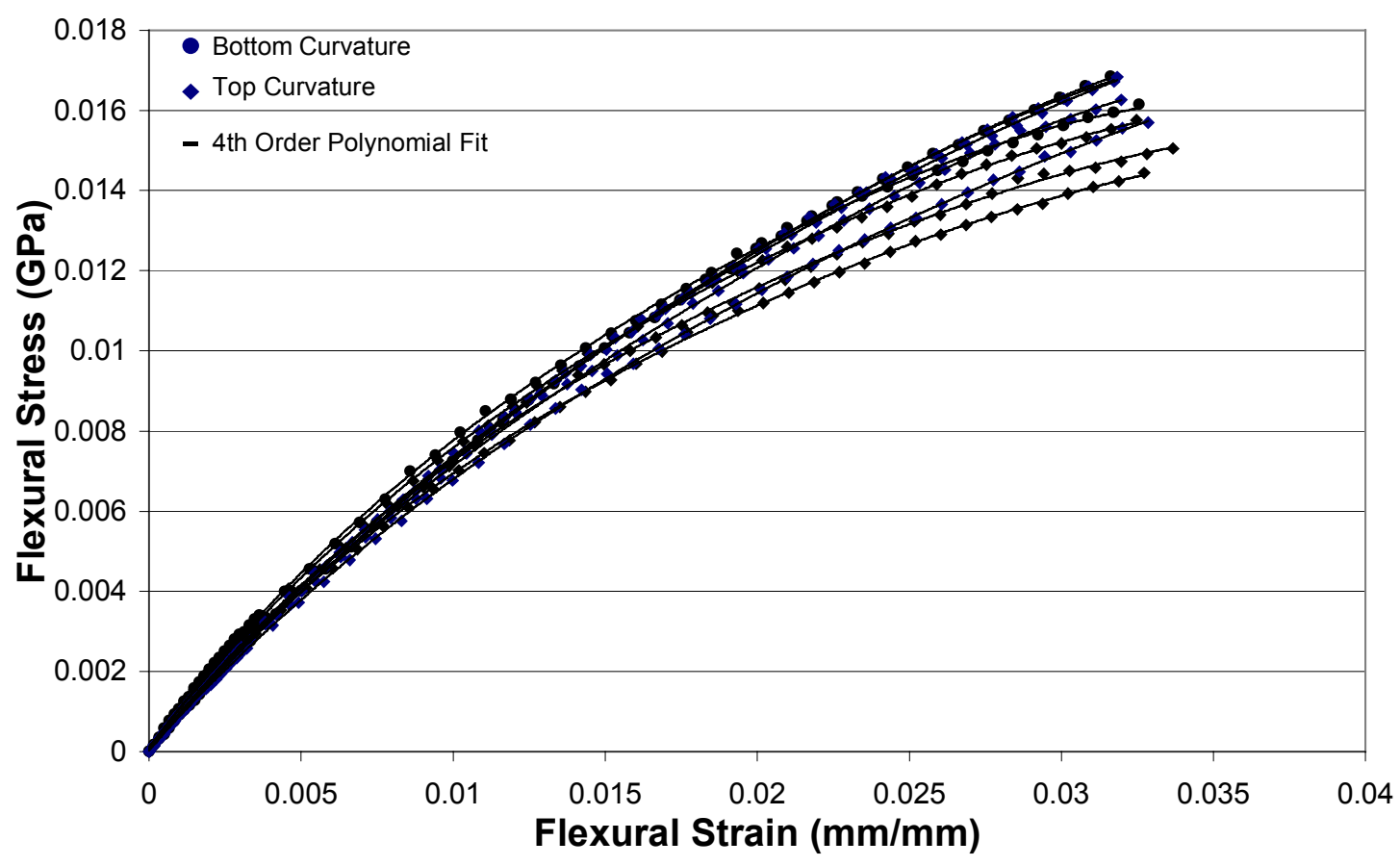

Figure 2.30 $4^{\text {th }}$ Order Polynomial fit of Stress Vs. Strain Curve for Material D (Considering deflections only up to $10 \%$ of the span) 


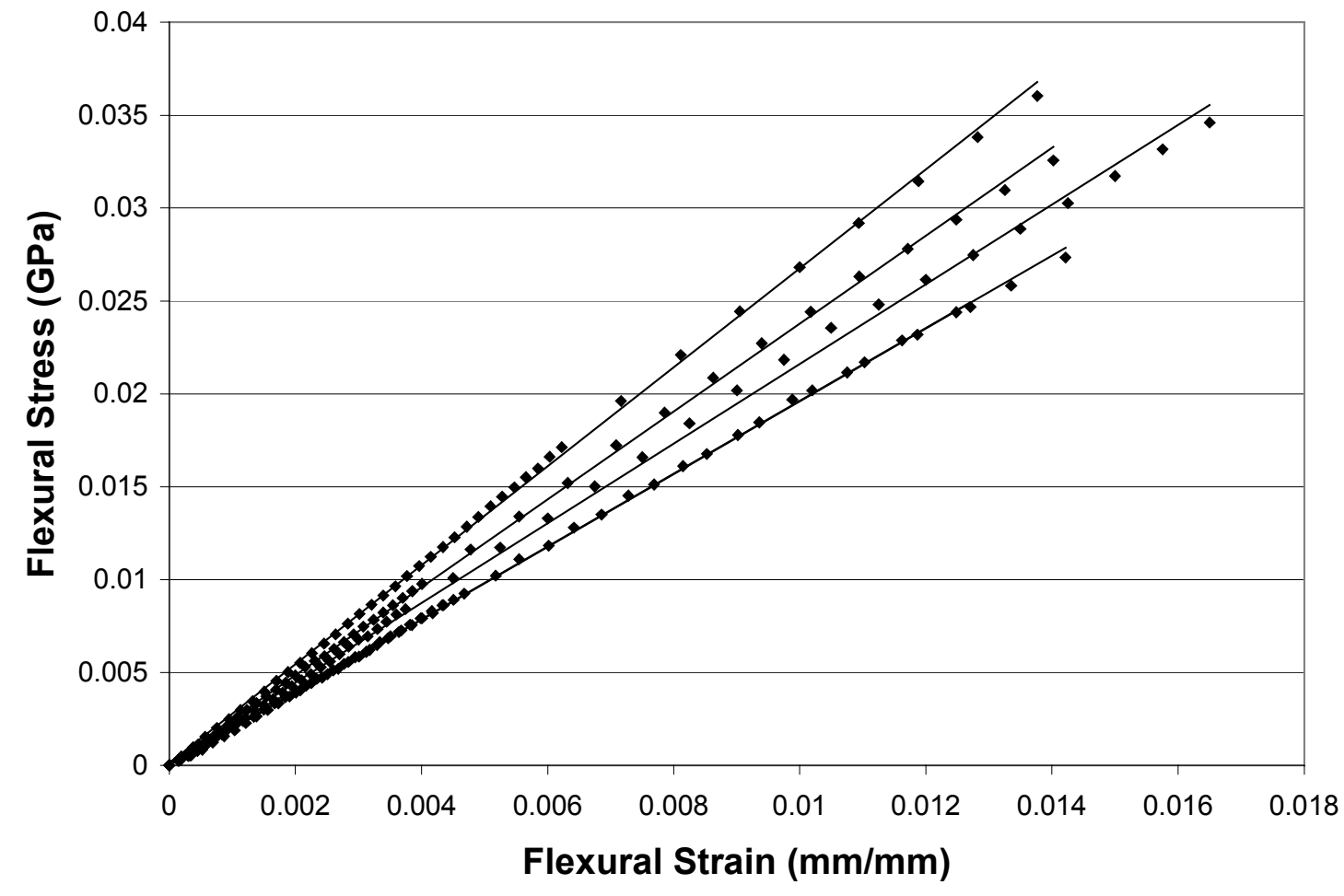

Figure 2.31 $4^{\text {th }}$ Order Polynomial fit of Stress Vs. Strain Curve for Material E (Considering deflections only up to Break Point)

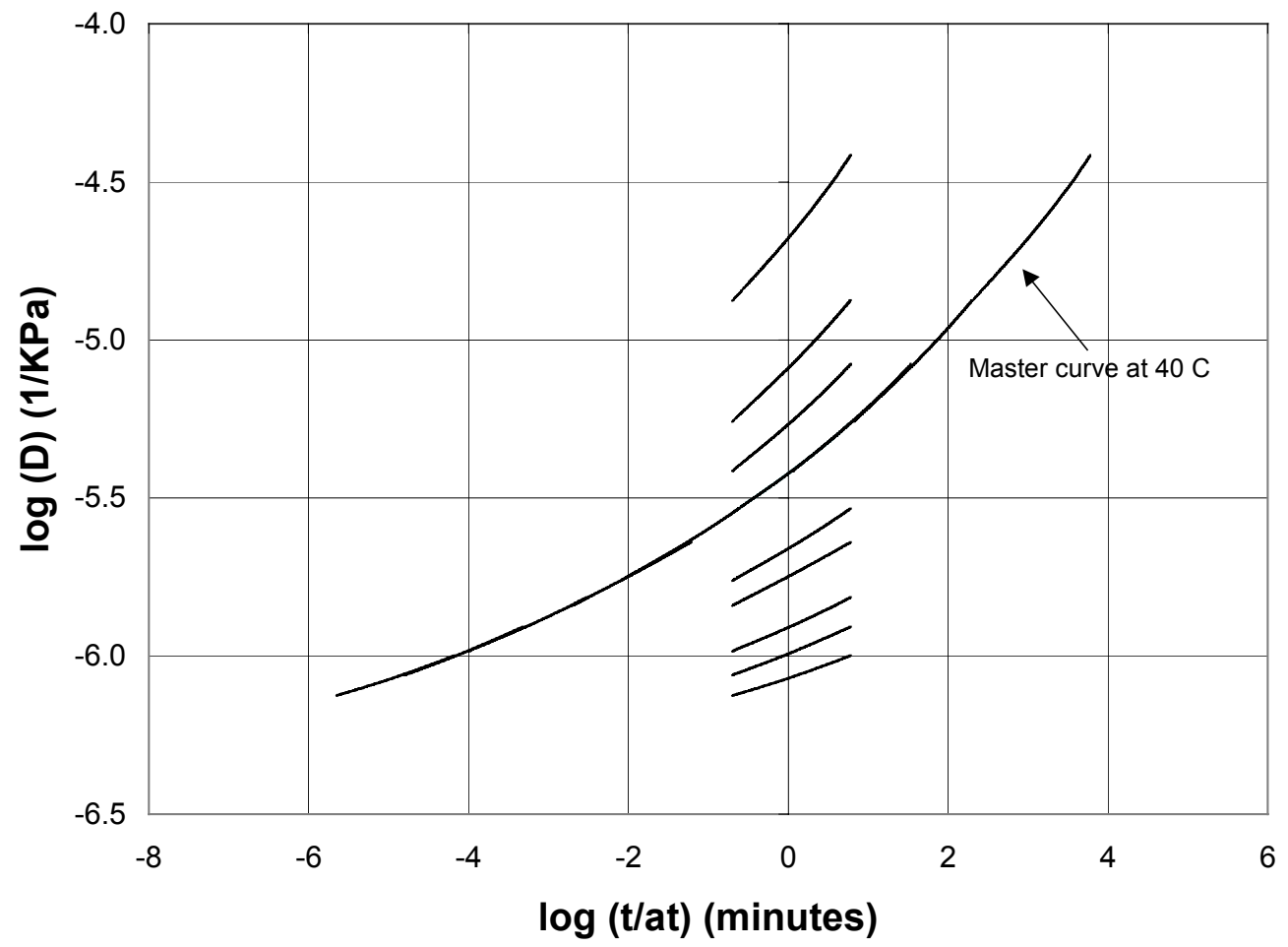

Figure 2.32 TTSP at $40{ }^{\circ} \mathrm{C}$ for Material A 


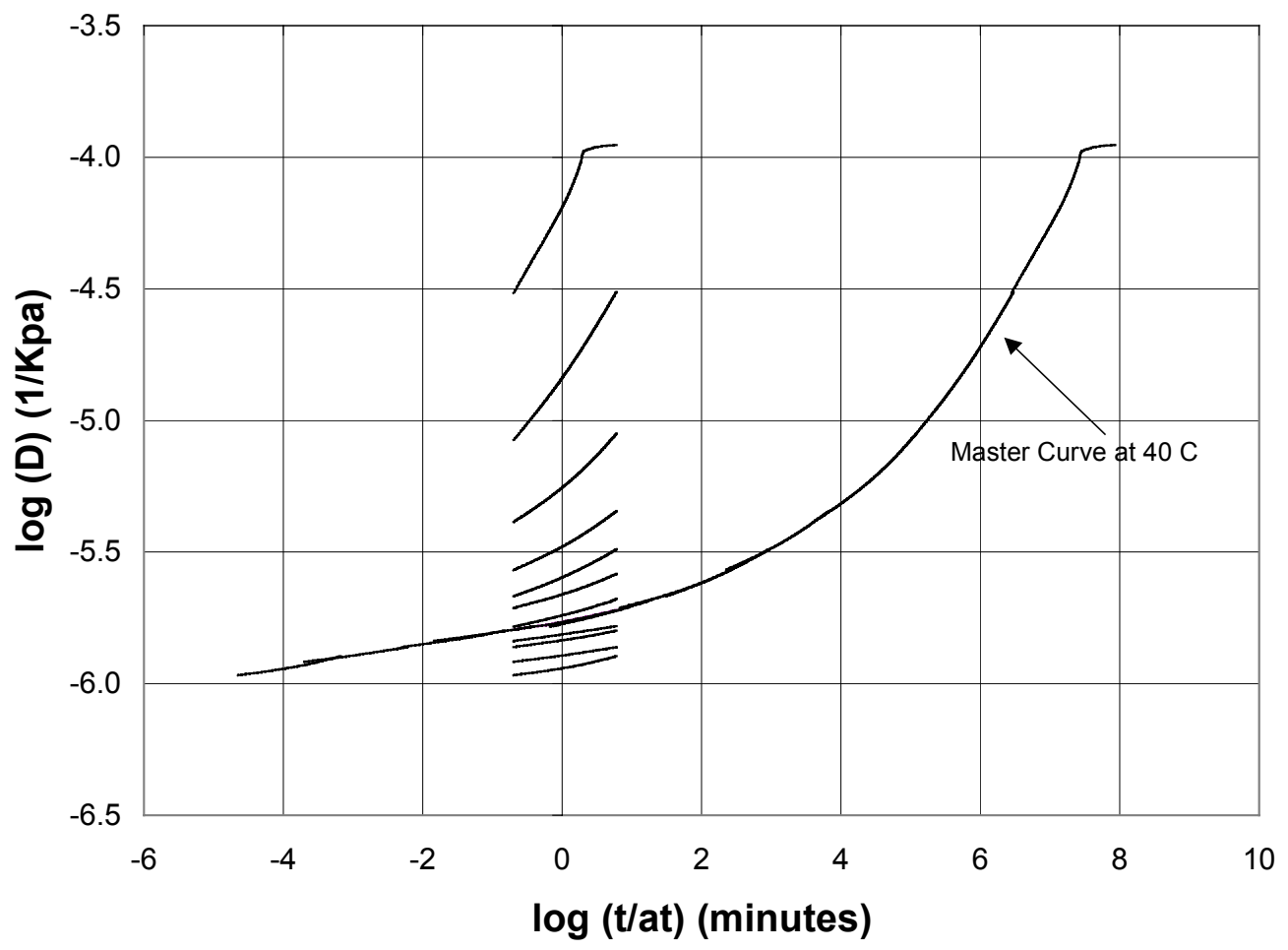

Figure 2.33 TTSP at $40{ }^{\circ} \mathrm{C}$ for Material B

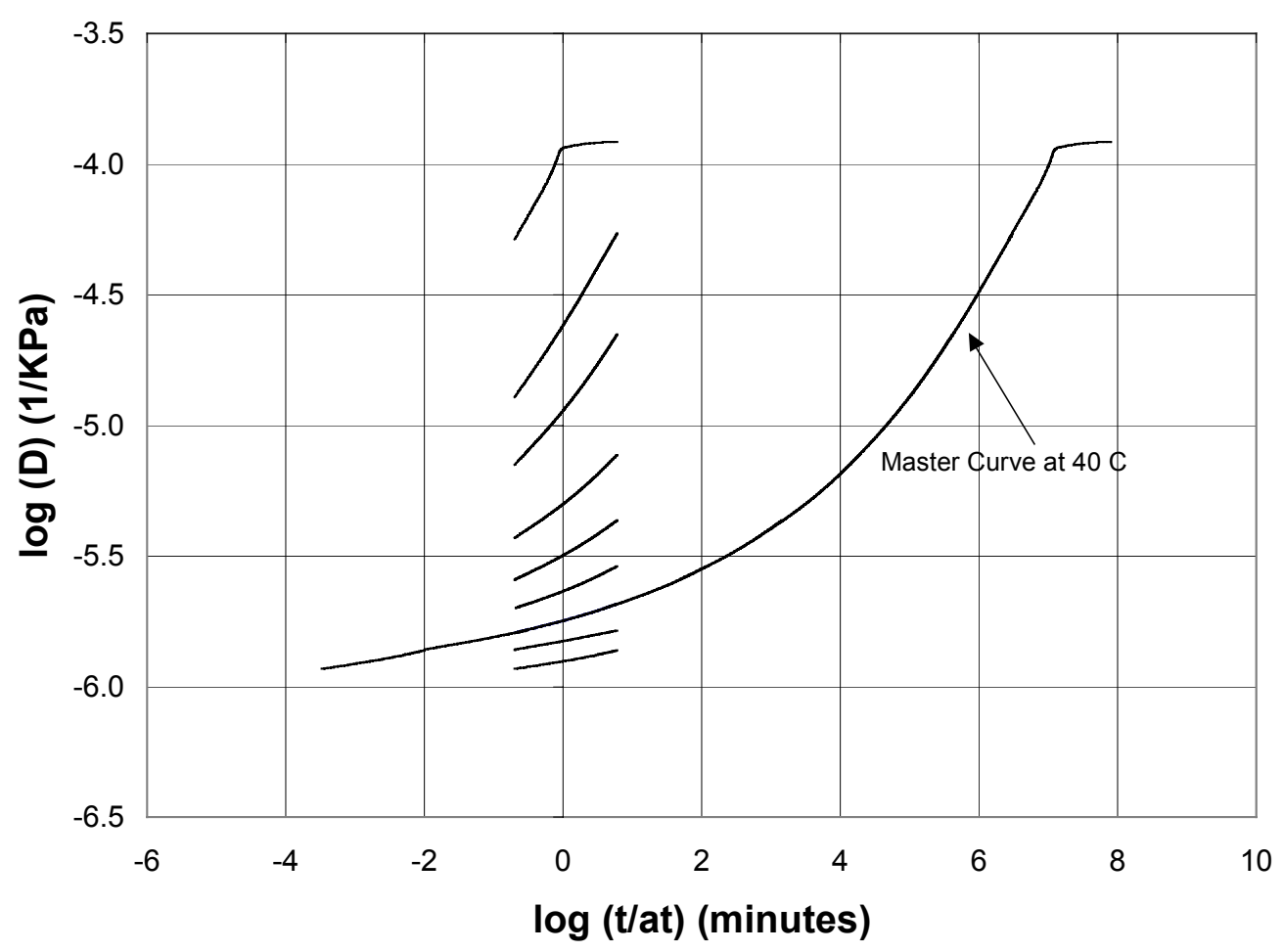

Figure 2.34 TTSP at to $40{ }^{\circ} \mathrm{C}$ for Material C 


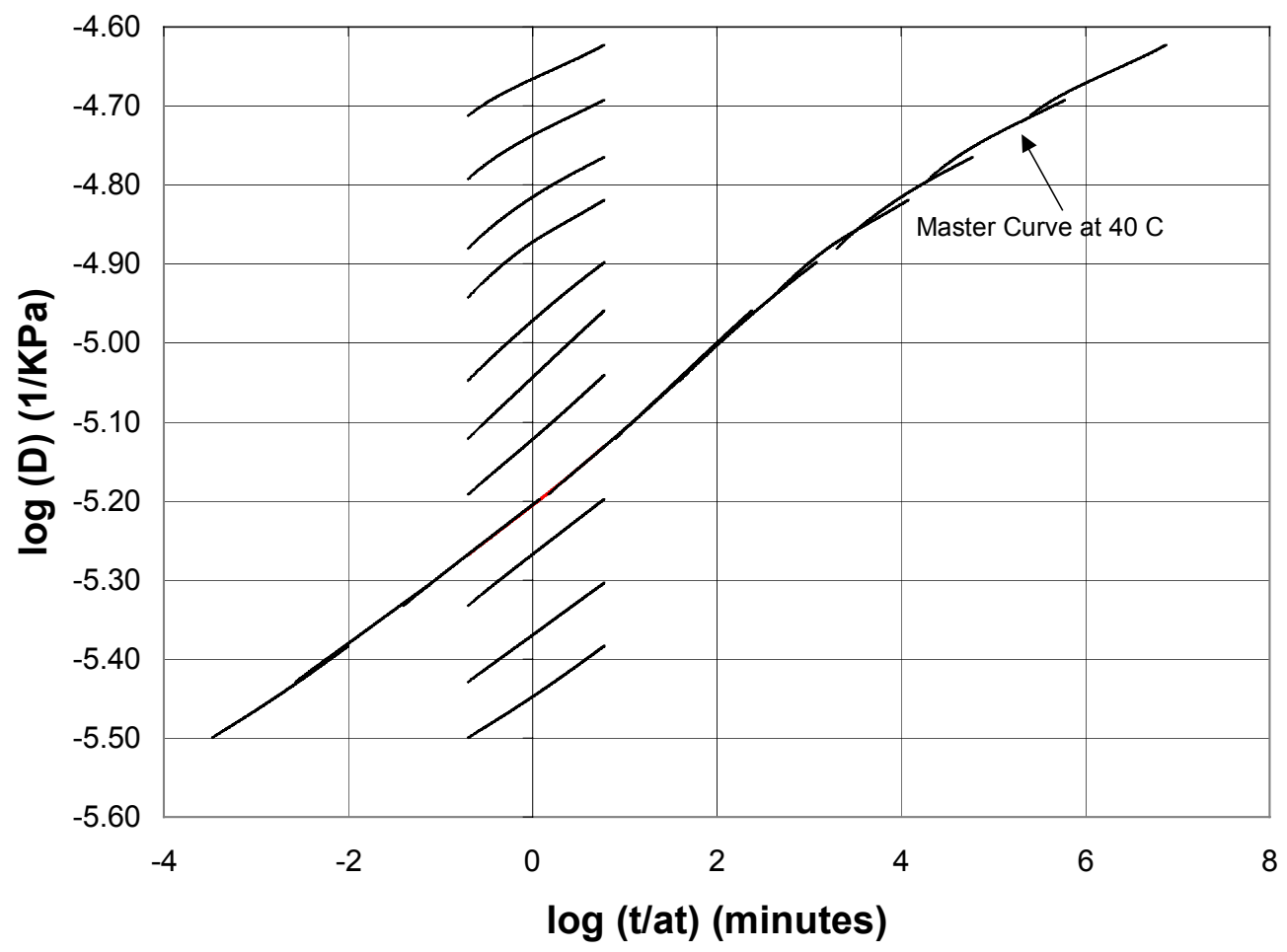

Figure 2.35 TTSP at $40{ }^{\circ} \mathrm{C}$ for Material D

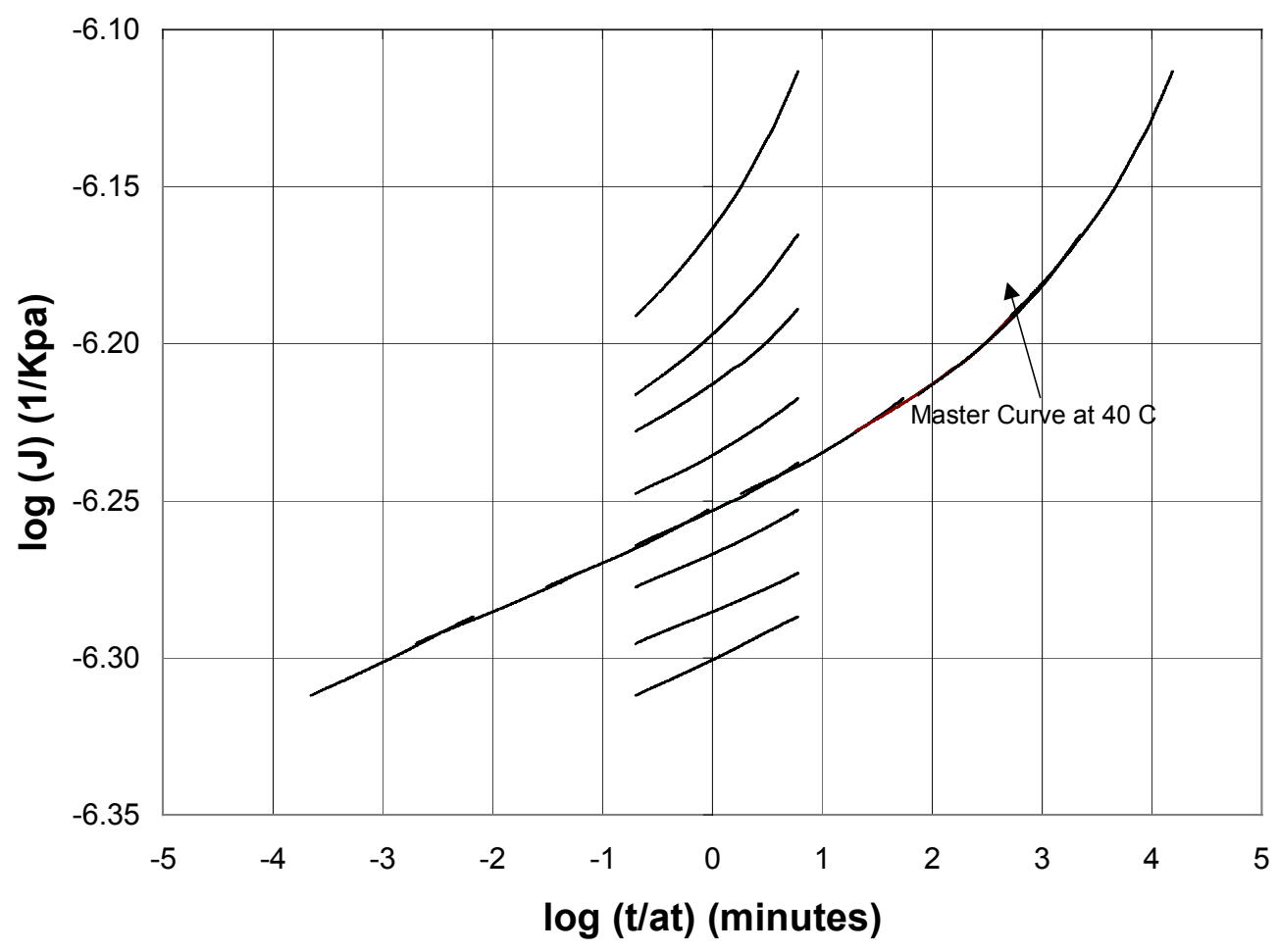

Figure 2.36 TTSP at $40{ }^{\circ} \mathrm{C}$ for Material E 


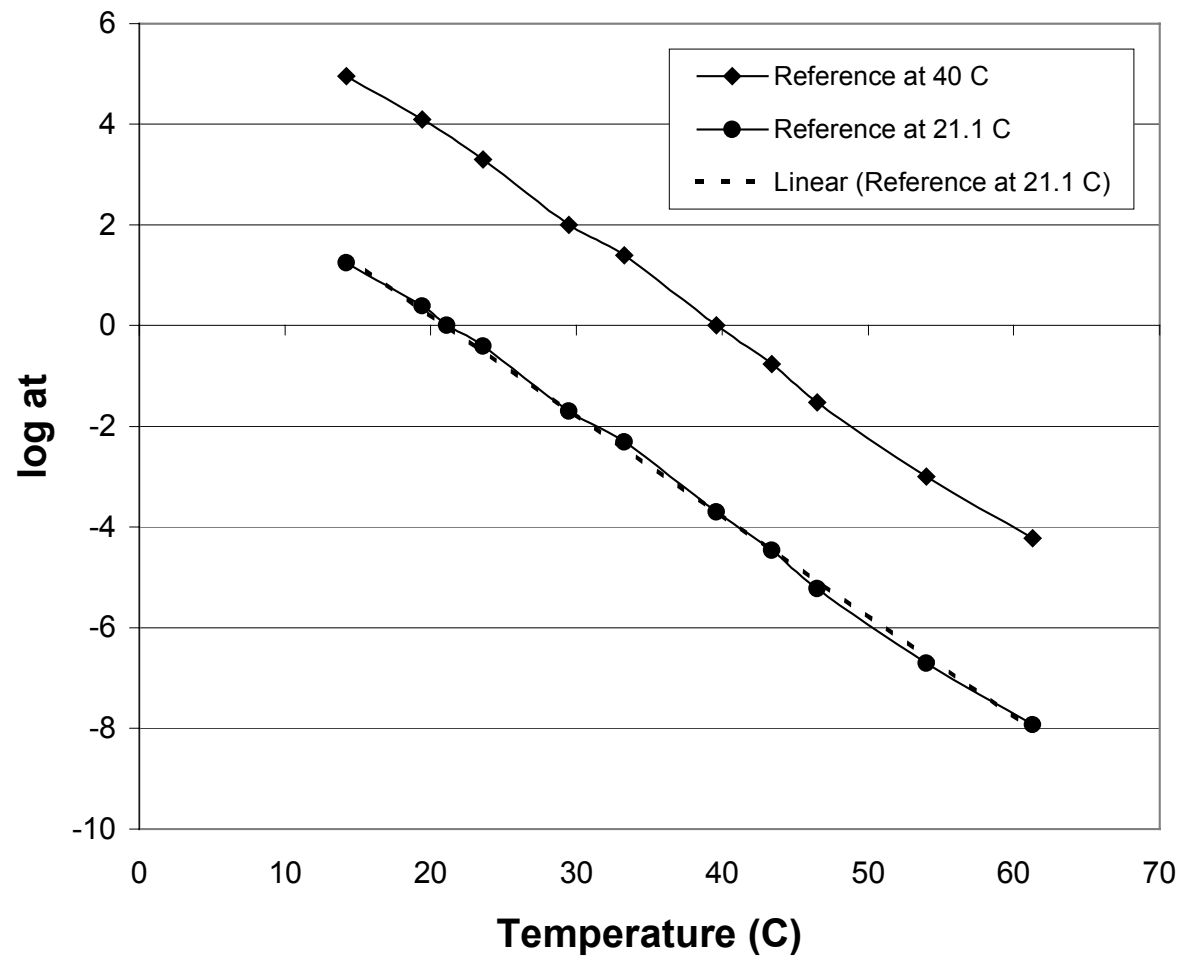

Figure 2.37 Log of Shift Factor Vs. Temperature for 40 and $21.1{ }^{\circ} \mathrm{C}$ for Material A

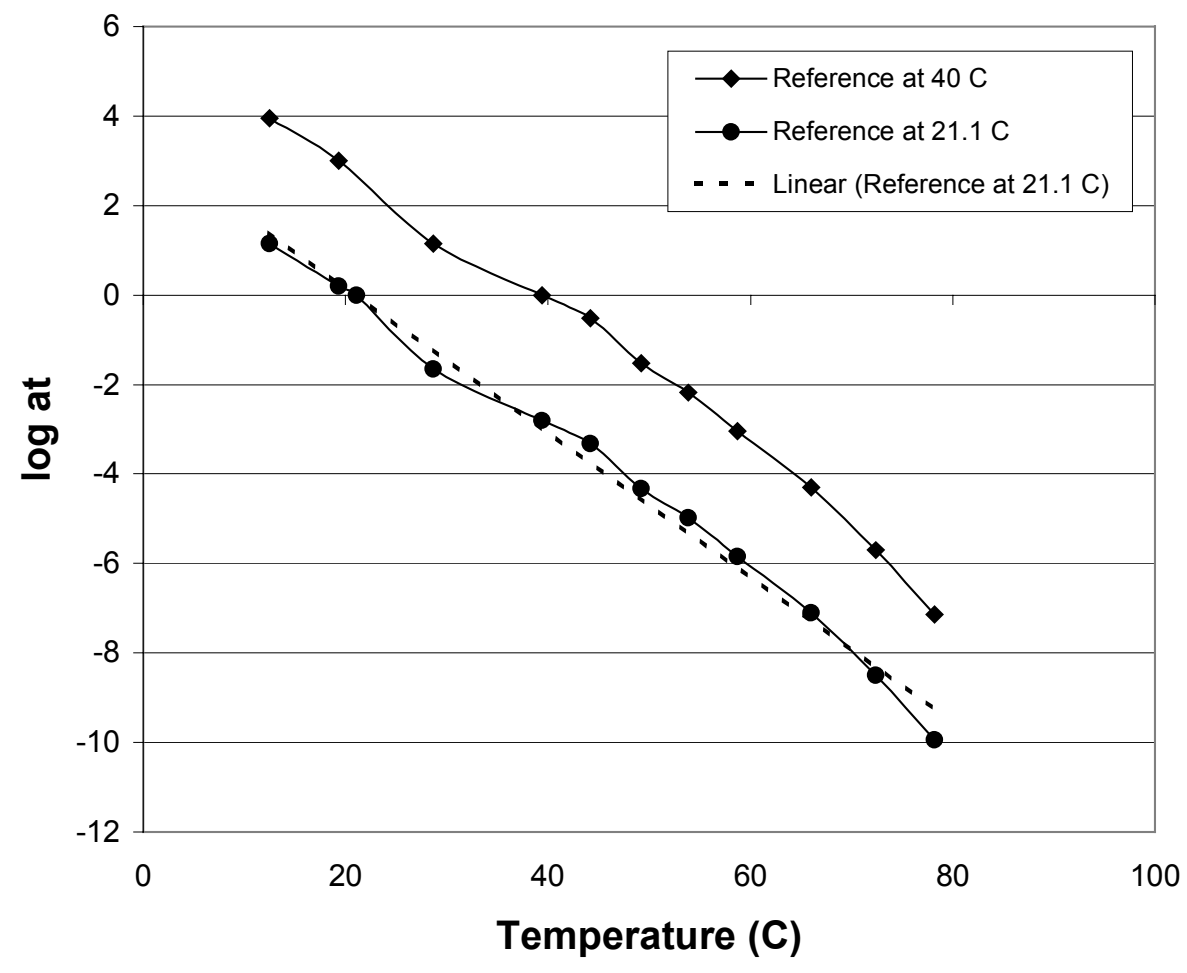

Figure 2.38 Log of Shift Factor Vs. Temperature for 40 and $21.1^{\circ} \mathrm{C}$ for Material B 


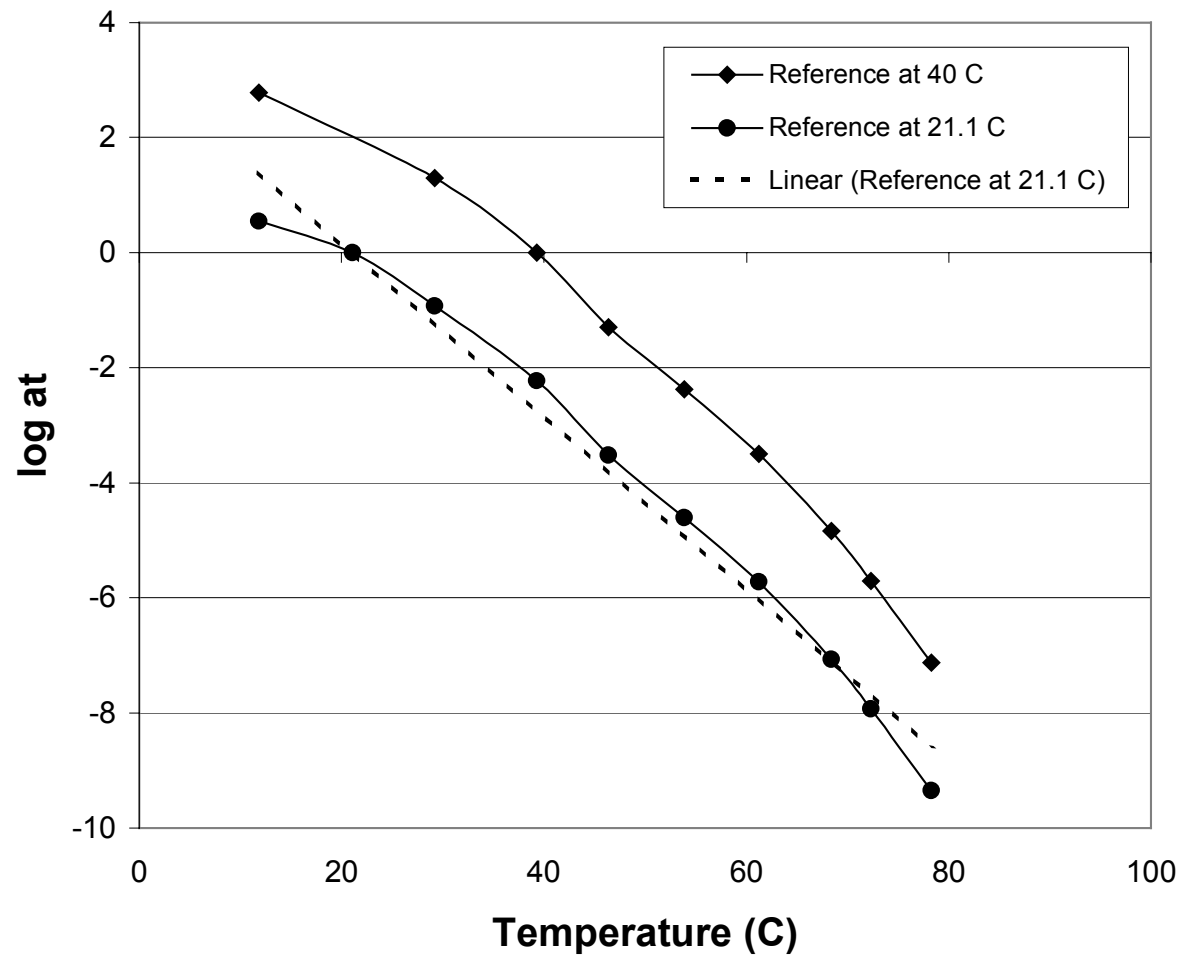

Figure 2.39 Log of Shift Factor Vs. Temperature for 40 and $21.1{ }^{\circ} \mathrm{C}$ for Material C

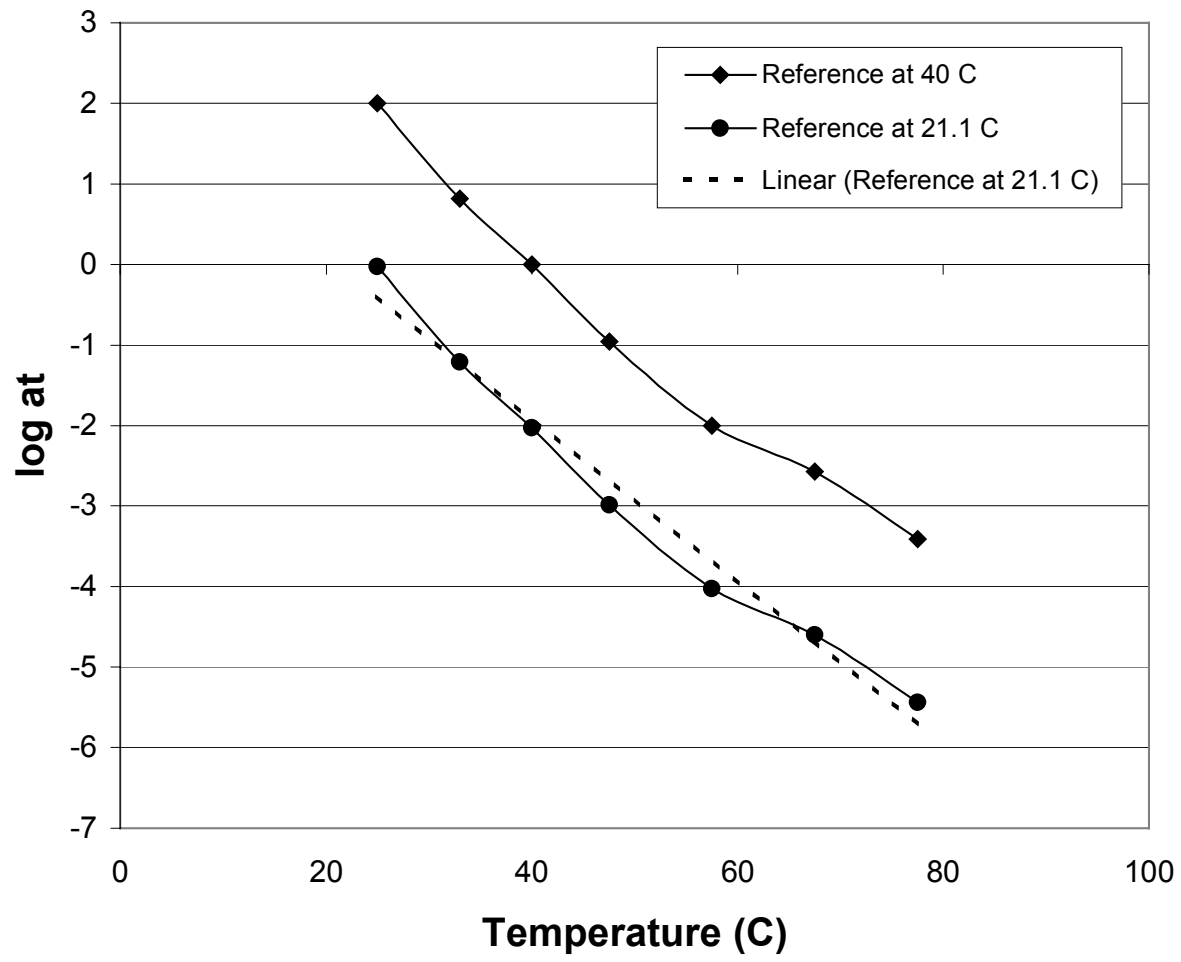

Figure 2.40 Log of Shift Factor Vs. Temperature for 40 and $21.1^{\circ} \mathrm{C}$ for Material D 


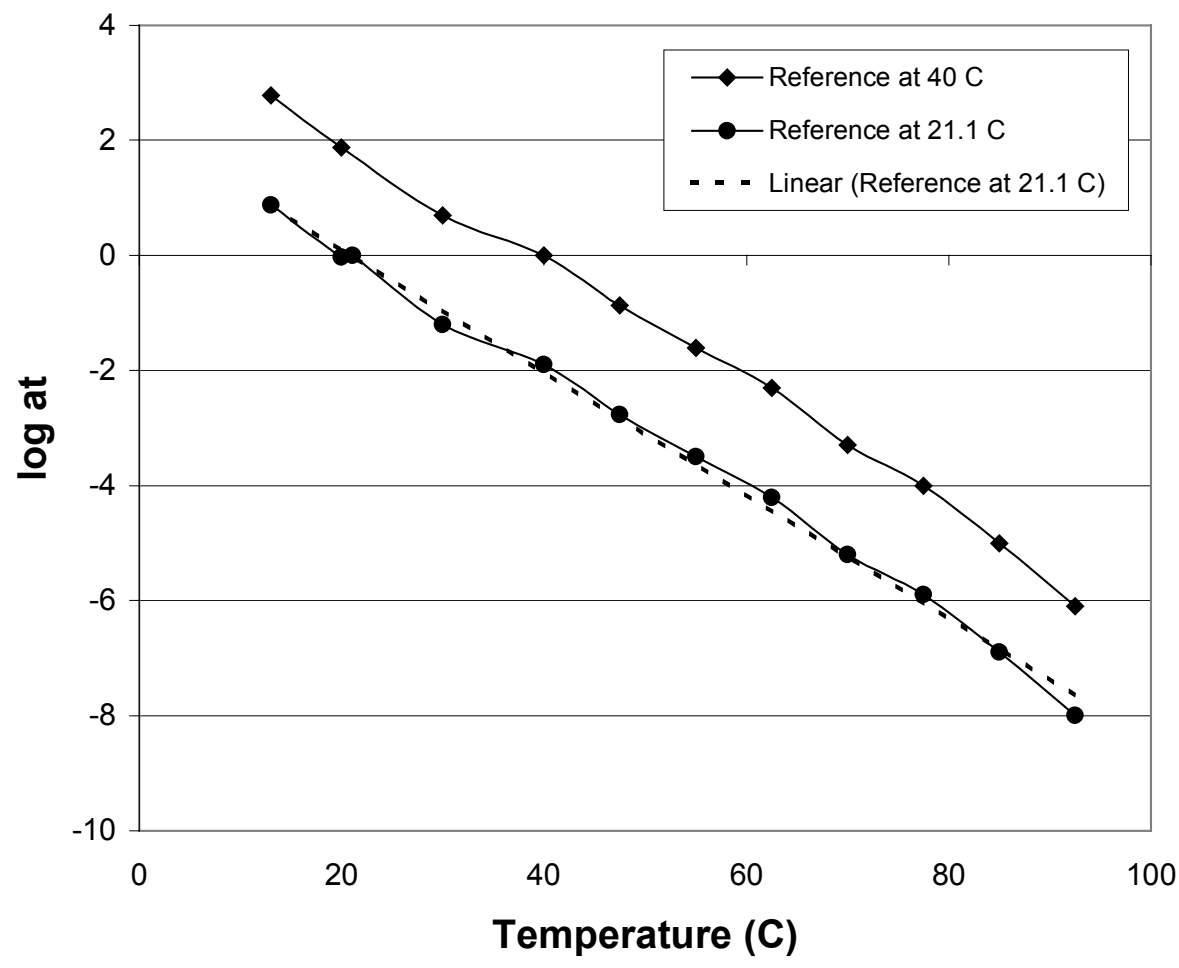

Figure 2.41 Log of Shift Factor Vs. Temperature for 40 and $21.1^{\circ} \mathrm{C}$ for Material E

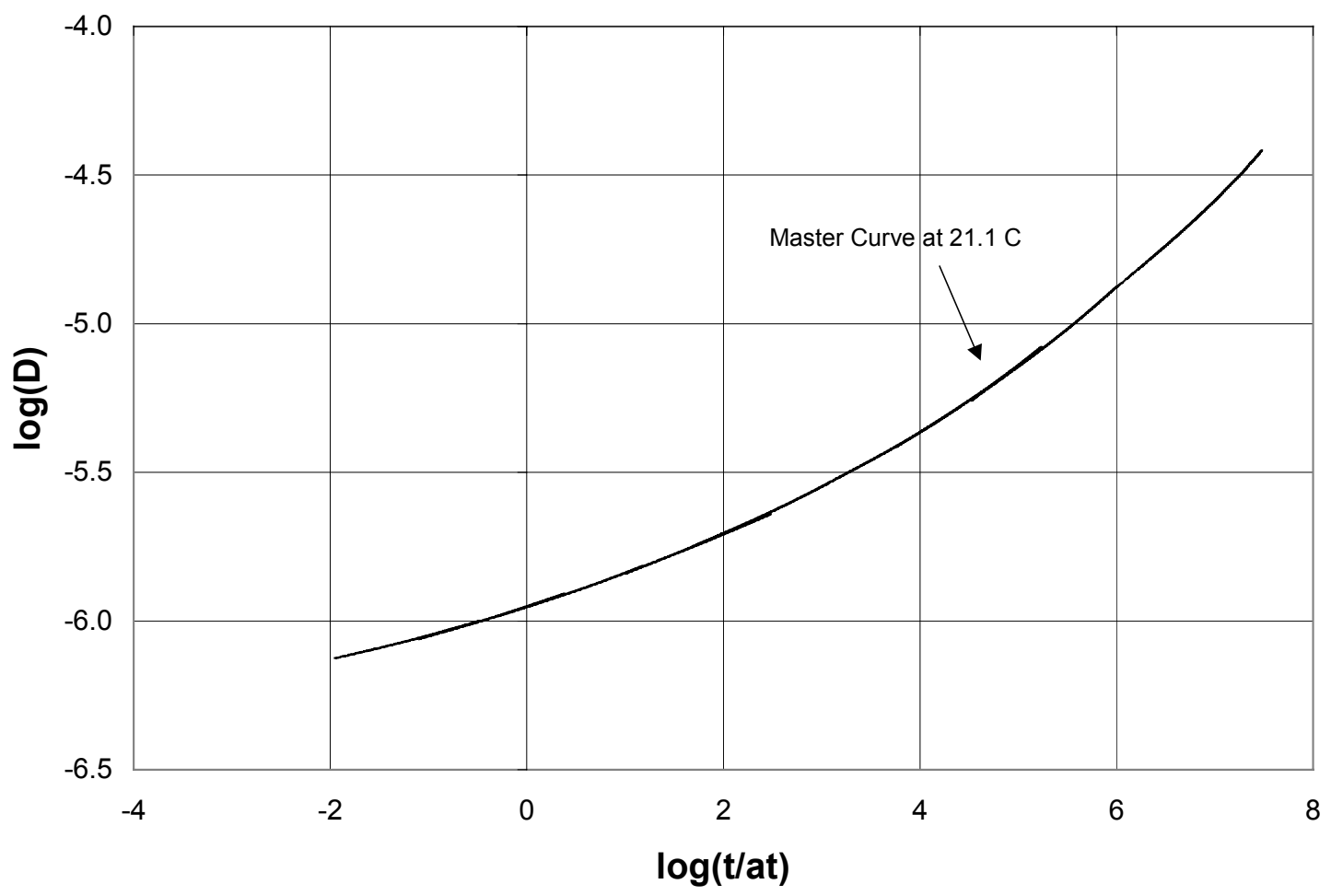

Figure 2.42 TTSP Curve Shifted to $21.1^{0} \mathrm{C}$ for Material A 


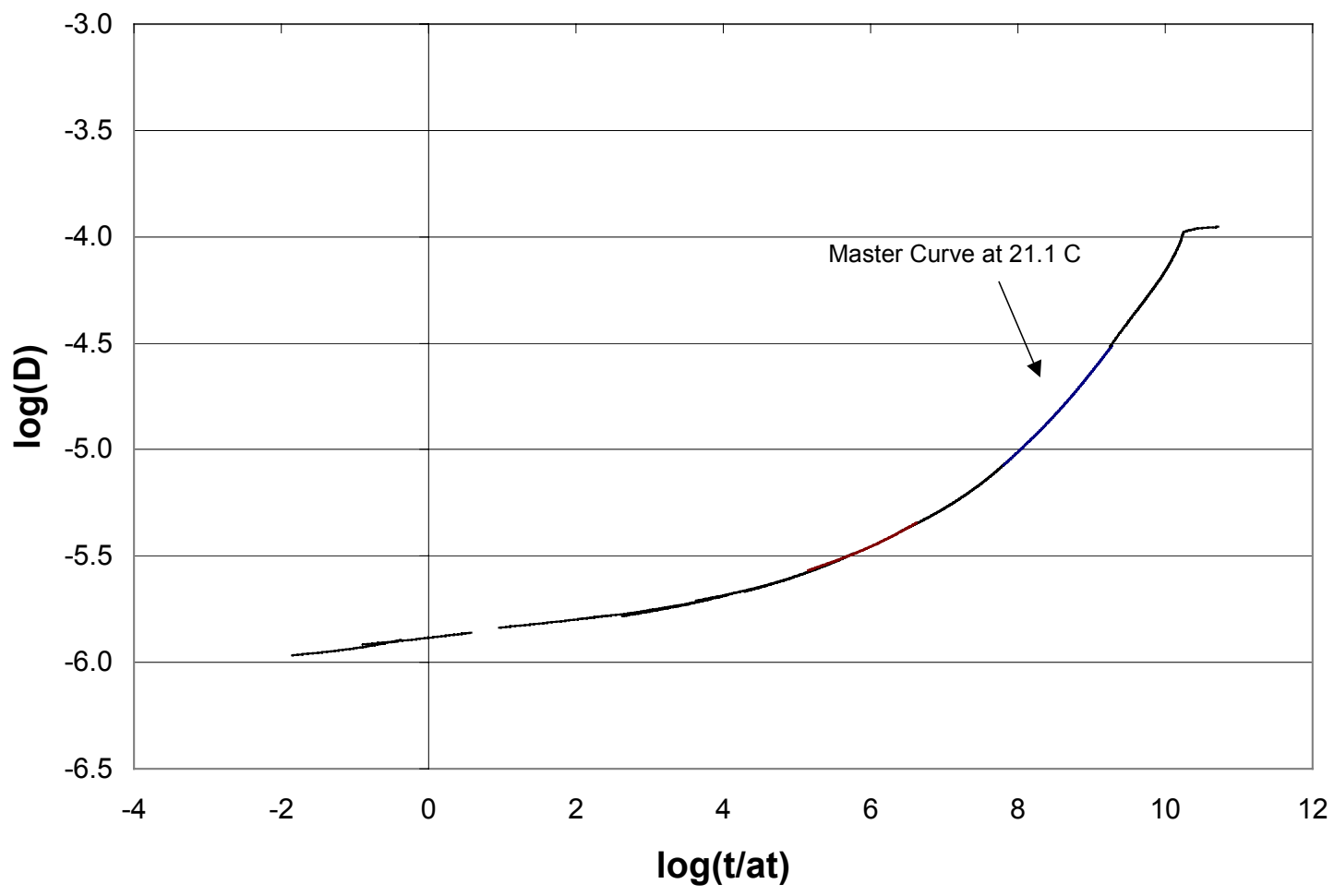

Figure 2.43 TTSP Curve Shifted to $21.1{ }^{0} \mathrm{C}$ for Material B

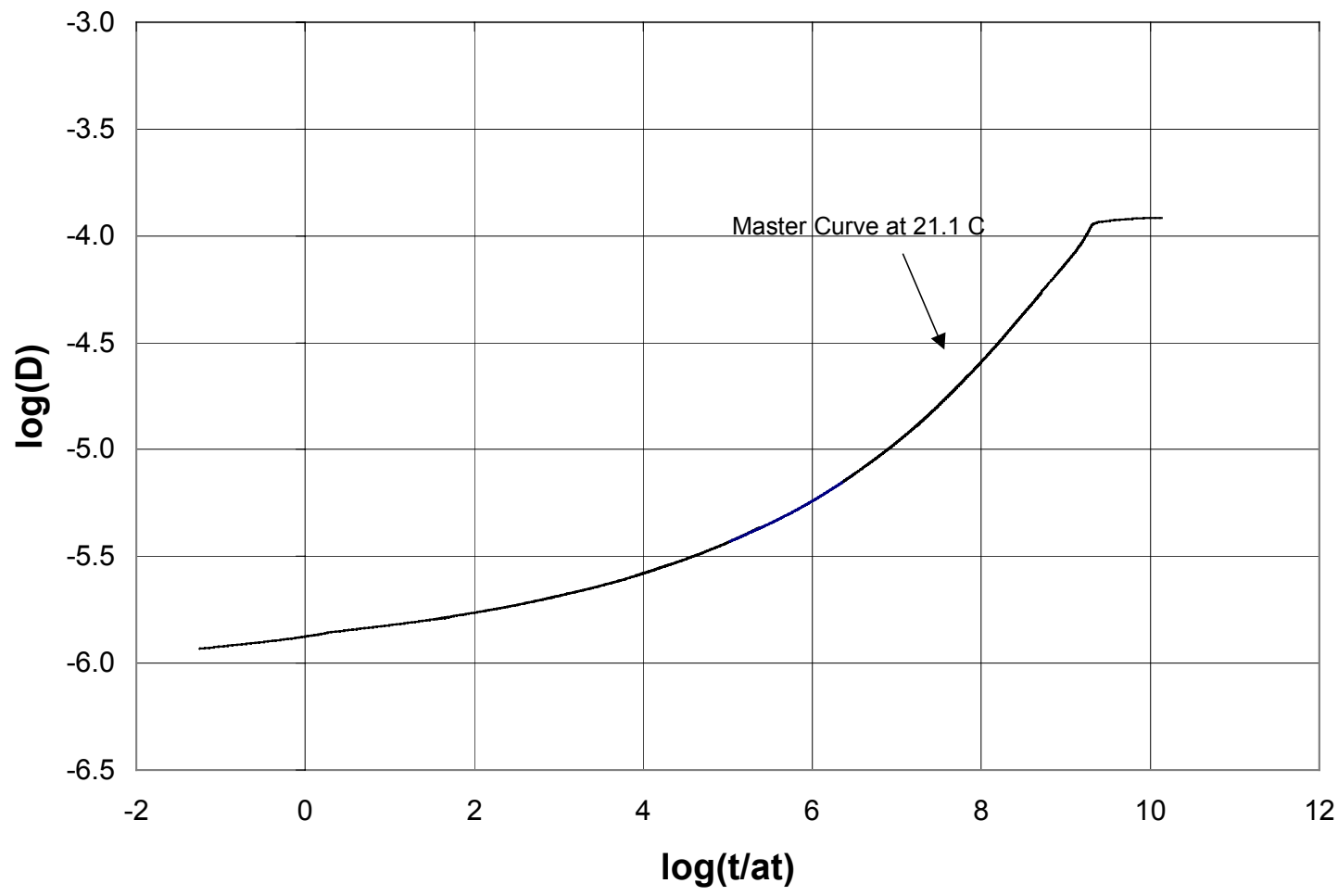

Figure 2.44 TTSP Curve Shifted to $21.1{ }^{\circ} \mathrm{C}$ for Material C 


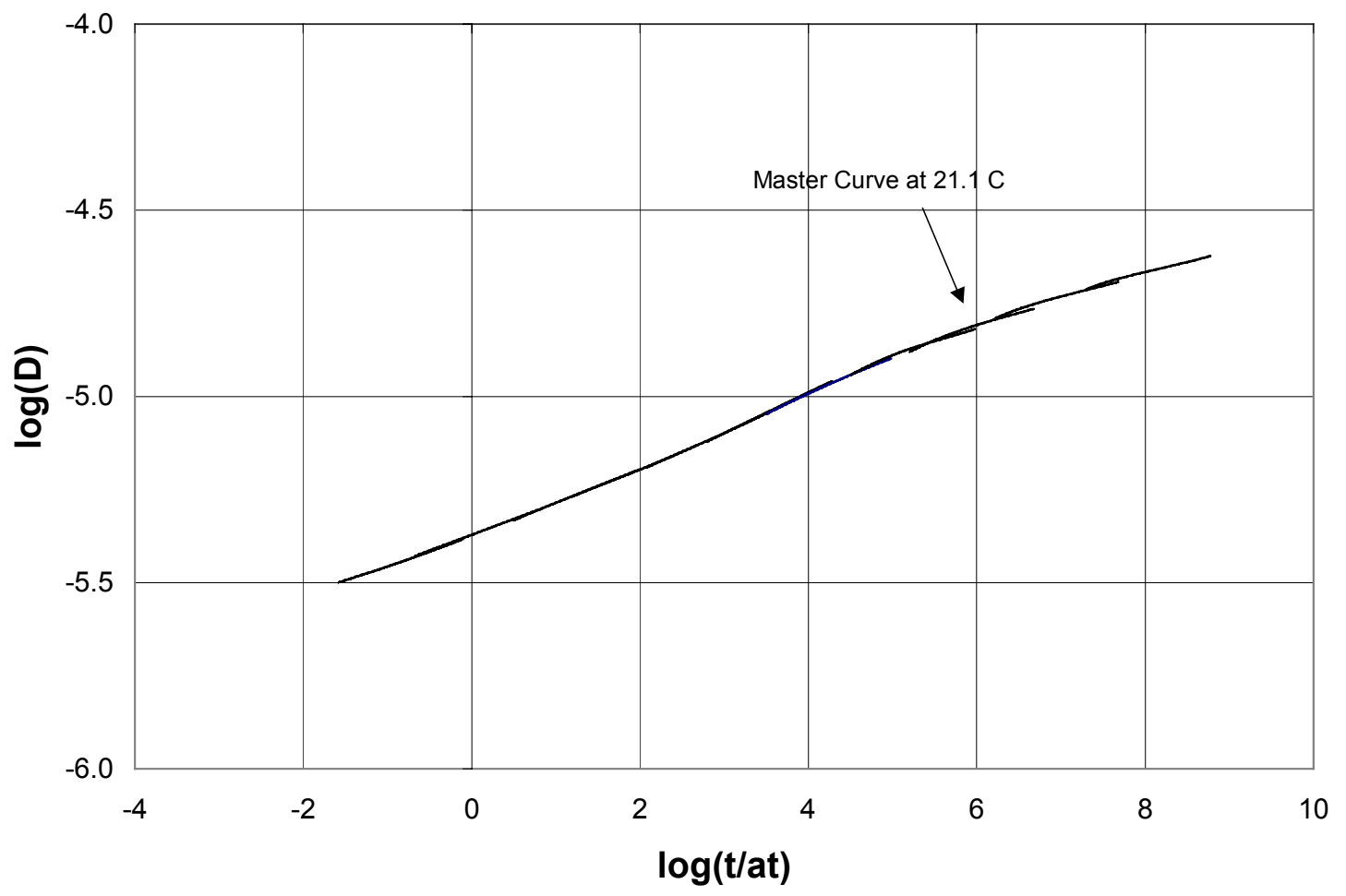

Figure 2.45 TTSP Curve Shifted to $21.1{ }^{0} \mathrm{C}$ for Material D

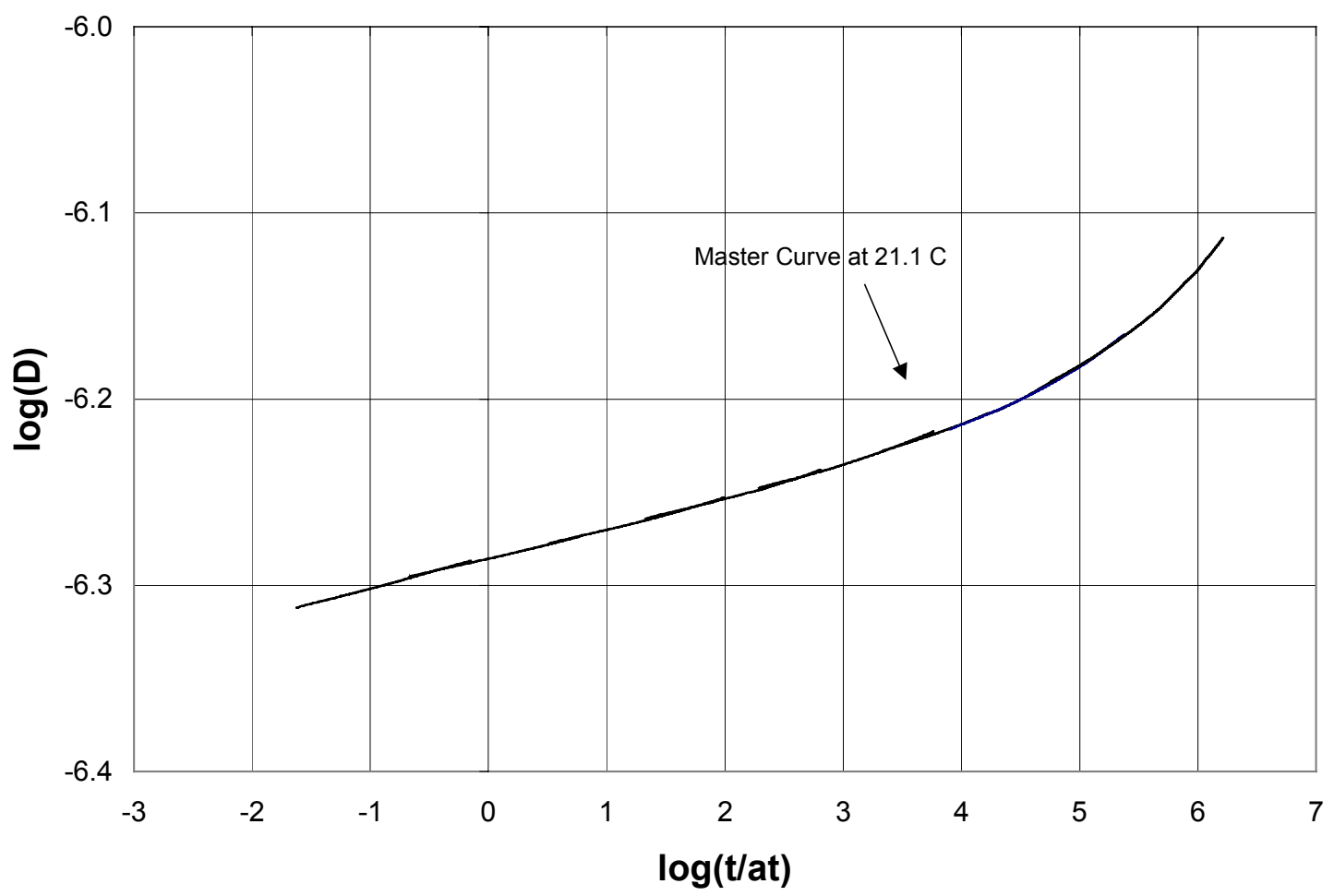

Figure 2.46 TTSP Curve Shifted to $21.1{ }^{0} \mathrm{C}$ for Material E 


\section{CHAPTER 3: LONG-TERM CREEP TEST}

Long-term compliance of polymers and polymer composites used as liners in trenchless rehabilitation is necessary for the prediction of the creep-buckling of the product over its life cycle. The objective of the thesis was to develop a long-term full-size test method to measure the creep-compliance of liners produced in standard industry conditions. The materials that were subjected to investigation were PVC (3 commercial blends), HDPE, and Polyester filled with a Polyester mat. These materials were commercial products used for trenchless pipes and hence allowed direct comparison of the full-size test data to the actual liners in the field. The data obtained from the testing was product specific, but the methodology is applicable to the long-term behavior of a variety of polymers and polymer matrix composites.

\subsection{FABRICATION OF ENCASED LINER SAMPLES}

The fabrication service was provided by the industries participating in the research. The thicknesses of the polymer liners were selected according to the typical use of each product in the field. Three specimens of each material sample ${ }^{1}$ were encased in 12 in Internal Diameter (ID), schedule 20 (1/4 in thickness), $6 \mathrm{ft}$ long welded steel pipes. The pipe liner was selected to have a length to diameter ratio of 6 to minimize end effects. Two $1 / 2$ in holes were drilled and fitted with $1 / 2$ in NPT female connectors welded to provide inlet and outlet as shown in Figure 3.1. The weld line was kept halfway through the depth of the pipe, on the left side of the pipe while looking form the inlet end as shown in Figure 3.2.

\footnotetext{
${ }^{1}$ Three specimens per sample. A sample is the whole of the material from one manufacturer, produced at a given time and date.
} 
The $1 / 2$ in NPT threaded bolts were placed at the inlet and outlet ports of the liner to prevent the liner from sealing the inlet and the outlet during fabrication. Before lining the host pipe, a polyethylene strip was placed at each end as shown in Figure 3.1. A space was created between the liner and steel host pipe due to the polyethylene strip. The pipe was lined and cooled down as per the standard practice of the manufacturer. Round Hydrotite $^{\circledR}$ [21] was inserted in the space between the liner and steel pipe that was created by the polyethylene strip. Finally, Epoxy grout was used to seal it completely as shown in Figure 3.3. On curing, water was fed gently through the bottom of the inlet to purge the air through the top outlet. This process caused the Hydrotite ${ }^{\circledR}$ to expand and seal the liner. The samples were kept wet for one week so that the Hydrotite ${ }^{\circledR}$ could expand completely.

A back up sealing mechanism was in place in case the pipes started to leak over time. An O-ring was to be used by pushing it against the end of the steel pipe and holding it with a plate as shown in Figure 3.4. It was not used since none of the pipes leaked.

\subsection{EXPERIMENTAL SET UP}

Fifteen encased liner specimens; 3 specimens each from each of the 5 manufacturers were tested. The liners were tested for their long-term creep behavior. All 15 liners samples were placed one next to another on a frame as shown in Figure 3.5. Strain gages were glued onto the inside of the liner in the hoop direction of the pipe. Each liner had six gages in the center of the pipe (at $3 \mathrm{ft}$ ) equally spaced at an angle of $60^{\circ}$. In addition to the six strain gages, the first sample of each material had another strain gage fixed at one foot from the center on the inside top of the liner. The gage placement on the pipes is shown in Figure 3.6. The strain gages, made of $\mathrm{Cu}-\mathrm{Ni}$ foil, were designed for low 
elastic modulus materials such as plastics and were configured to minimize the effect of gage tightening. The gages were self-temperature compensating and had the same thermal expansion as that of plastics (Gage \#: GFLA-6-350-50-5LT, TML, Inc.). Cyanoacrylate $(\mathrm{CN})$ adhesive was used to bond the gages to the inside of the plastic liner (M Bond 200 Adhesive Kit, Micromeasurements, Inc.).

The inlets of all the specimens were connected to the water source by half inch CPVC tubing. The set-up was such that the inlet to any sample could be individually turned on/off at any time during the testing period without disturbing the pressure on the other samples. A pressure gage, $0-100 \mathrm{psi}$, at the beginning of the water line to the experimental set-up, was provided to be able to read the source water pressure. A pressure regulator (0-20 psi) controlled the intensity of hydraulic pressure. A check valve was provided to prevent the backflow of water. A pressure gage (0-30 psi) in the line, just after the regulator, was used to read the inlet pressure to the pipes. The outlet of each pipe was connected to the sink and could be shut on/off at any time without disturbing the other pipes. The first specimen in each material had a pressure gage at the outlet to monitor pressure drop, if any, across the set-up. A pressure transducer was provided in the water line after the pressure regulator. It was connected to a Data Acquisition System (DAS) and was monitored continuously throughout the test. A thermocouple, attached inside the first plastic liner sample, was also connected to the DAS to continuously monitor the temperature of the liner. The strain gages on all the pipes were connected to the DAS and the strains were monitored and recorded continuously. The interval between each reading varied with time of the test as shown in Table 3.1. 
At the beginning of the test, all the gages were zeroed. The inlet to all the pipes were opened one at a time, keeping the outlet open. When the flow became steady and there were no air gaps, the outlet valve to that specimen was closed. The pipe liner samples remained at a pressure of 16.1 psi for the entire testing time. In case of a slight variation in pressure, the pressure was bought back to 16.1 psi by adjusting the pressure regulator. The strain data for all the gages, intensity of hydraulic pressure and the temperature were recorded into a file. The DAS software would indicate when the file was filled to its capacity. A new file would then be started by manually stopping the recording of data for a couple of seconds and restarting the recording in a new file. A consolidation file was maintained with a collection of readings from all the data files. The consolidation file was appended periodically with data from new files (Appendix B). 


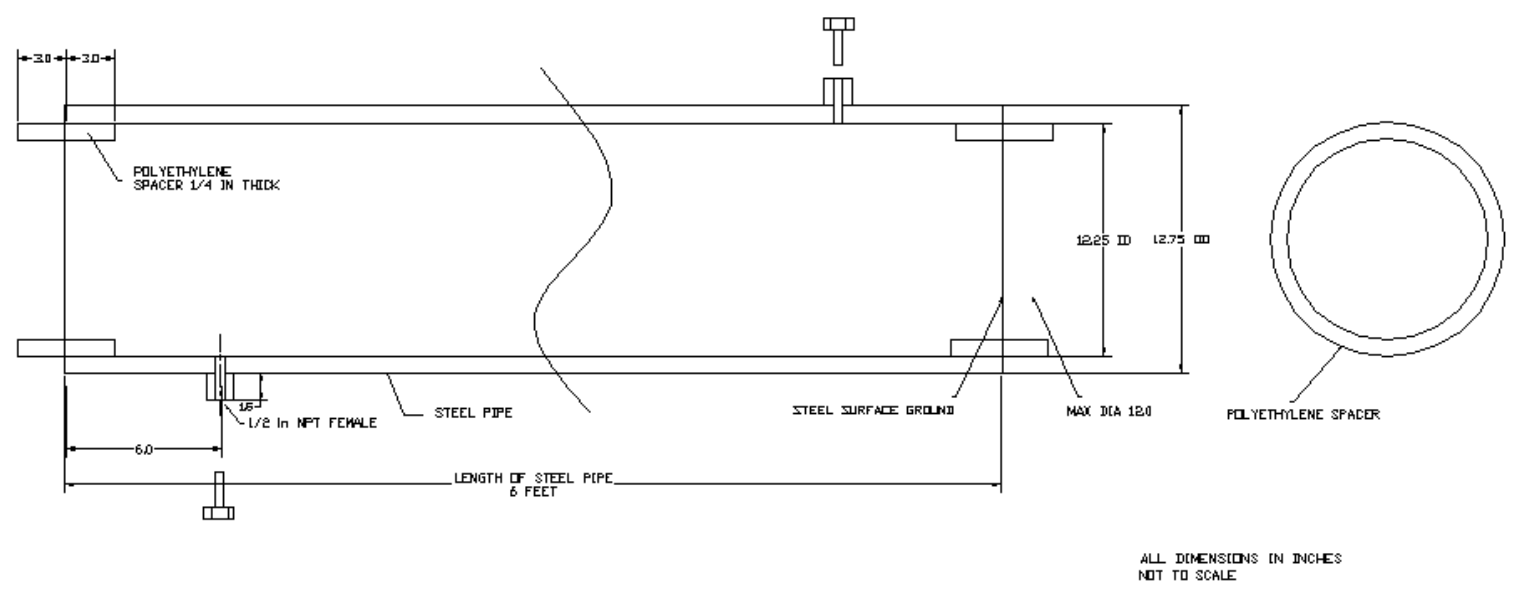

Figure 3.1 Steel pipe with polyethylene spacer

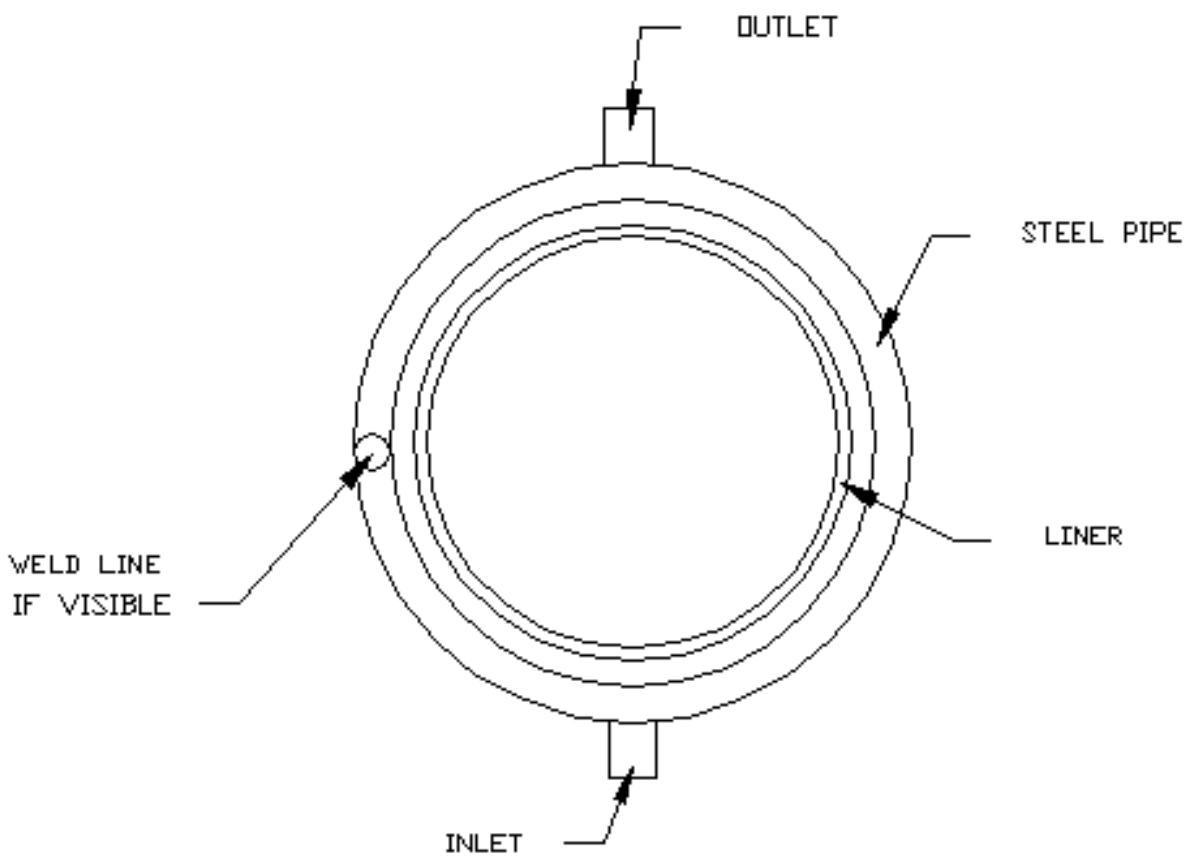

Figure 3.2 Front-view of pipe liner sample 


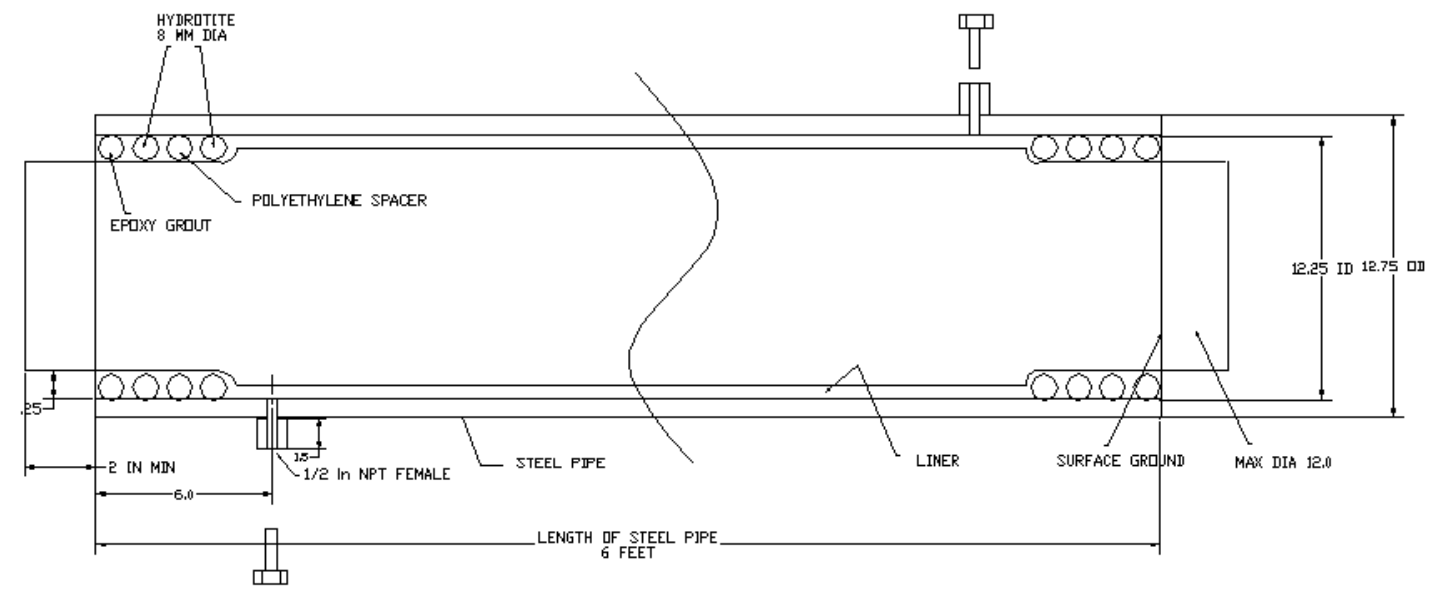

ALL DIMENSIDNS IN INCHES

Figure 3.3 End seals with Hydrotite ${ }^{\circledR}$, Polyethylene spacer and Epoxy grout

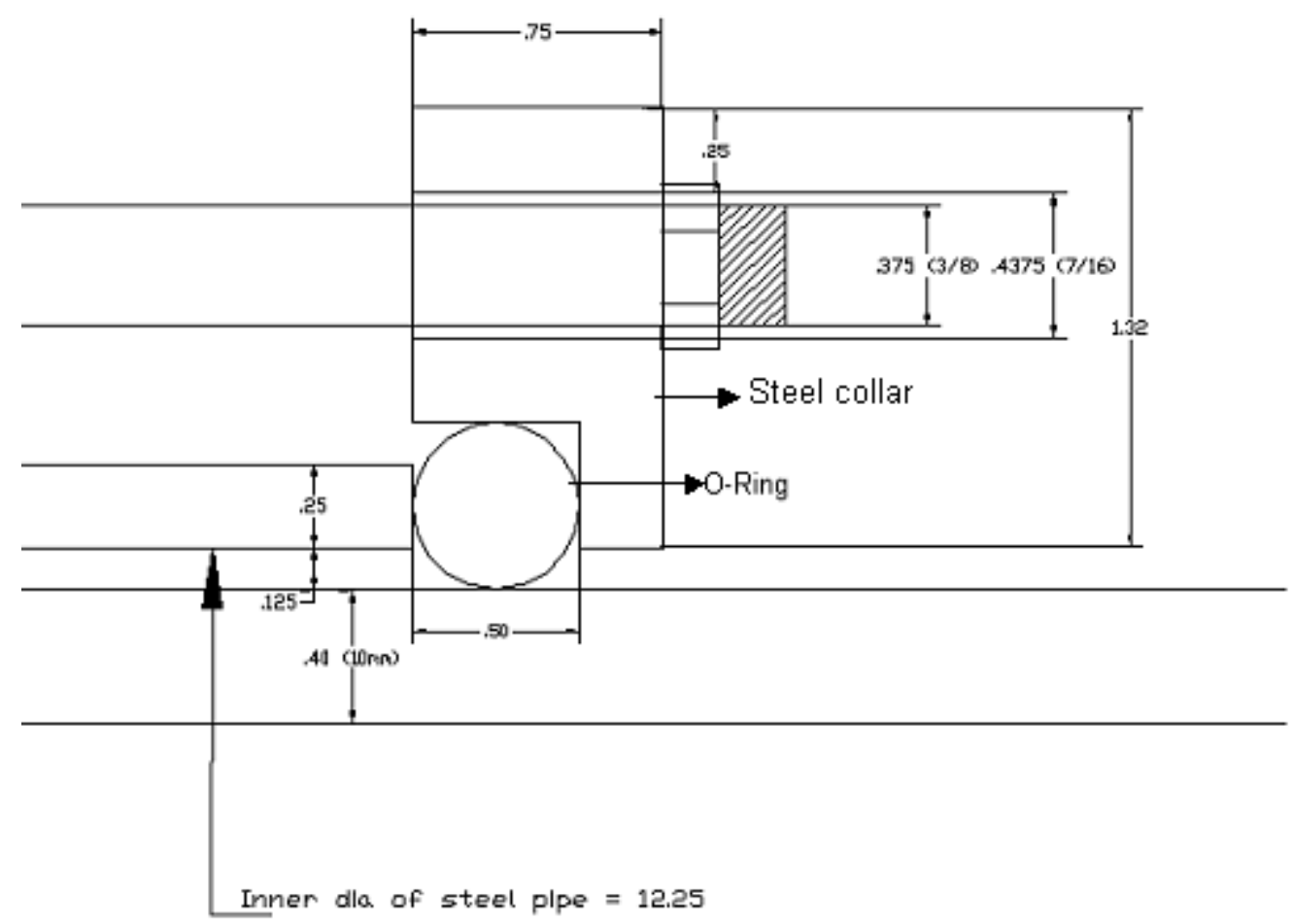

Figure 3.4 Alternative end seal using O-ring 


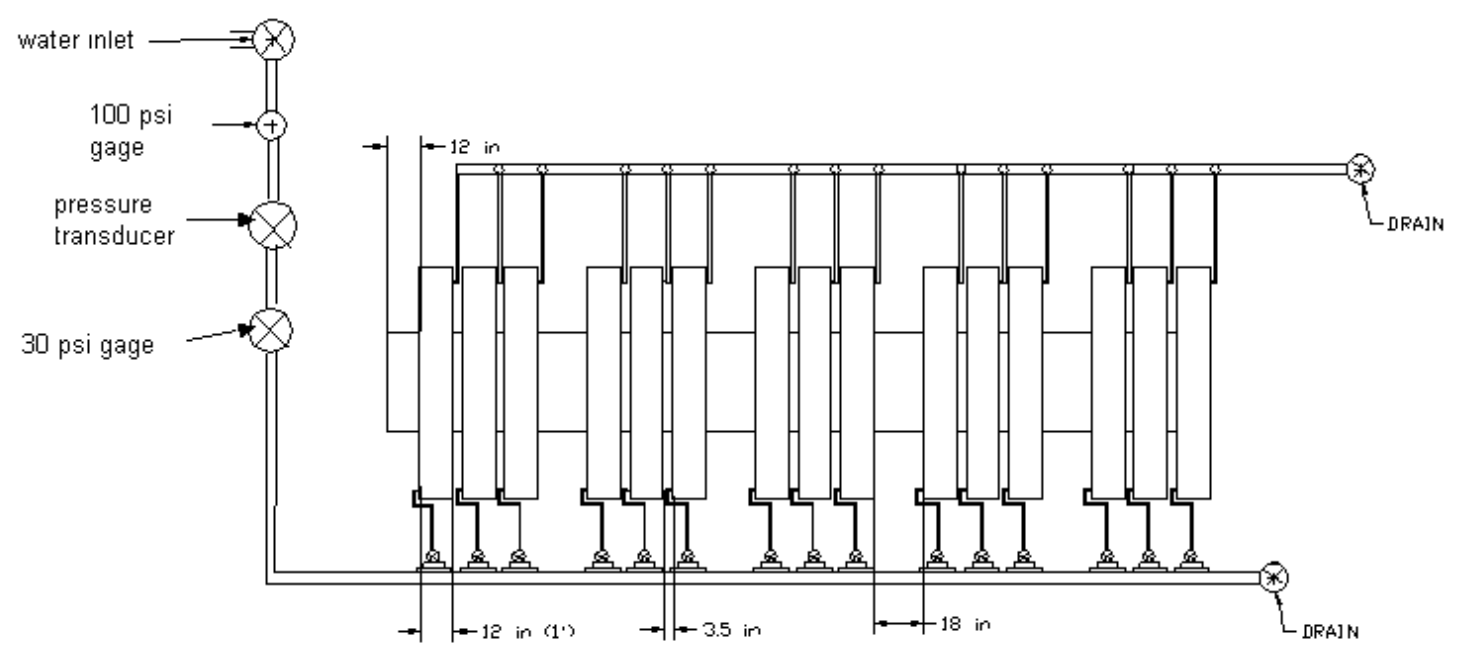

Figure 3.5 Liner samples arranged on a frame
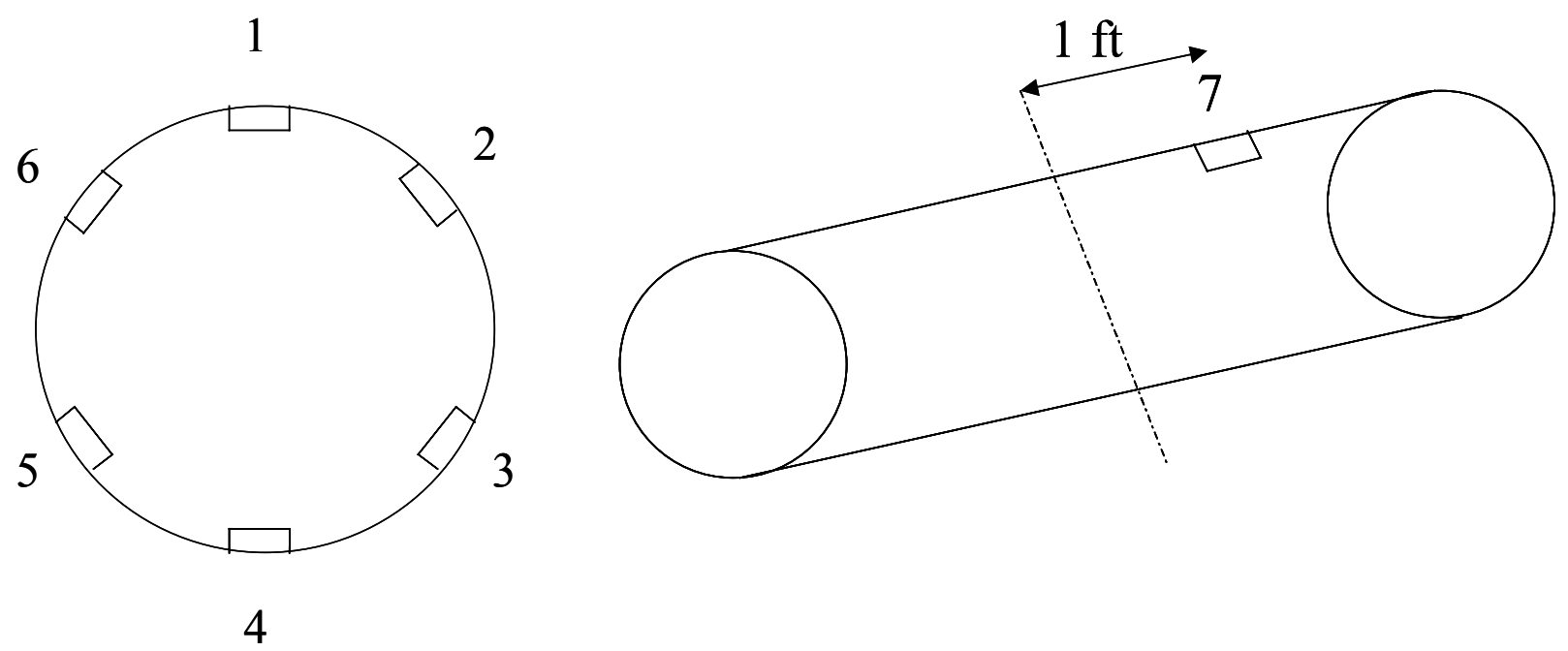

Figure 3.6 Strain gage placement in the liner sample 


\begin{tabular}{|c|c|}
\hline Time & Time between scans \\
\hline (Weeks) & (Seconds) \\
\hline & \\
\hline 1 & 2 \\
\hline 2,3 & 30 \\
\hline 4,5 & 60 \\
\hline 6 & 120 \\
\hline 7 & 180 \\
\hline 8 & 240 \\
\hline 9 & 300 \\
\hline 10 onwards & 360 \\
\hline
\end{tabular}

Table 3.1 Scan Rate for the testing period

\begin{tabular}{|c|c|c|}
\hline Data & Figures & Start Date \\
\hline Temperature & 4.17 & $12 / 4 / 2000$ \\
\hline Pressure & 4.16 & $12 / 4 / 2000$ \\
\hline Specimens A1-A3 & $4.1-4.3$ & $12 / 4 / 2000$ \\
\hline Specimens B1-B3 & $4.4-4.6$ & $5 / 2 / 2001$ \\
\hline Specimens C1-C3 & $4.7-4.9$ & $5 / 2 / 2001$ \\
\hline Specimens D1-D3 & $4.10-4.12$ & $5 / 2 / 2001$ \\
\hline Specimens E1-E3 & $4.13-4.15$ & $5 / 2 / 2001$ \\
\hline
\end{tabular}

Table 3.2 Test Start Date for all Materials. 


\section{CHAPTER 4: ANALYSIS OF LONG-TERM DATA}

The data obtained from the Data Acquisition System had to be processed. Simple moving average was applied. The moving average data points were then reduced to fewer data points for simplicity during plotting and calculations. Further, the data was compensated for temperature and variations in strain readings due to deformation modes. To effectively interpret the data and to evaluate the long-term material properties, a viscoelastic model was fit to the data.

\subsection{DATA SMOOTHING AND REDUCTION}

The strain readings of all the strain gages, the temperature readings of the thermocouple, and the pressure readings of the pressure transducer were all consolidated in a file. Since the data was recorded over a period of 10,000 hours, there were numerous data points and minor fluctuations in the strain readings. In order to reduce the effect of random variations in data, a moving average was done on the data. Further, picking every hundredth point from the moving average result reduced the size of the data file. A program was written in MATLAB $^{\circledR}$ to accomplish this. Moving average is defined as "a simple mathematical technique used primarily to eliminate aberrations and reveal the real trend in a collection of data points" [12].

$$
\begin{aligned}
& P_{1}=\frac{p_{1}+p_{2}+\ldots \ldots+p_{50}}{50} \\
& P_{2}=\frac{p_{2}+p_{3}+\ldots \ldots .+p_{51}}{50}
\end{aligned}
$$


The computed values of strains after performing moving average, represents the general trend of data recorded by the DAS. From the moving average data $\left(\mathrm{P}_{1}, \mathrm{P}_{2} \mathrm{P}_{3} \ldots\right.$, $\mathrm{P}_{\mathrm{N}}$ ), the program picked every hundredth data point, starting from the first one. These points formed the final values. Plots of strain, pressure and temperature readings after the moving average and data reduction are shown from Figure 4.1 to Figure 4.17 for the pressure transducer, thermocouple and all the gages of all the pipe liner samples. The data for pressure, temperature and specimen A1 to A3 were taken starting on 12/4/2000. All the remaining specimens were pressurized starting on 5/2/2001 (Table 3.2).

\subsection{VISCOELASTIC BEHAVIOR}

Materials can be broadly classified into Elastic, Viscous, or Viscoelastic materials. On the application of a sudden load, which is then held constant, the elastic material would undergo an instantaneous deformation, which would then remain constant for the loading period. The viscous material will flow at a constant rate. In case of viscoelastic materials, there is a steep instantaneous increase in deformation for small values of time, and then there is gradual increase in deformation with a slope that tends to infinity. When the load is released, the elastic material comes back to its original state. The viscous material remains as it is. The viscoelastic material regains its instantaneous deformation but takes time to regain the delayed response to the load. When the stress is held constant, the viscoelastic material undergoes three different phases of strain (Haddad 1995). The reversible strain that disappears upon removal of the load is the instantaneous strain $\left(\varepsilon_{\mathrm{e}}\right.$ in Figure 4.40). The delayed elastic strain requires time for recovery after the stress has been removed. This portion of strain is known as primary creep $\left(\varepsilon_{\mathrm{d}}\right.$ in Figure 4.40). The rate of increase of primary creep decreases with time. The final portion of 
strain is the viscous flow that is irreversible ( $\varepsilon_{\mathrm{v}}$ in Figure 4.40). It cannot be recovered on removal of load and is called secondary creep.

One of the important viscoelastic effects observed in solid polymers is creep. The phenomenon of creep is observed when a polymer is stressed at a constant level resulting in a strain increase over the time period. The creep modulus is defined by the equation,

$$
E(t)=\frac{\sigma(t)}{\varepsilon_{0}}
$$

where $\mathrm{E}(\mathrm{t})$ is the creep modulus, $\varepsilon_{0}$ is the constant strain that is applied and $\sigma(\mathrm{t})$ is the time dependent stress. Creep compliance D $(\mathrm{t})$ is defined as

$$
D(t)=\frac{\varepsilon(t)}{\sigma_{0}}
$$

where $\sigma_{0}$ is the constant applied stress and $\varepsilon(t)$ is the resulting time-dependent strain.

\subsection{TEMPERATURE COMPENSATION}

As mentioned in Chapter 2, temperature has a significant influence on the viscoelastic behavior polymers. With increasing temperature, the material softens and becomes more compliant. Since the test was conducted over a long period of time, the testing facility was subjected to differences in ambient temperature. A plot of temperature variation over the period of testing is shown in Figure 4.17. Due to this, the behavior of the material had undergone changes and these were reflected in the strain readings. Thus the strains obtained were compensated for changes in ambient temperature. This was done following the TTSP principle as explained in Chapter 2.

Only un-aged curves can be compensated for variations in temperature using the TTSP. The compliance curves obtained from the pipes are continuously aging curves. 
Thus, the un-aged version of the actual data had to obtained. Struik's [1] formula for obtaining un-aged times from aged times was used. The formula is

$$
\lambda=\frac{t_{e}}{\alpha}\left[\left(1+\frac{t}{t_{e}}\right)^{\alpha}-1\right]
$$

where, $\lambda$ is the un-aged time, $t$ is real time, $t_{e}$ is the age of the pipe (from manufacture date to test start date), and $\alpha$ is $(\mu-1)$, where $\mu$ is the aging parameter from Aging Studies [26]. The values of $\mu$ for different materials are given in Table 4.1.

A linear equation was used to fit the Temperature vs. $\log \mathrm{a}_{\mathrm{T}}$ curve (Chapter 2). Using that equation, the value of $\log \mathrm{a}_{\mathrm{T}}$ was computed for all the values of temperature recorded by the DAS. From the $\log \mathrm{a}_{\mathrm{T}}$ values, the shift factor $\mathrm{a}_{\mathrm{T}}$ was computed. The duration of time $(\Delta \lambda)$ for which the temperature was a certain value was calculated. This time was divided by the corresponding value of $\mathrm{a}_{\mathrm{T}}$ for that temperature $\left(\Delta \lambda / \mathrm{a}_{\mathrm{T}}\right)$. Then the corrected time increment $\Delta \lambda / \mathrm{a}_{\mathrm{T}}$ was added to the previous time to obtain the corrected accumulated time $\lambda^{\mid}=\lambda+\Delta \lambda / \mathrm{a}_{\mathrm{T}}$. This resulted in stretching the time scale when the test temperature was above the reference temperature of $21.1{ }^{\circ} \mathrm{C}$ and shrinking the time scale when the temperature was less than $21.1^{0} \mathrm{C}$.

To get back the aging time $t^{\dagger}$ from the un-aged time $\lambda^{\mid}$, the inverse of Equation 4.4 was used.

$$
t^{\prime}=\left[\left(\frac{\lambda \alpha}{t_{e}}+1\right)^{\frac{1}{\alpha}}-1\right] t_{e}
$$




\subsection{COEFFICIENT OF THERMAL EXPANSION COMPENSATION}

The strain gages used in the experiment were self-temperature compensating when bonded on a material, which has the same coefficient of thermal expansion (CTE) as that of the gage $\left(50 \mathrm{~mm} / \mathrm{mm}^{-}{ }^{0} \mathrm{C}\right)$. The CTE's of the material in this study are given in Table 4.2. But since a considerable change in temperature was recorded by the DAS, an attempt was made to correct the strain reading for temperature effect of the gage. Due to the influence of temperature, the strain gage reads a strain, which is either more or less than the actual strain, depending on the temperature. This strain read by the gage is known as the apparent strain or the thermal output of the gage. The manufacturer of the gages supplied a temperature correction sheet along with the gages. The equation used for computing the apparent strain $\left(\varepsilon_{\text {app }}\right)$, as a function of the temperature $\mathrm{T}$ is given by

$$
\text { Eapp }=1.97 \times 10^{1}-2.29 \times T^{1}+6.68 \times 10^{-2} \times T^{2}-1.39 \times 10^{-4} \times T^{3}+2.46 \times 10^{-6} \times T^{4}
$$

If the CTE of the liner material and the gage were the same, the actual strain could be computed by subtracting the apparent strain from the recorded strain. Since the CTE's were different, the following method was used for CTE compensation. The thermal output of a gage can be found by [22] as

$$
\varepsilon_{T / O}=\left[\frac{\beta_{G}}{F_{G}}-\alpha_{G}\right] \Delta T+\alpha_{S} \Delta T
$$

where $\varepsilon_{\mathrm{T} / \mathrm{O}}$ is the thermal output in strain units, $\beta_{\mathrm{G}}$ is the coefficient of resistance of the grid conductor, $F_{G}$ is the gage factor of the strain gage, $\left(\alpha_{S}-\alpha_{G}\right)$ is the difference in thermal expansion of substrate and grid, and $\Delta \mathrm{T}$ is the temperature change. The thermal output for the CTE of the gage can be written as 


$$
\varepsilon_{T / O}(50)=\left[\frac{\beta_{G}}{F_{G}}-\alpha_{G}\right] \Delta T+50 \Delta T
$$

and the thermal output for CTE of the material can be written as

$$
\varepsilon_{T / O}(\text { material })=\left[\frac{\beta_{G}}{F_{G}}-\alpha_{G}\right] \Delta T+\alpha_{S}(\text { material }) \Delta T
$$

Subtracting equations 4.8 and 4.9 , we get,

$$
\varepsilon_{T / O}(50)-\varepsilon_{T / O}(\text { material })=\left(50-\alpha_{S}(\text { material })\right) \Delta T
$$

Finding the $\varepsilon_{\mathrm{T} / \mathrm{O}}(50)$ from equation 4.10 and $\alpha_{\mathrm{S}}$ for different materials from Table 4.2 , the thermal output of the material can be calculated and subtracted from the gage reading to give the actual strain.

The apparent strain was found to be negligible compared to the strain read by the DAS. A plot showing the corrected and uncorrected strain is shown for one gage in Figure 4.18. Since the correction was negligible, it was ignored.

\subsection{COMPUTATION OF DEFLECTION OF THE PIPE LINERS}

The liner experiences free-ring buckling until is leans on the steel host pipe (Figure 4.20). The strains grow differently for each gage depending on how this free-ring buckling mode evolves. To find the buckling modes of the liner, the deflection of the liner at the mid span had to be determined. In order to determine the deflection of the pipe liner, the strains were first fit with an equation. Since the strains repeated it self periodically, that is every 360 degrees, Discrete Fourier Transform was done on the available strain data. When there is a given wave form, the process of determining its frequency is known as Fourier analysis. When the signal is in the form of discrete points, the Discrete Fourier Transform (DFT) is used to determine the frequency [19]. In this 
case, the frequency of sampling the data was known but the equation of the waveform was not known. Hence, the following equations were used to determine the equation for the variation of strain along the center inner circumference of the pipe.

$$
\begin{aligned}
& A n=\frac{2}{N} \sum_{r=1}^{N} y(r \Delta \theta) \cos \left(\frac{2 \pi r n}{N}\right) \quad n=0,1, \ldots, \frac{N}{2} \\
& B n=\frac{2}{N} \sum_{r=1}^{N} y(r \Delta \theta) \sin \left(\frac{2 \pi r n}{N}\right) \quad n=0,1, \ldots ., \frac{N}{2}-1 \\
& y\left(\theta_{r}\right)=\frac{A_{0}}{2}+\sum_{n=1}^{N / 2-1}\left[A_{n} \cos \left(\frac{2 \pi r n}{N}\right)+B_{n} \sin \left(\frac{2 \pi r n}{N}\right)\right]+\frac{A_{N / 2}}{2} \cos (\pi r)
\end{aligned}
$$

In the case of strains, $N$ is the number of points recorded over the sample domain $[0,2 \pi)$ at intervals of $\Delta \theta$. Since there are six gages around the circumference where strains are recorded, $\mathrm{N}=6, \Delta \theta=2 \pi / \mathrm{N}=\pi / 3$ radians, that is the angle interval. The value of $\mathrm{r}$ ranges from 0 to $N$. Hence $\theta_{r}=r \Delta \theta$. $A_{n}$ and $B_{n}$ are the coefficients of the cosine and sine terms and can be computer from the above equations. The final equation is given by the third equation of Equation 4.11, where the term $r \Delta \theta$ in the parenthesis of the cosine and sine is replaced by theta $(\theta)$, the angle, with $\Delta \theta=2 \pi / \mathrm{N}$, as follows.

$$
y(\theta)=\frac{A_{0}}{2}+A_{1} \cos (\theta)+B_{1} \sin (\theta)+A_{2} \cos (2 \theta)+B_{2} \sin (2 \theta)+\frac{A_{3}}{2} \cos (3 \theta)
$$

A plot of the actual strain data with the DFT points is plotted for one gage in Figure 4.19.

The equation obtained from the above procedure was equated to be $\varepsilon(\theta)$, that is, the variation of strain over the entire inner circumference. This is the total strain read by the strain gages. But this is the sum of the bending strain $\left(\varepsilon_{\mathrm{b}}\right)$ and membrane strain $\left(\varepsilon_{\mathrm{m}}\right)$ [20]. 


$$
\varepsilon(\theta)=\varepsilon_{b}+\varepsilon_{m}
$$

When the application of a force results in bending, the strain caused due to the force is called bending or moment strain. The membrane strain is the strain at the neutral axis due to the applied force. The membrane strain can be obtained from the equation

$$
\varepsilon_{m}=-\frac{p d D(t)}{2 h}
$$

The term $\mathrm{p}$ is the pressure exerted on the pipe, that is $16.1 \mathrm{psi}, \mathrm{d}$ is the diameter of the pipe, $h$ is the thickness of the pipe and $D(t)$ is the compliance of the pipe when subjected to constant pressure over the testing time period. The bending strain is proportional to the second derivative of the deflection $\mathrm{w}$.

$$
\begin{aligned}
& \varepsilon_{b}=-z \frac{\partial^{2} w}{\partial x^{2}} \\
& \text { but } x=a \theta \Rightarrow \partial^{2} x=a^{2} \partial \theta^{2} \\
& \therefore \varepsilon_{b}=-\frac{z}{a^{2}} \frac{\partial^{2} w}{\partial \theta^{2}}
\end{aligned}
$$

In the above equations, $\mathrm{a}=\mathrm{d} / 2$ is the radius of the pipe and $\theta$ is the angle at which the gages are placed, as shown in Figure 4.21. Hence to find the deflection, the equations $4.13,4.14$ and 4.15 can be combined to be written as

$$
-\frac{z}{a^{2}} w^{\|}=\frac{A_{0}}{2}+A_{1} \cos (\theta)+B_{1} \sin (\theta)+A_{2} \cos (2 \theta)+B_{2} \sin (2 \theta)+\frac{A_{3}}{2} \cos (3 \theta)+\frac{p d D(t)}{2 h}(4 .
$$

The above equation can be rearranged to separate the periodic and non-periodic functions. 


$$
\begin{gathered}
-\frac{z}{a^{2}} w^{\|}(\theta)=a_{0}+f(\theta) \\
\text { where } a_{0}=\frac{A_{0}}{2}+\frac{p d D(t)}{2 h}, \\
f(\theta)=A_{1} \cos (\theta)+B_{1} \sin (\theta)+A_{2} \cos (2 \theta)+B_{2} \sin (2 \theta)+\frac{A_{3}}{2} \cos (3 \theta)
\end{gathered}
$$

In the above equation, $\mathrm{a}_{0}$ is the non-periodic part and $\mathrm{f}(\theta)$ is the periodic function and ()$^{l}=\mathrm{d} / \mathrm{d} \theta$. Integrating the above equation twice to get the deflection $\mathrm{w}$, we get

$$
-\frac{z}{a^{2}} w=a_{0} \theta^{2}+k_{1} \theta+k_{2}+F^{||}(\theta)
$$

In Equation $4.18, \mathrm{k}_{1}$ and $\mathrm{k}_{2}$ are the constants of integration and $\mathrm{d}^{2} \mathrm{f} / \mathrm{d} \theta^{2}=\mathrm{F}^{\|}$. Since the pipe must close at $\theta=2 \pi$, the following compatibility conditions must be satisfied.

$$
\begin{aligned}
& w(0)=w(2 \pi) \\
& w^{\prime}(0)=w^{\prime}(2 \pi)
\end{aligned}
$$

The periodic part $f(\theta)$ will always satisfy the above conditions, but the nonperiodic part will not satisfy the conditions. We get from the above conditions,

$$
\begin{gathered}
w(0)=k_{2} \\
w(2 \pi)=a_{0}(2 \pi)^{2}+k_{1} 2 \pi+k_{2} \\
w^{\prime}(0)=k_{1} \\
w^{\prime}(2 \pi)=4 \pi a_{0}+k_{1}
\end{gathered}
$$


From Equation 4.21, we get the value of $\mathrm{k}_{1}$ to be zero. Substituting in Equation 4.20, we get $\mathrm{a}_{0}=0$. Hence, the above conditions can be satisfied only if $\mathrm{k}_{1}=\mathrm{k}_{2}=\mathrm{a}_{0}=0$. Having $\mathrm{a}_{0}$ as zero means that

$$
\frac{A_{0}}{2}=-\frac{p d D(t)}{2 h}
$$

But we have

$$
-\frac{p d D(t)}{2 h}=\varepsilon(m)
$$

Therefore, the only possible solution is that the average strain $A_{0} / 2$ be exactly equal to the membrane strain $\varepsilon(\mathrm{m})$ at any time. This was very important because it allowed us to compute the long-term compliance $\mathrm{D}(\mathrm{t})$ as

$$
D(t)=-\frac{A_{0}}{2} \frac{2 h}{p d}
$$

The deflection was computed from Equation 4.18, after substituting the values for $\mathrm{a}_{0}, \mathrm{k}_{1}$ and $\mathrm{k}_{2}$.

$$
w(\theta)=-\frac{a^{2}}{h / 2} F(\theta)
$$

The diagrams of the deflected mid-section of the pipe are shown in Figures 4.22 to 4.36. The figures also show the mode in which the deformation has taken place.

\subsection{MECHANICAL MODELS OF VISCOELASTICITY}

It is relatively easy to understand the viscoelastic behavior of polymers by representing them with mechanical models. These models consist mainly of combinations of springs and dashpots. Some of the simplest models consist of a spring and dashpot 
either in series or in parallel. The Maxwell model has a spring in series with a dashpot. A representation of the Maxwell model is shown in Figure 4.37. The expression for creep compliance as related to time for this model is

$$
J(t)=\frac{1}{E_{0}}+\frac{t}{\eta}
$$

where $E_{0}$ is the initial modulus or the stiffness of the spring and $\eta$ is the coefficient of viscosity of the dashpot. The main limitation of the Maxwell model is that it does not give a good prediction of the long-term behavior of the polymer. The creep behavior of the polymer cannot be represented accurately by only one exponential decay time. But the model gives a very good representation of the creep behavior at very short times. The Kelvin-Voigt model, shown in Figure 4.38 has a spring in parallel with the dashpot. The Kelvin-Voigt model can be represented as

$$
J(t)=\frac{1}{E_{0}}\left(1-e^{\frac{-t}{\tau}}\right)
$$

where $\tau$ is the relaxation time. For stress relaxation, the Kelvin model behaves like an elastic solid, which is not true for most viscoelastic materials. A Standard Solid (SLS) Model of Kelvin type is shown in Figure 4.39 and is given by the equation

$$
J(t)=\frac{1}{E_{\infty}}-\left(\frac{1}{E_{\infty}}-\frac{1}{E_{0}}\right) e^{\frac{-t}{\tau}}
$$

where $\mathrm{E}_{\infty}$ is the modulus of elasticity as time approaches infinity. The model consists of a spring in parallel to the Maxwell model. The model forces the material to behave like a solid as time approaches infinity. $\mathrm{E}_{\infty}$ is the long-term creep modulus of the material.

In the structural evaluation of polymer liners, it was very important to know both the short-term elastic modulus and the long-term viscoelastic modulus very accurately. 
The Four-parameter model as shown in Figure 4.40, is a combination of Kelvin-Voigt element in series with a spring and a damper. The equation to best represent the fourparameter model is

$$
J(t)=\frac{1}{E_{e}}+\frac{1}{E_{v e}}\left(1-e^{-\left(\frac{E_{v e}}{\eta_{2}}\right) t}\right)+\frac{t}{\eta_{1}}
$$

where $E_{e}$ is the Elastic modulus, $E_{v e}$ is the long term viscoelastic modulus and $\eta_{1}$ and $\eta_{2}$ are the viscosities of the two dampers. The first spring represents the initial elastic strain of the viscoelastic material. The spring and damper in parallel account for the retarded elastic strain, while the first dashpot accounts for the equilibrium viscous flow.

\subsection{CALCULATION OF MATERIAL PROPERTIES USING STANDARD LINEAR SOLID (SLS) MODEL}

From Equations, 4.22, 4.23 and 4.24 we can see that the membrane strain at a given time is equal to the average strain read by all the strain gages at that time. Hence, to compute the compliance of the material at a given time, the membrane strain at that time was divided by the stress. The membrane strain was obtained by taking the average of the stains around the circumference of the liner pipe. Plots of compliance vs. time were made for each specimen of each material. These were fit with an SLS model.

The data was fit with the SLS model using a data analysis software Origin ${ }^{\circledR}$. The following equation was used:

$$
y=a+b e^{-k x}
$$

Once the exponential linear equation was chosen and the initial guesses for the variables were made, the software automatically fit the data. The R-square and chi-square values 
were the parameters that decided whether the fit was a good representation of the data points or not. The significance of the R-squared value is explained in Chapter 2. The chisquare value is an estimation of the confidence level of the fit. The lower the chi-square value, the better the fit.

After fitting the data, the software gives the parameters $\mathrm{a}, \mathrm{b}$ and $\mathrm{k}$. By comparing equations 4.28 and 4.30 , we get

$$
\begin{gathered}
E_{\infty}=\frac{1}{a} \\
E_{0}=\frac{1}{b+\frac{1}{E_{\infty}}} \\
\tau=\frac{1}{k}
\end{gathered}
$$

The plots of the SLS fits of the compliances of the three pipes of each material are given in Figure 4.41 onwards. The values of the parameters above for the three samples of each material are given in Tables 4.3 to 4.7. The value of the elastic modulus $\left(E_{e}\right)$ obtained from the long-term tests is compared with the short-term ASTM D790 tests. The results are tabulated in Table 4.8.

The elastic modulus $\mathrm{E}_{\mathrm{e}}$ is heavily influenced by the short-time data, obtained while other factors (pressure, temperature, initial liner-to-casing contact, etc.) may be fluctuating. In an attempt to reduce random initial disturbance, the fit was repeated but the value of $\mathrm{E}_{\mathrm{e}}$ was fixed at the ASTM D790 value. The values are reported in Table 4.9. 


\begin{tabular}{|c|c|}
\hline Material & $\mathbf{m u}$ \\
\hline A & 0.48 \\
\hline B & 0.72 \\
\hline C & 0.71 \\
\hline D & 0.17 \\
\hline E & 0.60 \\
\hline
\end{tabular}

Table 4.1 Values of Aging Parameter [26]

\begin{tabular}{|c|c|c|c|c|c|}
\hline MATERIAL & A & B & C & D & E \\
\hline CTE $(\mathrm{micro} \mathrm{mm} / \mathrm{mm}-\mathrm{C})$ & 61.2 & $\sim$ & $\sim$ & 198 & $\sim$ \\
\hline
\end{tabular}

$\sim$ not provided by manufacturers

Table 4.2 Results of the Four-Parameter Fit on the Three Samples of Material B

\begin{tabular}{|c|c|c|c|c|c|c|c|c|}
\hline & & & & GPa & GPa & & & \\
\hline Pipe & a & b & k & E inf & E o & tau & Chi Sqr & R Sqr \\
\hline A1 & 5.75183 & -5.07202 & 0.00004 & 0.1739 & 1.4710 & 25000.00 & 0.04486 & 0.99155 \\
\hline A2 & 3.76735 & -3.16719 & 0.0001 & 0.2654 & 1.6662 & 10000.00 & 0.03883 & 0.97855 \\
\hline A3 & 3.4526 & -2.95776 & 0.00007 & 0.2896 & 2.0209 & 14285.71 & 0.02468 & 0.98062 \\
\hline Ave & & & & $\mathbf{0 . 2 4 3 0}$ & $\mathbf{1 . 7 1 9 4}$ & 16428.57 & 0.0361 & 0.9836 \\
\hline Stdev & & & & 0.0611 & 0.2788 & 7726.18 & 0.0104 & 0.0070 \\
\hline Cv & & & & $25 \%$ & $16 \%$ & $47 \%$ & $29 \%$ & $1 \%$ \\
\hline
\end{tabular}

Table 4.3 Results of the SLS Model Fits on the Three Samples of Material A 


\begin{tabular}{|c|c|c|c|c|c|c|c|c|}
\hline & & & & GPa & GPa & & & \\
\hline Pipe & $\mathbf{a}$ & $\mathbf{b}$ & $\mathbf{k}$ & E inf & E o & tau & Chi Sqr & R Sqr \\
\hline B1 & 1.28015 & -0.66768 & 0.00023 & 0.7812 & 1.6327 & 4347.83 & 0.00303 & 0.96759 \\
\hline B2 & 1.22959 & -0.60241 & 0.00054 & 0.8133 & 1.5944 & 1851.85 & 0.00267 & 0.96851 \\
\hline B3 & 1.29536 & -0.62339 & 0.00051 & 0.7720 & 1.4882 & 1960.78 & 0.00426 & 0.95373 \\
\hline Ave & & & & $\mathbf{0 . 7 8 8 8}$ & $\mathbf{1 . 5 7 1 8}$ & 2720.15 & 0.0033 & 0.9633 \\
\hline Stdev & & & & 0.0217 & 0.0749 & 1410.66 & 0.0008 & 0.0083 \\
\hline Cv & & & & $3 \%$ & $5 \%$ & $52 \%$ & $25 \%$ & $1 \%$ \\
\hline
\end{tabular}

Table 4.4 Results of the SLS Model Fits on the Three Samples of Material B

\begin{tabular}{|c|c|c|c|c|c|c|c|c|}
\hline & & & & GPa & GPa & & & \\
\hline Pipe & a & b & k & E inf & E o & tau & Chi Sqr & R Sqr \\
\hline C1 & 2.86469 & -1.97698 & 0.00034 & 0.3491 & 1.1265 & 2941.18 & 0.02256 & 0.97441 \\
\hline C2 & 2.44536 & -1.60663 & 0.00025 & 0.4089 & 1.1923 & 4000.00 & 0.01272 & 0.97683 \\
\hline C3 & 4.5634 & -3.47662 & 0.00027 & 0.2191 & 0.9201 & 3703.70 & 0.03351 & 0.98702 \\
\hline Ave & & & & $\mathbf{0 . 3 2 5 7}$ & $\mathbf{1 . 0 7 9 6}$ & 3548.29 & 0.0229 & 0.9794 \\
\hline Stdev & & & & 0.0970 & 0.1420 & 546.25 & 0.0104 & 0.0067 \\
\hline Cv & & & & $30 \%$ & $13 \%$ & $15 \%$ & $45 \%$ & $1 \%$ \\
\hline
\end{tabular}

Table 4.5 Results of the SLS Model Fits on the Three Samples of Material C

\begin{tabular}{|c|c|c|c|c|c|c|c|c|}
\hline & & & & GPa & GPa & & & \\
\hline Pipe & $\mathbf{a}$ & $\mathbf{b}$ & $\mathbf{k}$ & E inf & E o & tau & Chi Sqr & R Sqr \\
\hline D1 & 4.44329 & -2.83785 & 0.01127 & 0.2251 & 0.6229 & 88.73 & 0.54777 & 0.75049 \\
\hline D2 & 9.76132 & -5.9669 & 0.00942 & 0.1024 & 0.2635 & 106.16 & 1.00556 & 0.87631 \\
\hline D3 & 2.61648 & -1.60262 & 0.00765 & 0.3822 & 0.9863 & 130.72 & 0.09347 & 0.84209 \\
\hline Ave & & & & $\mathbf{0 . 2 3 6 6}$ & $\mathbf{0 . 6 2 4 3}$ & 108.54 & 0.5489 & 0.8230 \\
\hline Stdev & & & & 0.1402 & 0.3614 & 21.09 & 0.4560 & 0.0651 \\
\hline Cv & & & & $59 \%$ & $58 \%$ & $19 \%$ & $83 \%$ & $8 \%$ \\
\hline
\end{tabular}

Table 4.6 Results of the SLS Model Fits on the Three Samples of Material D 


\begin{tabular}{|c|c|c|c|c|c|c|c|c|}
\hline & & & & GPa & GPa & & & \\
\hline Pipe & a & b & k & E inf & E o & tau & Chi Sqr & R Sqr \\
\hline E1 & 0.38868 & -0.06 & 0.01448 & 2.5728 & 3.0425 & 69.06 & 0.00074 & 0.39057 \\
\hline E2 & 0.29927 & -0.05361 & 0.02466 & 3.3415 & 4.0707 & 40.55 & 0.00075 & 0.35066 \\
\hline E3 & 0.48489 & -0.64231 & 15.00626 & 2.0623 & -6.3524 & 0.07 & 0.00091 & 0.78265 \\
\hline Ave & & & & $\mathbf{2 . 6 5 8 9}$ & $\mathbf{3 . 5 5 6 6}$ & 36.56 & 0.0008 & 0.5080 \\
\hline Stdev & & & & 0.6439 & 5.7440 & 34.67 & 0.0001 & 0.2387 \\
\hline Cv & & & & $24 \%$ & $162 \%$ & $95 \%$ & $12 \%$ & $47 \%$ \\
\hline
\end{tabular}

Table 4.7 Results of the SLS Model Fits on the Three Samples of Material E

\begin{tabular}{|c|c|c|c|c|c|}
\hline MATERIAL & A & B & C & D & E \\
\hline ASTM D790 (te = inf) & 1.9293 & 2.0004 & 1.7190 & 0.9504 & 1.8581 \\
\hline 3 Param Model & 1.7194 & 1.5718 & 1.0796 & 0.6243 & 3.5566 \\
\hline \% DIFFERENCE & $11 \%$ & $21 \%$ & $37 \%$ & $34 \%$ & $-91 \%$ \\
\hline
\end{tabular}

Table 4.8 Comparison Between the Elastic Modulus (GPa) obtained from ASTM D790 and Long-Term Tests

\begin{tabular}{|c|c|c|c|c|c|c|}
\hline Material & Pipe 1 & Pipe 2 & Pipe 3 & Einf (GPa) & Stdev & Cv \\
\hline A & 0.1747 & 0.2663 & 0.2892 & 0.2434 & 0.0606 & $25 \%$ \\
\hline B & 0.7956 & 0.8254 & 0.7868 & 0.8026 & 0.0202 & $3 \%$ \\
\hline C & 0.3537 & 0.4175 & 0.2233 & 0.3315 & 0.0990 & $30 \%$ \\
\hline D & 0.2345 & 0.1176 & 0.3794 & 0.2439 & 0.1311 & $54 \%$ \\
\hline E & $\sim$ & 1.8587 & $\sim$ & 1.8587 & $\sim$ & $\sim$ \\
\hline \multicolumn{7}{|c}{ Curves Could not be fit }
\end{tabular}

Table 4.9 Values of $\mathrm{E}_{\text {inf }}$ in GPa (Forcing $\mathrm{E}_{0}$ to be equal to ASTM D790 test value) 


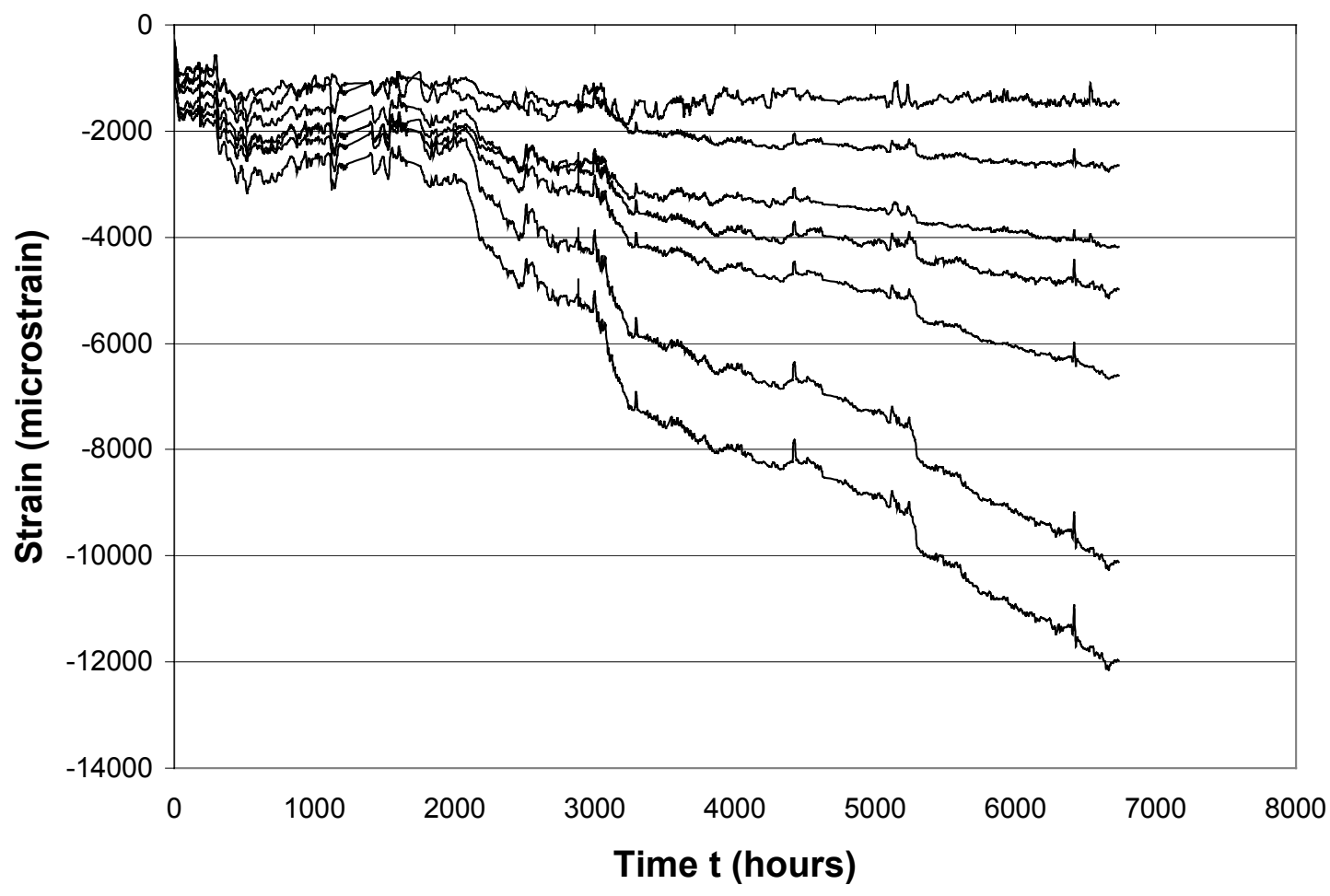

Figure 4.1 Strain Vs. Time For The Gages In Pipe A1

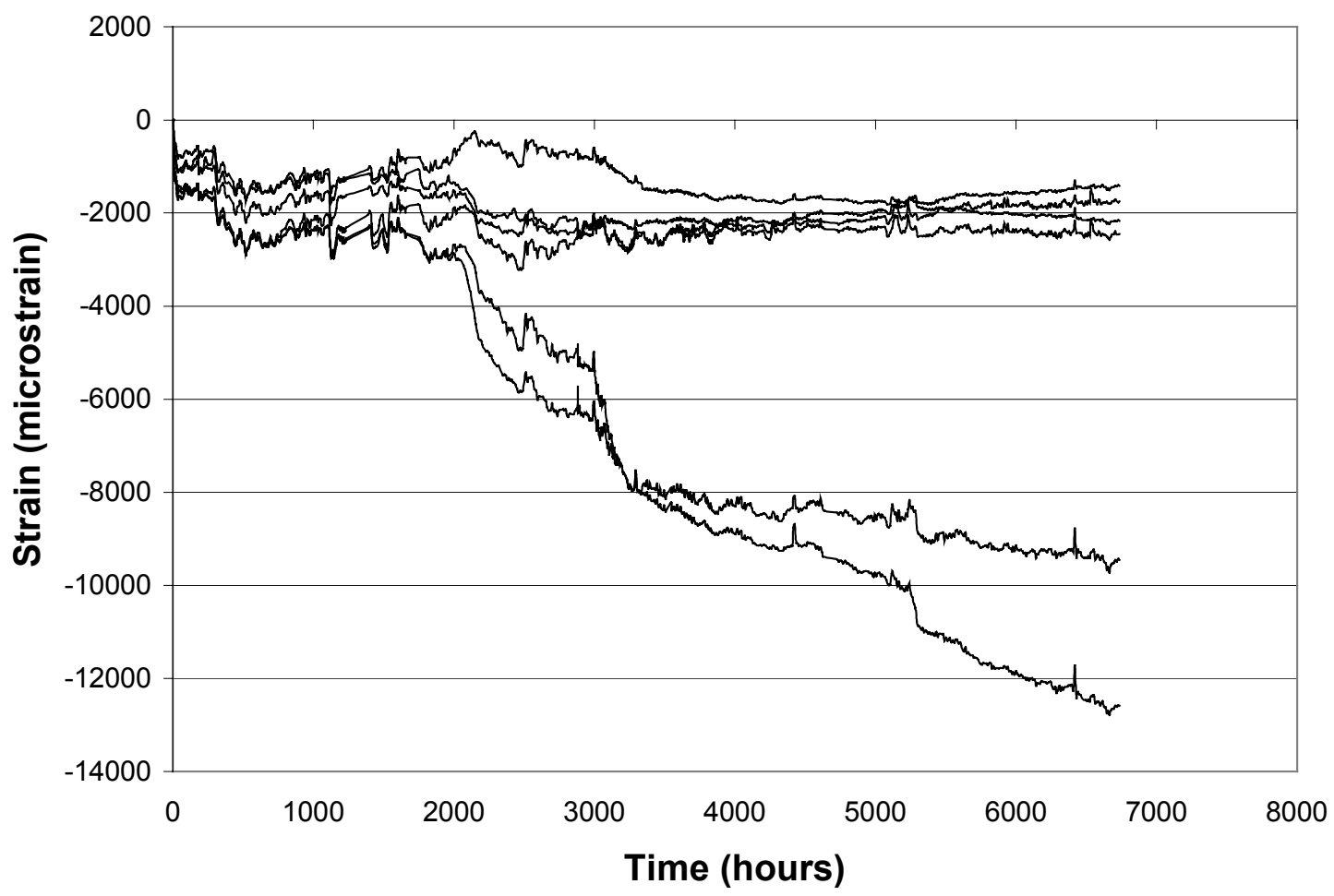

Figure 4.2 Strain Vs. Time For The Gages In Pipe A2 


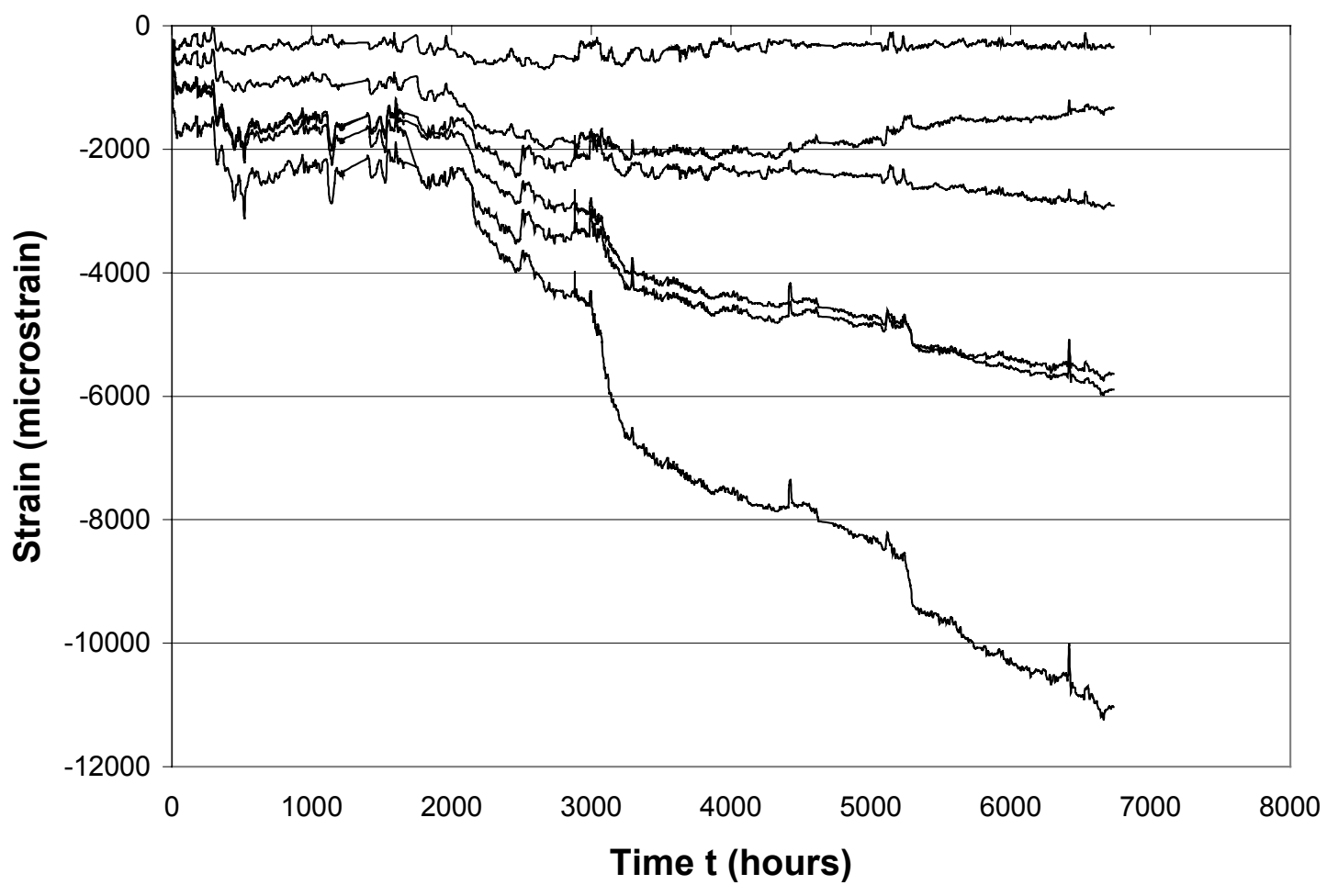

Figure 4.3 Strain Vs. Time For The Gages In Pipe A3

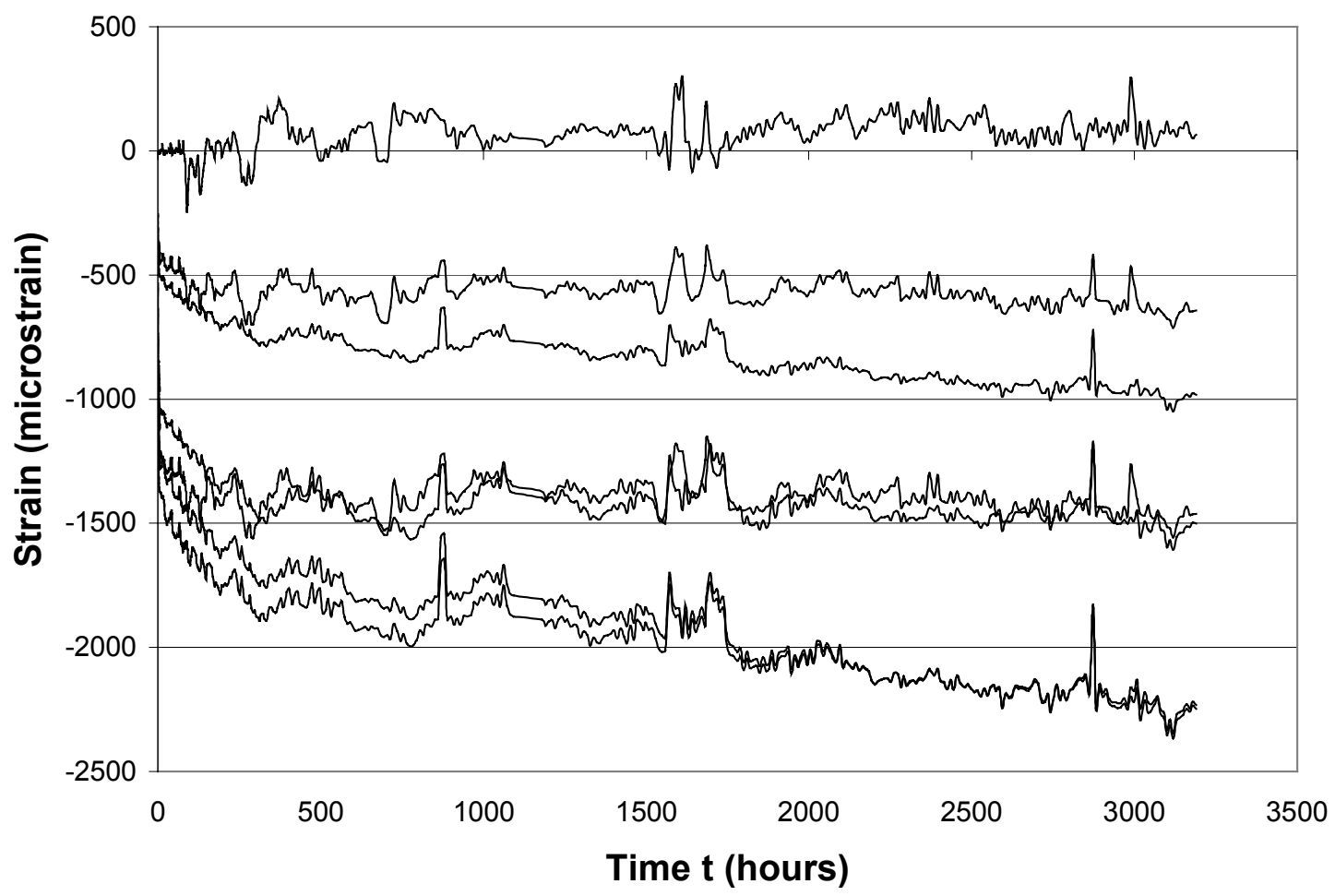

Figure 4.4 Strain Vs. Time For The Gages In Pipe B1 


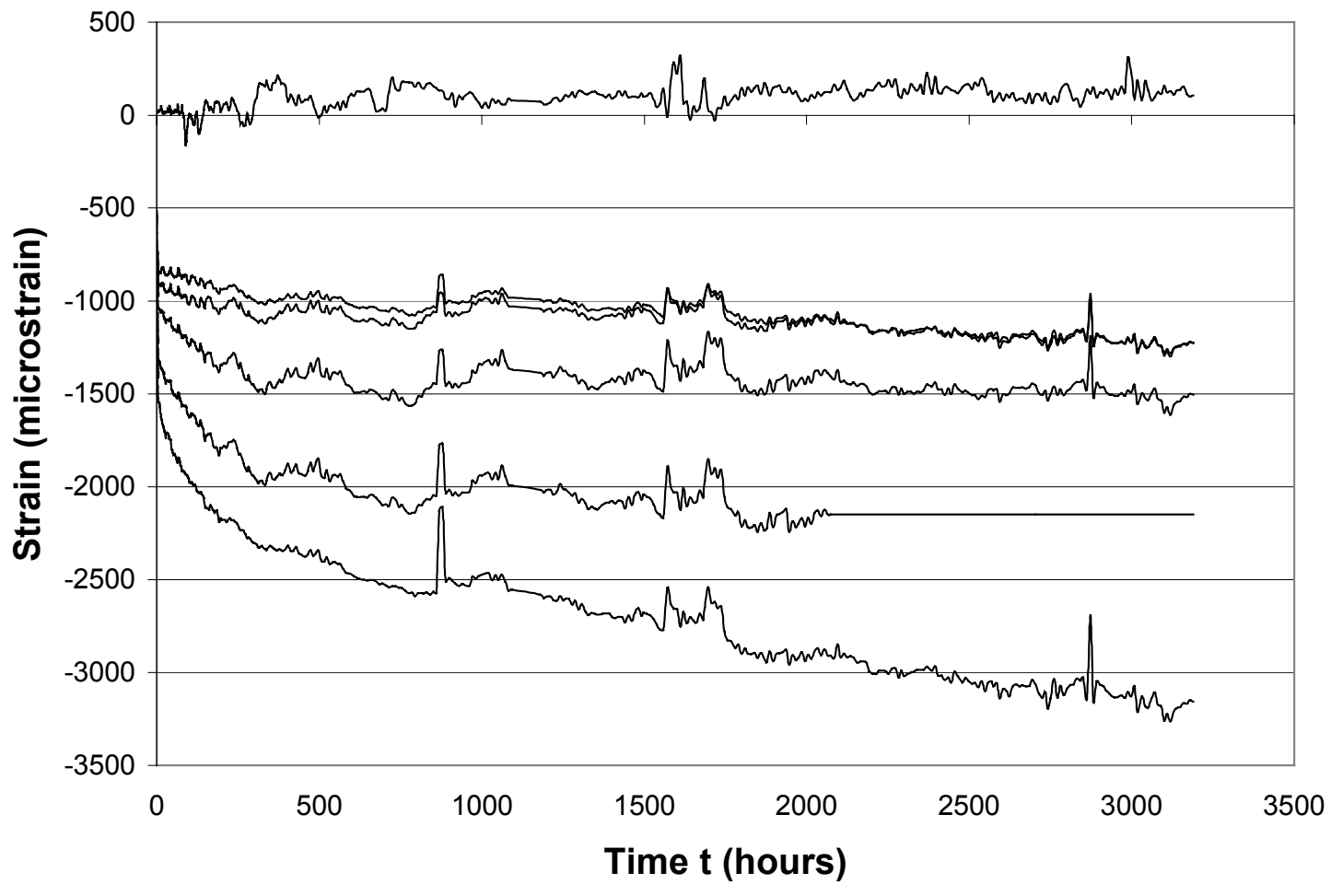

Figure 4.5 Strain Vs. Time For The Gages In Pipe B2

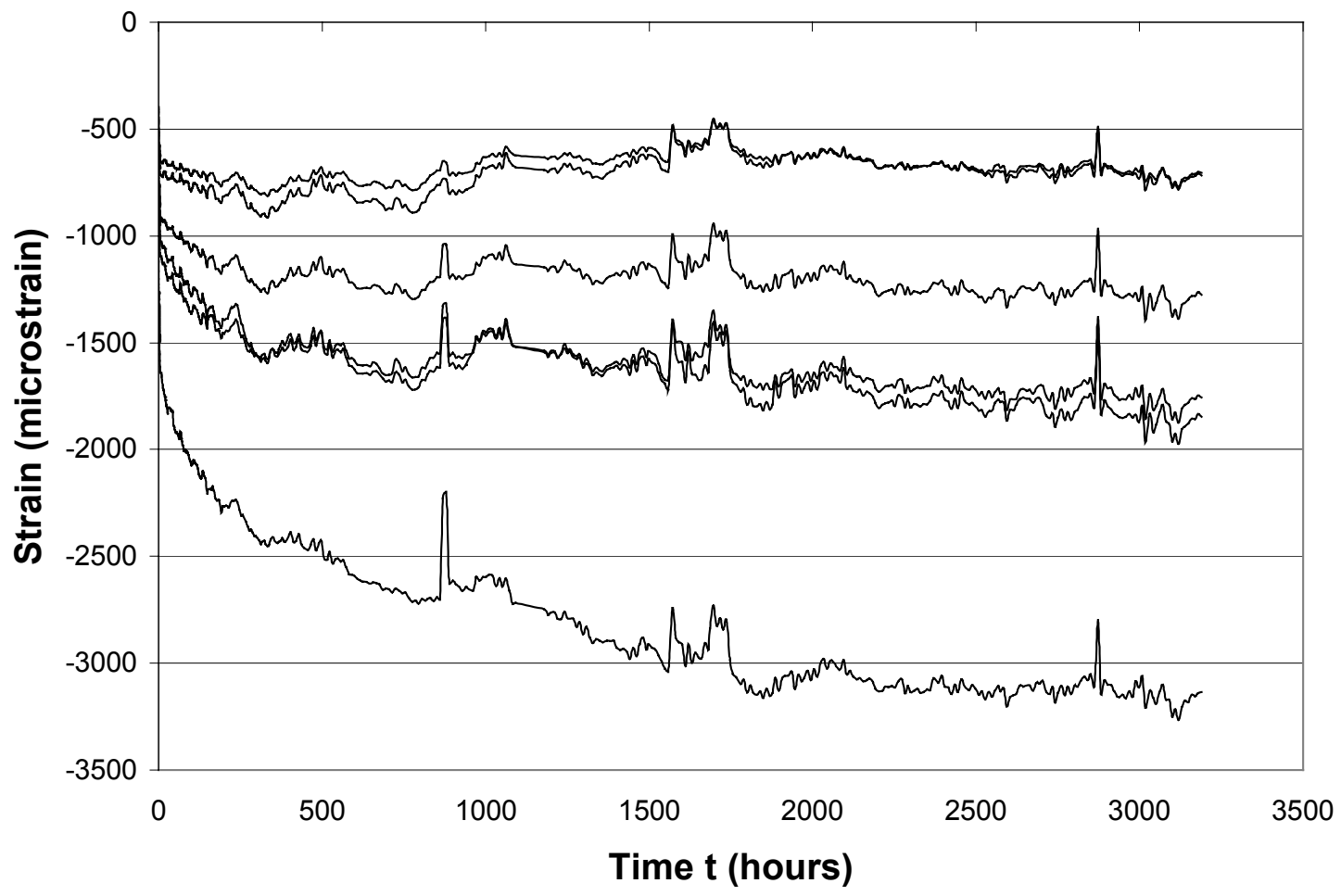

Figure 4.6 Strain Vs. Time For The Gages In Pipe B3 


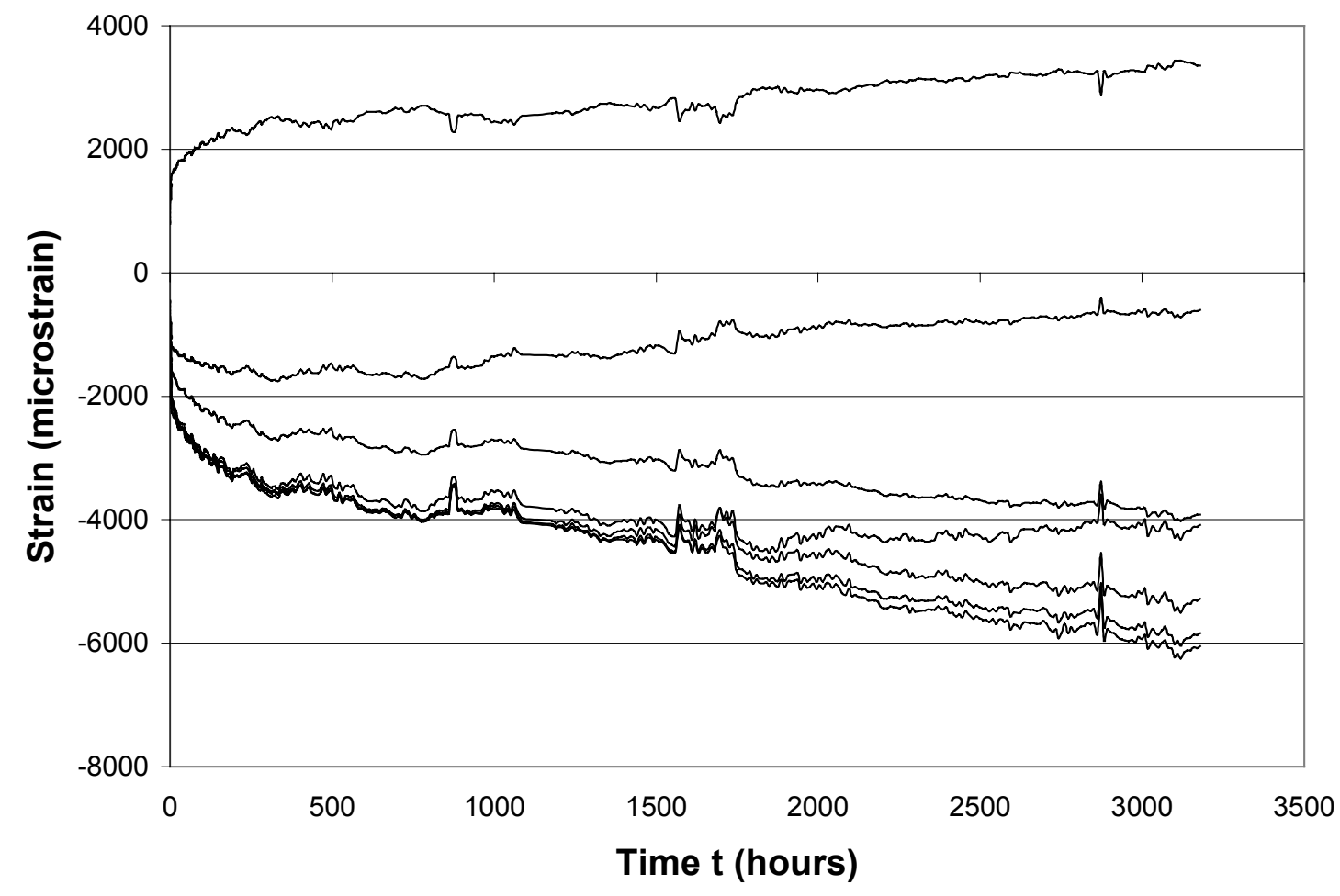

Figure 4.7 Strain Vs. Time For The Gages In Pipe C1

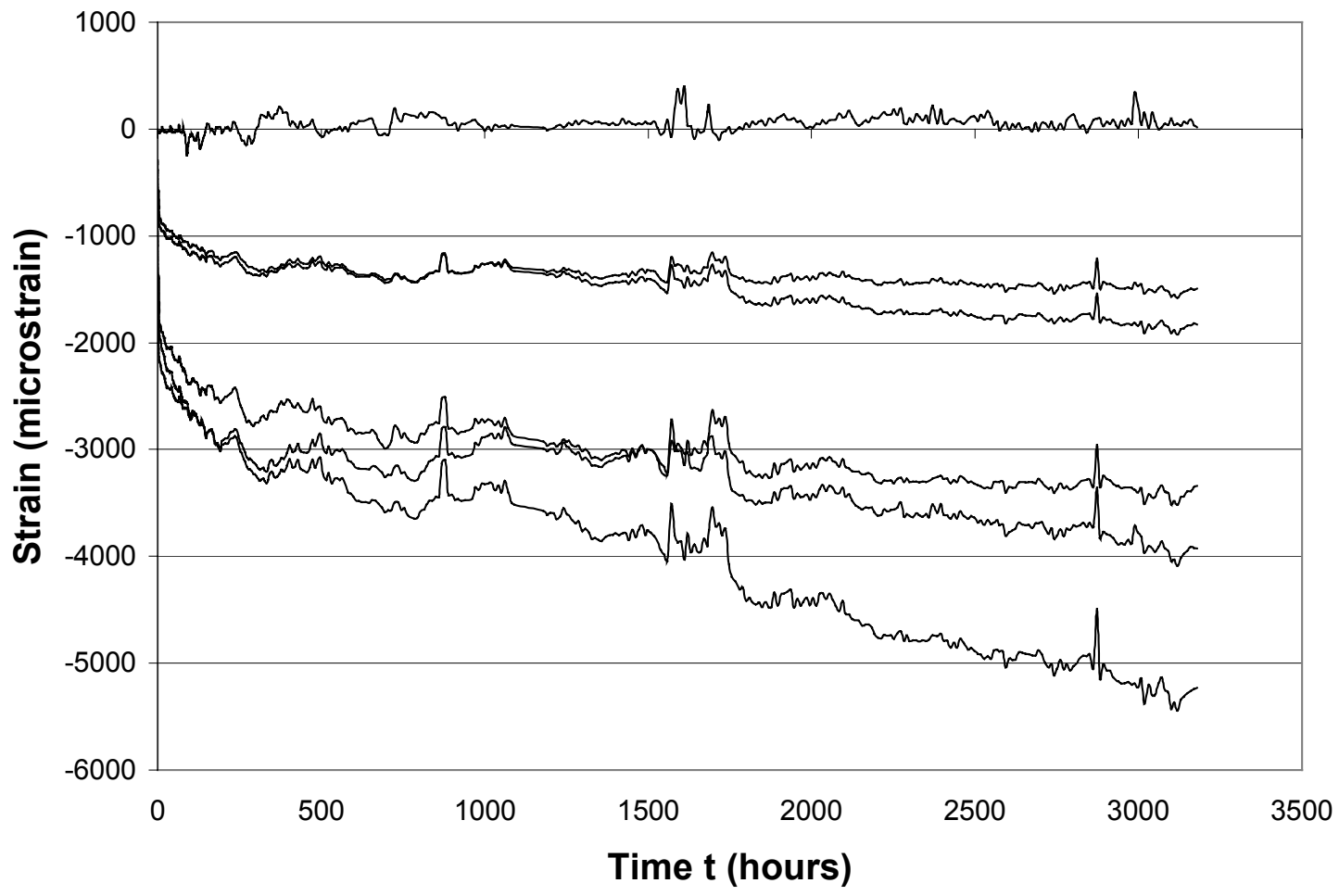

Figure 4.8 Strain Vs. Time For The Gages In Pipe C2 


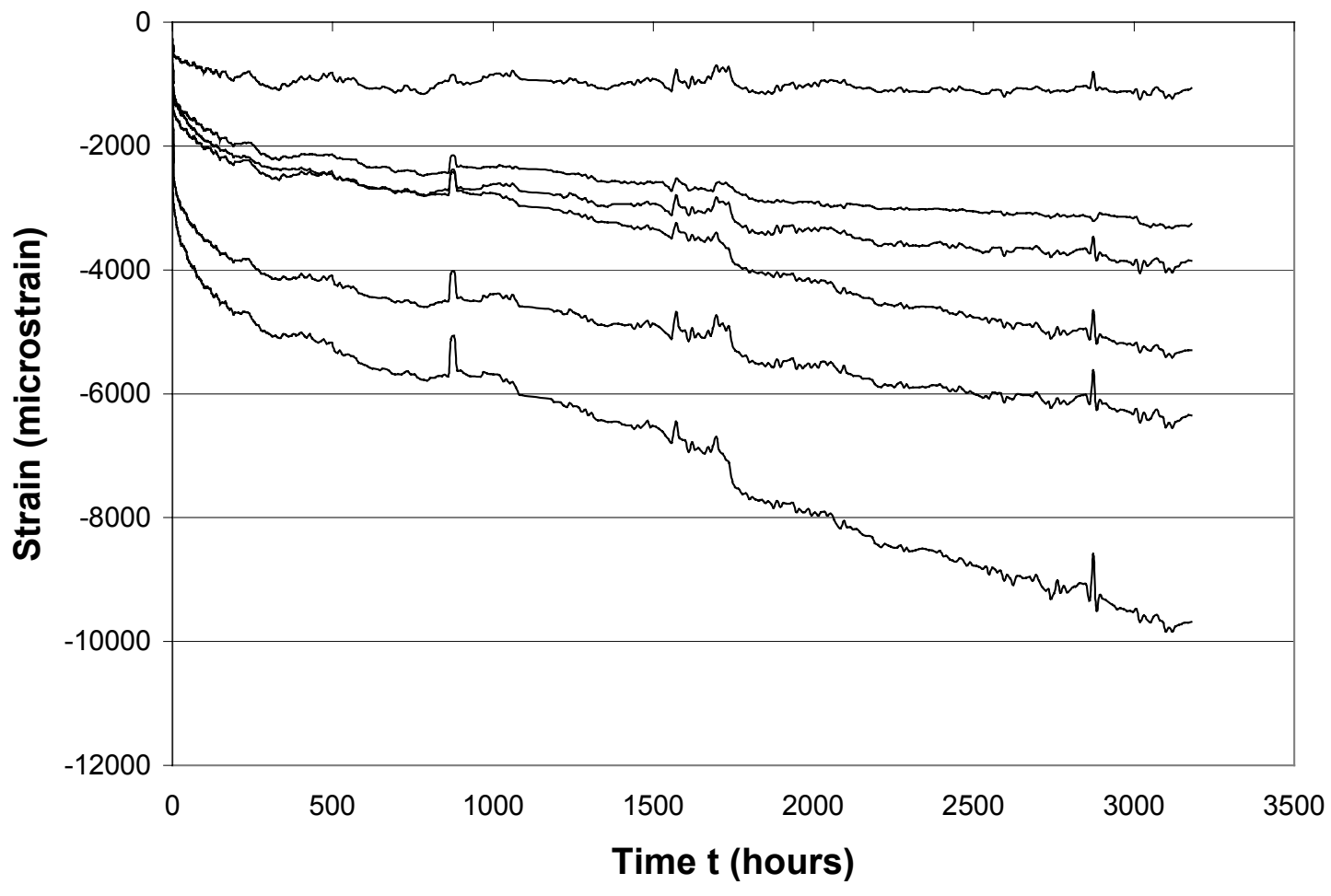

Figure 4.9 Strain Vs. Time For The Gages In Pipe C3

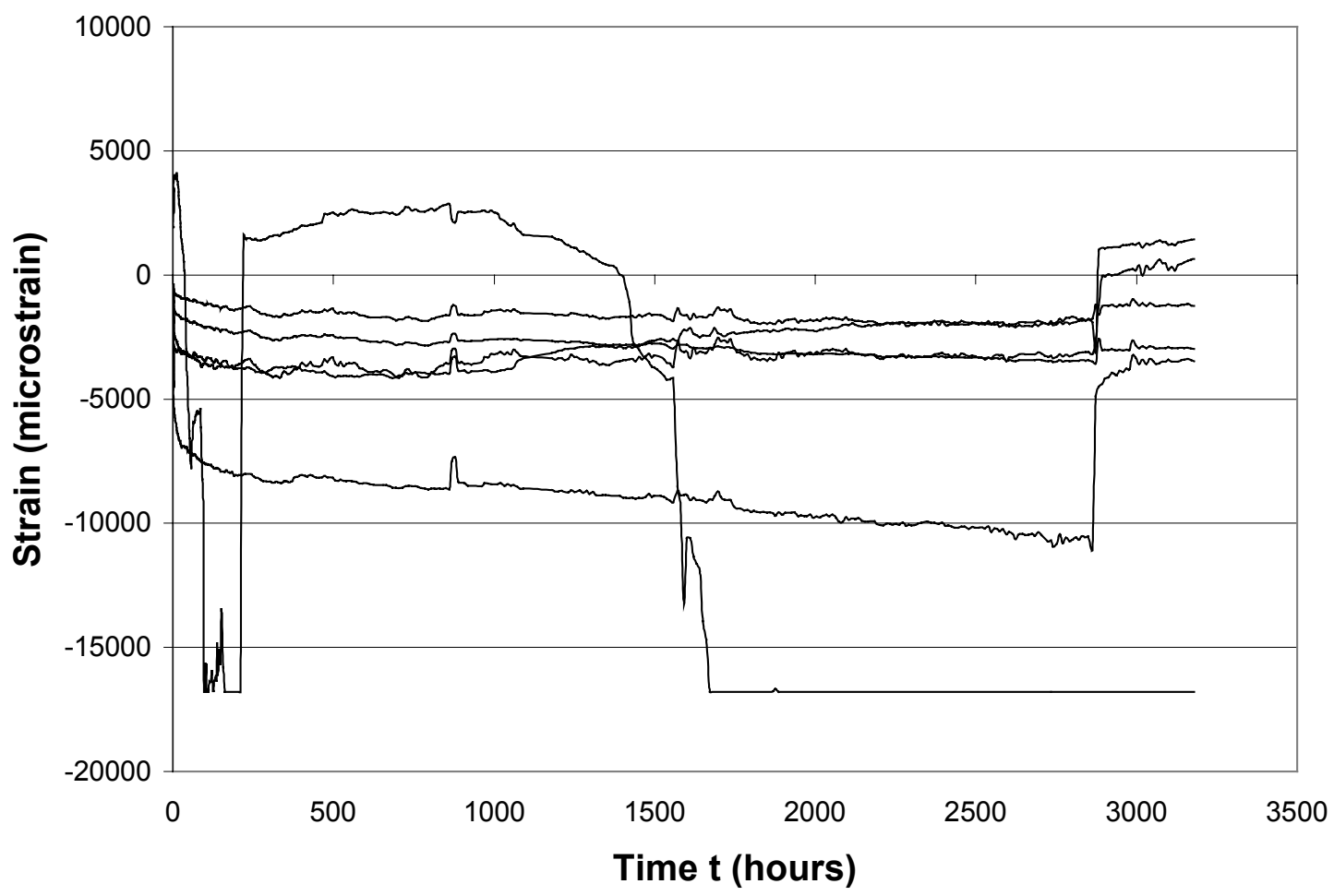

Figure 4.10 Strain Vs. Time For The Gages In Pipe D1 


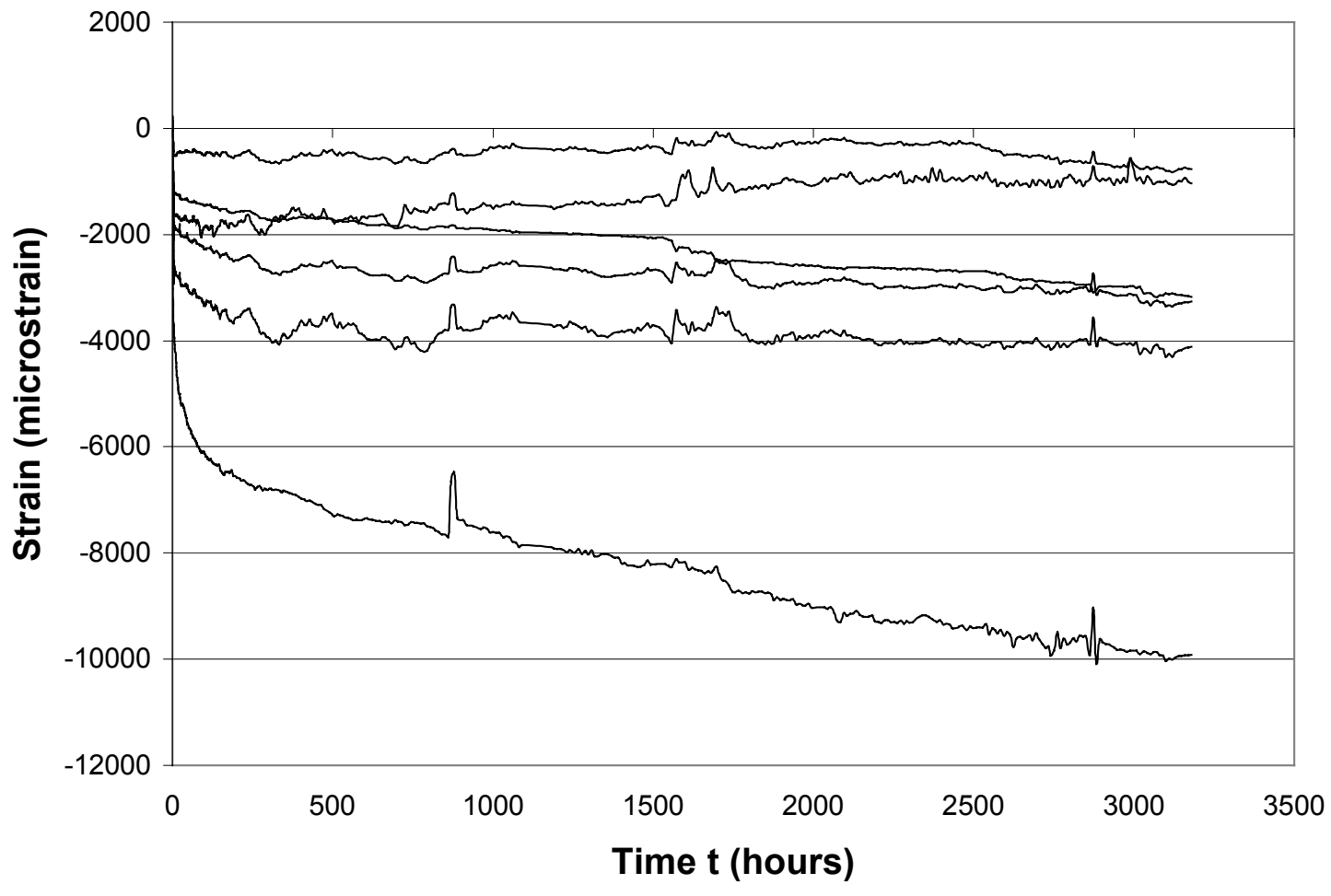

Figure 4.11 Strain Vs. Time For The Gages In Pipe D2

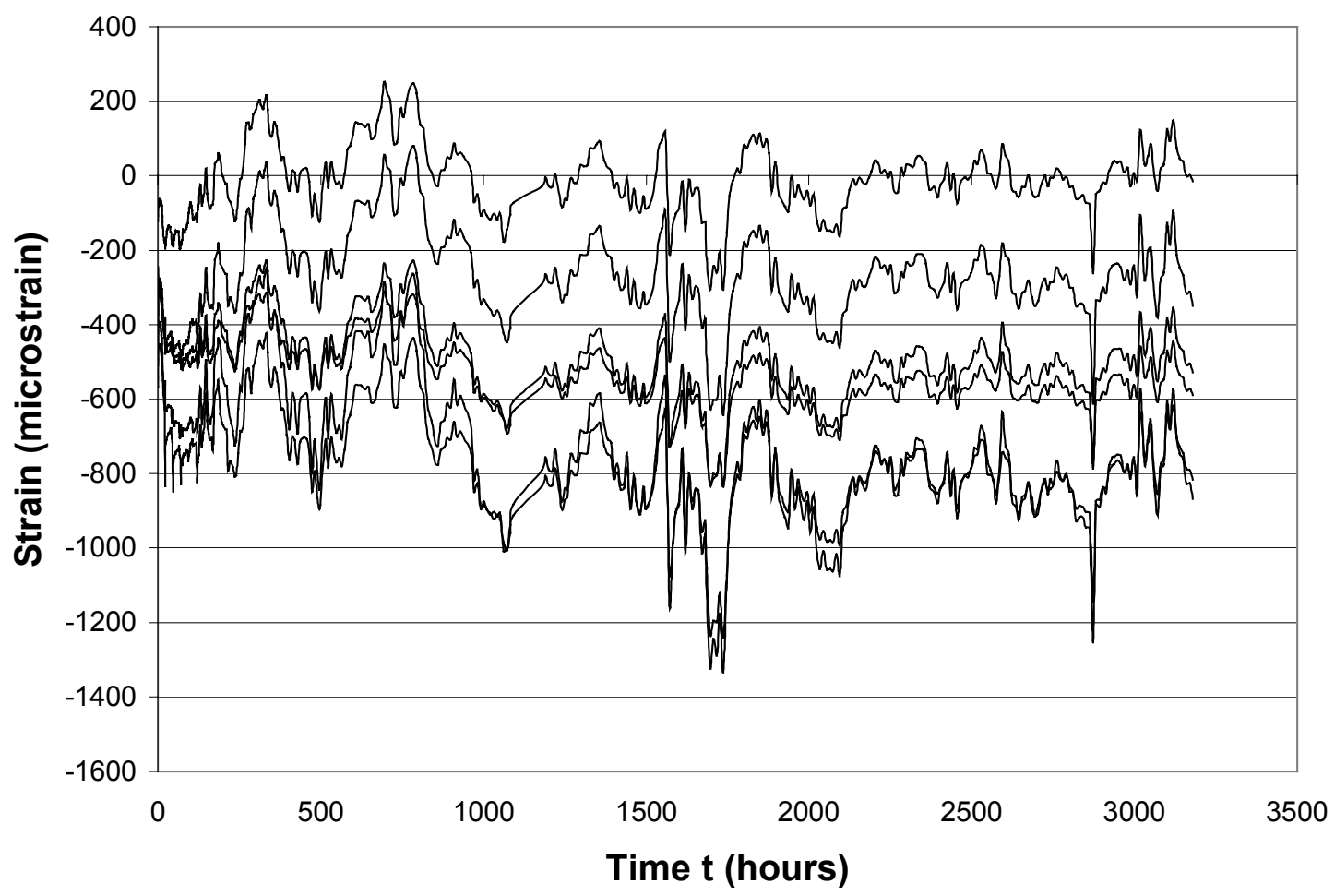

Figure 4.12 Strain Vs. Time For The Gages In Pipe D3 


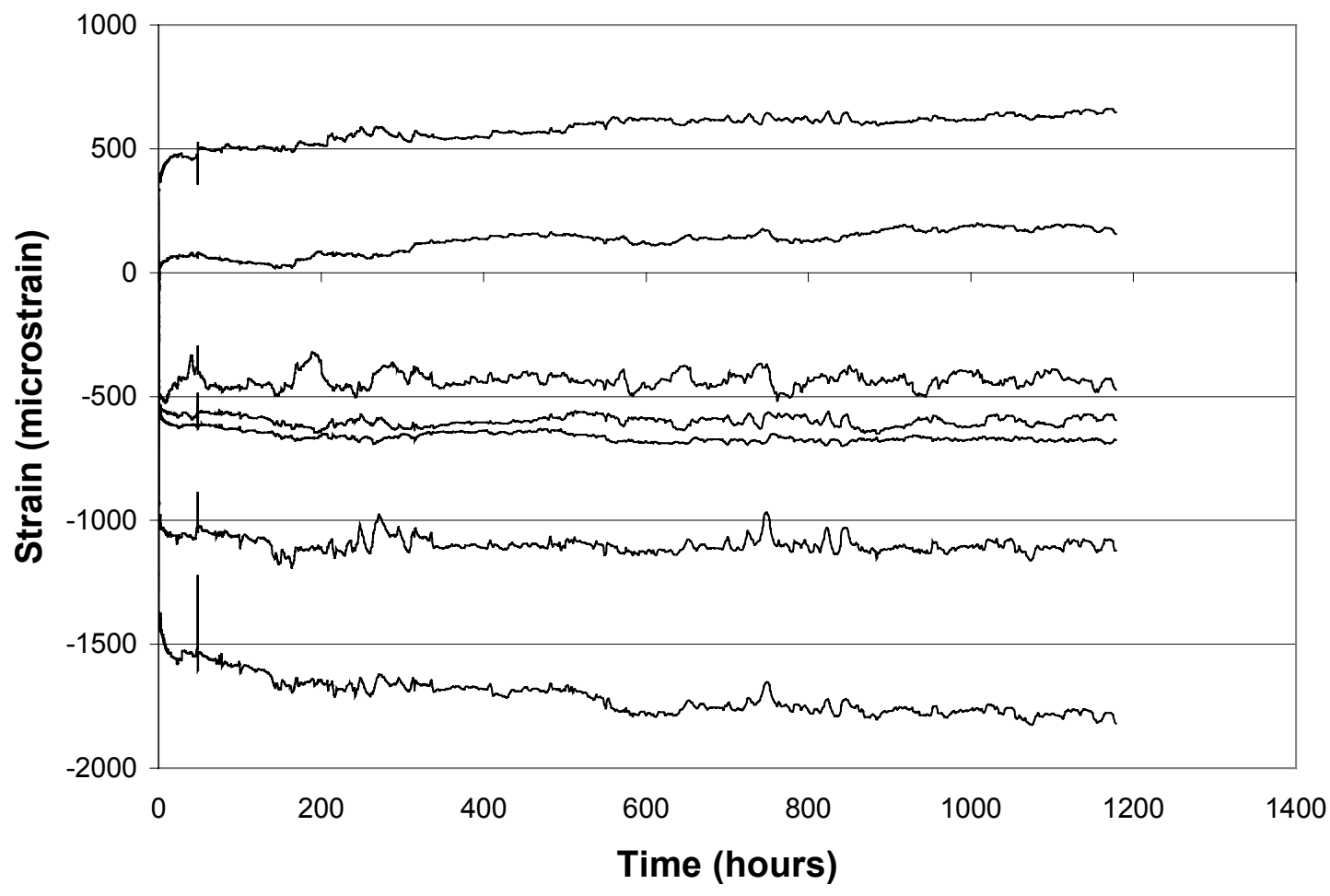

Figure 4.13 Strain Vs. Time For The Gages In Pipe E1

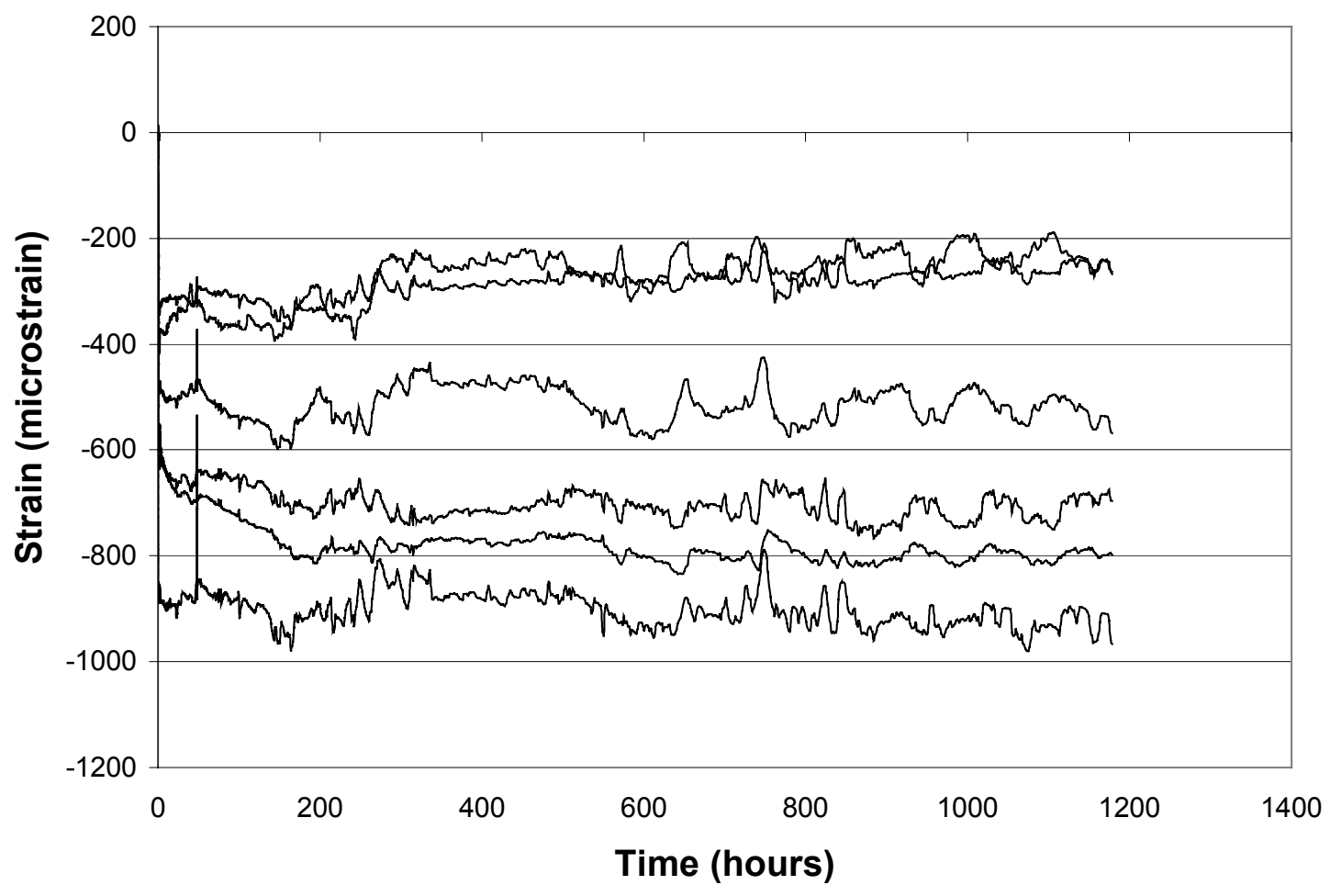

Figure 4.14 Strain Vs. Time For The Gages In Pipe E2 


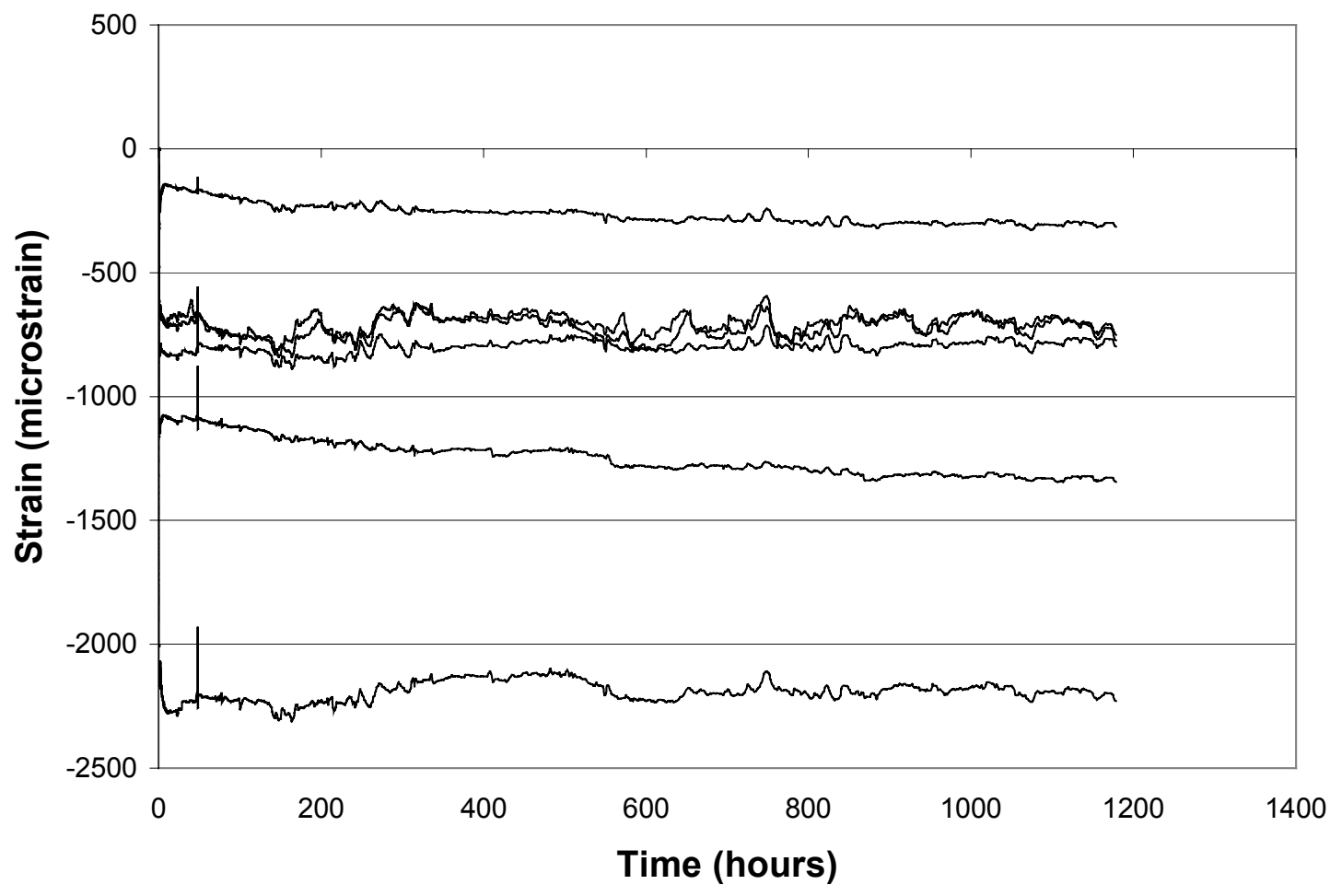

Figure 4.15 Strain Vs. Time For The Gages In Pipe E3

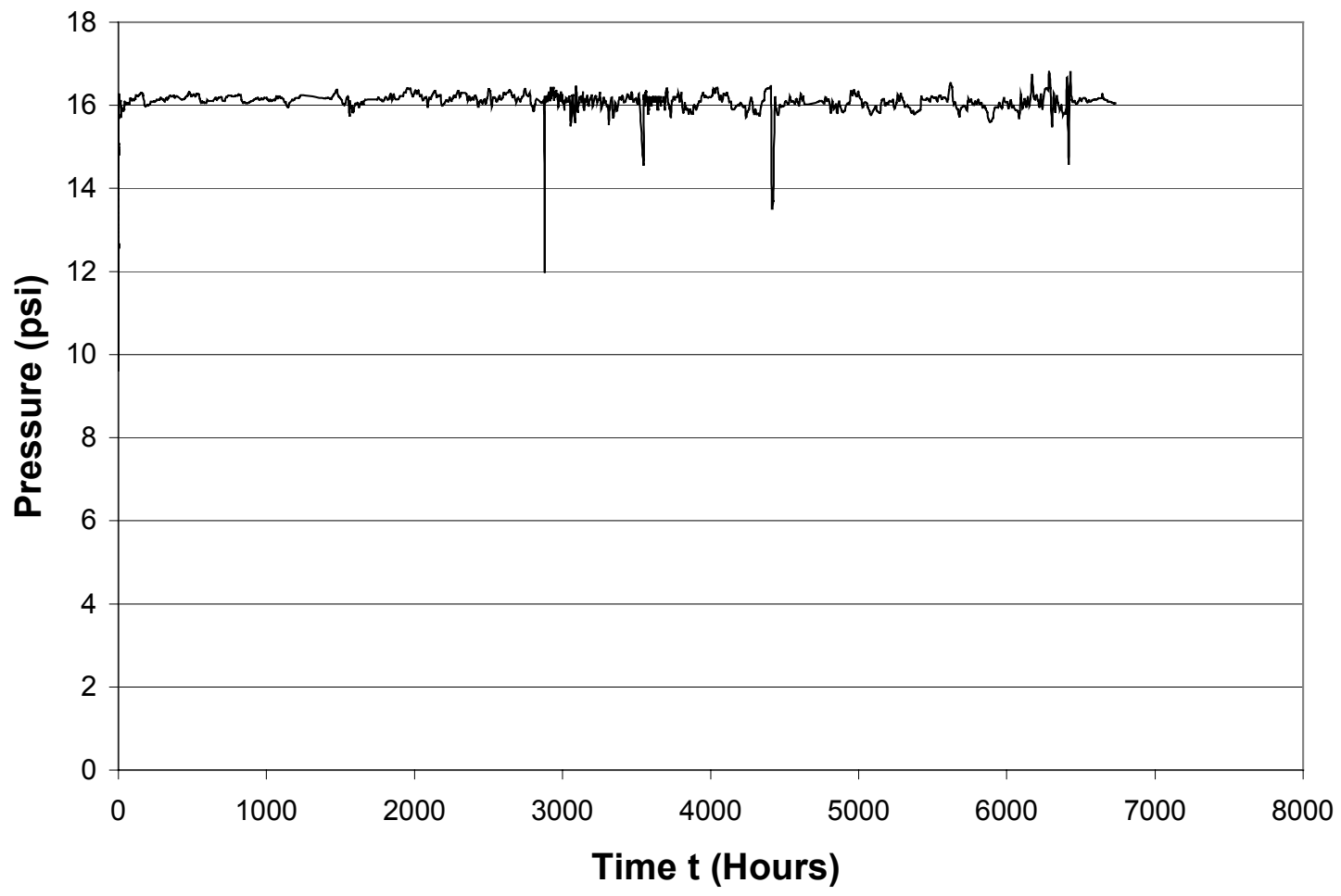

Figure 4.16 Pressure Vs. Time for the Testing Period 


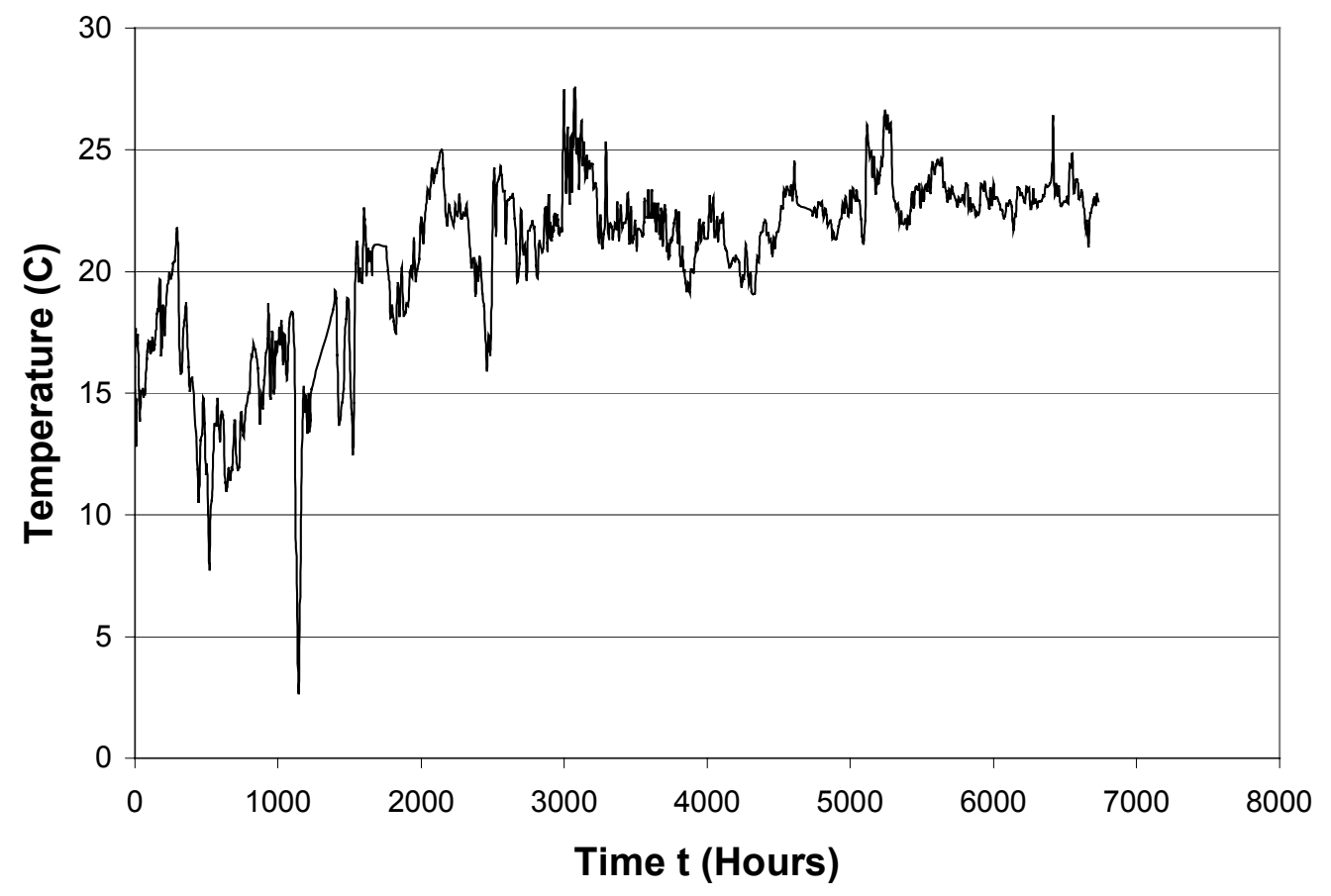

Figure 4.17 Temperature Vs. Time For The Testing Period

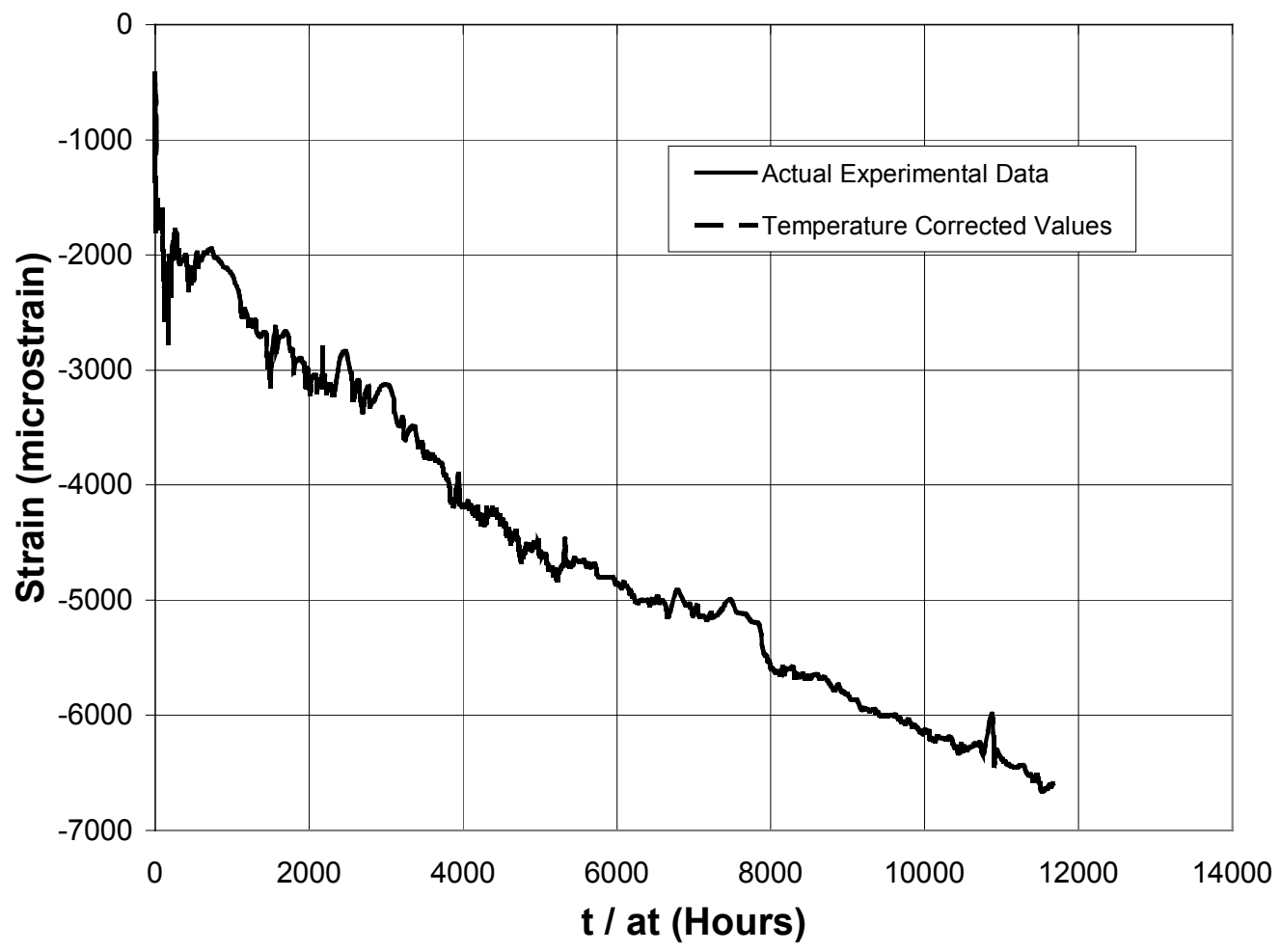

Figure 4.18 Comparison Of Experimental Strain And Strain Corrected For Thermal Expansion Of The Strain Gage 


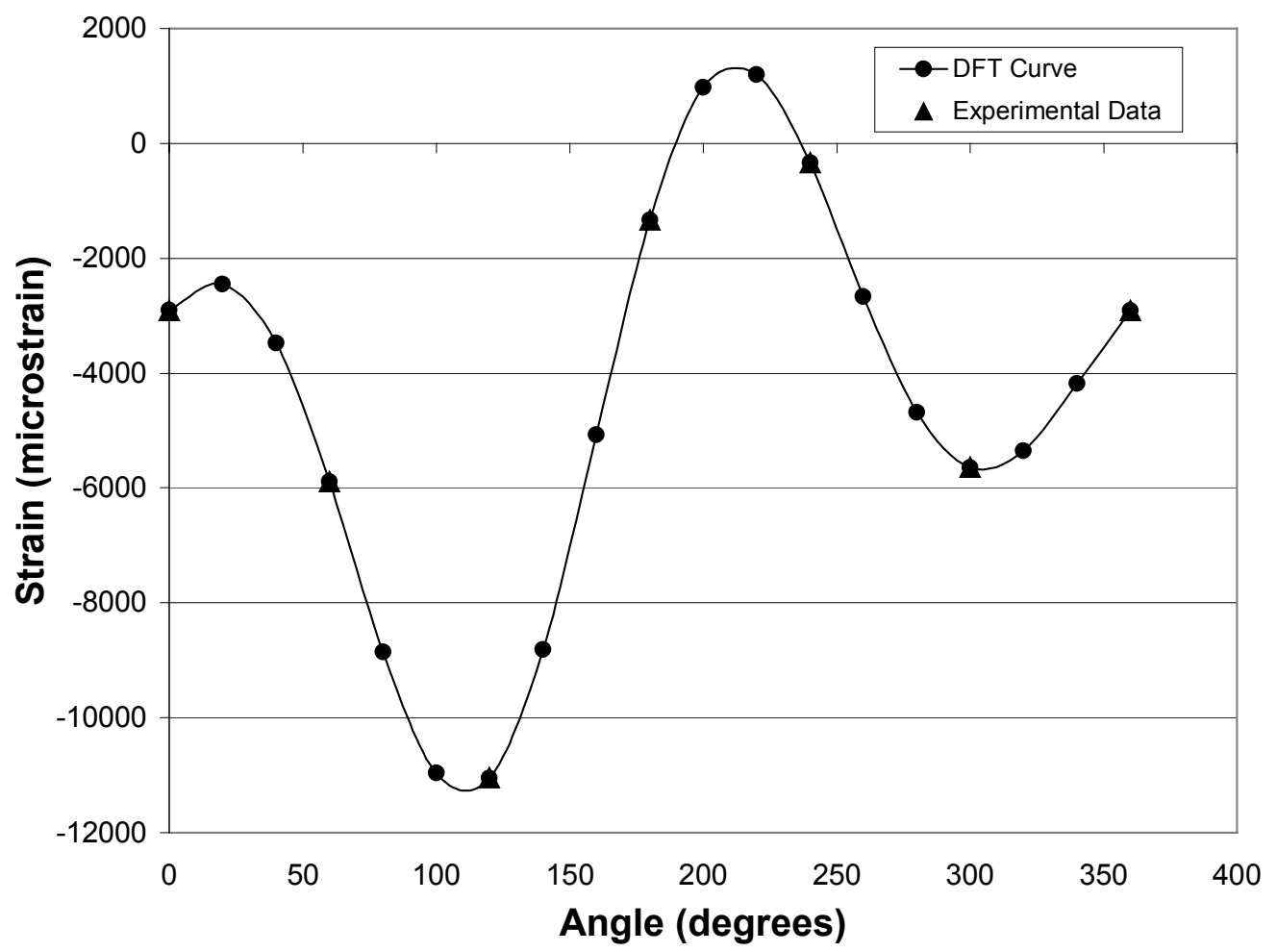

Figure 4.19 Comparison Of Actual Strain Data And DFT Points For One Gage 


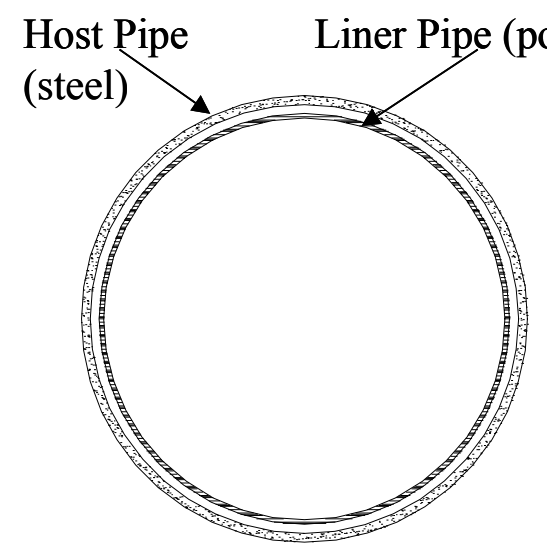

No hydrostatic pressure applied

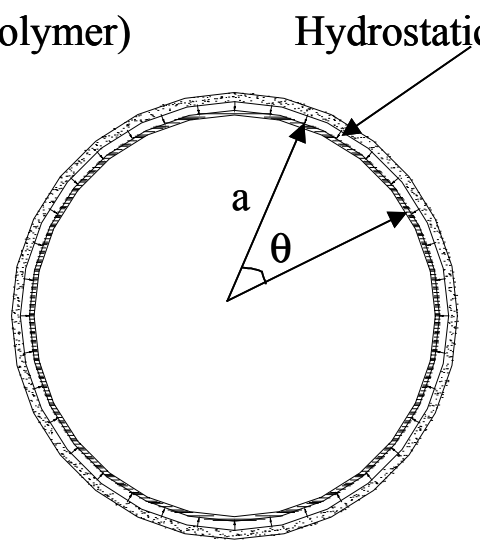

Hydrostatic pressure being applied

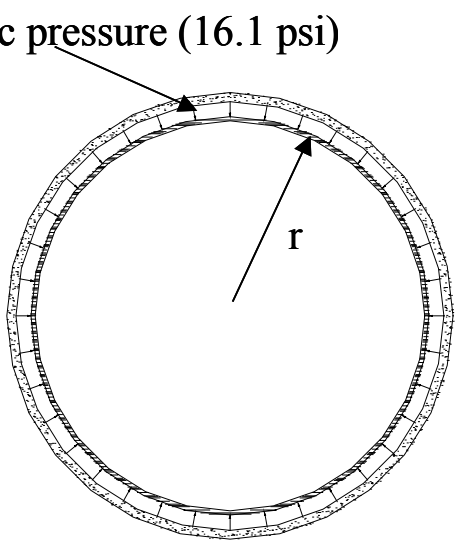

Initial free-ring buckling

(Liner shrinks instantly when pressure is applied)

Figure 4.20 Comparison of the Liner Before the Application of load till the initial Free-Ring buckling

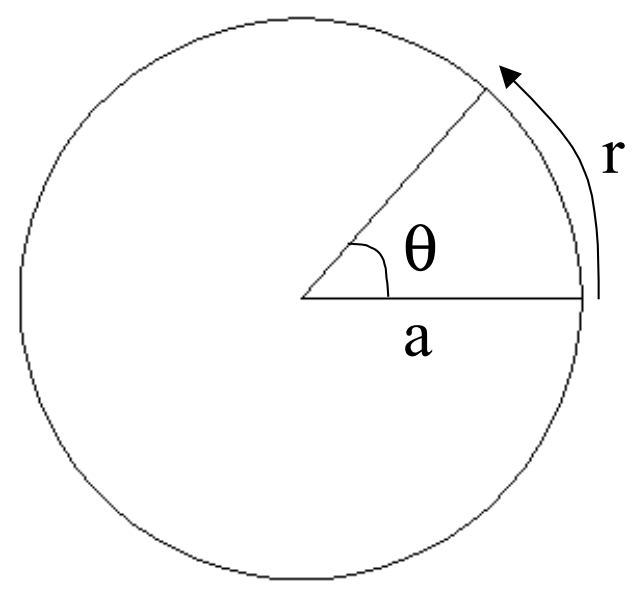

Figure 4.21 Liner Radius (a) and Angle $\theta$ at which the Gages are placed 

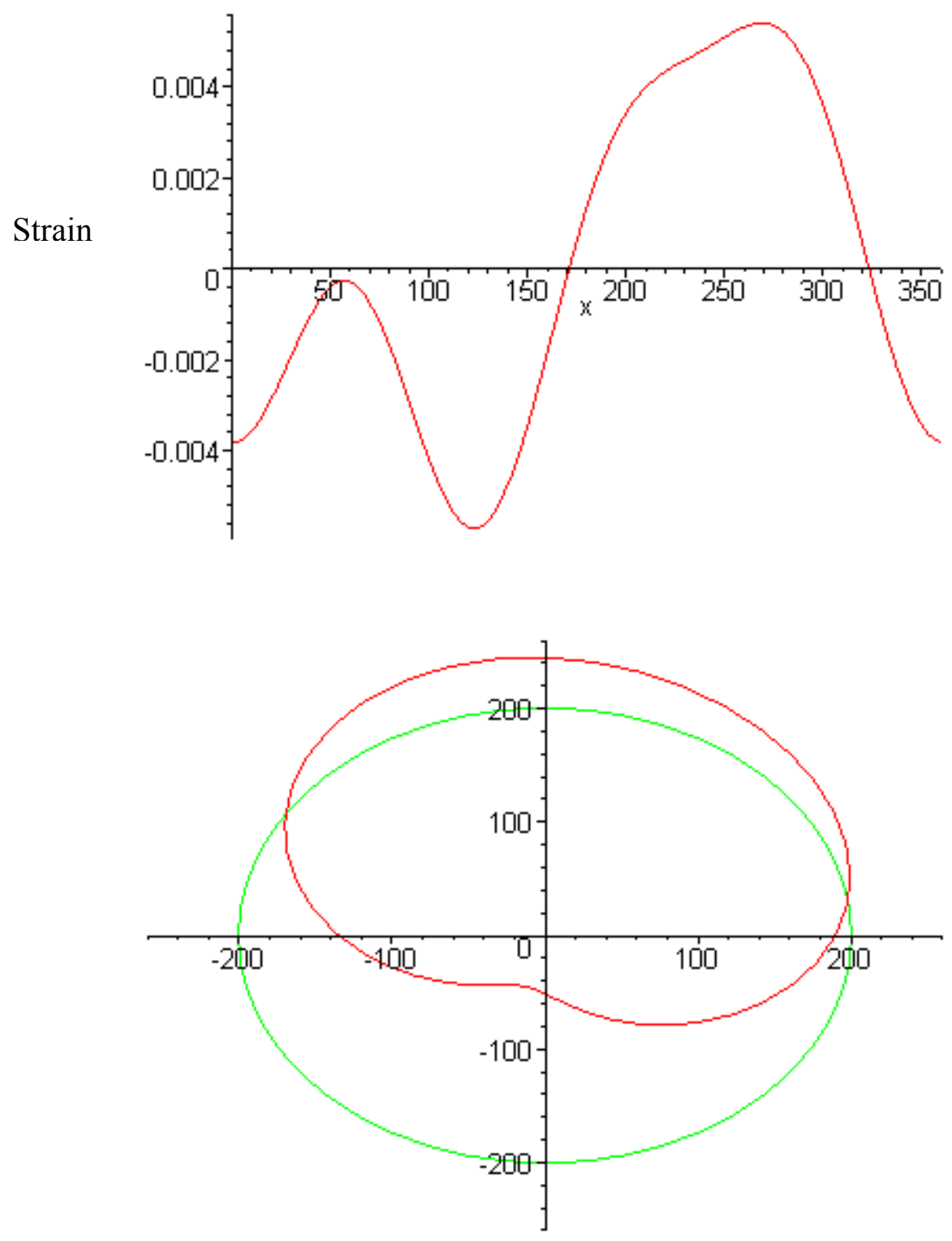

Figure 4.22 Strain and Deflected Shape at 11,500 hours for Pipe A1 

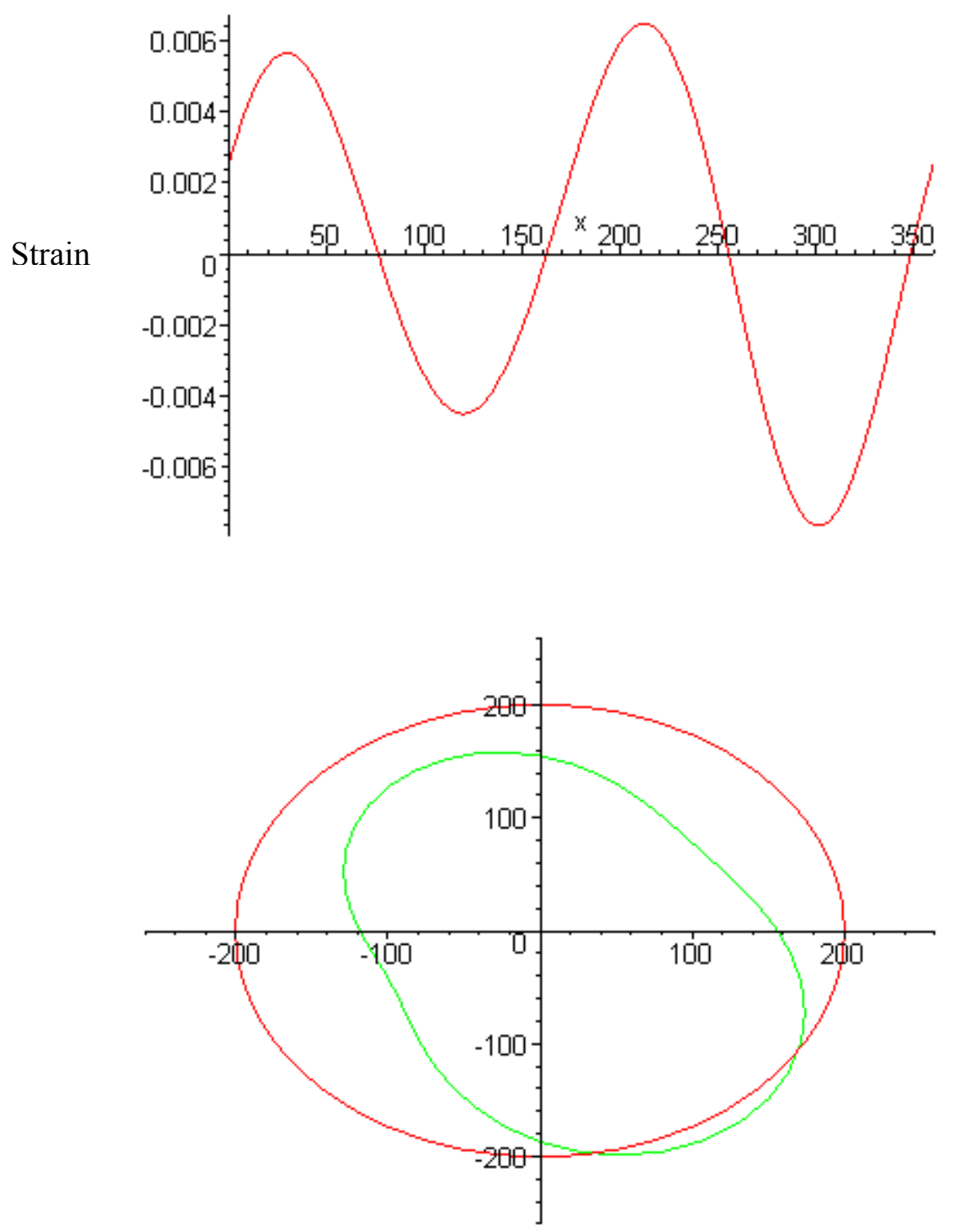

Figure 4.23 Strain and Deflection at 11,500 hours for Pipe A2 

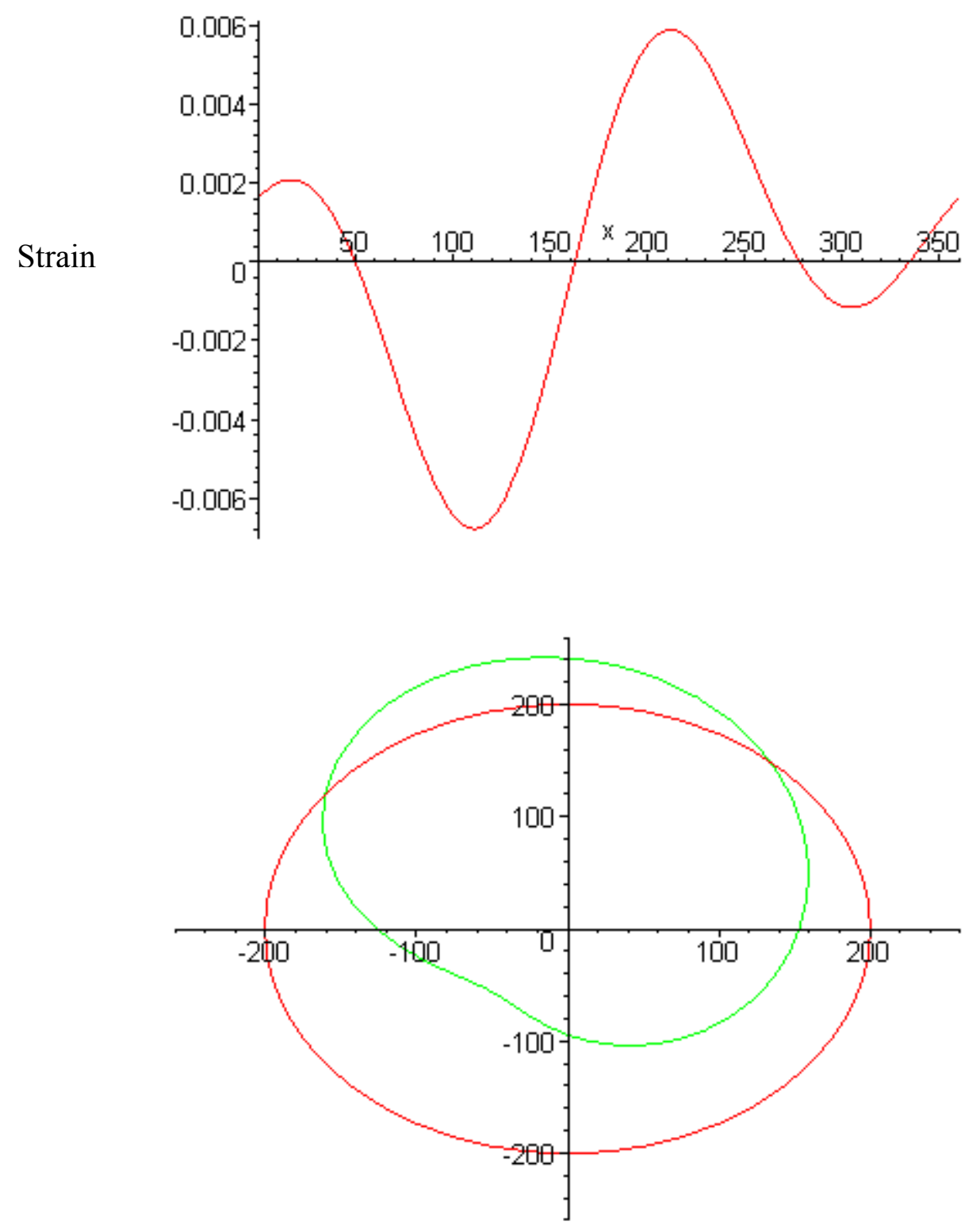

Figure 4.24 Strain and Deflection at 11,500 hours for Pipe A3 

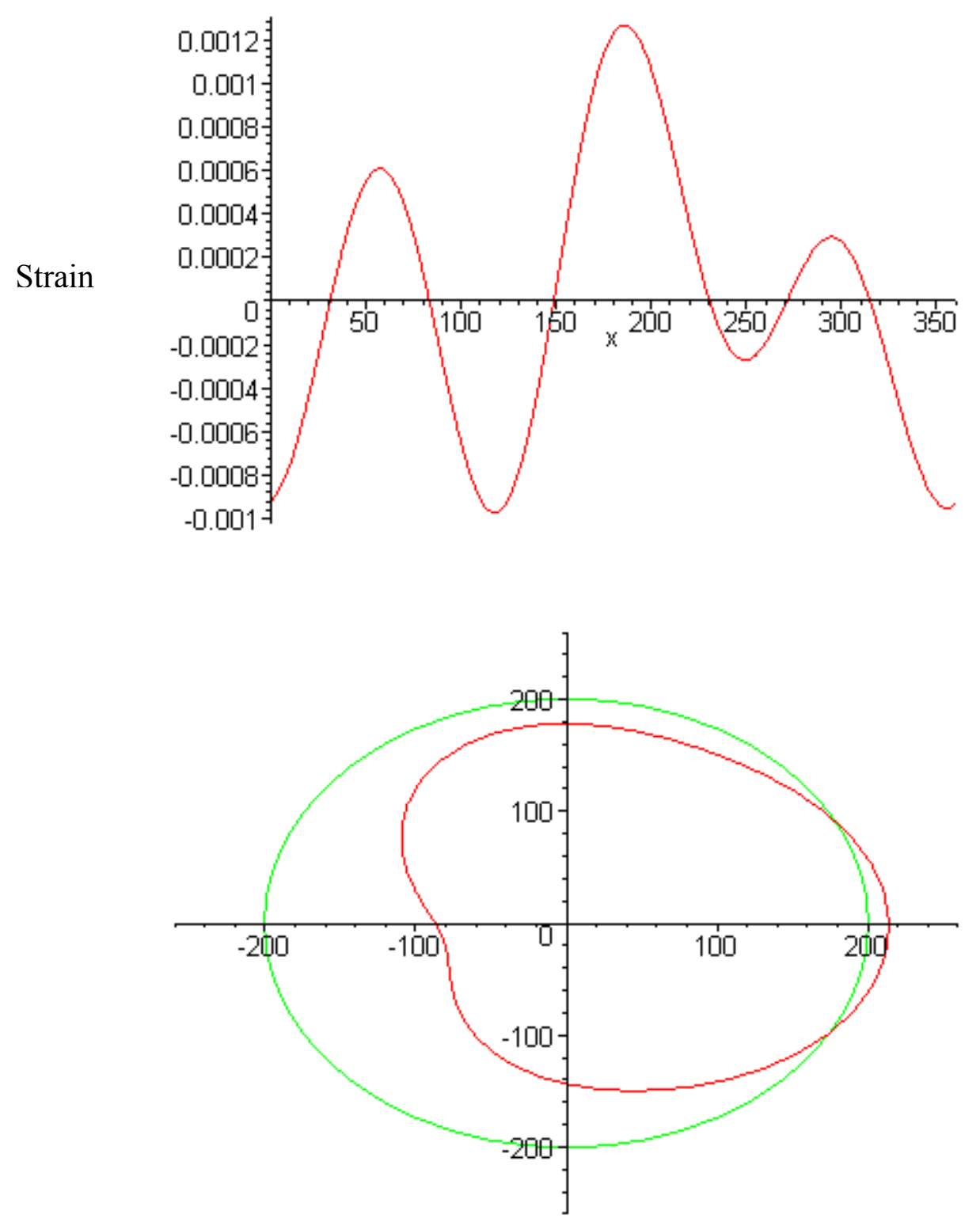

Figure 4.25 Strain and Deflection at 3,100 hours for Pipe B1 

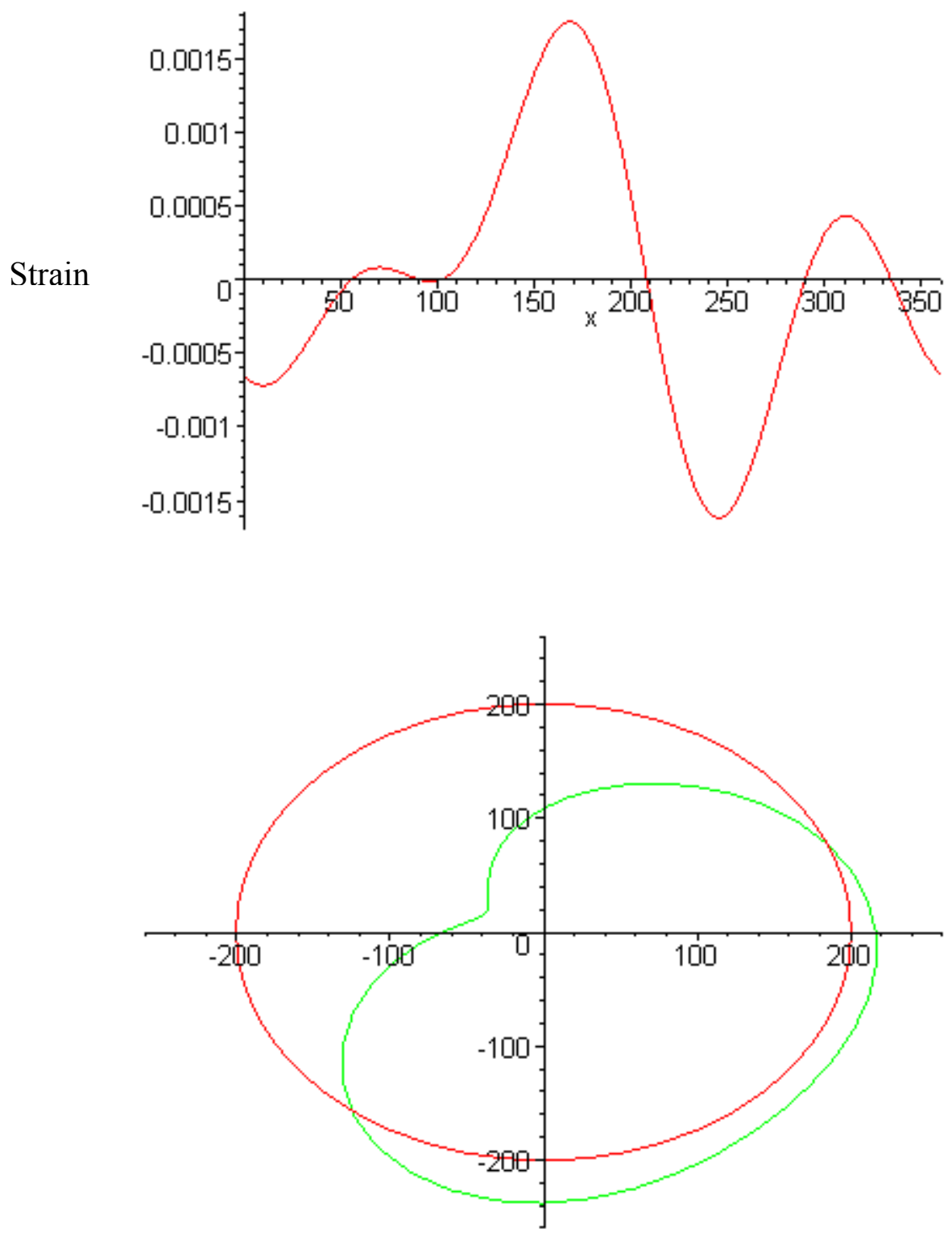

Figure 4.26 Strain and Deflection at 3,100 hours for Pipe B2 

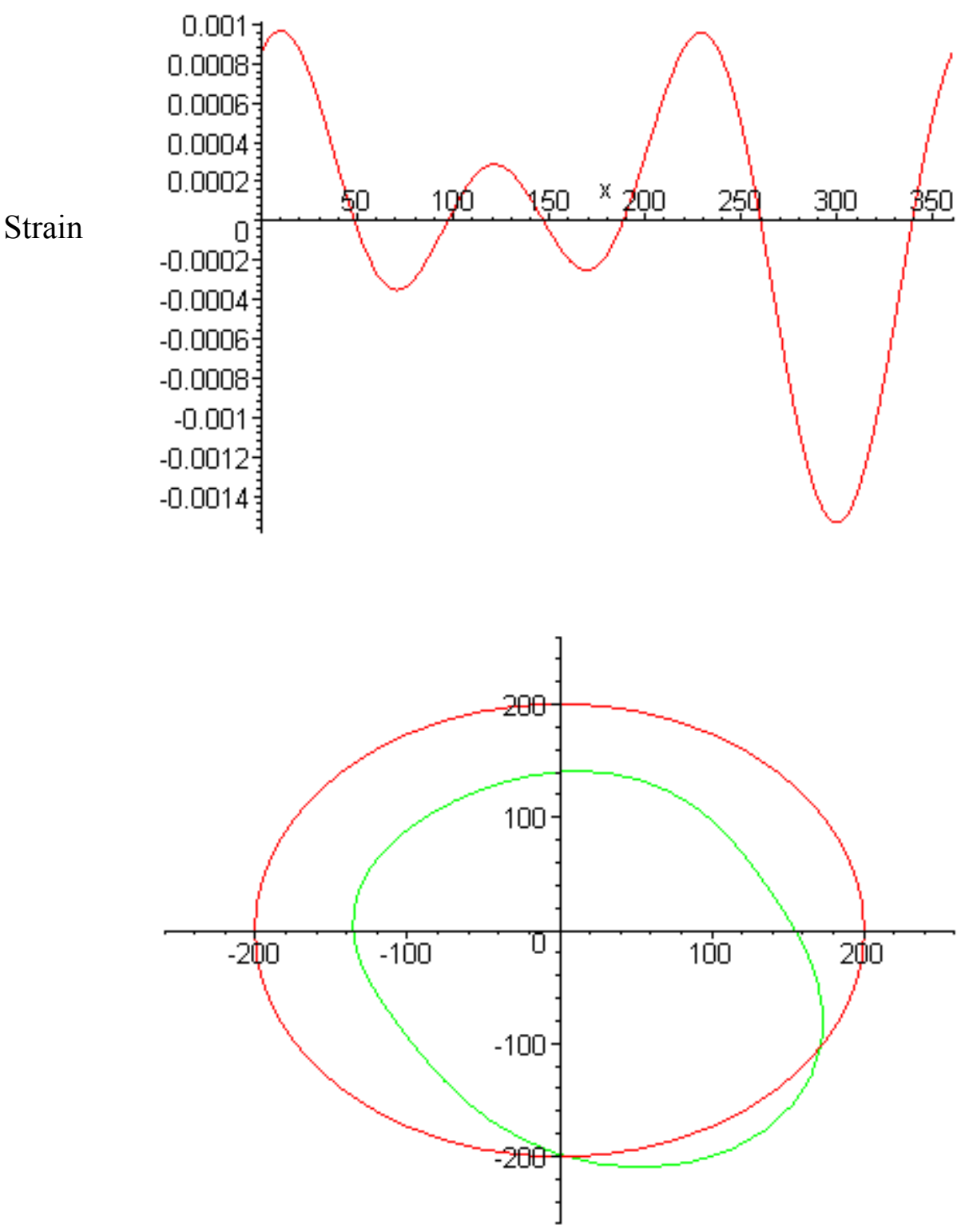

Figure 4.27 Strain and Deflection at 3,100 hours for Pipe B3 

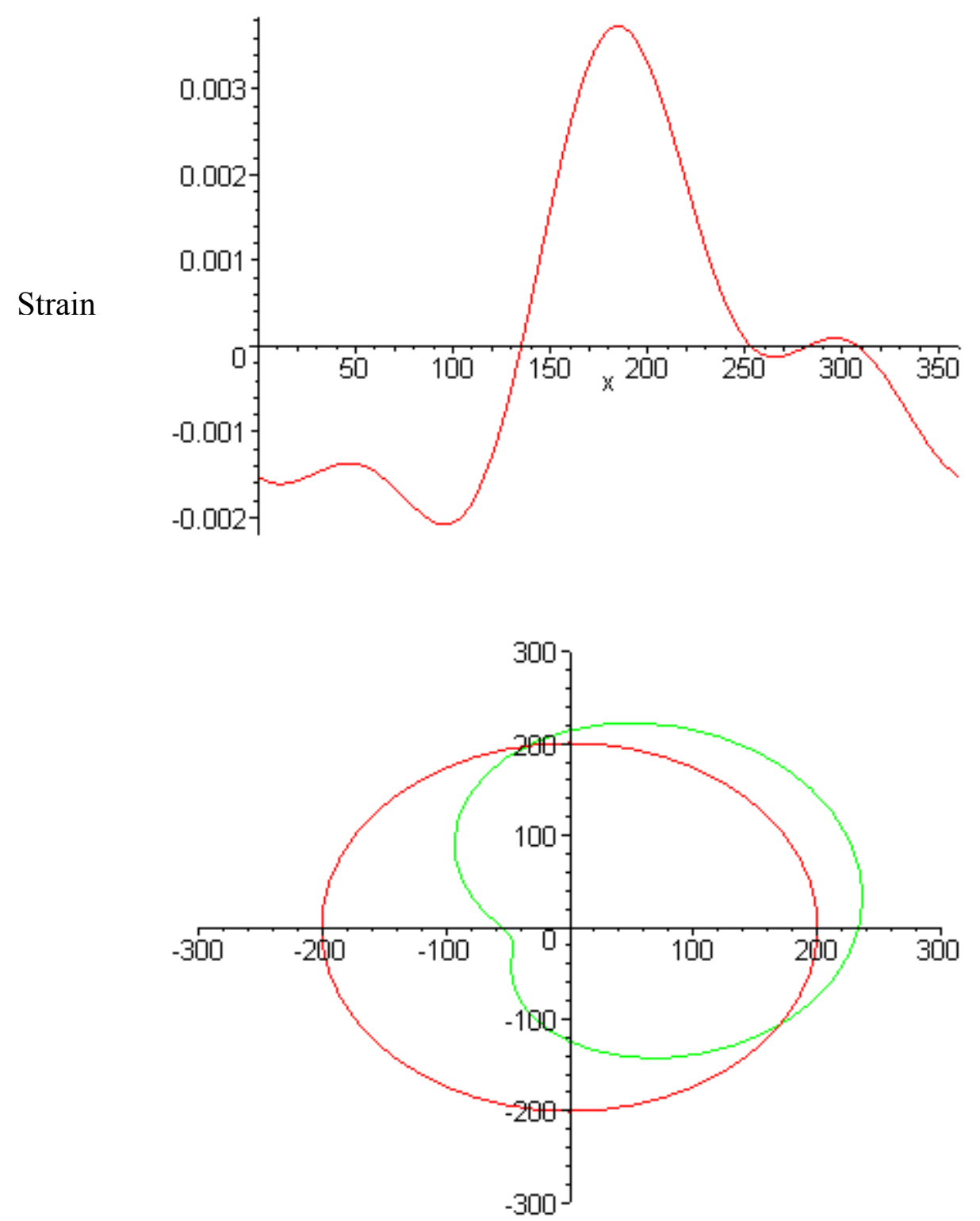

Figure 4.28 Strain and Deflection at 3,100 hours for Pipe C1 

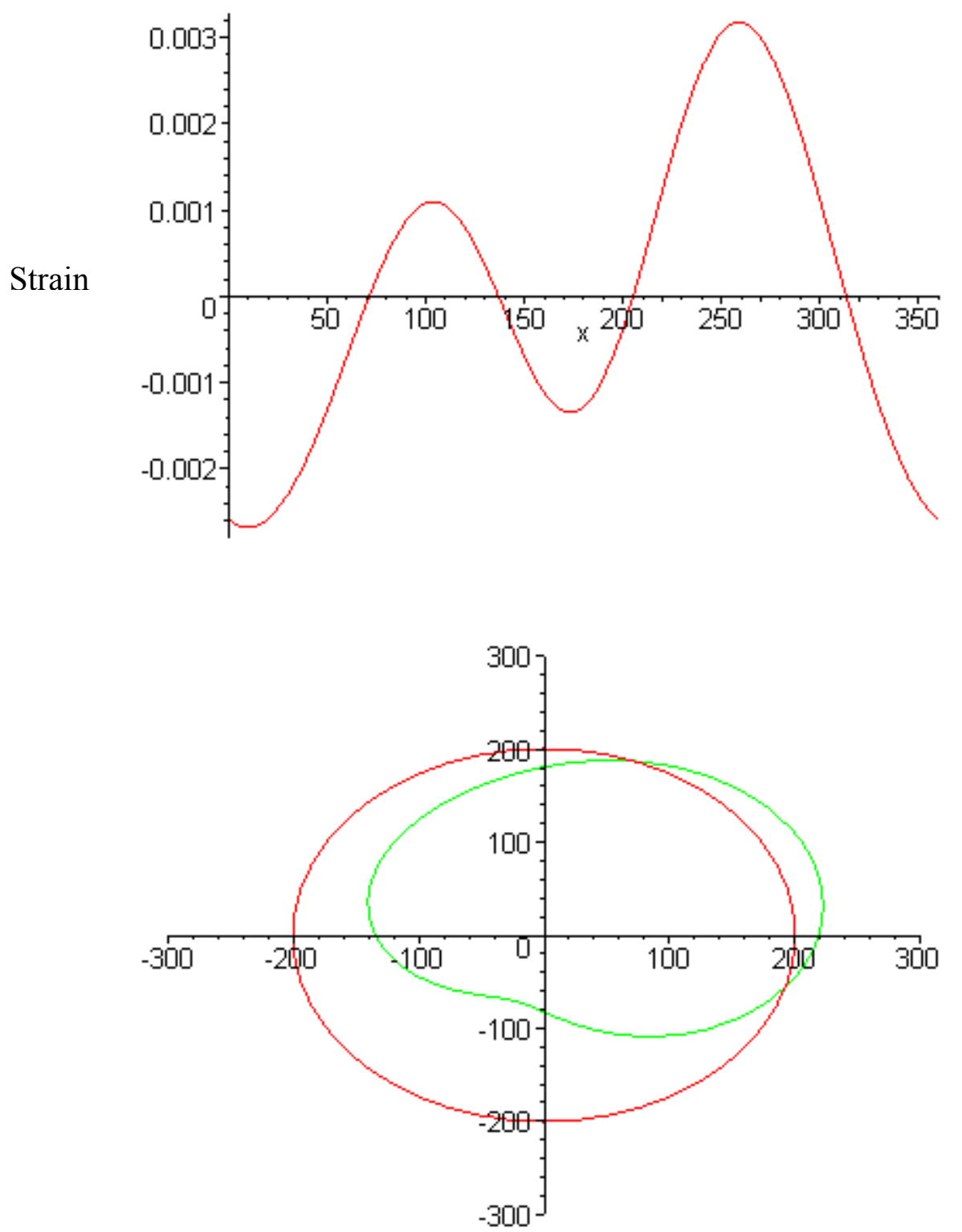

Figure 4.29 Strain and Deflection at 3,100 hours for Pipe C2 

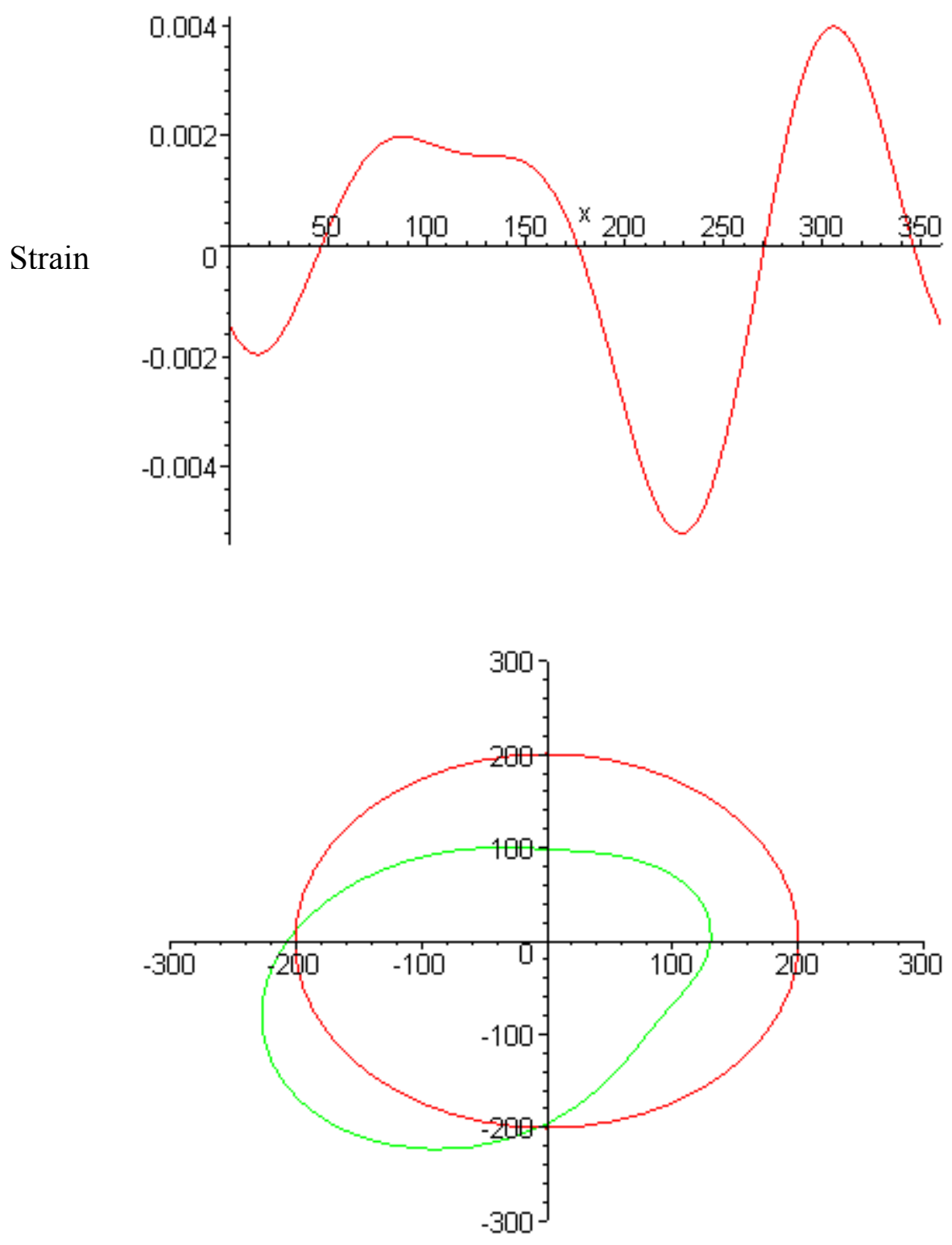

Figure 4.30 Strain and Deflection at 3,100 hours for Pipe C3 

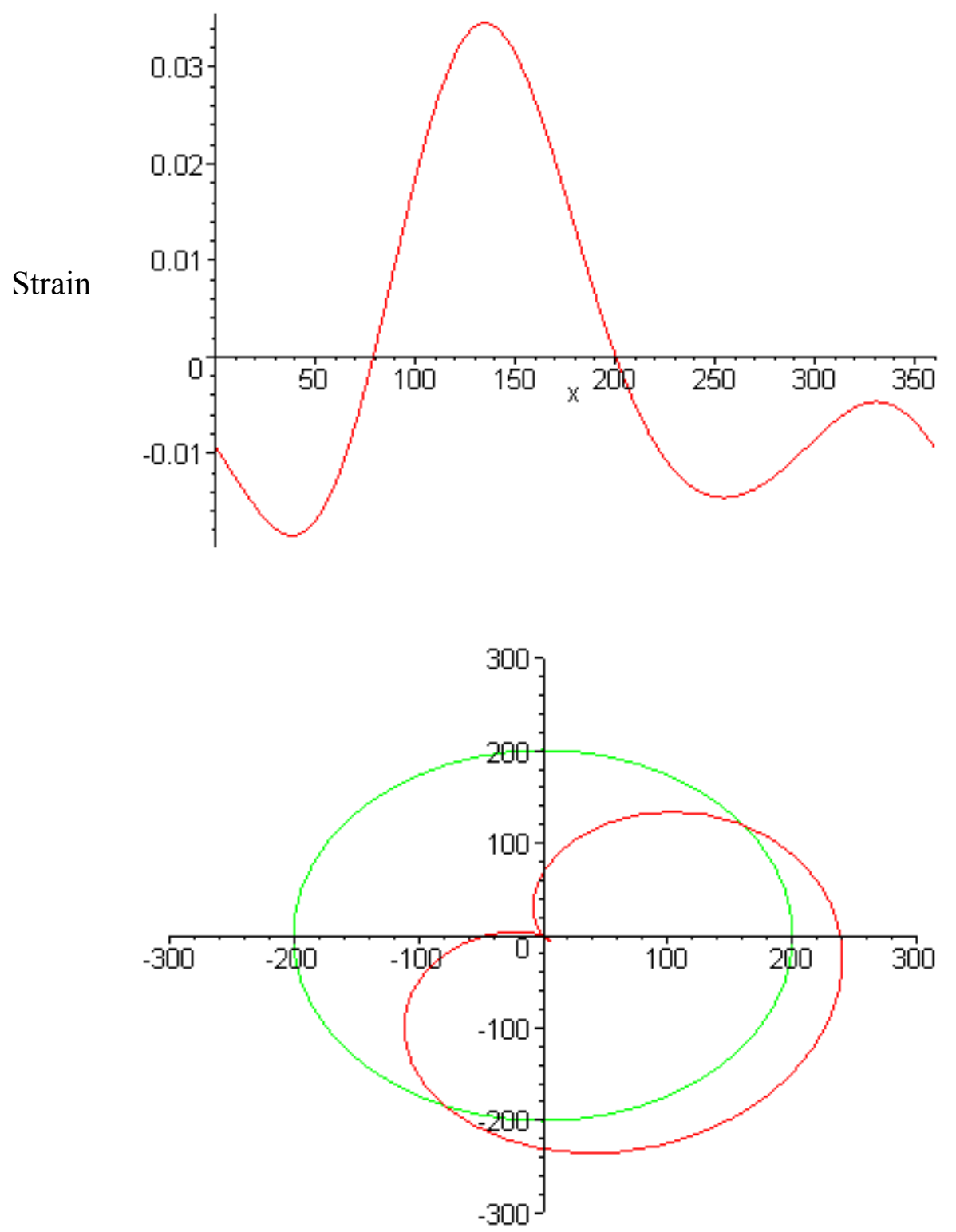

Figure 4.31 Strain and Deflection at 3,100 hours for Pipe D1 

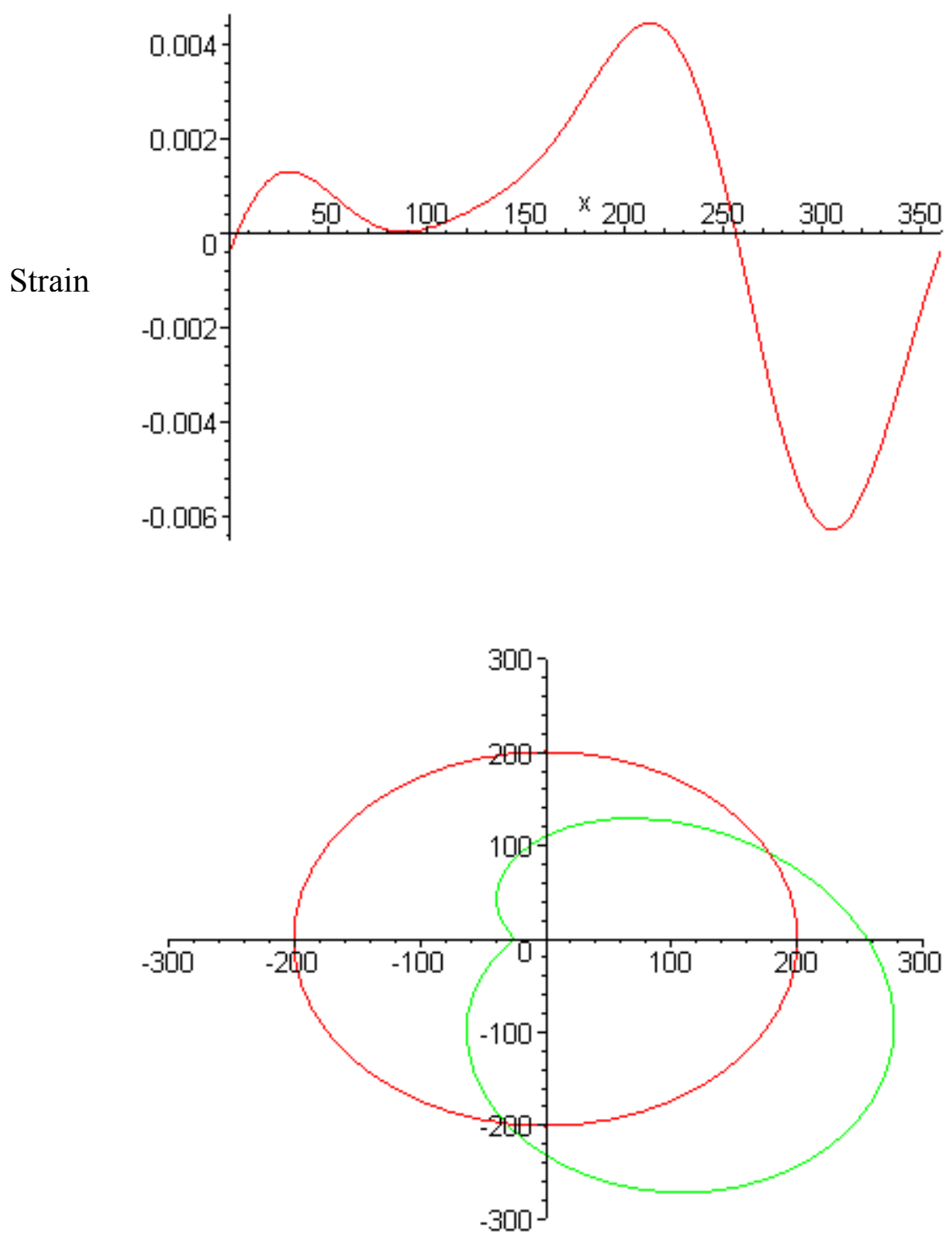

Figure 4.32 Strain and Deflection at 3,100 hours for Pipe D2 

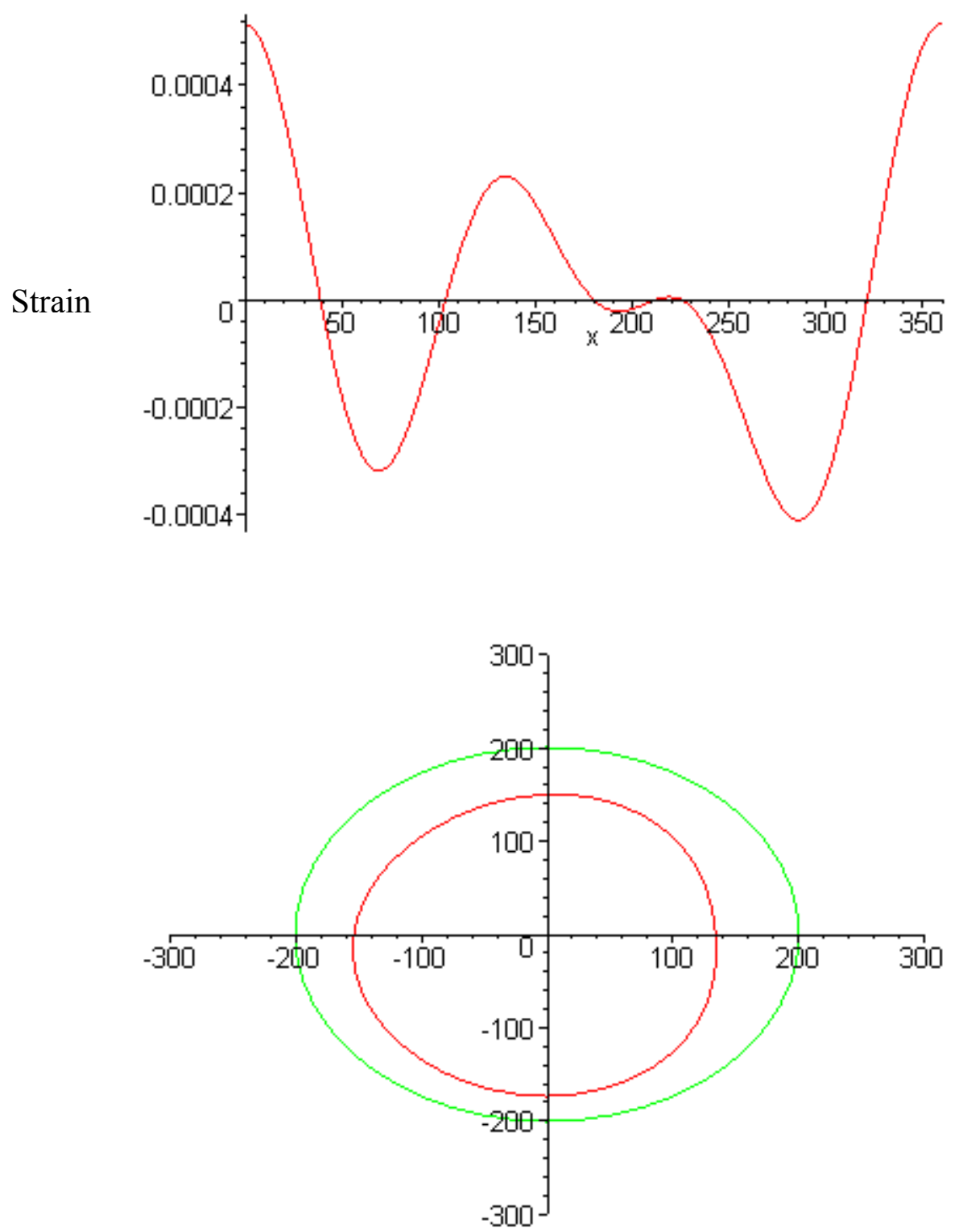

Figure 4.33 Strain and Deflection at 3,100 hours for Pipe D3 

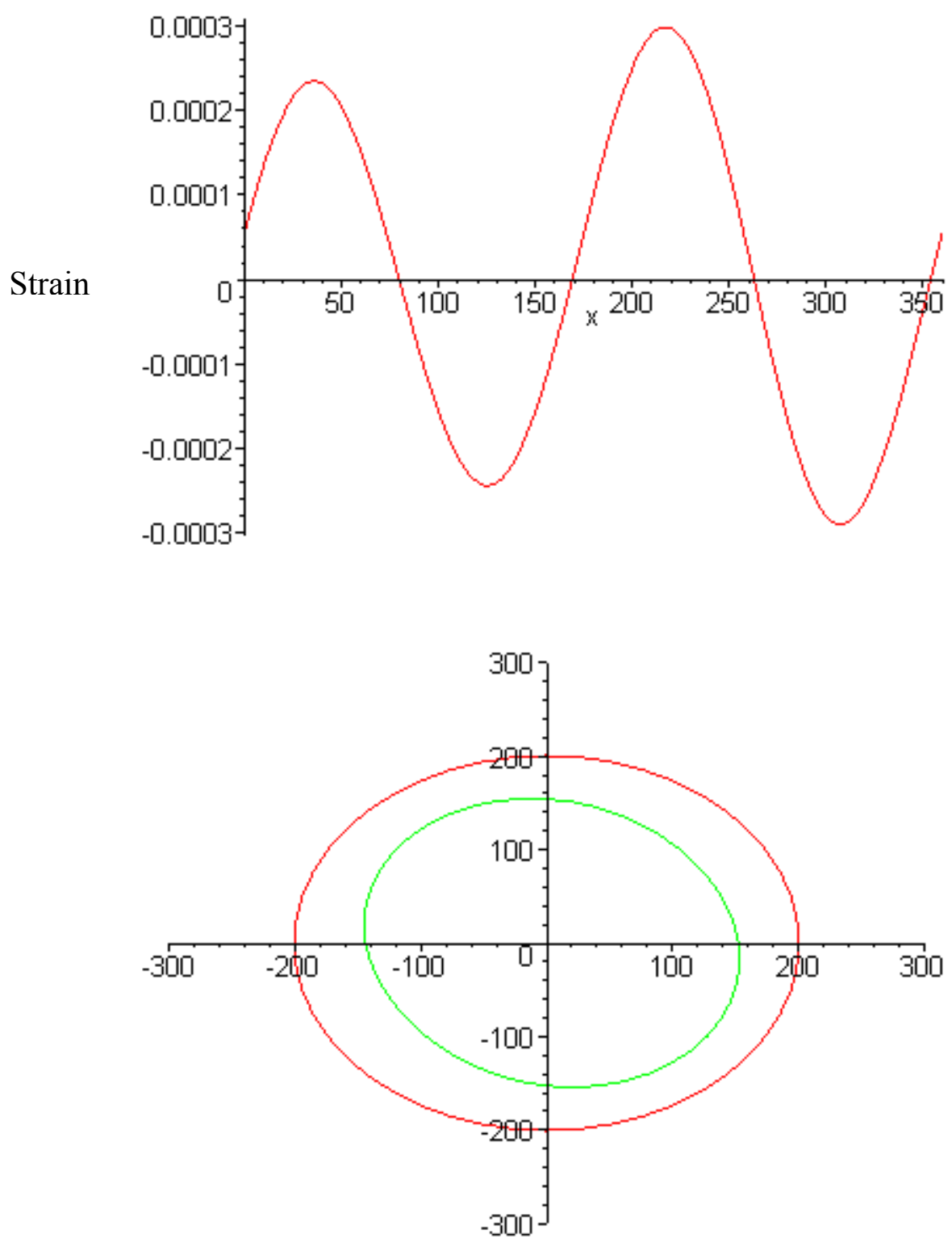

Figure 4.34 Strain and Deflection at 3,100 hours for Pipe E1 

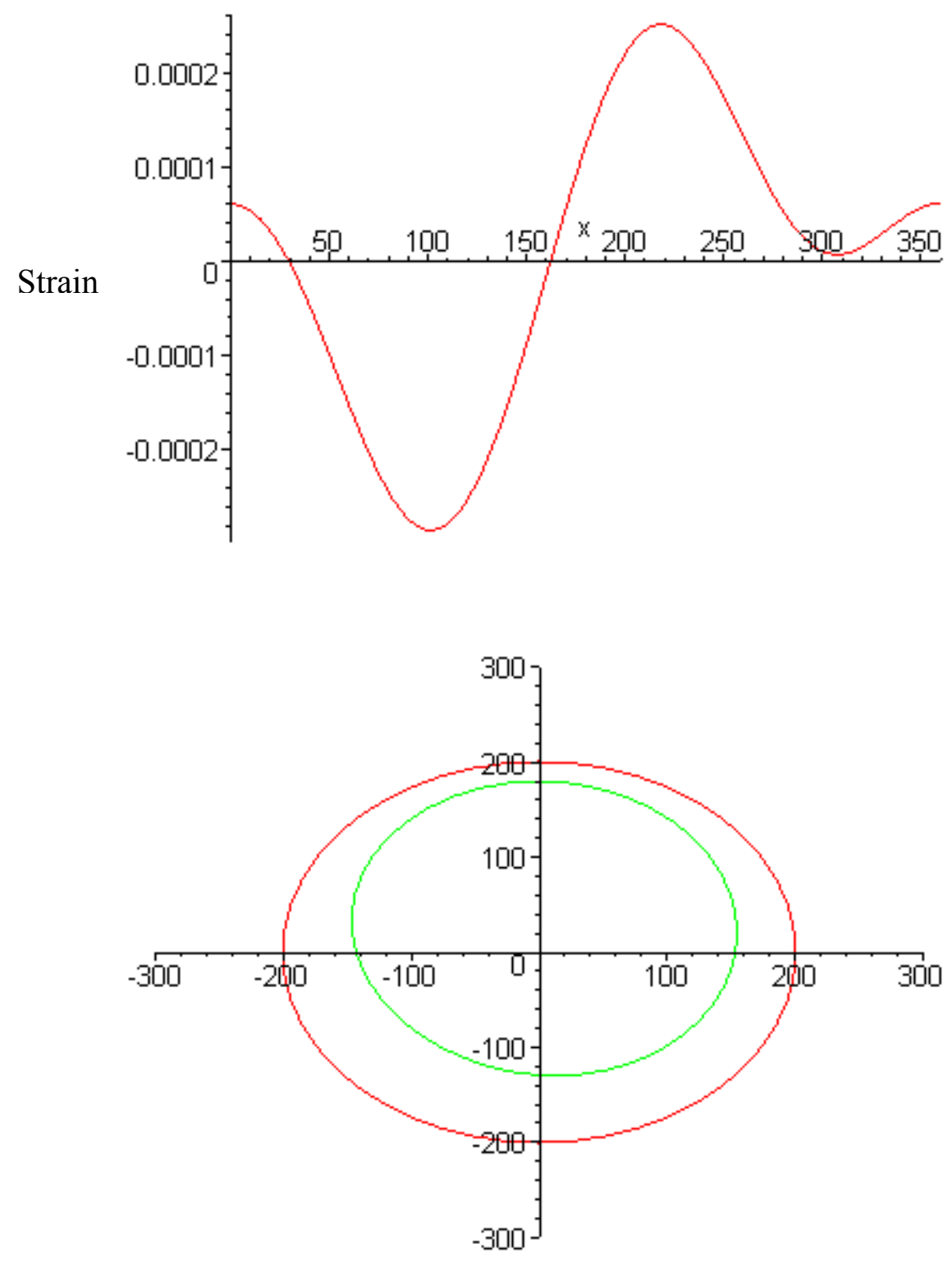

Figure 4.35 Strain and Deflection at 3,100 hours for Pipe E2 

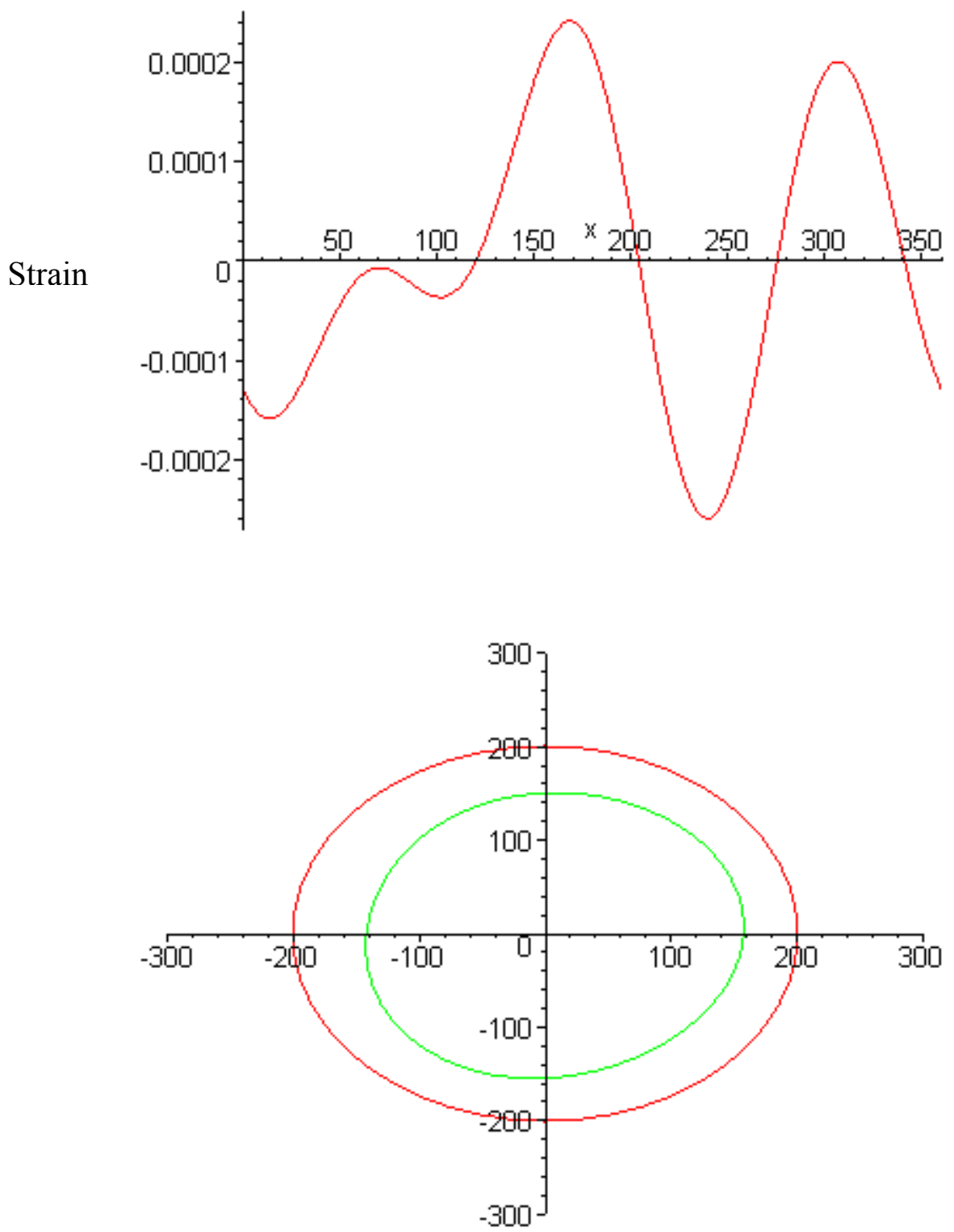

Figure 4.36 Strain and Deflection at 3,100 hours for Pipe E3 


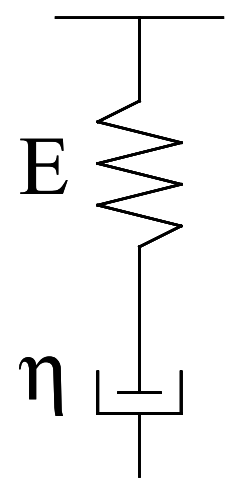

Figure 4.37 Maxwell Model

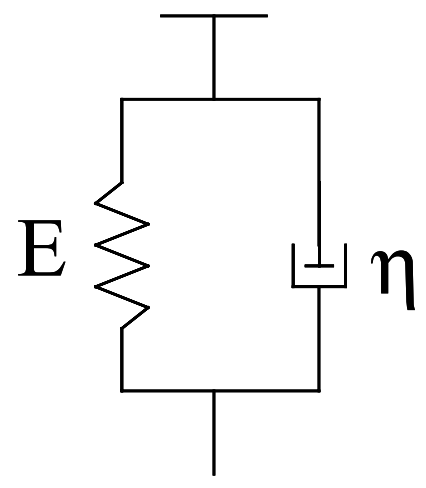

Figure 4.38 Kelvin - Voigt Model

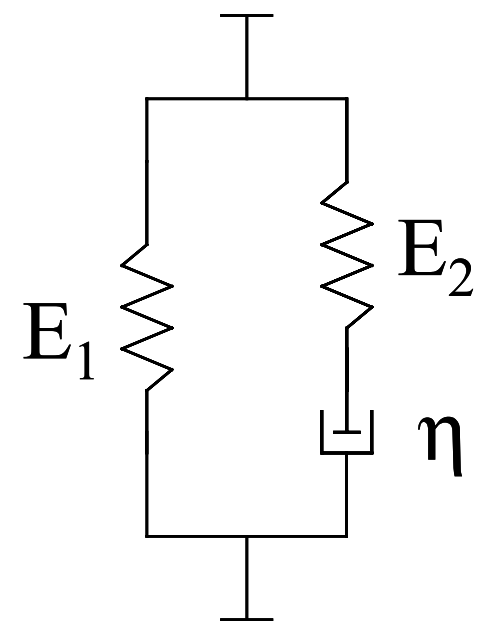

Figure 4.39 Standard Linear Solid (SLS) Model 


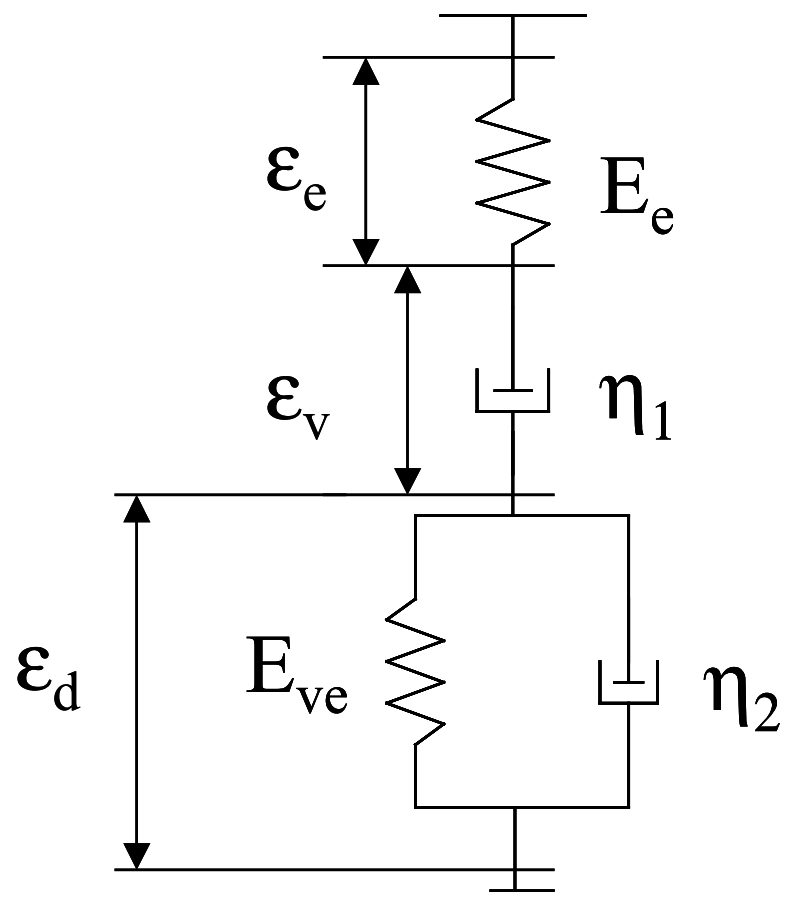

Figure 4.40 Four-Parameter Model

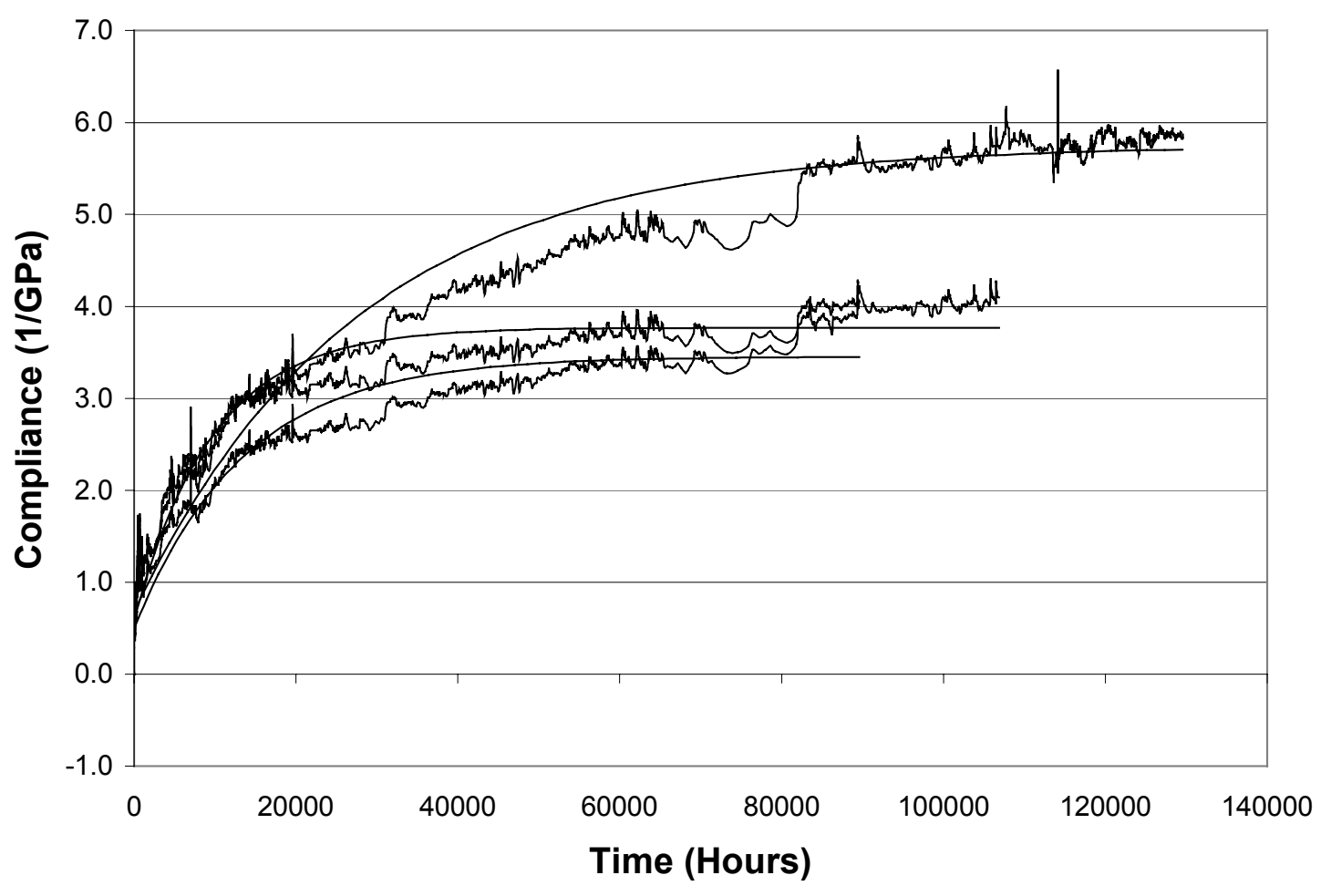

Figure 4.41 SLS model fit of three samples of Material A (A1, A2 and A3) 


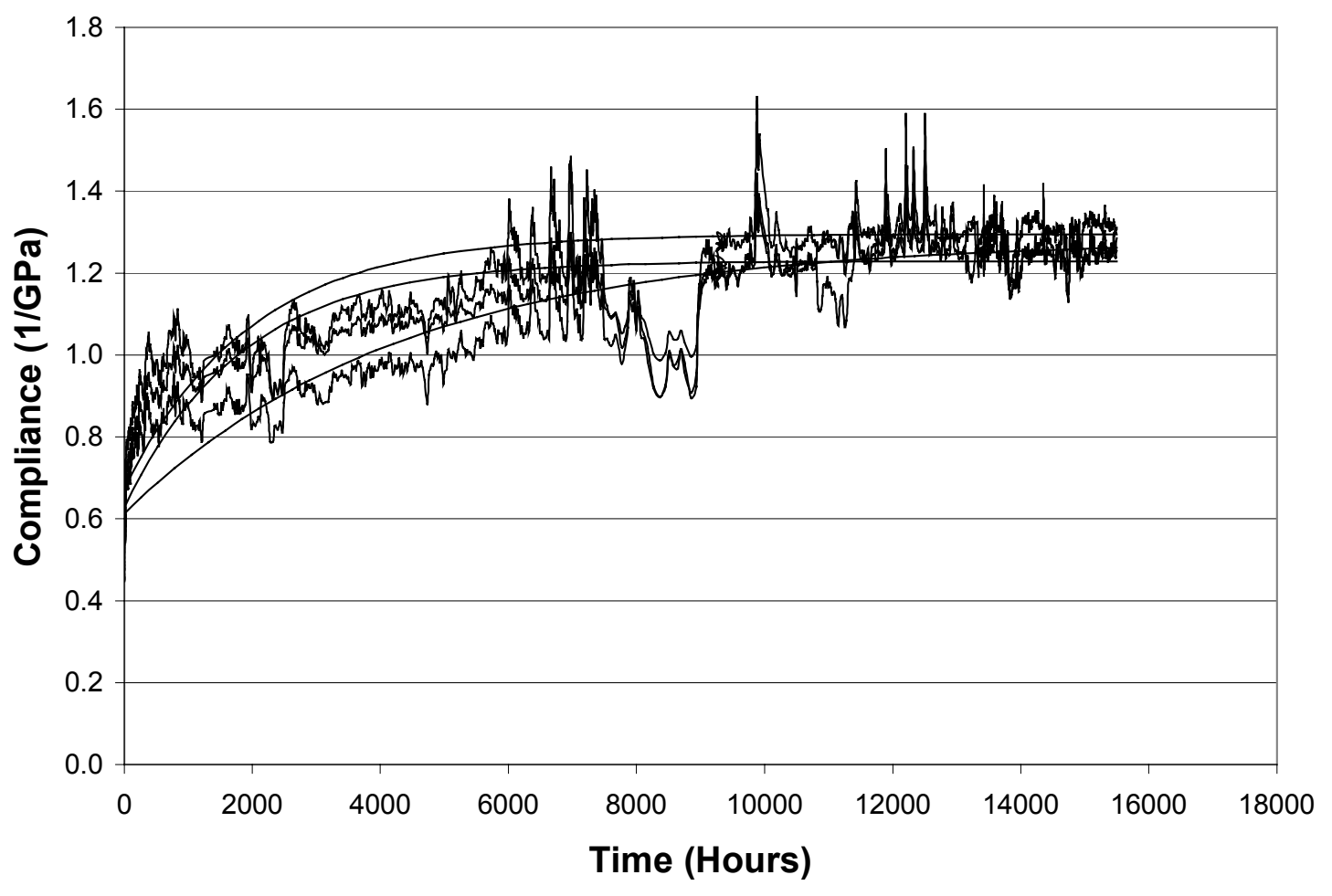

Figure 4.42 SLS model fit of three samples of Material B (B1, B2 and B3)

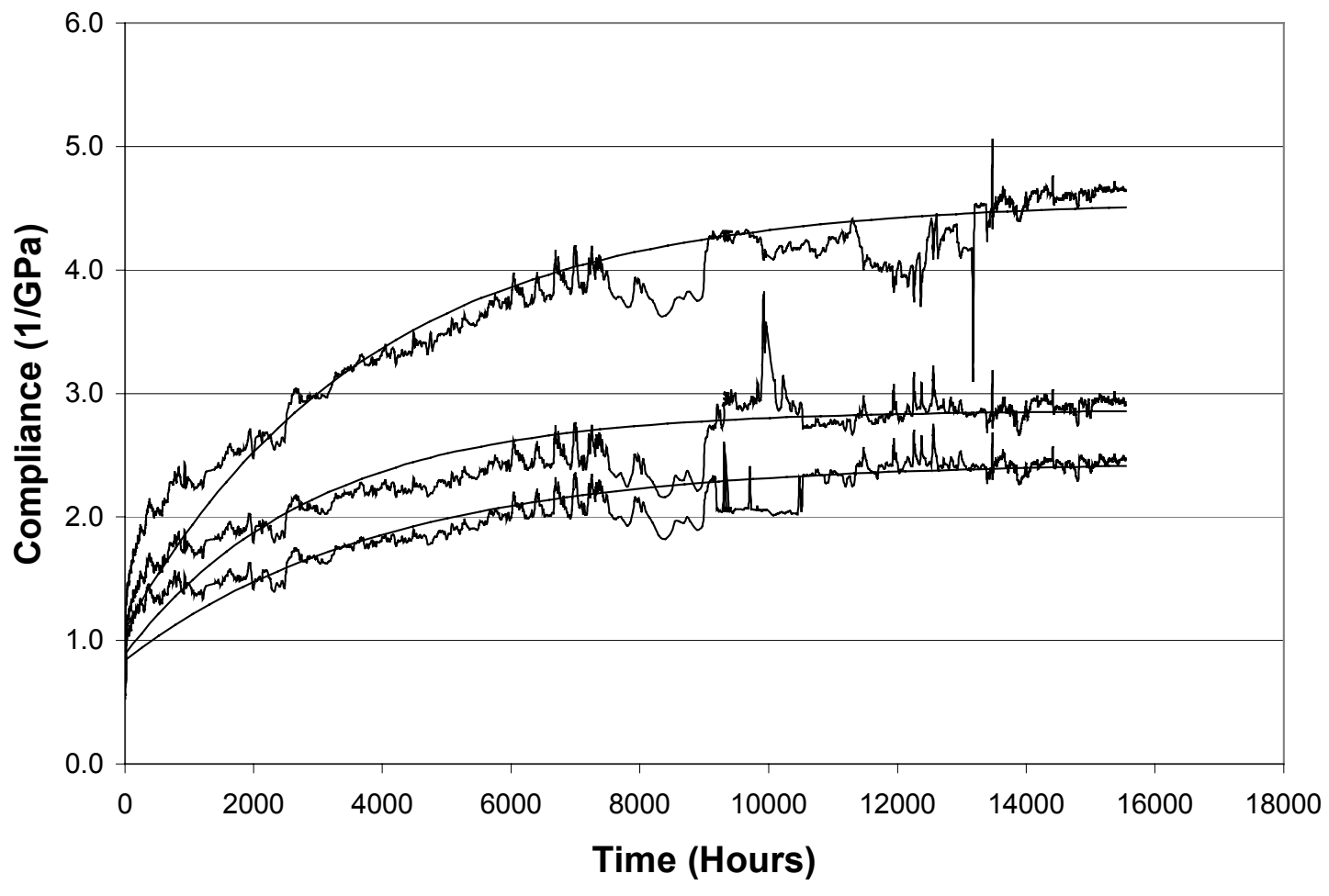

Figure 4.43 SLS model fit of three samples of Material C (C1, C2 and C3) 


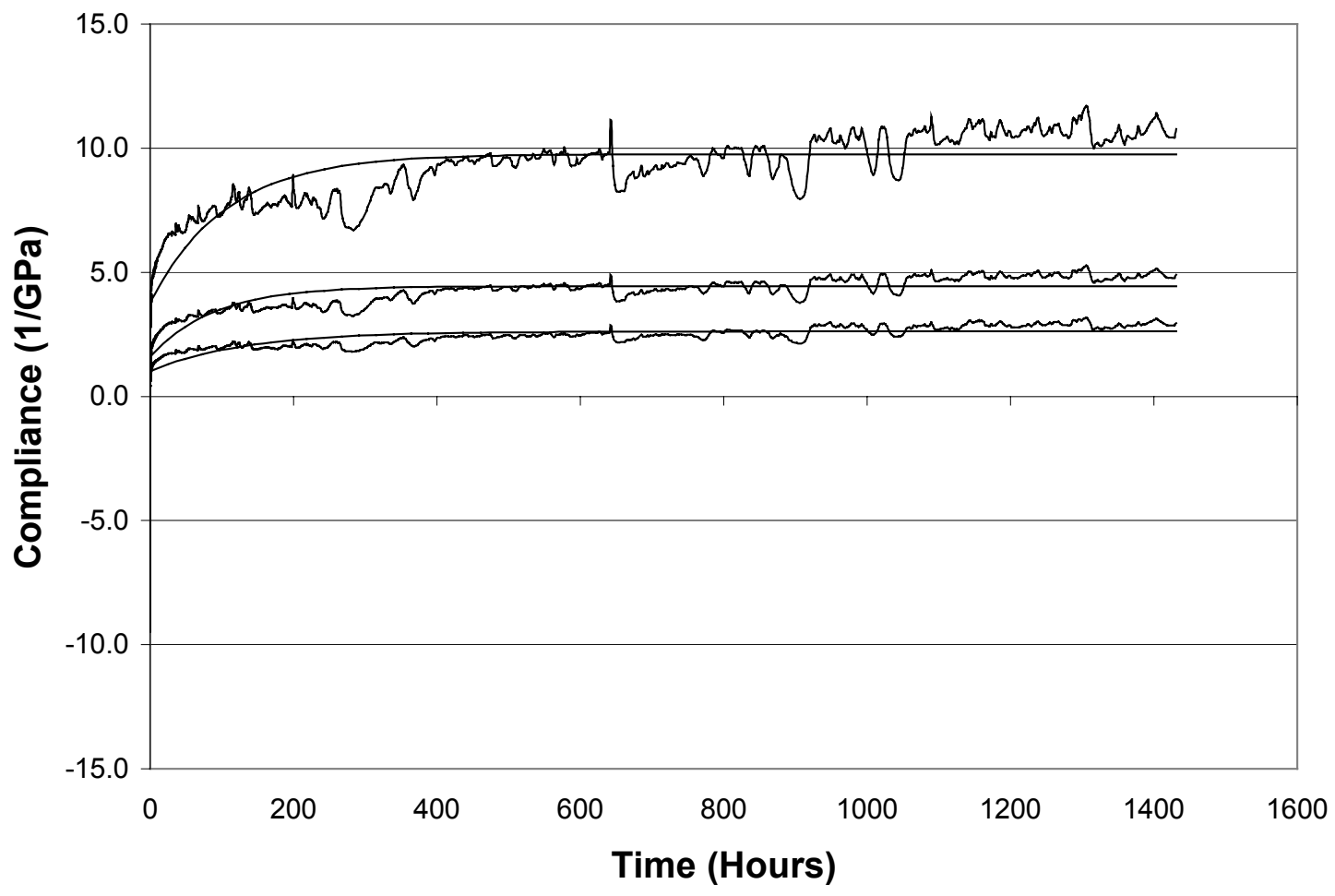

Figure 4.44 SLS model fit of three samples of Material D (D1, D2 and D3)

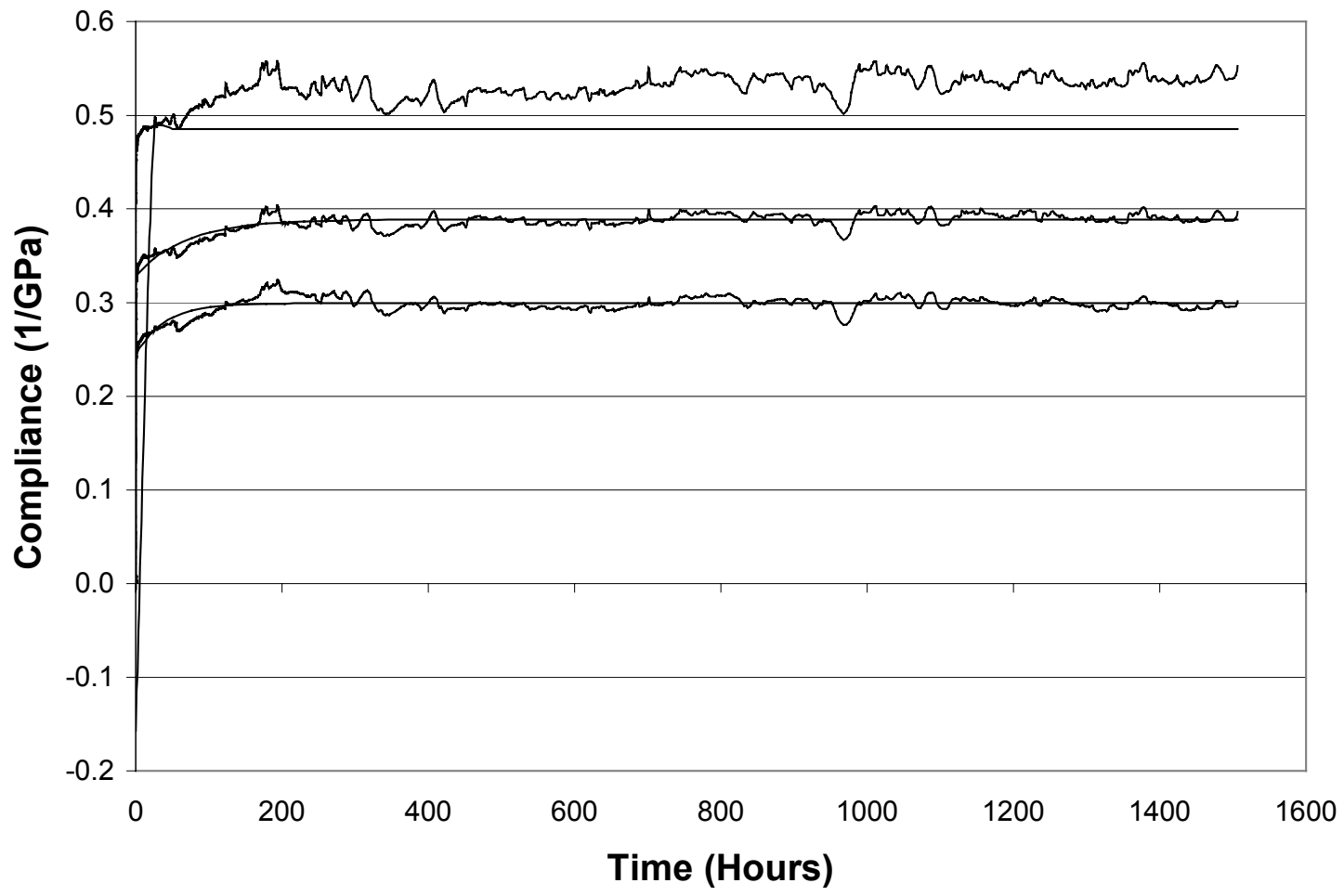

Figure 4.45 SLS model fit of three samples of Material E (E1, E2 and E3) 


\section{CHAPTER 5: SUMMARY AND CONCLUSIONS}

The presented study was aimed at developing a standard long-term test procedure for testing encased polymer pipe liners used for rehabilitation of deteriorated sewer liners. The proposed test procedure can be implemented independently of the type of polymer material used for the liner. The liner materials used for testing are commercially available blends of polymers that are used in typical field installations.

From the long-term tests it was seen that the data of materials fit the viscoelastic model well. It was also concluded that by the above-mentioned procedure, the deflection of the pipe liners and hence the deformation mode shapes can be directly computed from strain values. Hence, the need for additional instrumentation to measure the deflection is eliminated, thereby avoiding additional costs and time. It was observed that pipe liners of the same material, lined at the same time with the same procedure and tested under the same loading conditions, did not deform the same. There were differences observed both in shape of the deformed liner and magnitude of deflection. This can be attributed to imperfections and stresses induced in the liner during fabrication.

The values of elastic modulus of the materials obtained from long-term tests could be compared with the values obtained from the short-term ASTM D790 tests. The error between the two values could be attributed to the experimental errors during the ASTM testing procedure and during the various tests conducted at different temperatures for obtaining the master TTSP curves. 


\section{CHAPTER 6: RECOMMENDATIONS}

In addition to testing the liner materials by the above procedure, there are certain

other areas of testing and theoretical analyses that can be performed on polymer pipe liner materials to determine their material properties and evaluate their structural behavior over time. Some of the procedure that would be of good future investigation are listed below.

- Perform Finite Element Analysis (FEA) to determine the various buckling modes of the encased liner.

- Test liners with different geometries to study the effect of the shape of the liner on its long-term durability.

- Study the effect of moisture on the long-term material properties of the liner.

- Develop standard short-term testing procedures with small size liner samples and predict the long-term behavior using the results of the short-term tests. 


\section{References}

1. Boot, J.C. and Welch, A.J. 1996. "Creep Buckling of Thin-walled Polymeric Pipe Linings Subject to External Groundwater Pressure," Elsevier Science Ltd, Oxford, England, p 191-210.

2. W. Thomas Straughan, Leslie K. Guice, Members, ASCE, and Chalcy MalDuraipandian 1995. "Long-Term Structural Behavior of Pipeline Rehabilitation Systems," Journal of Infrastructure Systems, v1, n4, p 214-220.

3. Surya Chunduru, Michael E. Barber and Reda M. Bakeer 1996. "Buckling Behavior of Polyethylene Liner Systems," Journal of Materials In Civil Engineering, v8, n4, p 201-206.

4. Bakeer, R.M., Barber, M.E., Taylor, J.E. and Pechon, S.E. 2001. "Long-Term Buckling Performance of HDPE Liners," Journal of Materials in Civil Engineering, v13, n3, p 176-184.

5. Bakeer, R.M., Barber, M.E., Pechon, S.E., Taylor, J.E. and Chunduru, S. 1999. "Buckling of HDPE Liners Under External Uniform Pressure," Journal of Materials in Civil Engineering, v11, n4, p 353-361.

6. Mahalingam, R. 1996. "A Viscoelastic Model to determine the Long-Term Buckling Pressure of CIPP Liners,” M.S. Thesis, Louisiana Tech. University, Ruston LA.

7. Alexander C. Aalders, Reda M. Bakeer and Michael E. Barber 1997. "Deformation Measurement of Liners During Buckling Tests," Proceedings of the Conference on Trenchless Pipeline Projects, p 327-334. 
8. Sharff, Phillip A. and DelloRusso, Steven J. 1994. "Effects of Acid Environment and Constant Deflection on PVC Sewer Pipe," Proceedings of the Symposium on Buried Plastic Pipe Technology, v2, p 149-163.

9. Moore, I.D. and Hu, F. 1996. "Linear Viscoelastic Modeling of Profiled High Density Polyethylene Pipe," Canadian Journal of Civil Engineering, v23, n2, p 395-406.

10. Farshad, M. and Flueler, P. 1996. "Buckling resistance of Polymer pipes Under Hydrostatic Pressure," Plastics, Rubber and Composite Processing and Applications, v25, n8, p373-379.

11. Haddad, Y.M. 1995. "Viscoelasticity of Engineering Materials," Chapman and Hall, London, UK.

12. Melissa R. Weimer. "A Closer Look At the Advanced CODAS Moving Average Algorithm," DATAQ Instruments, Inc. www.dataq.com/applicat/articles/an14.htm

13. Moore, G.R. and Kline, D.E. 1984. "Properties and Processing of Polymers For Engineers," Prentice-Hall, Inc., NJ, USA.

14. Rosen, Stephen L. 1993. "Fundamental Principles of Polymeric Materials," John Wiley and Sons, NY, USA.

15. Arthur P. Boresi, Richard J. Schmidt and Omar M. Sidebottom 1993. "Advanced Mechanics of Materials," John Wiley and Sons, Inc., USA.

16. Menard, Kevin Peter 1999. "Dynamic Mechanical Analysis, A Practical Introduction," CRC Press LLC, Florida, USA.

17. Aklonis, John J., MacKnight, William J. and Shen, Mitchell C. 1972. "Introduction To Polymer Viscoelasticity," John, Wiley and Sons, USA. 
18. Barbero E.J., Julius, M and Yao, Z 2003. "Time and Frequency Viscoelastic Behavior Of Commercial Polymers," CCC-2003, Calabria, Italy.

19. Beckwith, Thomas G., Marangoni, Roy D., Lienhard, John H. V. 1995. "Mechanical Measurements,” Addison-Wesley Publishing Company, Inc., USA.

20. Barbero, E. J. 1999. “Introduction to Composite Materials Design,” Taylor and Francis, PA, USA.

21. Dean O' Bryan, Greenstreak Inside Sales, Greenstreak, Inc., 3400 Tree Court Industrial Blvd., St. Louis, MO 63122. Ph. No. 800-325-9504, 636-225-9400.

22. Tech Note TN-504-1. "Strain Gage Thermal Output and Gage Factor Variation with Temperature," Measurements Group Inc., North Carolina, USA.

23. Flugge, Wilhelm 1967. "Viscoelasticity," Blaisdell Publishing Company, USA.

24. Warren C Young 1989. "Roark's Formulas for Stress and Strain,” McGraw-Hill, Inc., USA.

25. Creus, G. J. 1986. "Viscoelasticity - Basic Theory and Applications to Concrete Structures," Springer - Verlag Berlin, Heidelberg, Germany.

26. Barbero E. J. and Ford, K. J. 2002. "Aging Model Of Commercial Polymers," SAMPE Conference, Maryland, USA. 


\section{Appendix A: Figure Files}

\begin{tabular}{|c|c|}
\hline FILE NAME & FIGURES \\
\hline $\begin{array}{c}\text { Instron } \backslash \text { ASTM D790\Excel Data } \backslash \text { Material } \\
\text { A } \backslash A H I 1 . x l s\end{array}$ & $2.2,2.7,2.12,2.17,2.22,2.27$ \\
\hline $\begin{array}{c}\text { Instron } \backslash \text { ASTM D790\Excel Data } \backslash \text { Material } \\
\text { B } \backslash \text { BHI1.xls }\end{array}$ & $2.3,2.8,2.13,2.18,2.23,2.28$ \\
\hline $\begin{array}{c}\text { Instron\ASTM D790\Excel Data \Material } \\
\text { ClCHI1.xls }\end{array}$ & $2.4,2.9,2.14,2.19,2.24,2.29$ \\
\hline $\begin{array}{c}\text { Instron } \backslash \text { ASTM D790\Excel Data } \backslash \text { Material } \\
\text { D } \backslash \text { DHI1.xls }\end{array}$ & $2.5,2.10,2.15,2.20,2.25,2.30$ \\
\hline $\begin{array}{l}\text { Instron\ASTM D790\Excel Data\Material } \\
\text { E\EHI1.xls }\end{array}$ & $2.6,2.11,2.16,2.21,2.26,2.31$ \\
\hline Instron $\backslash T T S P \backslash A$ 39.6.xls & 2.32 \\
\hline Instron $\backslash T T S P \backslash B$ 39.4.xls & 2.33 \\
\hline Instron $\backslash T T S P \backslash C$ 39.3.xls & 2.34 \\
\hline Instron $\backslash T T S P \backslash D$ 40.xls & 2.35 \\
\hline Instron $\backslash T T S P \backslash E$ 40.xls & 2.36 \\
\hline Instron $\backslash T T S P \backslash a t$ vs T(mod).xls & $2.37,2.38,2.39,2.40,2.41$ \\
\hline Instron $\backslash T T S P \backslash A$ 21.1.xls & 2.42 \\
\hline Instron $\backslash T T S P \backslash B$ 21.1.xls & 2.43 \\
\hline Instron $\backslash T T S P \backslash C$ 21.1.xls & 2.44 \\
\hline Instron $\backslash T T S P \backslash D$ 21.1.xls & 2.45 \\
\hline Instron $\backslash T T S P \backslash E$ 21.1.xls & 2.46 \\
\hline LONG TERM TEST/A/Data A.xls & $\begin{array}{c}4.1,4.2,4.3,4.16,4.17,4.18,4.19,4.20 \\
4.33,4.34\end{array}$ \\
\hline LONG TERM TEST/B/Adjusted B.xls & $4.4,4.5,4.6,4.21,4.22,4.23$ \\
\hline LONG TERM TEST/C/Data C.xls & $4.7,4.8,4.9,4.24,4.25,4.26$ \\
\hline LONG TERM TEST/D/Data D.xls & $4.10,4.11,4.12,4.27,4.28,4.29$ \\
\hline LONG TERM TEST/E/Data E.xls & $4.13,4.14,4.15,4.30,4.31,4.32$ \\
\hline
\end{tabular}




\begin{tabular}{|c|c|}
\hline LONG TERM TEST/A/Copy of Data A.xls & 4.35 \\
\hline LONG TERM TEST/DFT.xls & 4.36 \\
\hline $\begin{array}{c}\text { PONG Tiles.doc } \\
\text { LONG TERM TEST. }\end{array}$ & $4.39-4.53$ \\
\hline $\begin{array}{c}\text { LONT/s } \\
\text { B123.xls }\end{array}$ & 4.59 \\
\hline $\begin{array}{c}\text { LONG TERM TEST/4-param model/Pipe } \\
\text { LONG TERM TEST/4-param model/Pipe }\end{array}$ & 4.60 \\
\hline $\begin{array}{c}\text { DONG TERM TEST/4-param model/Pipe } \\
\text { E123.xls }\end{array}$ & 4.61 \\
\hline LONG TERM TEST/4-param model/Pipe & 4.62 \\
\hline
\end{tabular}




\section{Appendix B: Data Files}

Source data files are obtained in '*.con' format. They are converted to excel files ('*.xls') by using the Data Acquisition software. They are then processed with the following MATLAB program to generate another excel file containing the pressure, temperature and strain data after moving average and the picking of every hundredth data point process.

\section{MATLAB CODE}

$\%$ input len, mov \& mov1, where len=length of the data file, mov=moving average $\%$ value(n), mov1 $1=$ the rate to pick points

$\%$ reading the data into $\mathrm{A}$

len $=1700 ; \mathrm{mov}=50 ; \mathrm{mov} 1=100$;

fid=fopen('filename.txt','r');

$[\mathrm{A}]=$ fscanf(fid, $\% \mathrm{f}^{\prime},[97$, len $\left.]\right)$;

$\mathrm{A}=\mathrm{A}^{\prime}$;

$\%$ declaring $B$ in the size of $A$

$\mathrm{B}=\mathrm{zeros}(\operatorname{size}(\mathrm{A}))$;

\%code for computing the moving average

for $\mathrm{m}=1: 97$

for $\mathrm{i}=1:$ len-mov +1

sum $=0$;

for $\mathrm{k}=\mathrm{i}: \mathrm{i}+\mathrm{mov}-1$

sum $=$ sum $+A(k, m)$;

end;

avg=sum/mov;

\%storing moving average values in $\mathrm{B}$

$\mathrm{B}(\mathrm{i}+\mathrm{mov}-1, \mathrm{~m})=\operatorname{avg}$;

end;

\%declaring $\mathrm{C}$ in the size of $\mathrm{A}$ to store the chosen values

$\mathrm{C}=\operatorname{zeros}(\operatorname{size}(\mathrm{A}))$;

count $=0$;

$[\mathrm{x}, \mathrm{y}]=\operatorname{size}(\mathrm{A})$;

for $\mathrm{j}=$ mov:mov1: $\mathrm{x}$

$\mathrm{C}(\mathrm{j}, \mathrm{m})=\mathrm{B}(\mathrm{j}, \mathrm{m})$;

count $=$ count +1 ;

end;

$\%$ declaring $\mathrm{D}$ to store the final values picked

$\% \mathrm{D}=$ zeros(count,26); 


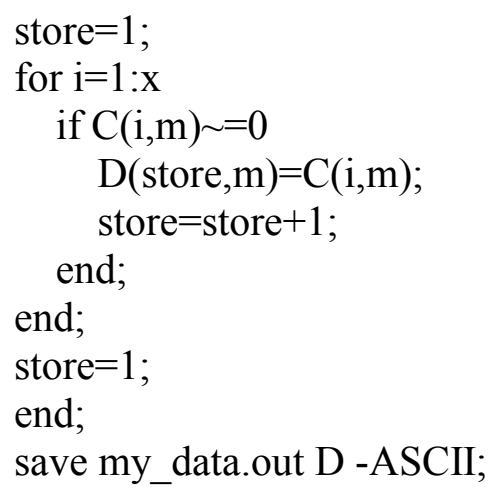

Data for each specimen 1-3 of each material A - E is separated manually to produce the following Excel files.

\begin{tabular}{|c|c|}
\hline FILE NAMES & MATERIAL \\
\hline LONG TERM TEST/A/Data A.xls & $\mathrm{A}$ \\
\hline LONG TERM TEST/B/Adjusted Data B.xls & $\mathrm{B}$ \\
\hline LONG TERM TEST/C/Data C.xls & $\mathrm{C}$ \\
\hline LONG TERM TEST/D/Data D.xls & $\mathrm{D}$ \\
\hline LONG TERM TEST/E/Data E.xls & $\mathrm{E}$ \\
\hline
\end{tabular}

